\title{
Experimental and Numerical Investigation of Residual Stresses in Shot Peened Flange Pin of Landing Gears
}

\author{
By \\ Yinda Cheng
}

A thesis submitted to the Faculty of Graduate and Postdoctoral Affairs in partial fulfillment of the requirements for the degree of

Master of Applied Science

in

Materials Engineering

Carleton University

Ottawa, Ontario

C2020, Yinda Cheng 


\begin{abstract}
Flange pin is a landing gear component, manufactured by Safran, which is made of high strength low alloy HY-TUF steel. It is conventionally peened with steel shots to improve its fatigue life, but recently Safran has proposed to substitute ZirShot-ZC600 ceramic shot for steel shot owing to the high reusability of ceramic shot. In this research, the residual stresses in the flange pin peened with ceramic shots are investigated experimentally with X-ray diffraction (XRD) technique and numerically via finite element analysis (FEA) using Abaqus package. The experimental data show that at the surface of the peened flange pin the residual stresses in longitudinal and circumferential direction of the flange pin are all compressive, with the latter much greater than the former in magnitude. Three-dimensional FEA models are created for simulating the flange pin surface peened by ceramic shot flow which is generated randomly using the MATLAB program. It is revealed that the residual stresses in the longitudinal, circumferential and radial direction all vary in depth from of the peened surface and are compressive; the maximum compressive stresses occur at the subsurface. The circumferential stress is much greater than the longitudinal stress in magnitude and both are much larger than the radial stress. According to the Von Mises stress values, in terms of the material failure criterion, local yielding has occurred in the surface layer during the shot peening, resulting in local plastic deformation. The effects of target surface curvature and shot peening angle on the residual stress profiles in the peened surface are also studied via FEA simulations. The results show that although the maximum compressive stress and its location vary with target surface curvature and shot peening angle, they do not exhibit direct relations. However, it can be suggested that the maximum residual stresses in flat surface are greater than that in the curved surfaces and with increasing peening angle the location of the maximum residual stresses moves down in depth of the peened surface.
\end{abstract}




\section{Acknowledgments}

I sincerely appreciate my thesis supervisor Dr. Rong Liu provided me such interesting research direction, guidance, support, and patience. I also want to thank Dr. Zhong Zhang for gave me technical support.

Also, I am grateful for the funding from NSERC Engage Program.

I would like to thank my parents for their encouragement and support. Without these I would not pass tough period.

I am grateful to my groupmates and friends who gave me understanding and help during I was preparing and writing my thesis. 


\section{List of Contents}

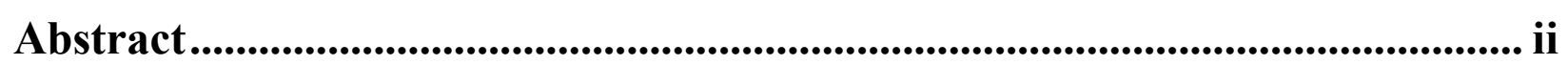

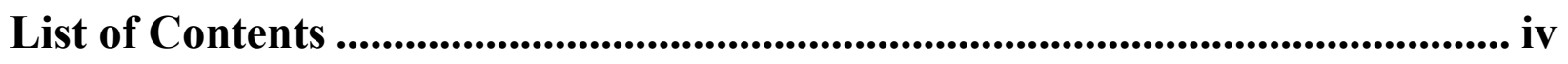

List of Tables ....................................................................................................... viii

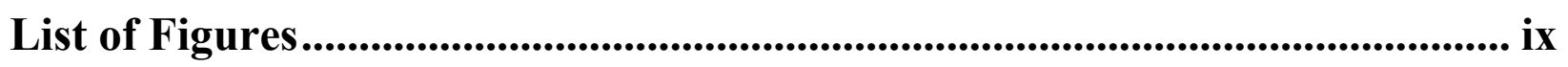

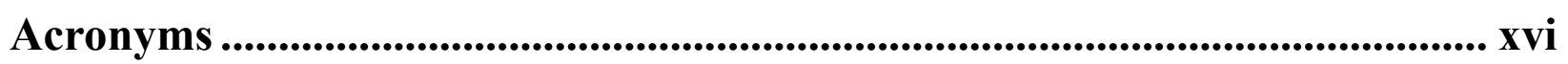

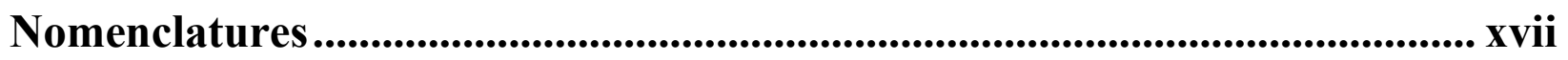

Chapter 1 Introduction................................................................................1

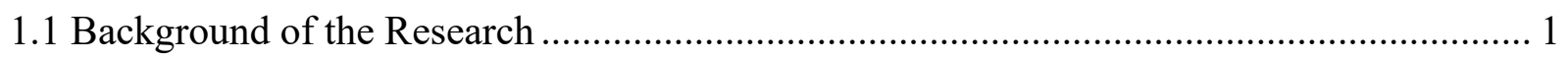

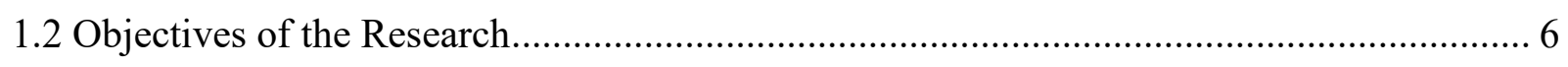

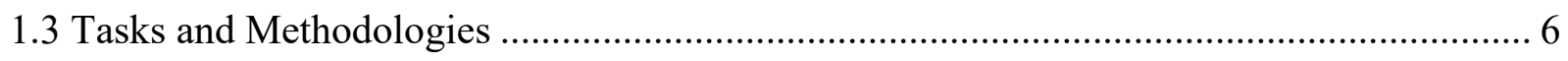

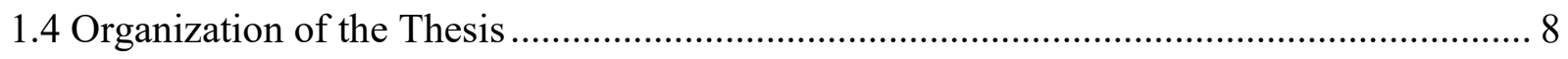

Chapter 2 Literature Review ...................................................................................................10

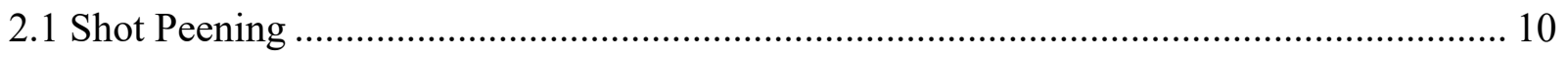

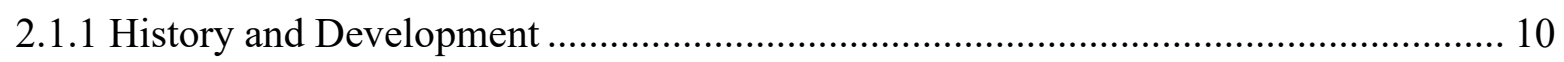

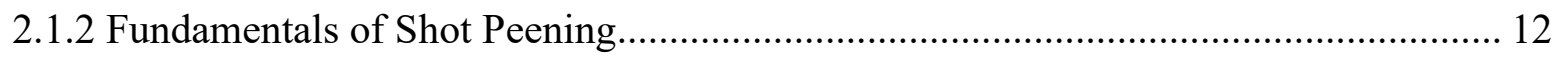

2.1.3 Shot Peening Effects on Fatigue Life ......................................................... 18

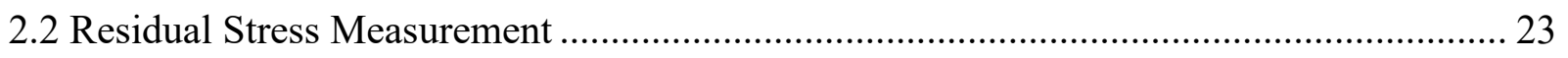


2.2.1 Sectioning Technique.

2.2.2 Deep Hole Method ................................................................................................ 25

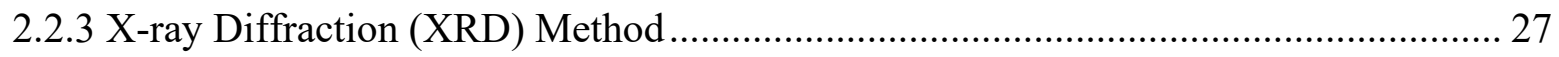

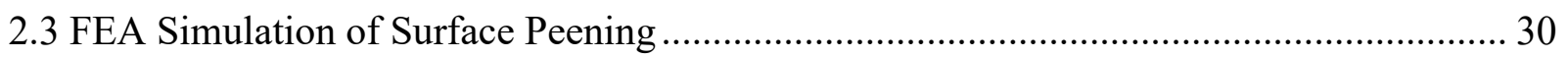

2.3.1 FEA Modelling of Residual Stresses in TC4 Surface Layer ........................................ 31

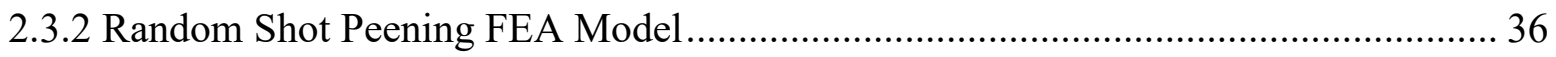

2.3.3 Peening Angle and Shot Diameter Models................................................................ 39

2.3.4 Peening Process Thermal Effect Model........................................................................ 42

Chapter 3 Experimental Details .......................................................................44

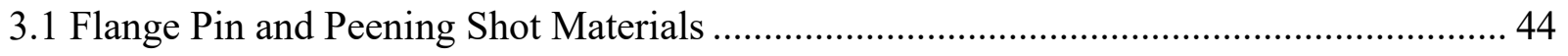

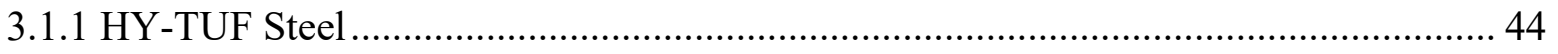

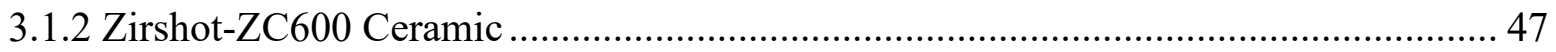

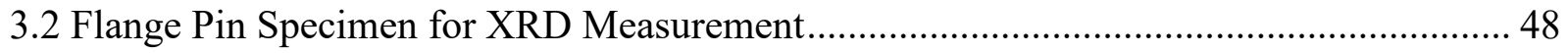

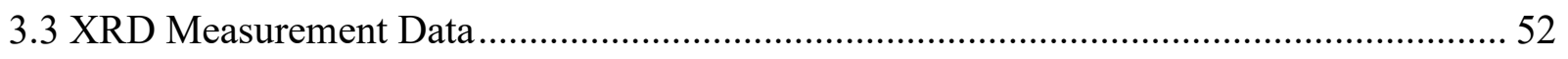

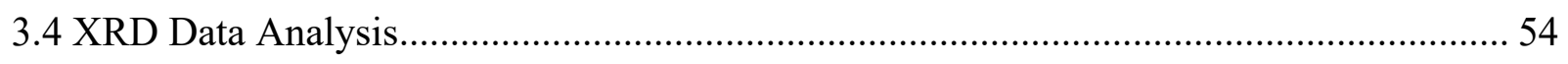

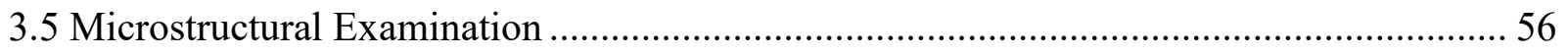

Chapter 4 FEA Simulation of Shot Peening on Flange Pin ..................................58

4.1 Material Data for FEA Model ..................................................................................... 59

4.1.1 Material Data of Flange Pin ..................................................................................... 59

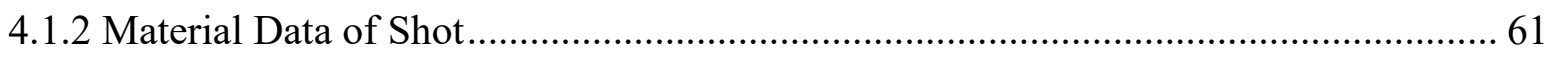


4.2 FEA Geometric Model 62

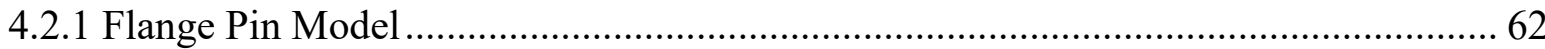

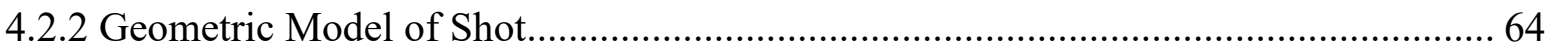

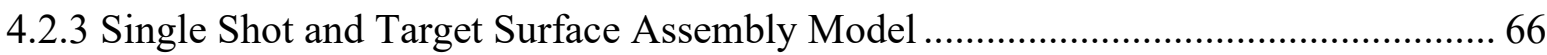

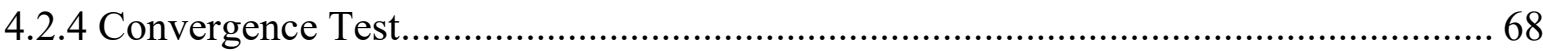

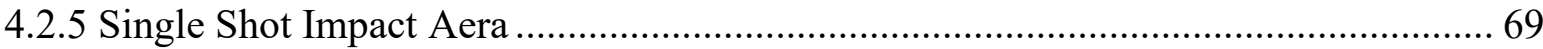

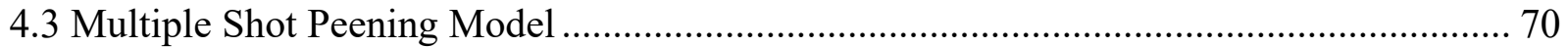

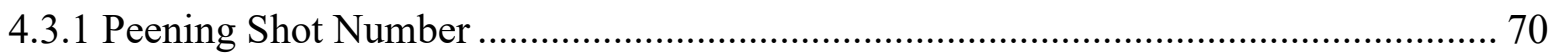

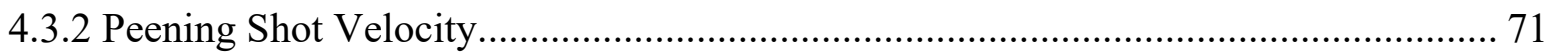

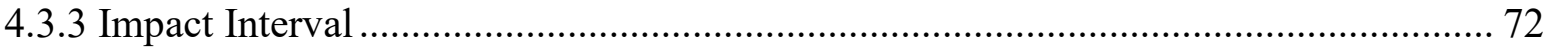

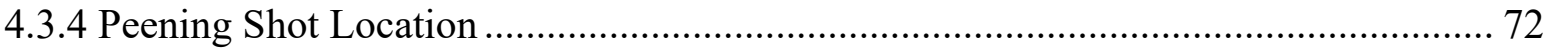

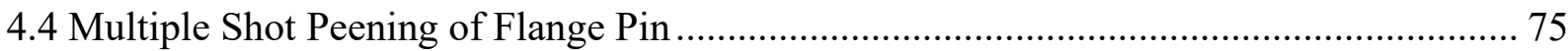

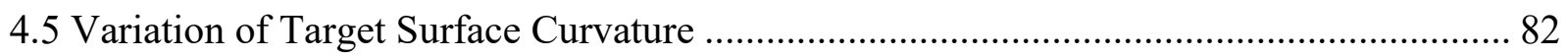

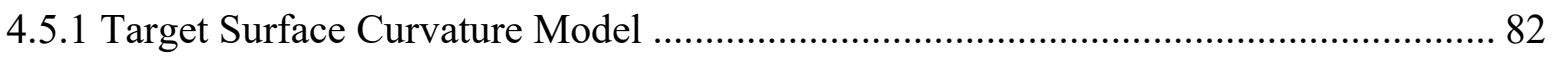

4.5.2 Residual Stress Profiles in Peened Surface with Small Curvature Radius .................. 84

4.5.3 Residual Stress Profiles in Peened Surface with Infinite Curvature Radius................. 87

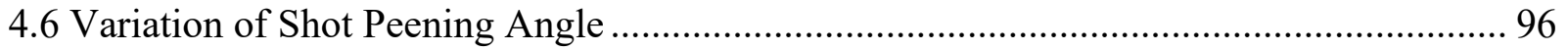

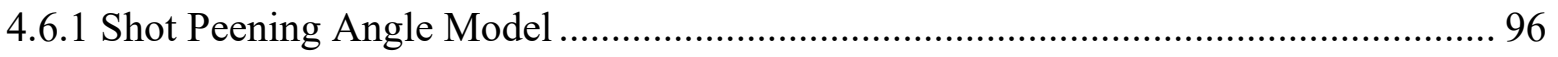

4.6.2 Residual Stress Profiles in Target Surface Peened at 30 Angle ................................. 98

4.6.3 Effects of Peening Angle on Residual Stress Profiles .............................................. 102 


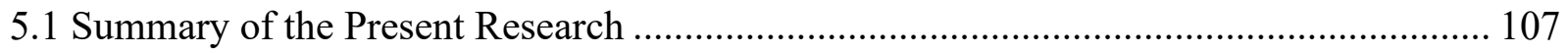

5.2 Conclusions from the Present Research.................................................................. 108

5.3 Significant Contributions of the Present Research ................................................ 110

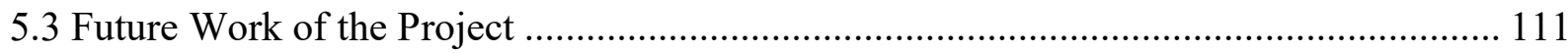

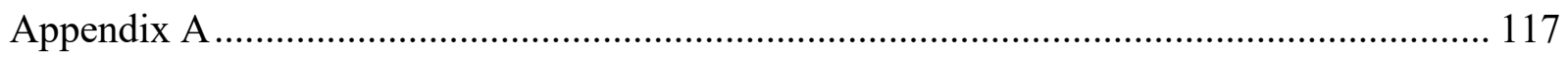

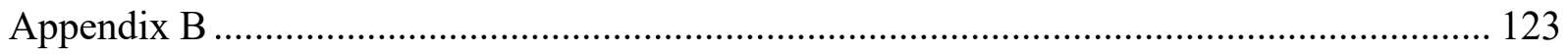

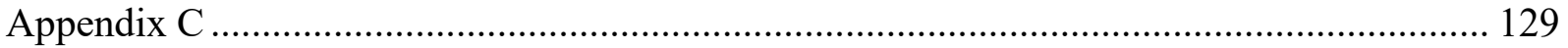

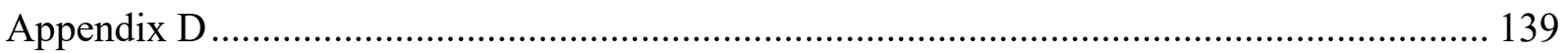




\section{List of Tables}

Table 3-1 Chemical composition (wt \%) of AMS 6425 (HY-TUF steel) ................................. 44

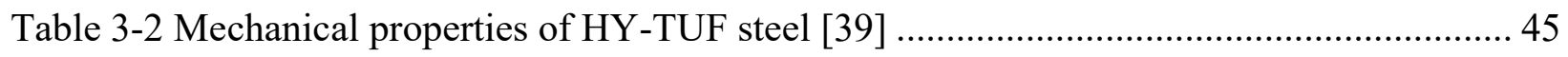

Table 3-3 Summary of locations on pin specimens for residual stress measurement ................ 51

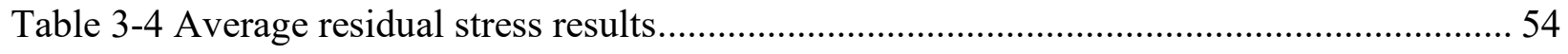

Table 3-5 Summary of residual stress results for peened flange pin ................................... 55

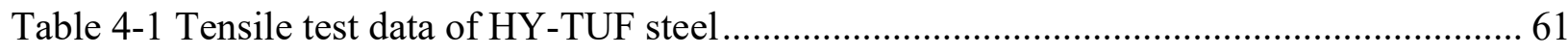

Table AP-1 Peening shot locations on the target surface of flange pin ................................ 123

Table AP-2 Peening shot locations for $30^{\circ}$ peening angle model ....................................... 124

Table AP-3 Peening shot locations for $45^{\circ}$ peening angle model ....................................... 125

Table AP-4 Peening shot locations for $60^{\circ}$ peening angle model ....................................... 126

Table AP-5 Peening shot locations for $75^{\circ}$ peening angle model ….................................. 127

Table AP-6 Peening shot locations for $90^{\circ}$ peening angle model ........................................ 128 


\section{List of Figures}

Figure 1-1 Flange structure: (a) in a landing gear system; (b) flange pin [1] .............................. 2

Figure 1-2 Schematic diagram of shot peening surface treatment: (a) surface deformation; (b)

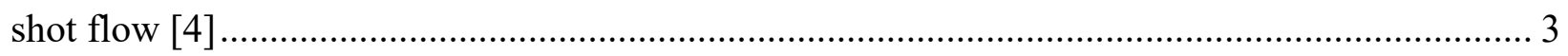

Figure 2-1 Influences of target surface thickness, hardness and peening velocity on residual stress

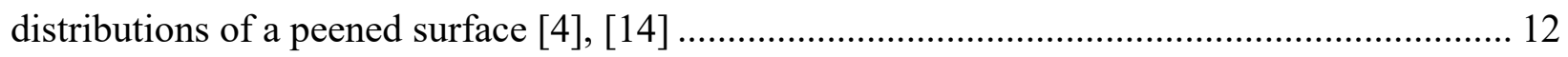

Figure 2-2 Flange pin of landing gear from Safran .............................................................. 13

Figure 2-3 Shot peened AISI 304 steel near surface regions [17] ........................................ 14

Figure 2-4 Effects of varying impression radius, $r$, at given peening rate, $R[18] \ldots \ldots \ldots \ldots \ldots \ldots \ldots \ldots . . .15$

Figure 2-5 Effects of varying impression size for fixed shot throwing rate [18] ........................ 15

Figure 2-6 Peened surfaces of various coverage levels [21] ................................................. 16

Figure 2-7 Residual stress-depth distributions for various coverage levels [21] ........................ 17

Figure 2-8 Almen strip for shot peening intensity measurement................................................ 18

Figure 2-9 Residual stress profiles in different treated surfaces [23] ........................................ 19

Figure 2-10 Fatigue life chart for different treated surfaces [23] ............................................. 20

Figure 2-11 Fatigue crack paths in (a) unpeened 7010 alloy specimen, (b) peened 7010 alloy specimen, (c) unpeened 8090 alloy specimen, (d) peened 8090 alloy specimen [24]................. 21

Figure 2-12 Percentage of initial residual stress versus number of cycles under fatigue loading. Dashed line indicates the critical boundary of threshold-residual stress relaxation [25] ............. 22 Figure 2-13 Residual stress depth profiles of fatigued laser-shock peened AISI 304 after 2000

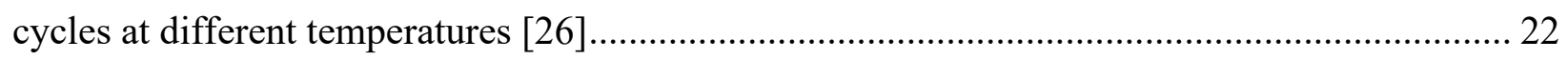

Figure 2-14 HE 360B wide flange section after sectioning for residual stress measurement [30]24 
Figure 2-15 Geometry and coordinate system for deep hole method of residual stress measurement [31] 25

Figure 2-16 Illustration of the principle of X-ray diffraction stress measurement: (a) $\psi=0$; $\psi=\psi$ (sample rotated through some known angle $\psi$ ). $\mathrm{D}$, $\mathrm{x}$-ray detector; $\mathrm{S}$ x-ray source; $\mathrm{N}$, normal to the surface [32]

Figure 2-17 Simulation of shot peening: (a) 2D FEA model; (b) 3D FEA model [35] ................. 32 Figure 2-18 FEA simulation results of 2D model: (a) stress contour of $\sigma_{11}$; (b) variation of residual

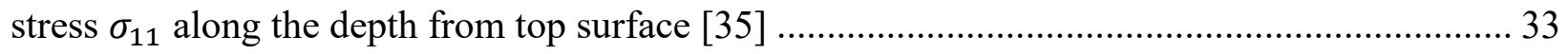

Figure 2-19 Coverage rates of shot peening with different impacts [35] .................................... 34

Figure 2-20 Simulation results of 3D model: (a) stress contour of $\sigma_{11}$; (b) contour of deformed

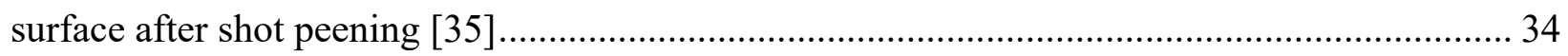

Figure 2-21 Variations of residual stress $\sigma_{11}$ in 3D model along the depth from top surface and

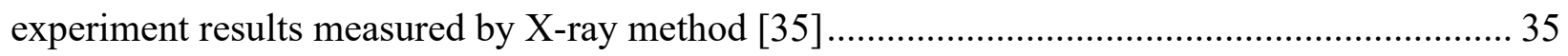

Figure 2-22 FEA model with two hundred shots impacting target surface at random positions [36] 36

Figure 2-23 Contour of displacement in depth direction of target surface due to 200 impacts [36]

Figure 2-24 Contour of Von Mises stress due to 200 impacts within whole peening region [36]

Figure 2-25 Contour of stress $\sigma_{11}$ in $x$ direction due to 200 impacts within whole peening region [36] 38

Figure 2-26 Average stress within peened region versus peening shot number [36] ................... 38

Figure 2-27 FEA model for multiple shot impact using Abaqus package [37] ........................... 39 
Figure 2-28 Peened surface showing the simulation area of FEA model [37]

Figure 2-29 Residual stress variation in depth direction $Y$ from top surface peened at angle $90^{\circ}(R$ represnts different peening shot diameters) [37]..... 40

Figure 2-30 Residual stress variation in depth from topsurface peened at angle $35^{\circ}(R$ represnts

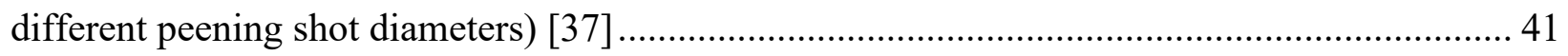

Figure 2-31 Three random RV FEA meshed models [38] .................................................... 42

Figure 2-32 Comparison of FEA simulation results with and without thermal effect included [38]

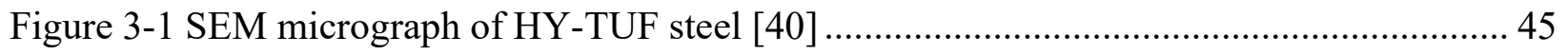

Figure 3-2 TEM micrograph of HY-TUF steel [41] .......................................................... 46

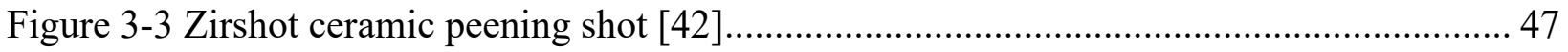

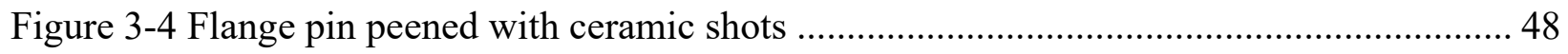

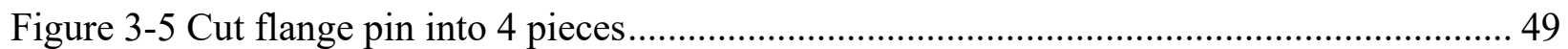

Figure 3-6 Indication of X-ray scan locations on the surface of cut pin................................ 50

Figure 3-7 Rigaku Ultima IV X-ray Diffractometer........................................................ 50

Figure 3-8 Illustration of X-ray measurement angles or scan directions ................................ 52

Figure 3-9 XRD measurement data for the top of specimen without hole at $0^{\circ}$ scan ............... 53

Figure 3-10 SEM microstructure (a) near peened surface of flange pin; (b) far from the peened

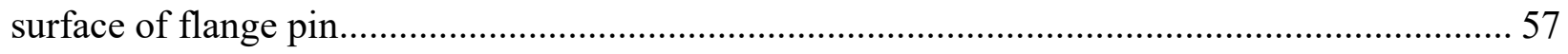

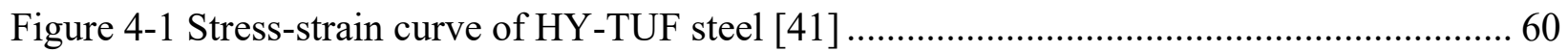

Figure 4-2 FEM geometric model of target surface part ................................................ 62

Figure 4-3 Meshed FEM model of target surface part...................................................... 63

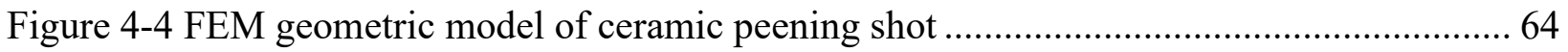




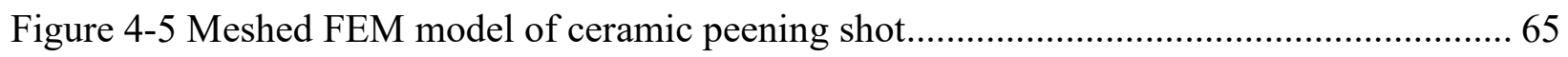

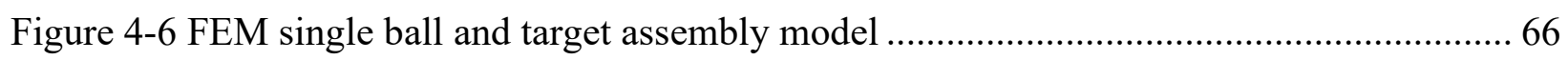

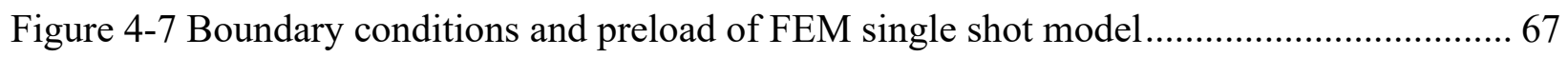

Figure 4-8 Maximum Von Mises stress versus meshing size ..................................................... 68

Figure 4-9 Cross-section of deformed model showing plastic or residual deformations of target

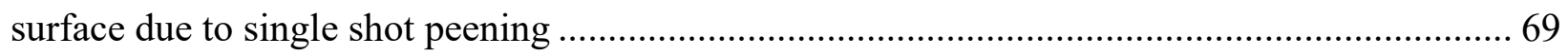

Figure 4-10 Schematic diagram showing the impact angle of peening shot flow: (a) 3D view; (b)

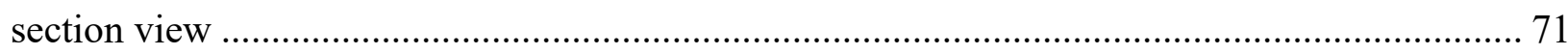

Figure 4-11 FEA model for simulating real peening process of flange pin.................................. 75

Figure 4-12 Longitudinal section of peened surface layer of flange pin showing Von Mises stress

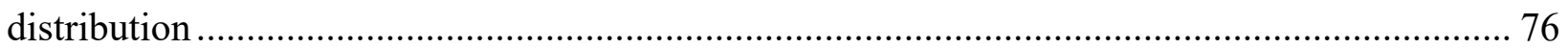

Figure 4-13 Longitudinal stress profile in the central area of peened surface simulating actual

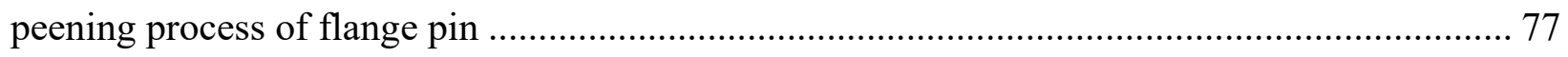
Figure 4-14 Circumferential stress profile in the central area of peened surface simulating actual

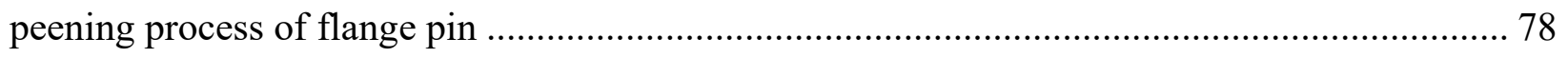
Figure 4-15 Radial stress profile in the central area of peened surface simulating actual peening

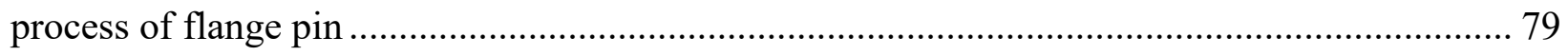

Figure 4-16 Von Mises stress distribution in the central area of peened surface simulating actual

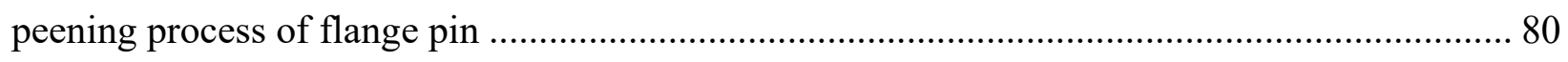

Figure 4-17 Variations of residual stresses in depth of peened flange pin surface....................... 82 Figure 4-18 Target surface curvature model: (a) curvature radius of $10 \mathrm{~mm}$; (b) infinite curvature

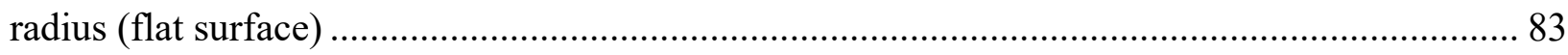


Figure 4-19 Residual stress profile in peened surface with curvature radius of $10 \mathrm{~mm}$ :

longitudinal stress; (b) circumferential stress; (c) radial stress........................................... 85

Figure 4-20 Von Mises stress profile in peened surface with curvature radius of $10 \mathrm{~mm}$.......... 86

Figure 4-21 Variations of residual stresses in depth of peened surface with curvature radius of 10

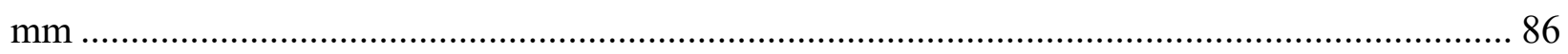

Figure 4-22 Residual stress profile in peened surface with infinite curvature radius:

longitudinal stress; (b) circumferential stress; (c) radial stress ......................................... 89

Figure 4-23 Von Mises stress profile in peened surface with infinite curvature radius .............. 89

Figure 4-24 Variations of residual stresses in depth of peened surface with infinite curvature radius

Figure 4-25 Comparison of residual stresses in target surface with different curvatures:

longitudinal stress; (b) circumferential stress; (c) radial stress; (d) Von Mises stress.

Figure 4-26 Comparison of maximum residual stresses in target surface with different curvatures:

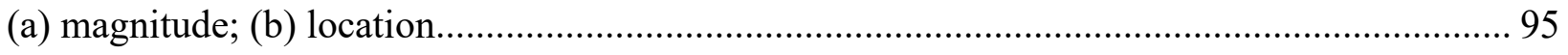

Figure 4-27 FEA shot peening angle model: (a) 30 impact; (b) $90^{\circ}$ impact ........................... 97

Figure 4-28 FEA flat target surface model for shot peening angle simulation study ................ 97

Figure 4-29 Residual stress profile in peened surface by $30^{\circ}$ angle impact: (a)

longitudinal stress; (b) circumferential stress; (c) radial stress ......................................... 100

Figure 4-30 Von Mises stress profile in peened surface by $30^{\circ}$ angle impact........................ 100

Figure 4-31 Variations of residual stresses in depth of peened surface by $30^{\circ}$ angle impact.... 101

Figure 4-32 Comparison of residual stresses in target surface peened at different angles:

longitudinal stress; (b) circumferential stress; (c) radial stress; (d) Von Mises stress. 104 
Figure 4-33 Comparison of maximum residual stresses in target surface peened at different angles:

(a) magnitude; (b) location 106

Figure AP-1 XRD measurement data for the top of specimen without hole at $180^{\circ}$ scan ........ 117

Figure AP-2 XRD measurement data for the top of specimen without hole at $270^{\circ}$ scan 117

Figure AP-3 XRD measurement data for the middle of specimen without hole at $0^{\circ}$ scan ....... 118

Figure AP-4 XRD measurement data for the middle of specimen without hole at $90^{\circ}$ scan ..... 118

Figure AP-5 XRD measurement data for the middle of specimen without hole at $180^{\circ}$ scan ... 119

Figure AP-6 XRD measurement data for the middle of specimen without hole at $270^{\circ}$ scan ... 119

Figure AP-7 XRD measurement data for the bottom of specimen without hole at $0^{\circ}$ scan ....... 120

Figure AP-8 XRD measurement data for the bottom of specimen without hole at $90^{\circ}$ scan ..... 120

Figure AP-9 XRD measurement data for the bottom of specimen without hole at $180^{\circ}$ scan $\ldots 121$

Figure AP-10 XRD measurement data for the top of specimen with holes at $0^{\circ}$ scan ............. 121

Figure AP-11 XRD measurement data for the top of specimen with holes at $180^{\circ}$ scan .......... 122

Figure AP-12 XRD measurement data for the top of specimen with holes at $270^{\circ}$ scan .......... 122

Figure AP-13 FEA model of target surface with curvature radius $20 \mathrm{~mm}$............................ 129

Figure AP-14 Residual stress profile in peened surface with curvature radius of $20 \mathrm{~mm}$ : (a)

longitudinal stress; (b) circumferential stress; (c) radial stress; (d) Von Mises stress............... 131

Figure AP-15 FEA model of target surface with curvature radius $30 \mathrm{~mm}$........................... 131

Figure AP-16 Residual stress profile in peened surface with curvature radius of $30 \mathrm{~mm}$ : (a)

longitudinal stress; (b) circumferential stress; (c) radial stress; (d) Von Mises stress............... 133

Figure AP-17 FEA model of target surface with curvature radius $40 \mathrm{~mm}$........................... 134

Figure AP-18 Residual stress profile in peened surface with curvature radius of $40 \mathrm{~mm}$ : (a)

longitudinal stress; (b) circumferential stress; (c) radial stress; (d) Von Mises stress............... 136 
Figure AP-19 FEA model of target surface with curvature radius $50 \mathrm{~mm}$............................... 136

Figure AP-20 Residual stress profile in peened surface with curvature radius of $50 \mathrm{~mm}$ : (a)

longitudinal stress; (b) circumferential stress; (c) radial stress; (d) Von Mises stress................. 138

Figure AP-21 FEA model of flat target surface peened at $45^{\circ}$ angle impact ............................. 139

Figure AP-22 Residual stress profile in peened surface by $45^{\circ}$ angle impact: (a)

longitudinal stress; (b) circumferential stress; (c) radial stress; (d) Von Mises stress................ 141

Figure AP-23 FEA model of flat target surface peened at $60^{\circ}$ angle impact ............................. 141

Figure AP-24 Residual stress profile in peened surface by $60^{\circ}$ angle impact: (a)

longitudinal stress; (b) circumferential stress; (c) radial stress; (d) Von Mises stress................ 143

Figure AP-5-25 FEA model of flat target surface peened at 75 angle impact .......................... 144

Figure AP-26 Residual stress profile in peened surface by $75^{\circ}$ angle impact: (a)

longitudinal stress; (b) circumferential stress; (c) radial stress; (d) Von Mises stress................ 146 


\section{Acronyms}

EDM Electrical Discharge Machining

FEA Finite Elements Analysis

GF Ground Fresh

GWL Ground White Layer

HTF Hard Turned Fresh

HTWL Hard Turned White Layer

SEM Scanning Electron Microscope

TEM Transmission Electron Microscope

UTS Ultimate Tensile Strength

XRD X-ray Diffraction Method 


\section{Nomenclatures}

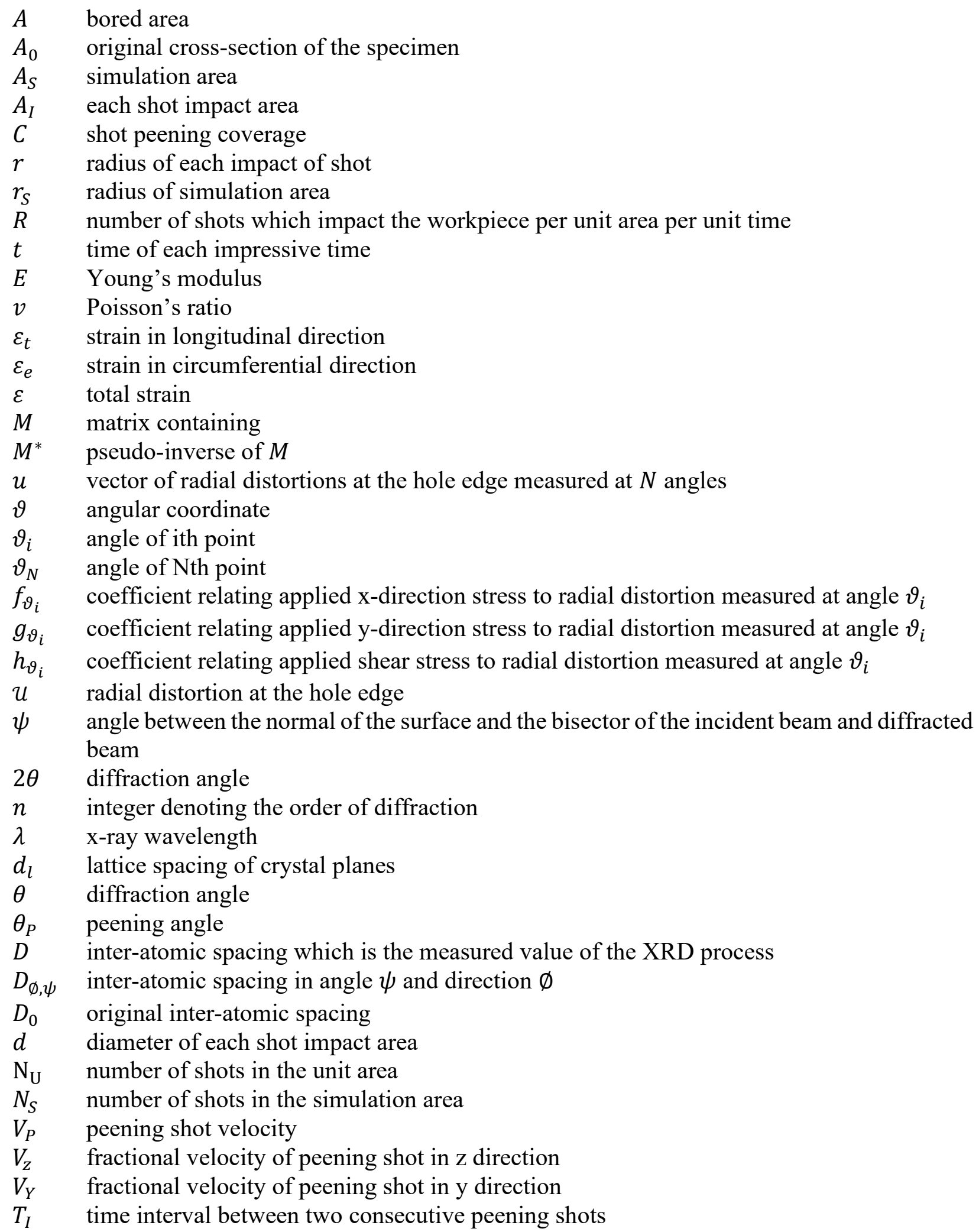


$D_{I_{Z}} \quad$ distance interval in the z-direction

$D_{I_{Y}} \quad$ distance interval in the y-direction

$\alpha h_{p} \quad$ depth of maximum residual stress in thick surface

$\beta h_{p} \quad$ depth of maximum residual stress in thin surface

$h_{p} \quad$ depth of residual stress

$h$ residual stress wave depth in thin material surface

$\sigma_{\mathrm{R}} \quad$ residual stress 


\section{Chapter 1 Introduction}

\subsection{Background of the Research}

Landing gear system is the indispensable part of spacecraft and aerospace products. The reliability of the flange pin as the connecting mechanism in a landing gear system has always attracted much attention because it concerns the safety of passengers and crew. During the operation of landing gear, the flange pin is subjected to fatigue loading. Therefore, in the aircraft and aerospace industry, increasing the fatigue life of the flange pin, which can improve reliability and durability of the flange pin, is ongoing target, since it is directly linked to the safety of airplane and maintenance cost. Figure 1-1 shows the flange structure in a landing gear system [1].

Fatigue life of a component is affected by cyclic stresses, residual stresses, material properties, internal defects, grain size, temperature, design geometry, surface quality, oxidation, corrosion, etc. There are many techniques that can be applied to enhance the fatigue strength of materials and components. Work hardening processes can produce a compressive stress layer on metal components which will significantly enhance the fatigue life of the components, but most work hardening processes such as rolling or cold forging can cause obvious deformation of the components. One of the most effective work hardening processes can be the surface treatment technique, named shot peening. It is a cold work process which consists of producing a compressive stress layer by continuous impingement of metal or ceramic shots and modifying the mechanical properties of metals thus to extend service life [2], [3]. In order to achieve this, a metallic surface can be impacted by small spherical abrasive media (round metallic, glass, or ceramic particles) with force sufficient enough to create permanent deformation of the surface, as illustrated in Figure 1-2. 


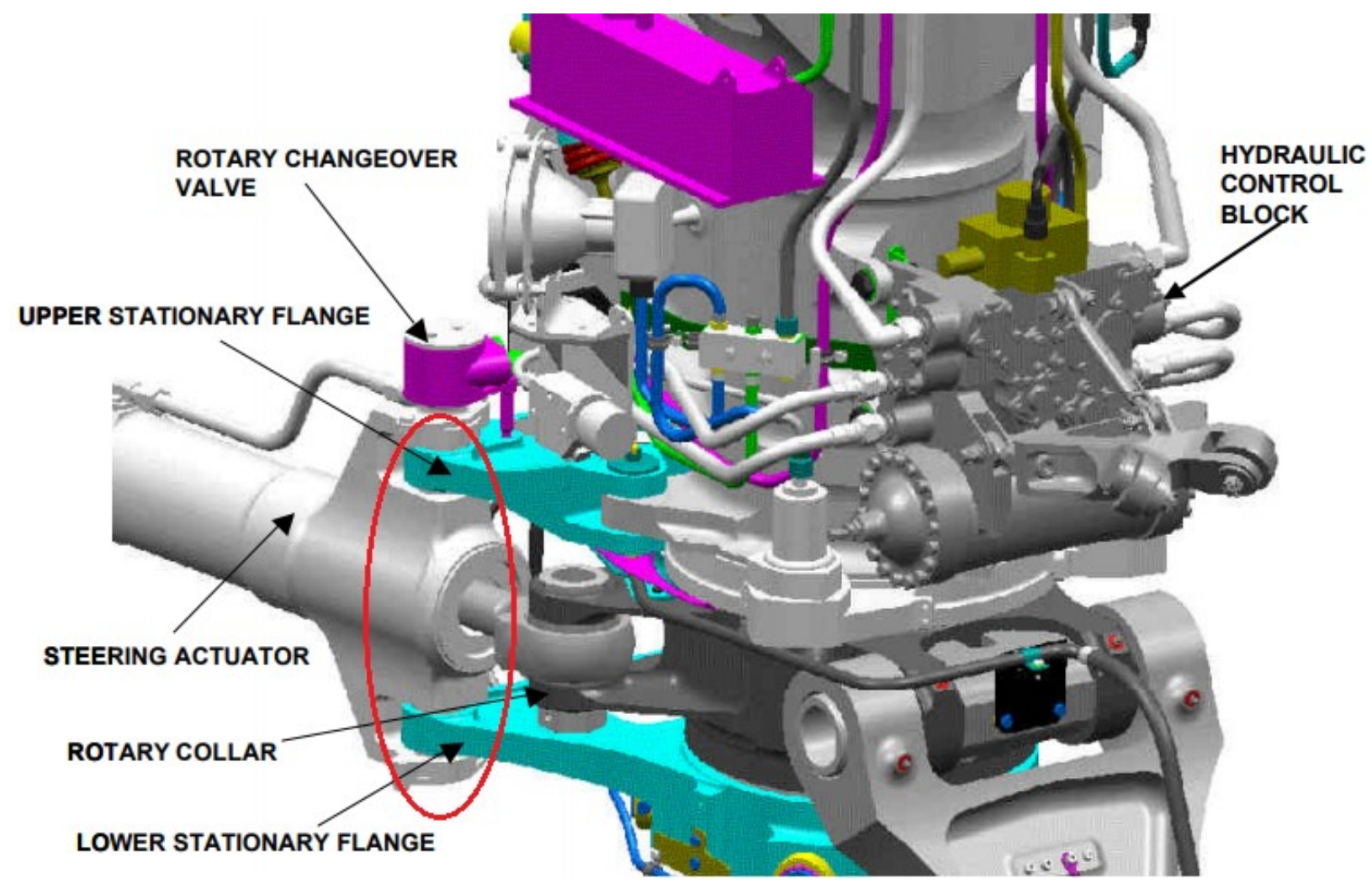

(a)

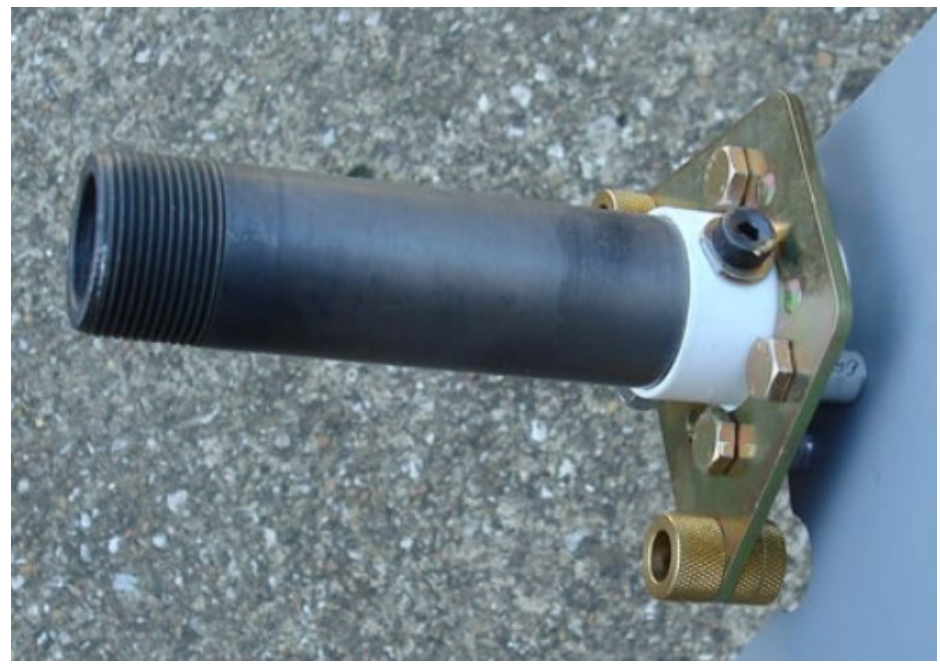

(b)

Figure 1-1 Flange structure: (a) in a landing gear system; (b) flange pin [1] 


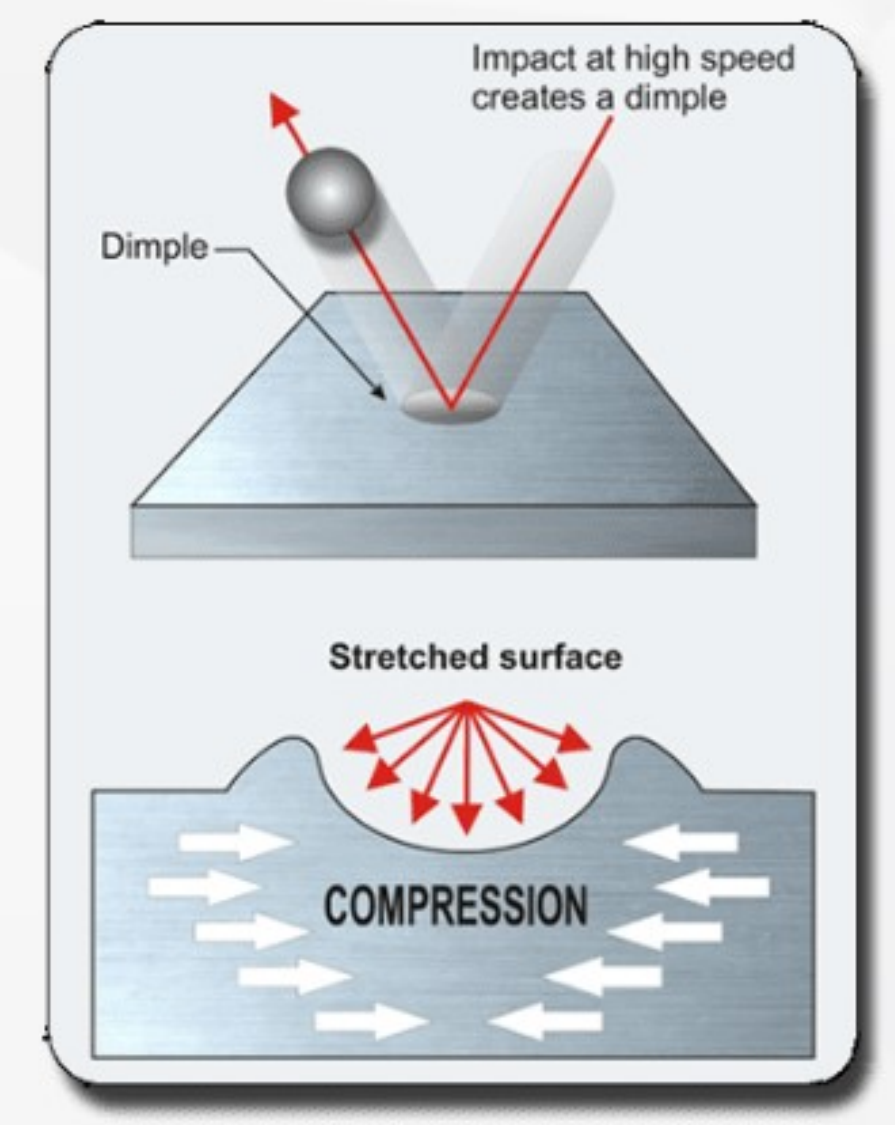

(a)

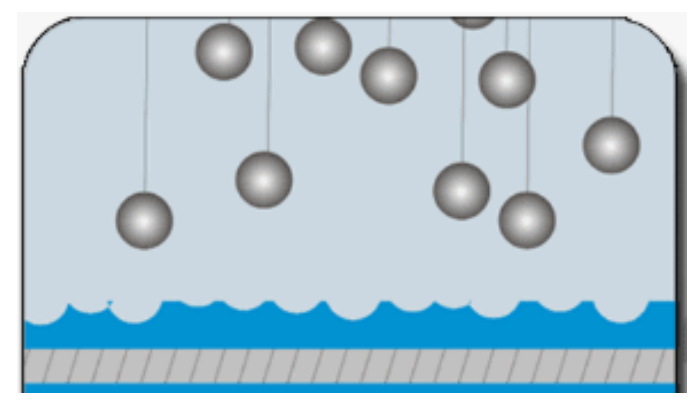

(b)

Figure 1-2 Schematic diagram of shot peening surface treatment: (a) surface deformation; (b) shot flow [4] 
Technological requirements in all industrial sectors, especially the aeronautic and aircraft industries, are becoming more and more extensive, particularly with regards to shot peening, which is an important and, for safety reasons, essential process in these fields. In industries like aircraft, automotive, and railway manufacturing, shot peening is an inescapable process when it comes to forming components with enhanced mechanical strengths while yet using minimal amounts of material to reduce overall weight.

As mentioned above, shot peening also enhances the mechanical strength of components and reduces the risk of failure when they are subjected to extreme conditions. For these reasons, drive components (gears) and flange pins often experience shot peening process in order to induce compressive stress, which considerably increases their resistance to fatigue and reduces the risk of cracks during operating life while these components are subjected to multiple tensile and compression stresses.

The current shot peening processes on the flange pins of landing gears are using steel shots. However, the problems of using steel shots have been identified. First, the mechanical properties such as yield stress, ultimate tensile strength, the young's modulus, etc. between flange pins and peening steel shots are similar, the high-speed impact during peening process will lead to severe plastic deformation of conventional steel shots, therefore, steel shots are not reusable, which increases the cost of shot peening process. Second, steel shots leave residues (corrosion, other metallic dusts) on processed components, necessitating further cleaning and/or decontamination, thus making the overall process time consuming. Third, inelastic deformation of metal shots can cause impact energy loss thus reducing shot peening effect [5]. Last, high impact speed of steel shots on peened surface generates friction heat which causes "welding" of the contact surfaces. 
Recently, Safran Landing Systems, as the world's largest manufacturer of aircraft landing gears, aiming at designing, developing and manufacturing various aircraft landing gears, wheels and brakes, has proposed to improve the fatigue strength of the flange pins in their landing gear components by peening the surfaces using ceramic shots to replace steel shots, because ceramic shot has higher strength and hardness which can enhance peening effect. It can also reduce surface "welding" during peening process. Safran is thus interested in performing peening with ceramic shots, which has proven to render better endurance properties and surface finish of peened structural components. Ceramic peening shots, owing to excellent corrosion resistance and high strength to deformation, exhibit high reusability and are high-quality alternative of steel shots. The ceramic shot used for peening the flange pins of Safran is ZirShot-ZC600 ceramic shot (chemical composition in weight: $60 \%$ to $70 \% \mathrm{ZrO}_{2}, 28 \%$ to $33 \% \mathrm{SiO}_{2}$ and less than $10 \% \mathrm{Al}_{2} \mathrm{O}_{3}$.), which is supplied by Saint-Gobain, France. The pin coupons, made of a high strength low alloy steel, HYTUF steel (nominal composition in weight: $0.25 \% \mathrm{C}, 1.4 \% \mathrm{Mn}, 1.6 \% \mathrm{Si}, 1.8 \% \mathrm{Ni}, 0.3 \% \mathrm{Cr}, 0.45 \%$ Mo, Bal. Fe), are conventionally peened with steel shot to improve the fatigue life, but in this research they were peened using ZirShot-ZC600 ceramic shots at the Metal Improvement Company.

As mentioned above, the main beneficial effect of shot peening process is to create compressive stresses in the target surface to enhance the fatigue resistance of the peened component. Since ZirShot-ZC600 ceramic shot had never been used to peen the HY-TUF steel flange pins before, the residual stress profiles in the peened flange pin are unknown. In order to optimize the peening process, Safran sponsored this project for an opportunity to investigate the use of ceramic shots for improving high strength steel endurance. It is expected that the ceramic shots can create a 
higher level of compressive stress in the surface layer of the flange pins compared to the conventional steel shots, thus preventing crack initiation and propagation from the surface and subsurface regions thereby extending the fatigue life of the flange pins.

\subsection{Objectives of the Research}

As indicated above, to upgrade ceramic shot peening process, determination of residual stresses in the peened surface is necessary. Therefore, the first objective of this research is to experimentally evaluate the residual stresses in the flange pin peened by ZirShot-ZC600 ceramic shots. The second objective of this research is to better understand the ceramic shot peening process on the flange pin of landing gears, via finite element analysis (FEA), by creating a FEA model to simulate the shot peening process. The third objective of this research is to investigate the effects of target surface curvature and shot peening angle on the residual stress profile in the peened surface, hence to optimize the peening process in order to achieve desirable residual stress distribution for a given flange pin geometry, because Safran has different flange pin products.

\subsection{Tasks and Methodologies}

Toward the research goals set, the entire research work in this thesis can be divided into three main parts, as detailed below. The planned tasks that have been completed and associated means that been used are described briefly.

Part I - Experimental measurement of residual stresses using X-ray diffraction technique 
(1) Prepare the samples from the peened flange pin provided by Safran for experimental measurement of the residual stresses.

(2) Measure the residual stresses in the prepared samples along longitudinal and circumferential direction of the flange pin using X-ray diffraction (XRD) technique.

(3) Analyze the XRD measurement data by JADA software and summarize the experimental results of residual stresses at different locations of the flange pin.

Part II - FEA simulation of actual shot peening of flange pin using Abaqus package

(1) Build a FEA assembly model of target surface with one shot peening to determine the radius of each shot impact area.

(2) Determine the mesh density of the model by conducting convergence test.

(3) Determine the material parameters of the target surface and ceramic shot for the FEA model based on the material properties of HY-TUF steel and ZirShot-ZC600 ceramic shot.

(4) Determine shot number in terms of peening coverage and generate shot flow locations on the target surface randomly using the MATLAB program.

(5) Create a multiple shot peening flow model for simulating actual peening process of flange pin.

(6) Examine the FEA simulation results of residual stresses in longitudinal, circumferential, and radial direction of the flange pin as well as Von Mises stress.

(7) Analyze the residual stress results, compared with the XRD measurement data, and discuss the discrepancy. 
(8) Examine the variations of longitudinal, circumferential, and radial stress along the depth of the peened surface layer and locate the maximum residual stresses.

(9) Analyze the Von Mises results in terms of material failure criterion and discuss the plastic deformation and strain hardening behavior of the peened surface.

Part III - FEA simulations of different surface curvatures and peening angles using Abaqus package

(1) Create FEA target surface models with different curvature radii from $10 \mathrm{~mm}$ to infinite (flat target surface).

(2) Create FEA shot flow models for different peening angles from $30^{\circ}$ to $90^{\circ}$ (normal to target surface).

(3) Investigate the variations of maximum residual stress and location in longitudinal, circumferential, and radial direction with target surface curvature.

(4) (4) Investigate the variations of maximum residual stress and location in longitudinal, circumferential, and radial direction with shot peening angle.

\subsection{Organization of the Thesis}

The entire research work presented in this thesis can be covered by five chapters, as detailed below. Chapter 1 is an introduction to this research, indicating the motivation and objectives of this research, the main tasks that have been completed and methodologies that are used in this research, as well as the outline of this thesis. 
Chapter 2 covers an extensive literature review of the fundamentals and basic concepts of shot peening surface treatment, as well as the history and development of shot peening technique. Various experimental methods for determining residual stresses in peened surfaces and numerical approaches with FEA simulation of shot peening processes as well as relevant studies to the present research are also reviewed.

Chapter 3 delineates the details of the experiments for determining the residual stresses in the peened flange pin, including sample preparation, XRD machine and measurement parameters, data collection and analysis, as well as the microstructure examination of the peened surface layer with scanning electron microscopy (SEM).

Chapter 4 describes the FEA simulation procedures and results for the peening process of the flange pin with ceramic shots using Abaqus package. The FEA models for single shot peening, multiple shot flow peening, different surface curvatures and different peening angles are created, and the associated simulation results are presented. The analyses of the residual stress variations along the depth of the surface layer in longitudinal, circumferential and radial direction of the flange pin as well as Von Mises stress are also included in this chapter, along with the analyses of surface curvature and peening angle effects on the residual stress behavior in the peened surface layer.

Chapter 5 summarizes this research and delineates the conclusions drawn from this research. The significant contributions of this research are highlighted and future work for this project is recommended. 


\section{Chapter 2 Literature Review}

\subsection{Shot Peening}

\subsubsection{History and Development}

From 2700 B.C., people started to use cold working method to alter the properties and shape of metallic materials. In ancient times, the main function of cold working was shaping the metal, such as coining, sharping the sword, and producing hauberk, until workers found that using cold working can increase the material properties. For example, in 1789, people in London used hammers to increase the material strength of gun barrels' outer surface [6]. This method can be regarded as the predecessor of shot peening. However, at that time, workers cannot explain how the hammer changed the mechanical properties of material. Until 1812, one of the earliest controlled hardness tests - Mohs hardness test was created, which was a type of scratch-hardness test based on a relative scratch hardness scale [7]. This method effectively improved the accuracy of hardness measurement and laid a solid foundation for later development of surface working. Workers found that cold working can increase the material hardness. Hence, researchers developed multiple cold working methods for the work hardening of materials. From the mid-1800s to the later, rolling, as a cold working method, was used on rail [6]. A few studies were published at the

end of the 19th century, focusing on the relationship between mechanical stressing and manufacturing procedures [8]. For instance, in 1895 Supplement on Surface Rolling determined the mechanical stressing between two contacted bodies via mathematical analysis [9]. Mechanical stressing process refers to the processing means where the required stress is actively introduced into the workpiece. The stress which is residual in the material caused by all kinds of manufacturing and processing means is termed as residual stress [10]. 
In the 20th century, the World War I and the World War II led people to focusing on increasing the strength and reliability of steels on weaponry [8]. Shot peening, as a cold work option, had gradually become a mainstream processing technology which increased the fatigue life of the components without changing the main shape. At the same time, the residual stresses in the peened surfaces were discovered, which were found correlating to the fatigue life. This discovery had a profound impact on the production and development of the shot peening industry [11], [12].

Since then, researchers had developed analytical models to predict the residual stress distribution in a materials surface caused by peening shot impact. They built mathematical models through inputting shot peening parameters, such as shot size, shot and target material properties, to simulate the residual stress distribution in the material surface. Researchers categorized four typical residual stress profiles, as shown in Figure 2-1. Figure 2-1 A and B show the residual stress distributions in thick peened target and thin peened target, respectively. Figure 2-1 C shows the hardness influence and Figure 2-1 D shows the velocity effect on the residual stress distribution. In Figure 2-1, $\alpha h_{p}$ and $\beta h_{p}$ are the depth of maximum residual stress in thick and thin target surfaces, respectively, $h_{p}$ is the depth of residual stress, $h$ is residual stress wave depth in thin material surface and $\sigma_{R}$ is residual stress. In addition, there was an alternative application of shot peening for shaping material, for example, one side of a metal plate was shot peened, which would produce spherical curvature on the plate. By implementing strict control of this process, the metal plate can be shot peened to the panels of large aircraft wings or other required shapes [4], [11], [13], [14]. 

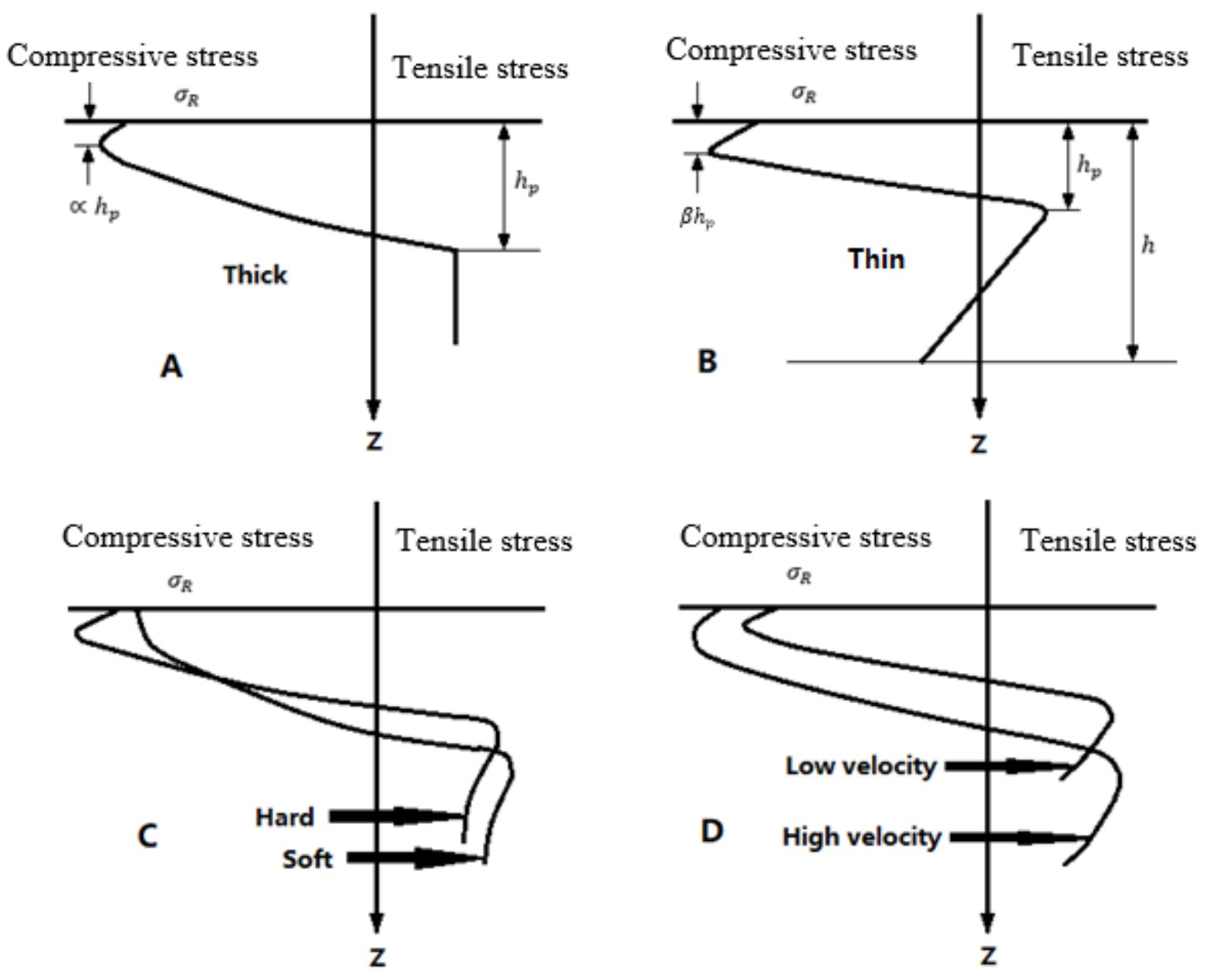

Figure 2-1 Influences of target surface thickness, hardness and peening velocity on residual stress distributions of a peened surface [4], [14]

\subsubsection{Fundamentals of Shot Peening}

Landing gear dynamics describes the shimmy, oscillation, and brake-induced vibration of landing gears, which is a significant issue that can affect the functions of all aircraft. These problems will lead to shortened fatigue life of the landing gear parts [15]. To improve the fatigue life, surface treatment is necessary for the components of landing gears, in particular, the flange pins of landing gears, as shown in Figure 2-2. 


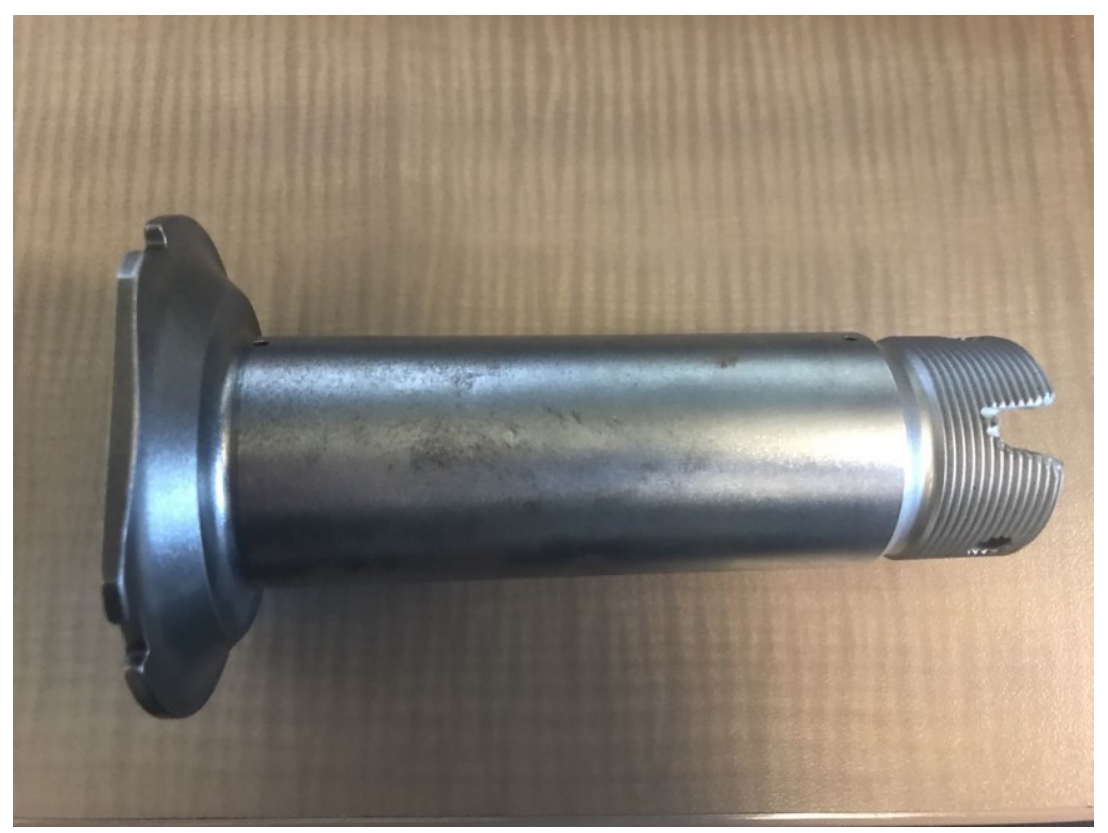

Figure 2-2 Flange pin of landing gear from Safran

Shot peening is a surface treatment, where small spherical peening shots are accelerated to a desired speed at target surface that can cause plastic deformation of the surface, generating residual stresses in the material surface [16]. It was convinced that the effect of shot peening was mainly related to induced residual stresses, especially for high-strength materials [17]. The complex nearsurface structure was composed of amorphous region, deformation zone and high dislocation density layer induced by the strains due to shot peening, as shown in Figure 2-3. The stacked dislocations can slow down the movement of the cracks in the material surface. These microstructure changes affected the cyclic deformation behavior and significantly reduced the plastic strain amplitude and cyclic fatigue life of the peened component [17]. The surface performance can be affected by induced residual stresses due to shot peening, and was also influenced by original surface defects, roughness, stacking energy and microstructure [4], [14]. 


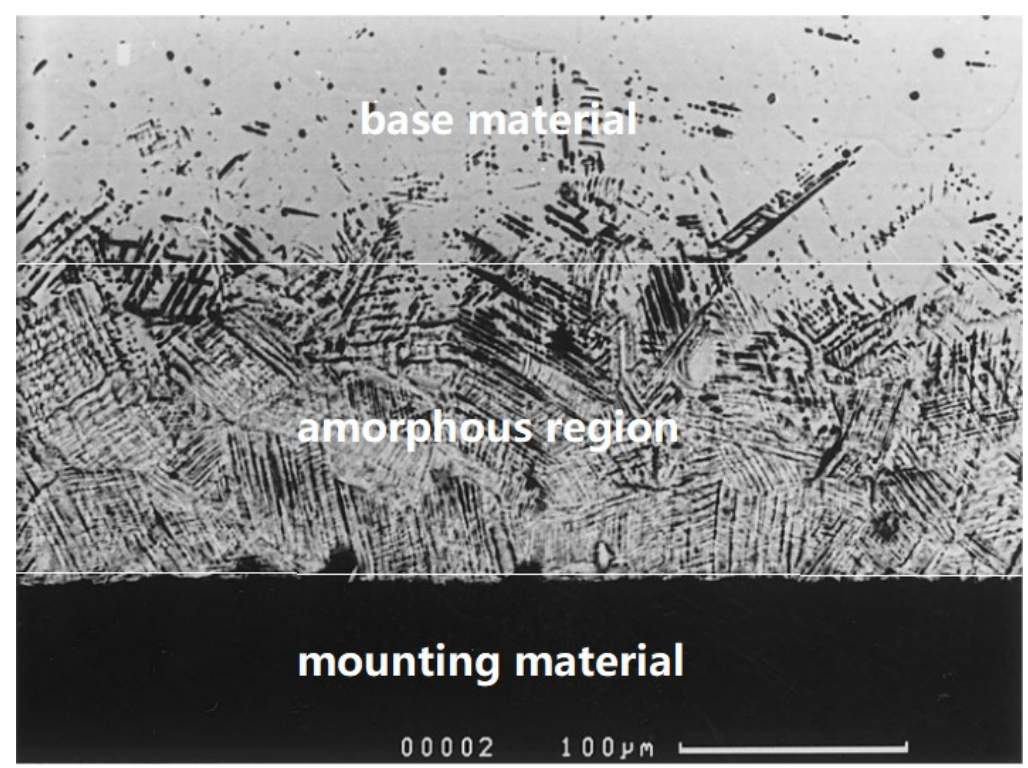

Figure 2-3 Shot peened AISI 304 steel near surface regions [17]

Shot peening coverage is a key parameter, which describes shot peening degree on the surface. Coverage up to $100 \%$ refers to the percentage of shot peened surface area. It is defined as the percentage of peened area in a given peened time, which can be described by Avarmi Equation [18]-[20]:

$$
C=\left[1-\exp \left(-\pi r^{2} \times R \times t\right)\right] \times 100 \%
$$

where $C$ is the coverage of shot peening, $r$ is the radius of each impact of shot, $R$ is the number of shots which impact the workpiece per unit area per unit time and $t$ is the time during which the impressions are being created.

The effects of shot size and each impression radius during the time length when shot peening can achieve 100\% coverage are illustrated in Figure 2-4 and Figure 2-5, respectively [18]. Figure 2-4 shows peened surfaces of different coverage levels. Figure 2-5 shows the residual stress distributions due to different coverage levels. [18], [19], [21]. 


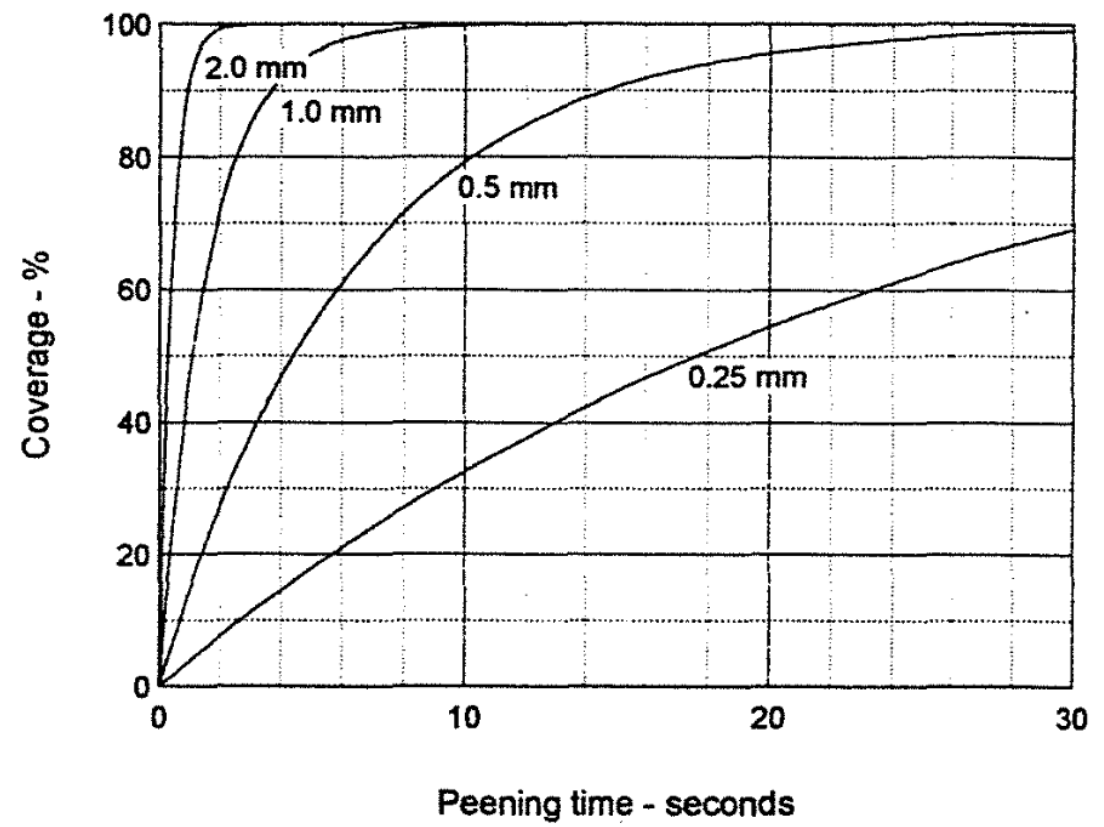

Figure 2-4 Effects of varying impression radius, $r$, at given peening rate, $R$ [18]

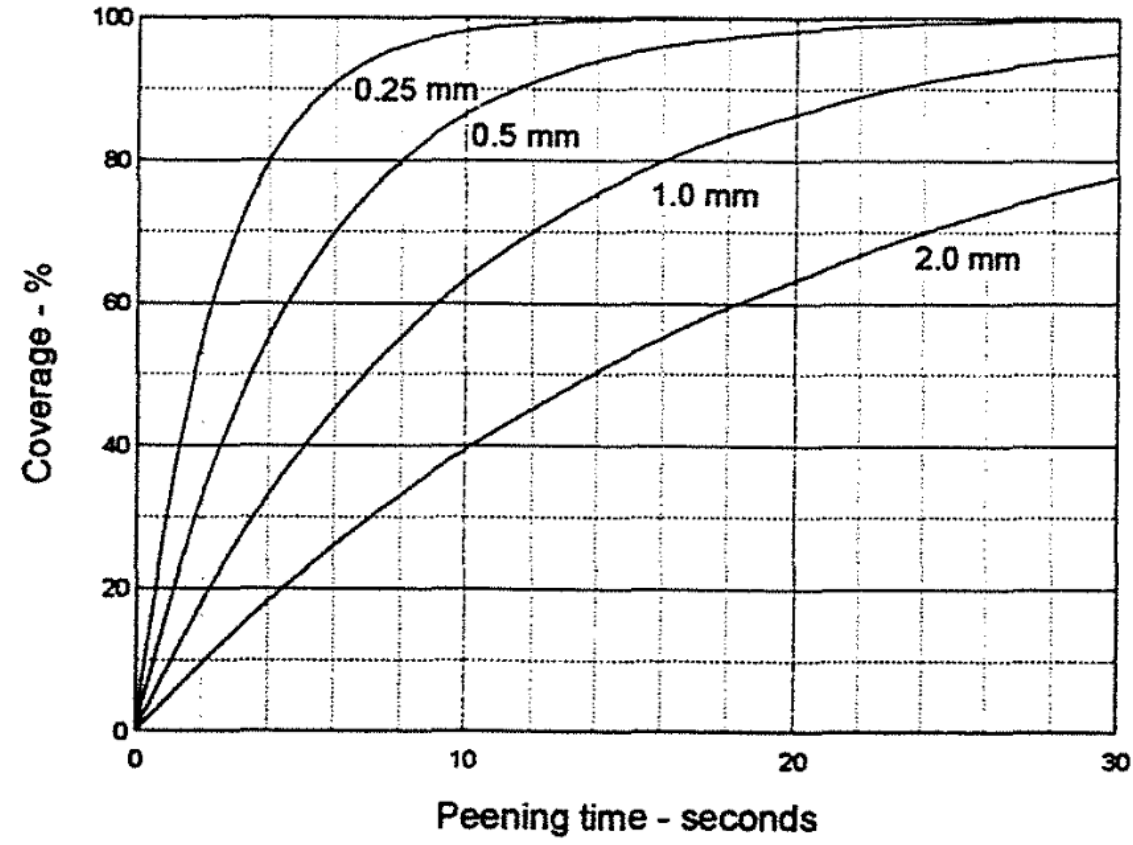

Figure 2-5 Effects of varying impression size for fixed shot throwing rate [18] 

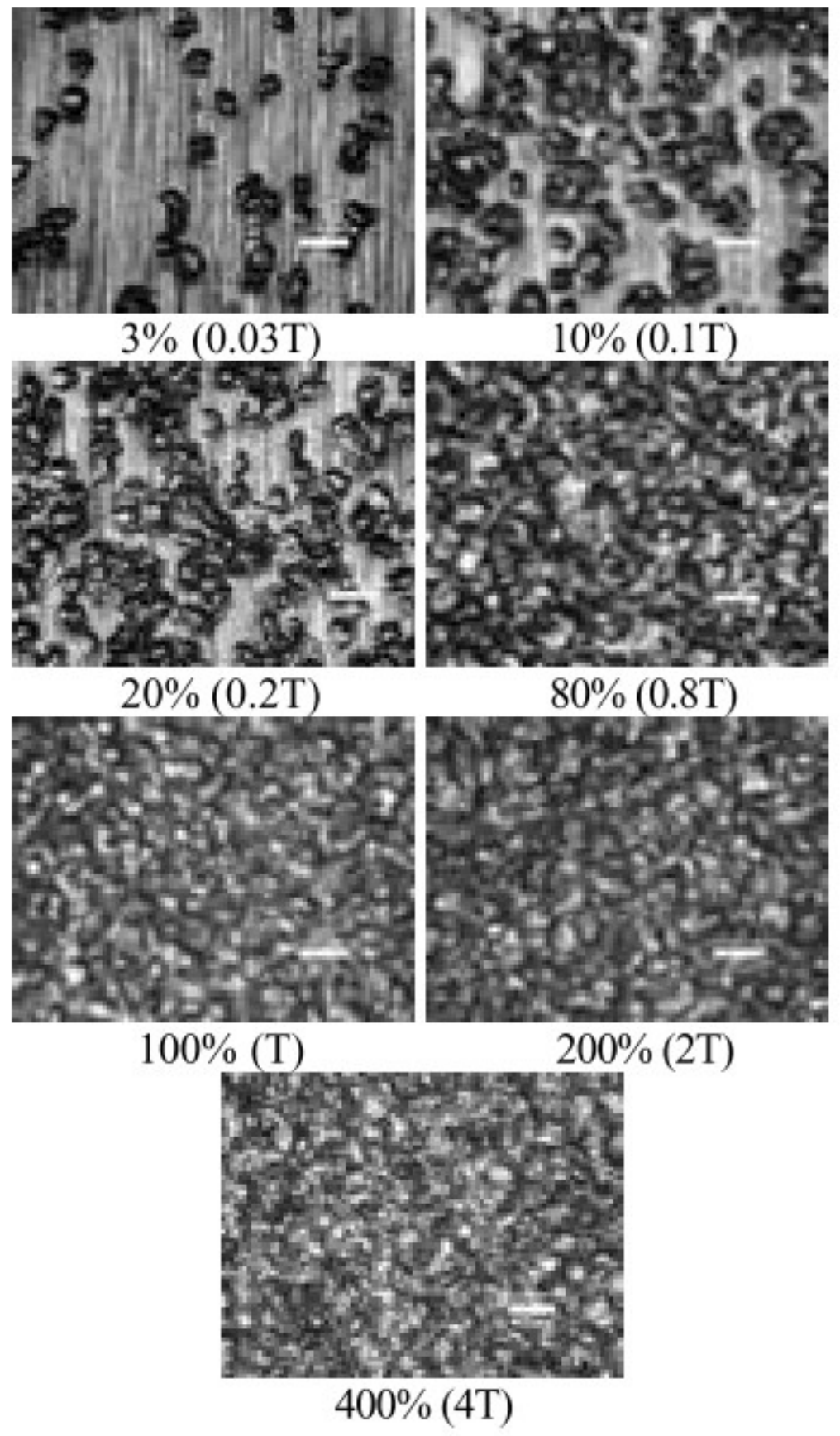

Figure 2-6 Peened surfaces of various coverage levels [21] 


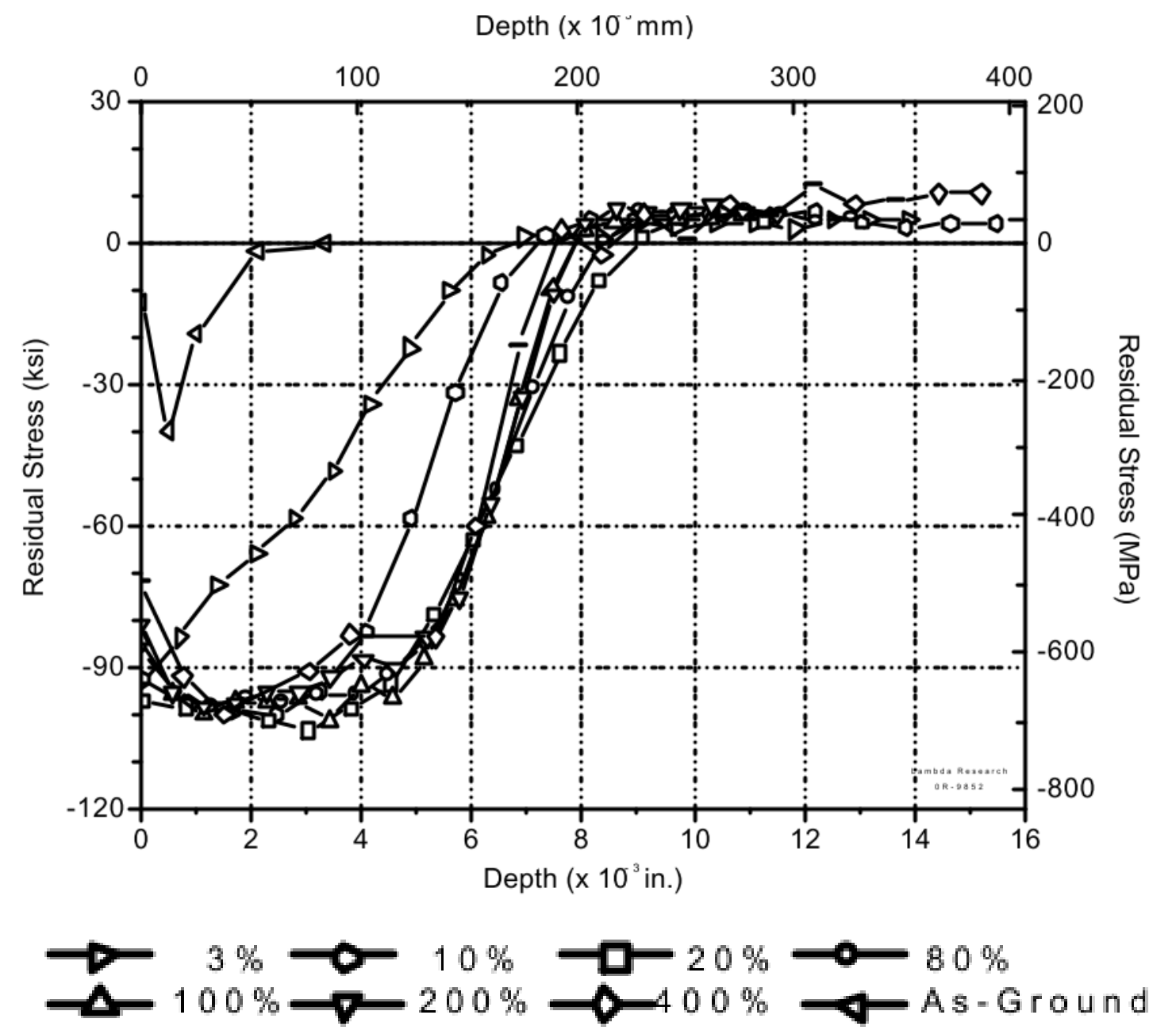

Figure 2-7 Residual stress-depth distributions for various coverage levels [21]

Theoretically, a peened surface can only achieve a coverage close to $100 \%$ according to Eq 2-1. Therefore, over $98 \%$ coverage is considered as "full coverage" and the time to achieve this coverage is the full coverage unit time. For example, $200 \%$ coverage needs twice the full coverage time, $150 \%$ coverage needs one and half the full coverage time, etc.

Almen intensity is another common indicator used to describe shot peening intensity. It requires shot peening full coverage. With the known shot type and velocity, the intensity can be determined. Almen strip is a thin steel strip made of SAE 1070 steel. The compressive stresses produced by 
peening operation cause the steel strip to change into an arch shape, where the Almen intensity corresponds to the arch height, $h$, as shown in Figure 2-8. Almen intensity can be divided into three types: A, N and C, which differ in used Almen strip type. The type of Almen strip is defined by its thickness. The unit of Almen intensity is the type of used Almen strip [22].
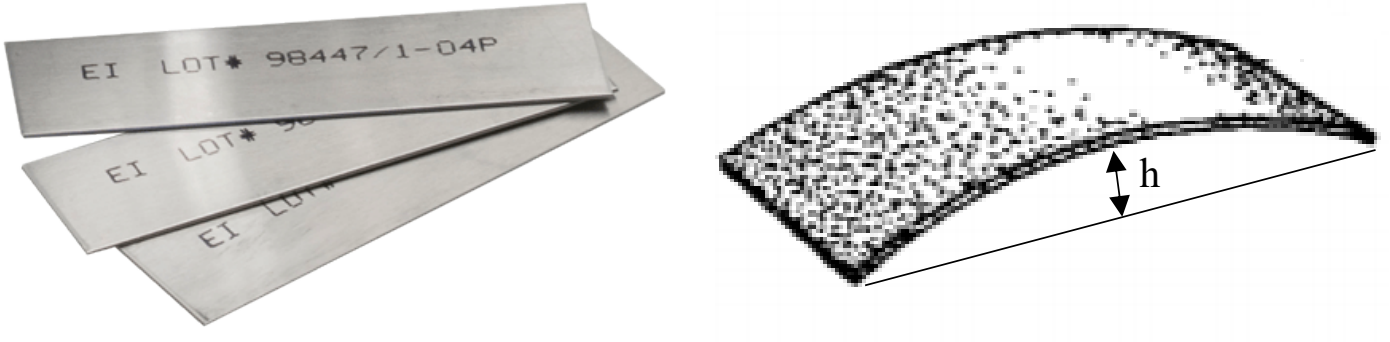

Figure 2-8 Almen strip for shot peening intensity measurement

\subsubsection{Shot Peening Effects on Fatigue Life}

Shot peening produces a compressive stress layer on the target surface [12]. These compressive stresses can delay the generation of initial cracks and slow down the growth of the cracks. With the development of various measuring techniques and the availability of advanced measuring equipment, the detailed shot peening results can be gained. People attempted various shot peening settings, properties and sizes of peening shots for different residual stresses and related them with the fatigue life of the peened component [2], [3], [18], [21]. The increased fatigue life was found to relate with the maximum residual stress and depth of the residual stress distribution [11]. As illustrated in Figure 2-9, the residual stress distributions vary in five different treated surfaces. The HTF surface is hard turned fresh, HTWL represents hard turned white layer which is a phase transformed layer at the surface by work hardening, GF is ground fresh and GWL is ground white layer. Among these surfaces, the fatigue life of the HTF surface is the longest, which has the largest 
and deepest compressive stresses. However, the tensile residual stress near the surface can cause low fatigue life of the component. The difference of residual stress between the GF and GWL surface is that the latter has some tensile residual stresses near the surface. Then the difference in fatigue life between these two surfaces shows a harmful effect of tensile residual stresses near the surface [23], as indicated in Figure 2-10.

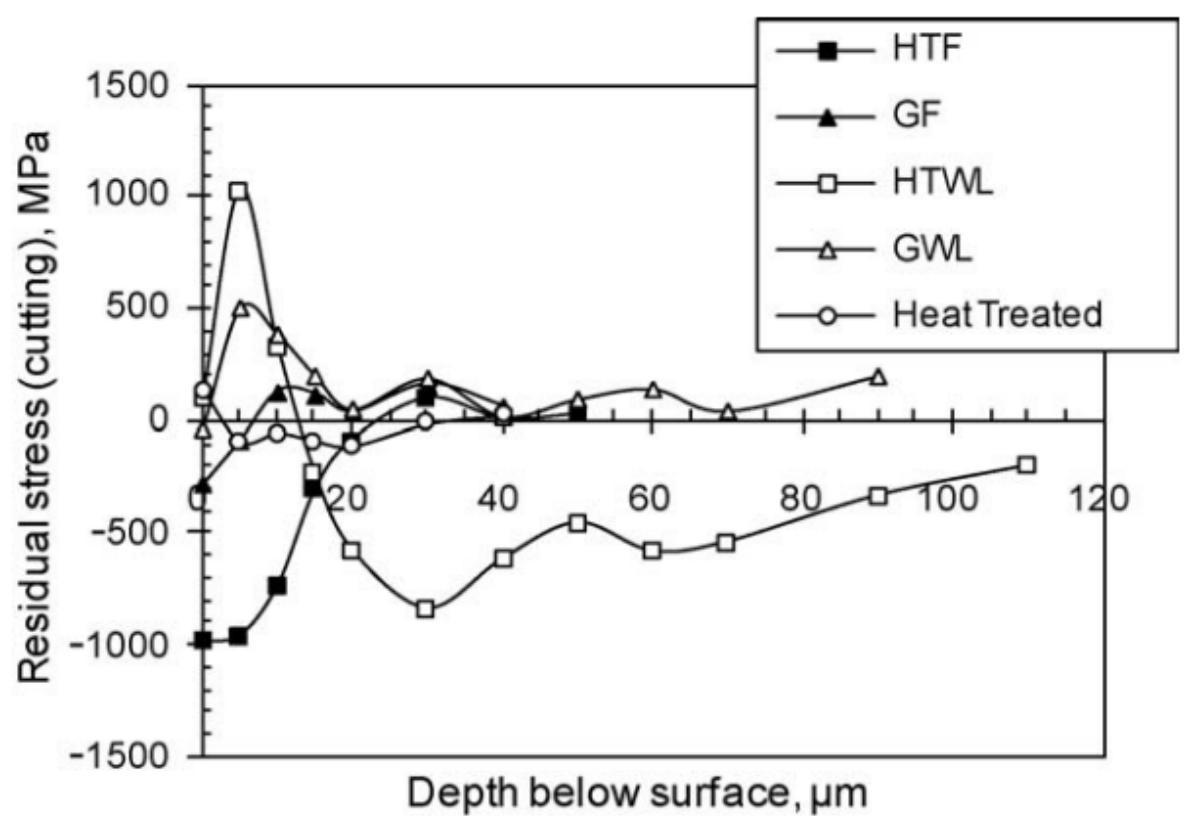

Figure 2-9 Residual stress profiles in different treated surfaces [23] 


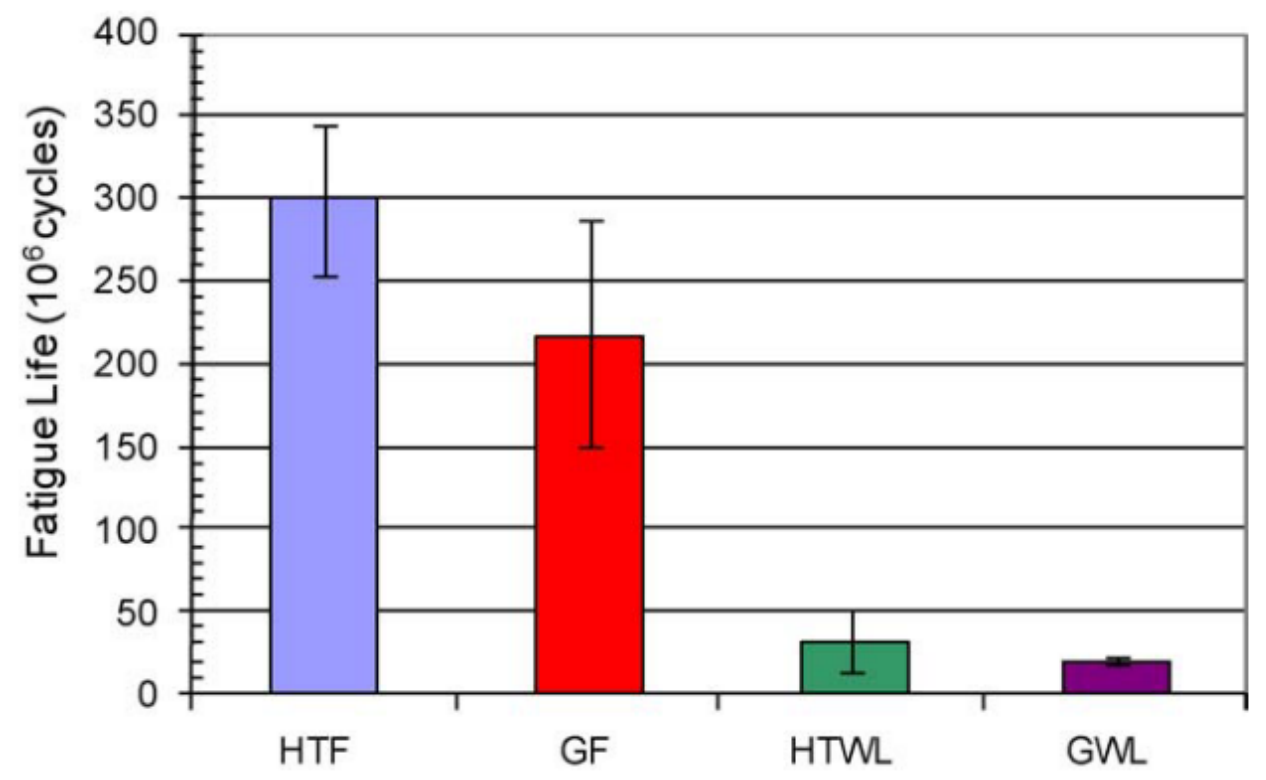

Figure 2-10 Fatigue life chart for different treated surfaces [23]

Shot peening does not always improve the fatigue life of the component. For example, high intensity shot peening on some high strength alloys might lead to "fold-like" defects, as shown in Figure 2-11. These defects will cause stress concentrations that accelerate crack initiation [24]. 

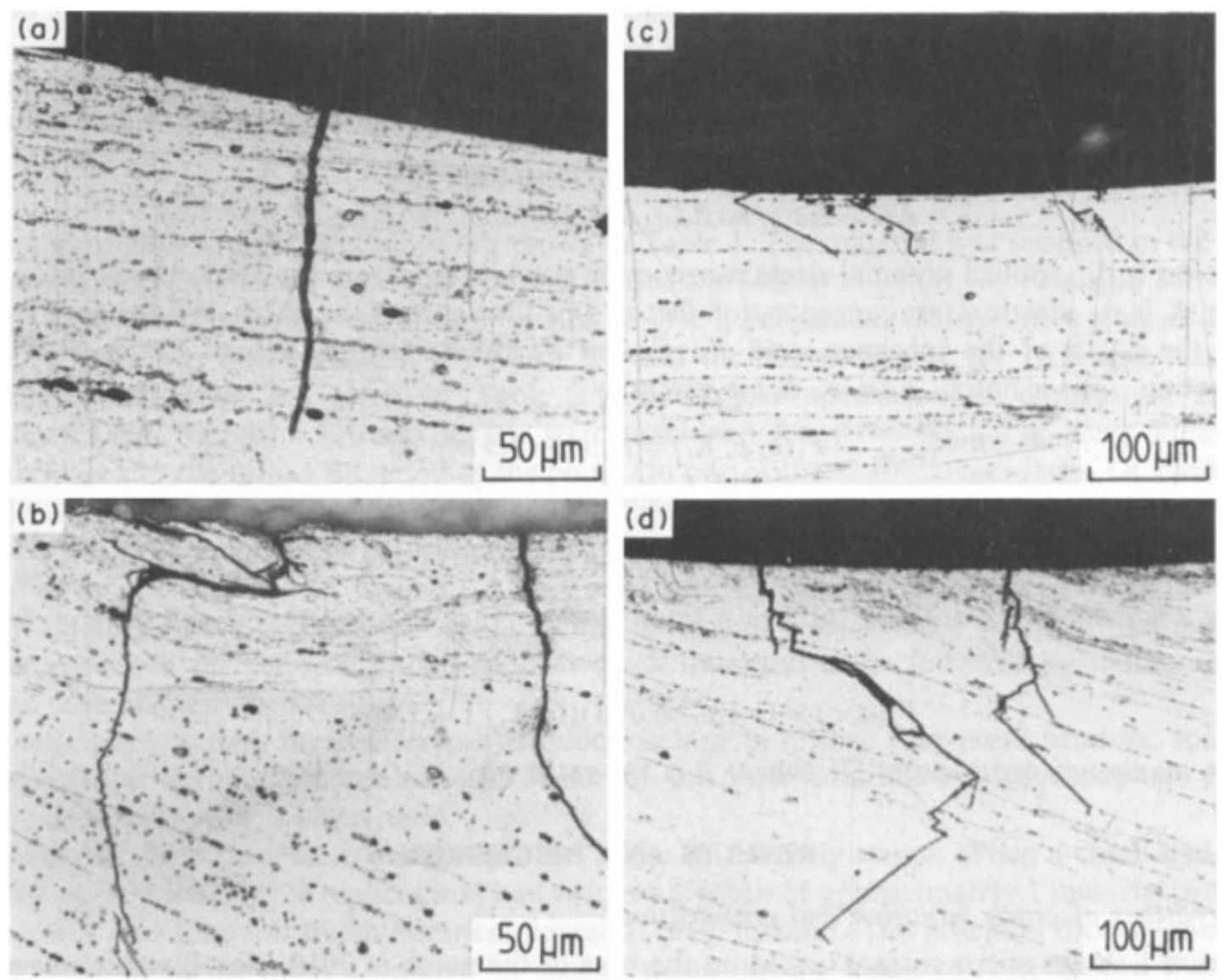

Figure 2-11 Fatigue crack paths in (a) unpeened 7010 alloy specimen, (b) peened 7010 alloy specimen, (c) unpeened 8090 alloy specimen, (d) peened 8090 alloy specimen [24]

In most cases, residual stresses can effectively increase the fatigue life of the peened component. However, load, temperature, and fatigue cycling, etc. can lead to residual stress relaxation which cause the reduction of residual stress. Thus, the increased fatigue life due to residual stresses will diminish with the stress relaxation. The residual stresses can also be alleviated with temperature increase. For example, a research showed that larger fatigue load can speed up residual stress relaxation and reduce the fatigue life, as illustrated in Figure 2-12. Figure 2-13 shows that high temperature can also cause residual stress relaxation [23], [25], [26]. 


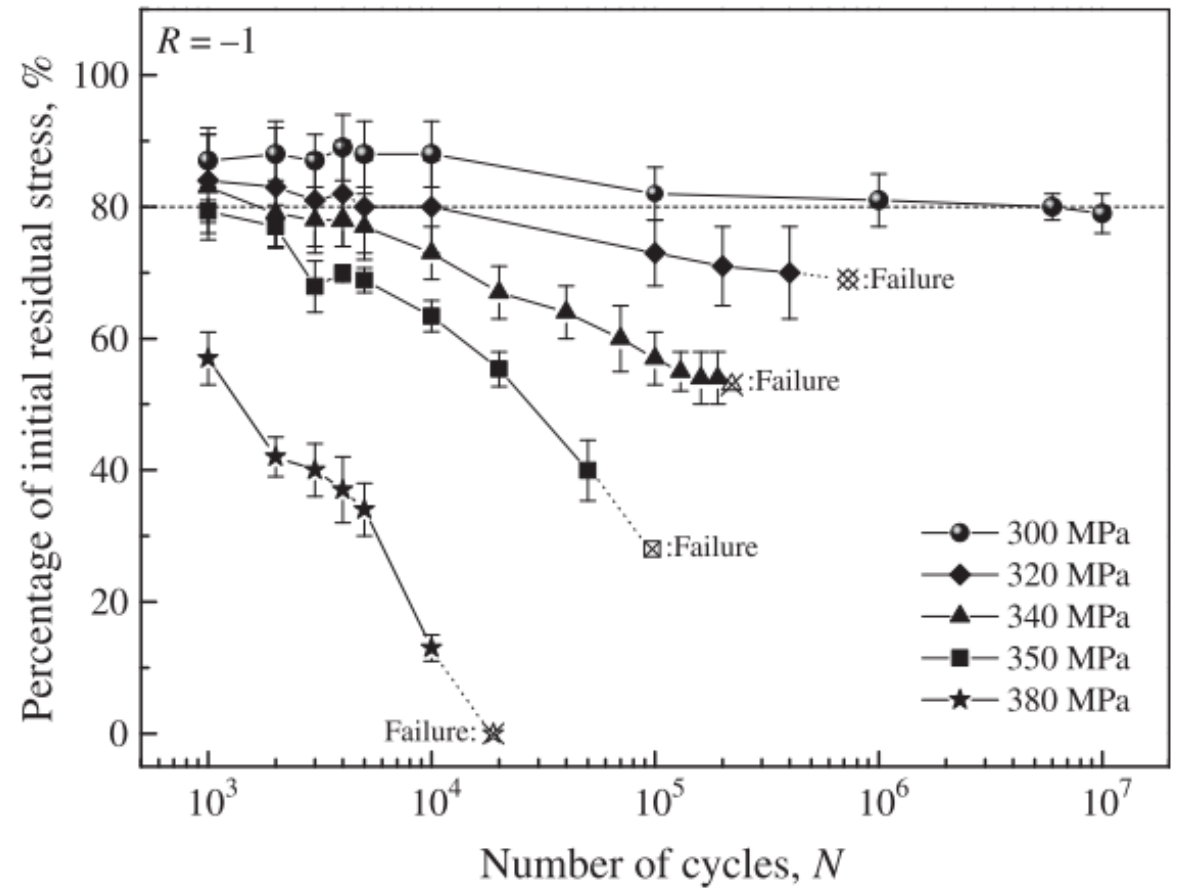

Figure 2-12 Percentage of initial residual stress versus number of cycles under fatigue loading. Dashed line indicates the critical boundary of threshold-residual stress relaxation [25]

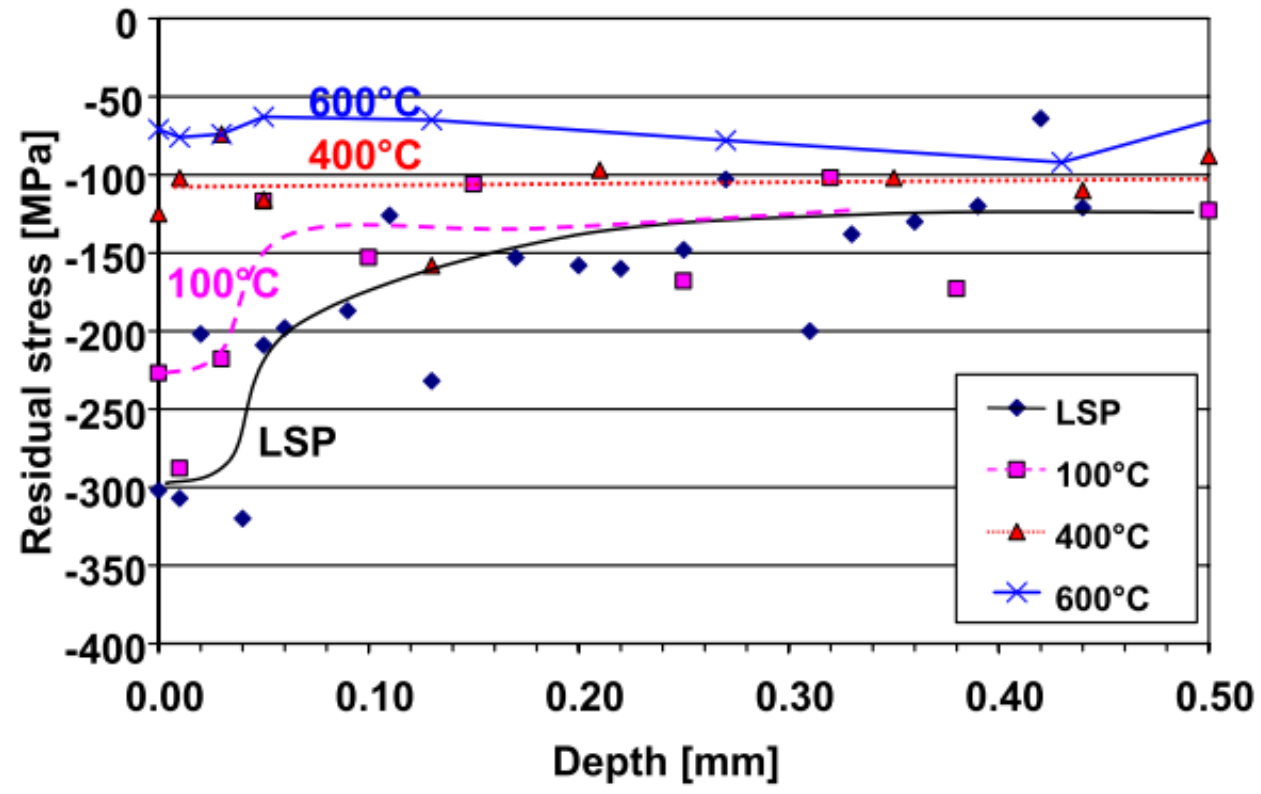

Figure 2-13 Residual stress depth profiles of fatigued laser-shock peened AISI 304 after 2000 cycles at different temperatures [26] 


\subsection{Residual Stress Measurement}

As discussed above, residual stresses in a component can considerably influence the material performance, such as fatigue life, distortion, dimensional stability, corrosion resistance, brittle fracture, etc. These material characteristics usually govern significant costs in replacing and repairing of the component. Therefore, residual stress measurement is a necessary process in material design stage. Residual stress measurement methods can be classified into three different categories: destructive, semi-destructive and non-destructive method. A typical destructive method is sectioning technique. Deep-hole method as a developed method from sectioning technique belongs to semi-destructive method. Base on the accuracy and practicability, X-ray diffraction method is a mainstream non-destructive method [27], [28].

\subsubsection{Sectioning Technique}

The sectioning technique for residual stress measurement has been applied for decades. It is a destructive method that requires to break the tested specimen. It measures the specimen deformation due to the release of residual stress. This method is through slitting the specimen into multiple slices and measuring their changes in length thus to calculate the residual stresses [28], [29].

Plastic deformation and heat should be avoided to introduce into the specimen during sectioning [28], [29]. The residual stress can be calculated from the following formula, which is widely used in the residual stress analysis of structural carbon steel, aluminum and stainless steel.

$$
\sigma=\frac{E}{1-v^{2}}\left[\frac{\left(A_{0}-A\right) \varepsilon}{2 A}\right]
$$


where $E$ is the Young's modulus, $v$ is Poisson's ratio, $A_{0}$ is original cross-section of the specimen, $A$ is bored area, $\varepsilon$ is $\varepsilon_{t}+\mu \varepsilon_{e}$ where $\varepsilon_{t}$ and $\varepsilon_{e}$ are the strains in longitudinal and circumferential directions, respectively [28], [29]. Figure 2-14 shows HE 360B wide flange section after sectioning [30].

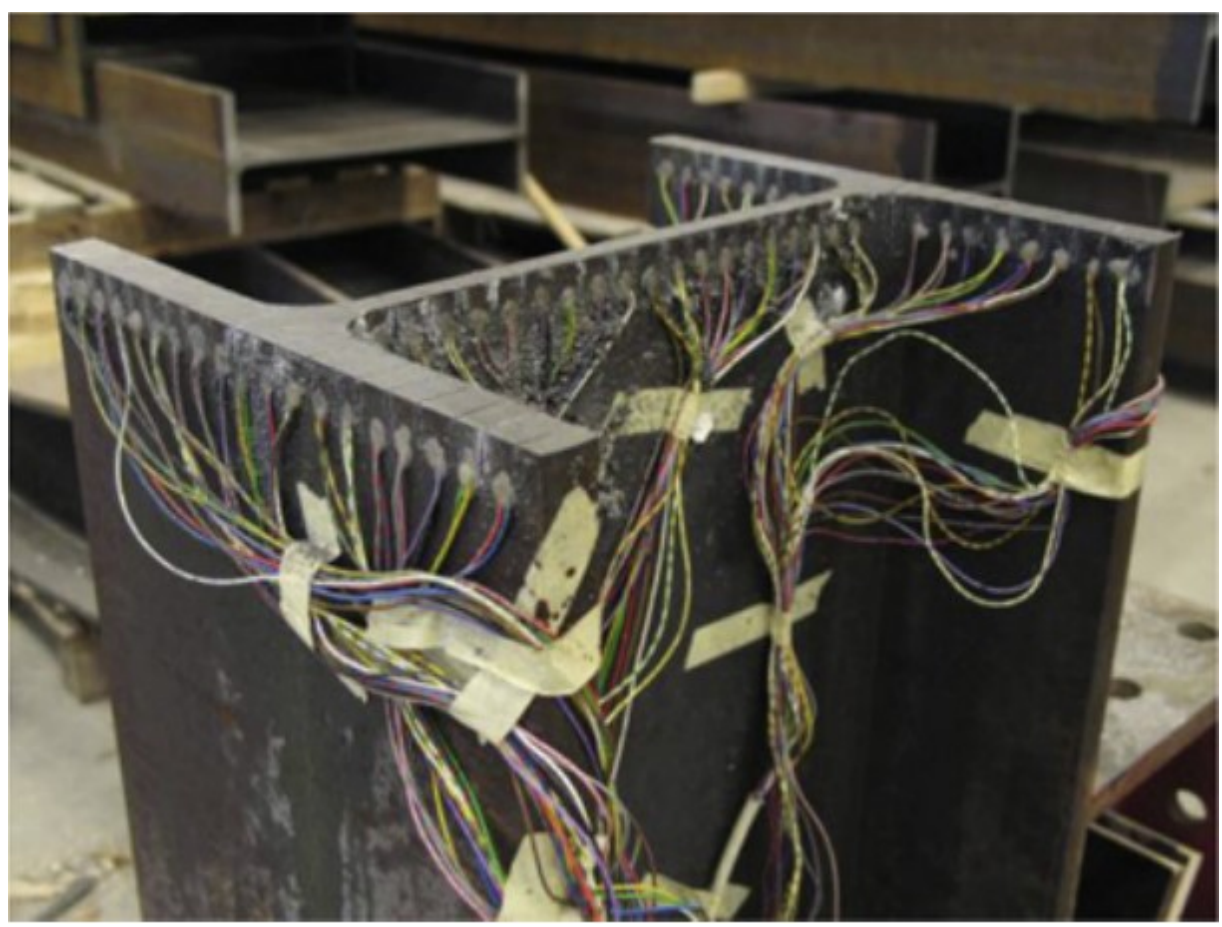

Figure 2-14 HE 360B wide flange section after sectioning for residual stress measurement [30] 


\subsubsection{Deep Hole Method}

The deep hole method for residual stress measurement combines hole-drilling and ring-core.

Firstly, a hole is drilled through the specimen and the diameter of the hole is measured. The core material of the hole is then removed to release the residual stresses in the core. Finally, the diameter of the hole is remeasured, and the residual stresses are calculated according to the change of the hole diameter. The coordinate system for deep-hole measurement is defined in Figure 2-15, where $\vartheta$ is angular coordinate [31].

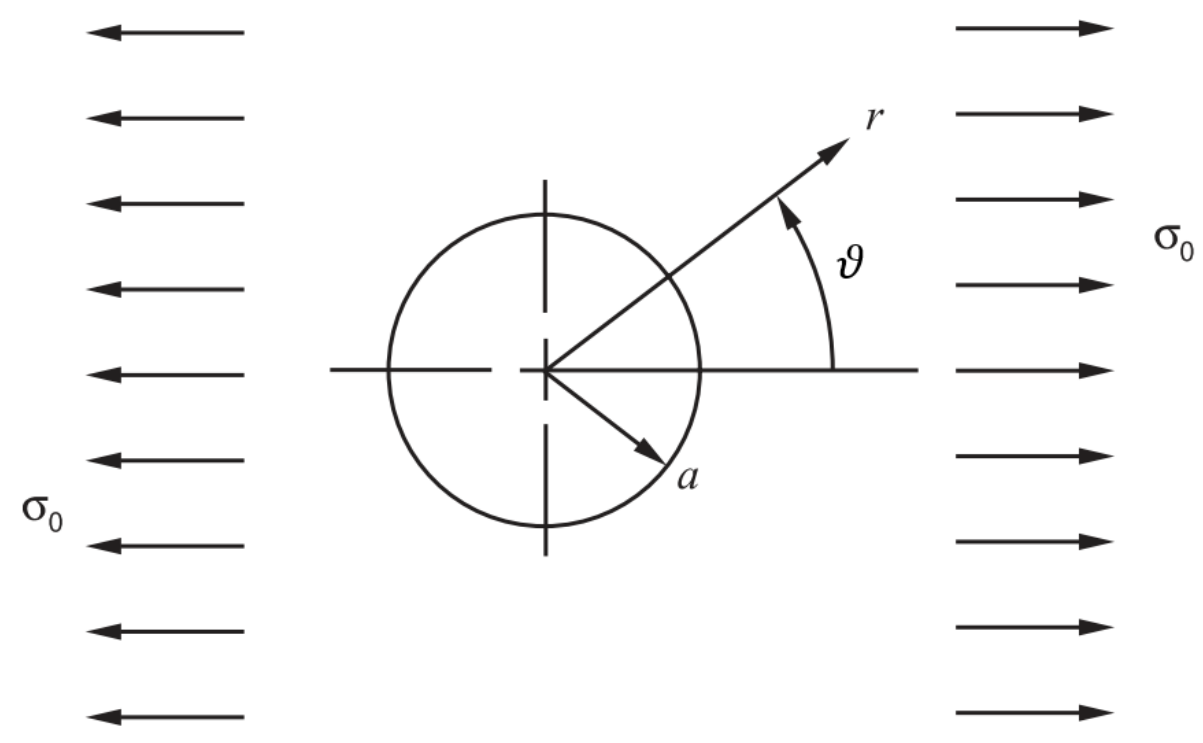

Figure 2-15 Geometry and coordinate system for deep hole method of residual stress measurement [31]

The residual stress is [31]

$$
\sigma=-E M^{*} \cdot u
$$


where $E$ is young's modulus, $M$ is the matrix containing $f_{\vartheta_{i}}, g_{\vartheta_{i}}$ and $h_{\vartheta_{i}}$ coefficients and relating applied stresses to measured radial distortions, $M^{*}$ is the pseudo-inverse of $M$ and $u$ is the vector of radial distortions at the hole edge measured at $\vartheta_{N}$ angles. $M$ is determined as [31]

$$
M=\left[\begin{array}{ccc}
f_{\vartheta_{1}} & g_{\vartheta_{1}} & h_{\vartheta_{1}} \\
\vdots & \vdots & \vdots \\
f_{\vartheta_{i}} & g_{\vartheta_{i}} & h_{\vartheta_{i}} \\
\vdots & \vdots & \vdots \\
f_{\vartheta_{N}} & g_{\vartheta_{N}} & h_{\vartheta_{N}}
\end{array}\right]
$$

where $f_{\vartheta_{i}}$ is the coefficient relating applied $x$-direction stress to radial distortion measured at angle $\vartheta_{i}, g_{\vartheta_{i}}$ is the coefficient relating applied $y$-direction stress to radial distortion measured at angle $\vartheta_{i}$ and $h_{\vartheta_{i}}$ is the coefficient relating applied shear stress to radial distortion measured at angle $\vartheta_{i}$. $f_{\vartheta_{i}}, g_{\vartheta_{i}}$ and $h_{\vartheta_{i}}$ are determined as [31]

$$
\mathrm{u}=\left[\begin{array}{c}
\left.\mathcal{U}\right|_{\vartheta=\vartheta_{1}} \\
\vdots \\
\left.\mathcal{U}\right|_{\vartheta=\vartheta_{\mathrm{i}}} \\
\vdots \\
\left.\mathcal{U}\right|_{\vartheta=\vartheta_{\mathrm{N}}}
\end{array}\right]
$$

where $u$ is radial distortion at the hole edge [31].

The deep hole technique for residual stress measurement has become a standard method for isotropic materials. This method has low cost and wide application. However, when the residual stress exceeds $50 \%$ of the yield stress, the local yield may cause errors. [31]. 


\subsubsection{X-ray Diffraction (XRD) Method}

The X-ray diffraction method for residual stress measurement is considered as a non-destructive technique which has been widely used in various surfaces of materials. This technique does not need to break the specimen surface, but in some cases, the size limitation of the X-ray equipment requires the specimen to be cut to fit the device chamber. The XRD technique takes advantages of the fact that when a metal is subjected to stresses, the resulting elastic strain will cause the atomic planes in the metal crystal structure to change their spacing. XRD can directly measure the atomic distance between these planes so that the total stresses in the metal can be determined.

\subsubsection{X-ray diffraction theory}

The diffraction principle of a monochromatic X-ray beam in two directions relative to the X-ray beam at a large diffraction angle $(2 \theta)$ on the surface of the stressed specimen is illustrated in Figure 2-16. The angle between the normal of the surface and the bisector of the incident beam and diffracted beam is the angle $\psi$. Bragg's Law defines the diffraction occurring at an angle $2 \theta$ :

$$
n \lambda=2 d_{l} \sin \theta
$$

where $n$ is an integer denoting the order of diffraction, $\lambda$ is the X-ray wavelength, $d_{l}$ is the lattice spacing of crystal planes, and $\theta$ is the diffraction angle. If there is a tensile stress in the specimen the lattice contracts with a Poisson's ratio. Hence, the lattice spacing decreases, and the diffraction angle $2 \theta$ slightly increases. Then the measurement direction is defined by angle $\varnothing$ and the specimen is rotated through a known angle $\psi$, as shown in Figure 2-16, the tensile stress on the surface increases the lattice spacing and decreases $2 \theta$. The residual stress in the specimen surface on the diffraction plane can be calculated by measuring the change of the diffraction peak in 
different values of angle $\psi$. Each calculation needs at least two different values of angle $\psi$ of the specimen rotation [32].

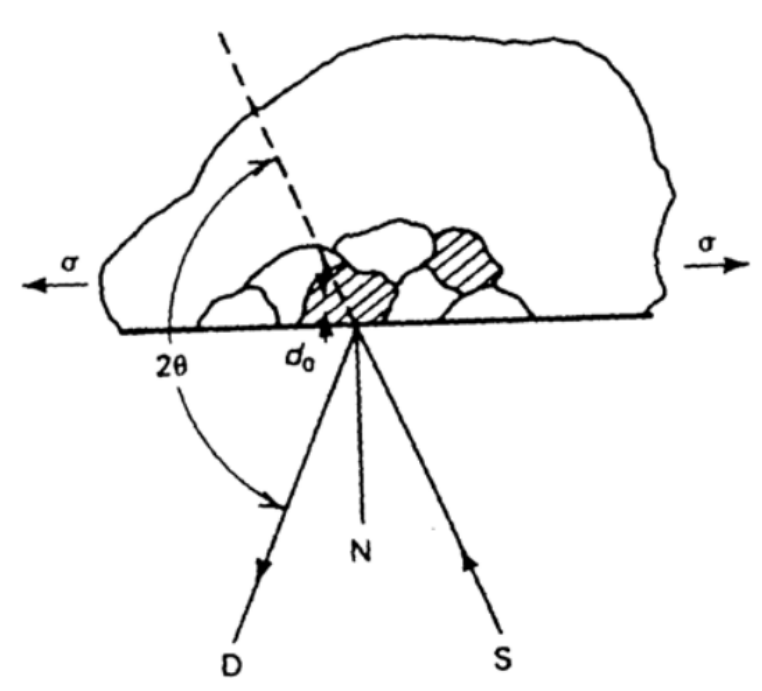

(a)

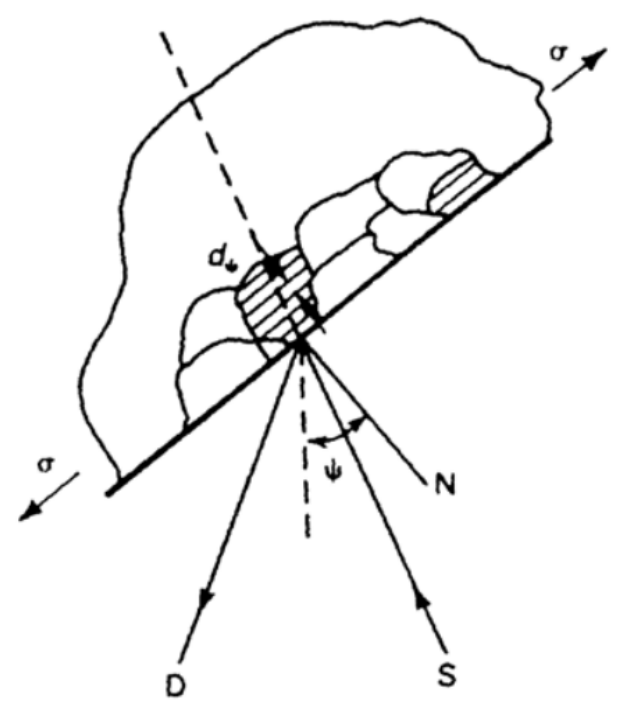

(b)

Figure 2-16 Illustration of the principle of X-ray diffraction stress measurement: (a) $\boldsymbol{\psi}=\mathbf{0}$; (b) $\boldsymbol{\psi}=\boldsymbol{\psi}$ (sample rotated through some known angle $\boldsymbol{\psi}$ ). D, x-ray detector; S x-ray source; $\mathrm{N}$, normal to the surface [32] 


\subsubsection{Linear $D-\sin 2 \psi$ relation}

XRD residual stress measurement starts with angle $\psi=0$, followed by gradually increasing the angle $\psi$, in order to obtain linear correlation as accurately as possible.

The strain $\varepsilon_{\emptyset, \psi}$ in the direction defined by the angles $\varphi$ and $\psi$ is:

$$
\varepsilon_{\varnothing, \psi}=\frac{D_{\varnothing, \psi}-D_{0}}{D_{0}}=\left(\frac{1+v}{E}\right) \sigma_{\varnothing} \sin ^{2} \psi
$$

where $E$ is the modulus of elasticity, $v$ is Poisson's ratio. $D$ denotes the inter-atomic spacing which is the measured value of the XRD process. Each peak in a diffractogram results from a corresponding inter-atomic spacing. The foot marker of $D$ indicates the measurement angle $\psi$ and direction $\emptyset . D_{0}$ denotes the original inter-atomic spacing.

Because $D$ is the measured value and angle $\psi$ is measurement setting, thus, using $\frac{D_{\emptyset, \psi}-D_{0}}{D_{0}}$ as the $y$ axis and $\sin ^{2} \psi$ as the $x$-axis of the measurement output, a linear relation can be obtained, with the slope being $\left(\frac{1+v}{E}\right) \sigma_{\emptyset}$. Since the elastic modulus $E$ and Poisson's ratio $v$ values are known, because they are material properties, the residual stress $\sigma_{\emptyset}$ can be calculated [32], [33]. 


\subsection{FEA Simulation of Surface Peening}

Finite element method (FEM) or finite element analysis (FEA) is a popular approach to solving engineering problems. Typical cases include structural load analysis, heat transfer, fluid flow, mass transfer and electromagnetic potential. Experimental determination of residual stress has certain limitation due to the facility capacities. For example, XRD technique can only measure the stresses at a surface. If the stress distribution within a certain depth is required, experimental methods exhibit deficiency. Differently, FEA simulation is able to deal with the residual stress problems which cannot be solved experimentally. In industry, using FEM simulation to predict the stress distribution is a trending way for cost-saving purpose. Particularly, FEA can simulate the effects of different shot materials, peening intensity and coverage on the generated residual stress profile.

FEM is favorable to simulate shot peening process and analyze the residual stresses generated in the peened surface for several reasons:

1. FEM can predict the surface performance (stress and strain or deformation) after peened with given process parameters.

2. FEM can provide guidelines to achieve desired residual stress distribution in the surface layer by changing the peening process parameters.

3. FEM can help designers optimise shot peening process and reduce the experimental and measurement necessary.

The type of FEA model used depends on the requirements of the analysis and the desired results [22], [34]. 


\subsubsection{FEA Modelling of Residual Stresses in TC4 Surface Layer}

2D and 3D FEA models were created for simulating the residual stress layer on TC4 surface resulting from shot peening process, as shown in Figure 2-17. The stress contour of $\sigma_{11}$ (residual stress in $X$ direction) in 2D shot peening model is shown in Figure 2-18 (a) and Figure 2-18 (b) shows the variation of the residual stress $\sigma_{11}$ along the depth from top surface at three chosen locations in the 2D model. Figure 2-19 shows the coverage rate of shot peening with different impacts in the $3 \mathrm{D}$ model. Single impact means the coverage rate is $25 \%$ and each impact can increase $25 \%$ coverage rate until $100 \%$. Figure $2-20$ (a) shows the stress contour of $\sigma_{11}$ in the 3D shot peening model and Figure 2-20 (b) shows the contour of deformed surface after shot peening. Figure 2-21 illustrates the variation of residual stress $\sigma_{11}$ along the depth from top surface at five chosen locations in the 3D model and the experiment results measured by X-ray method for comparison [35]. However, for saving the calculation time this model is fragmentary and peening impacts are regular, which does not represent real peening process. Certainly, this simplified model would deteriorate the accuracy of the simulation. 

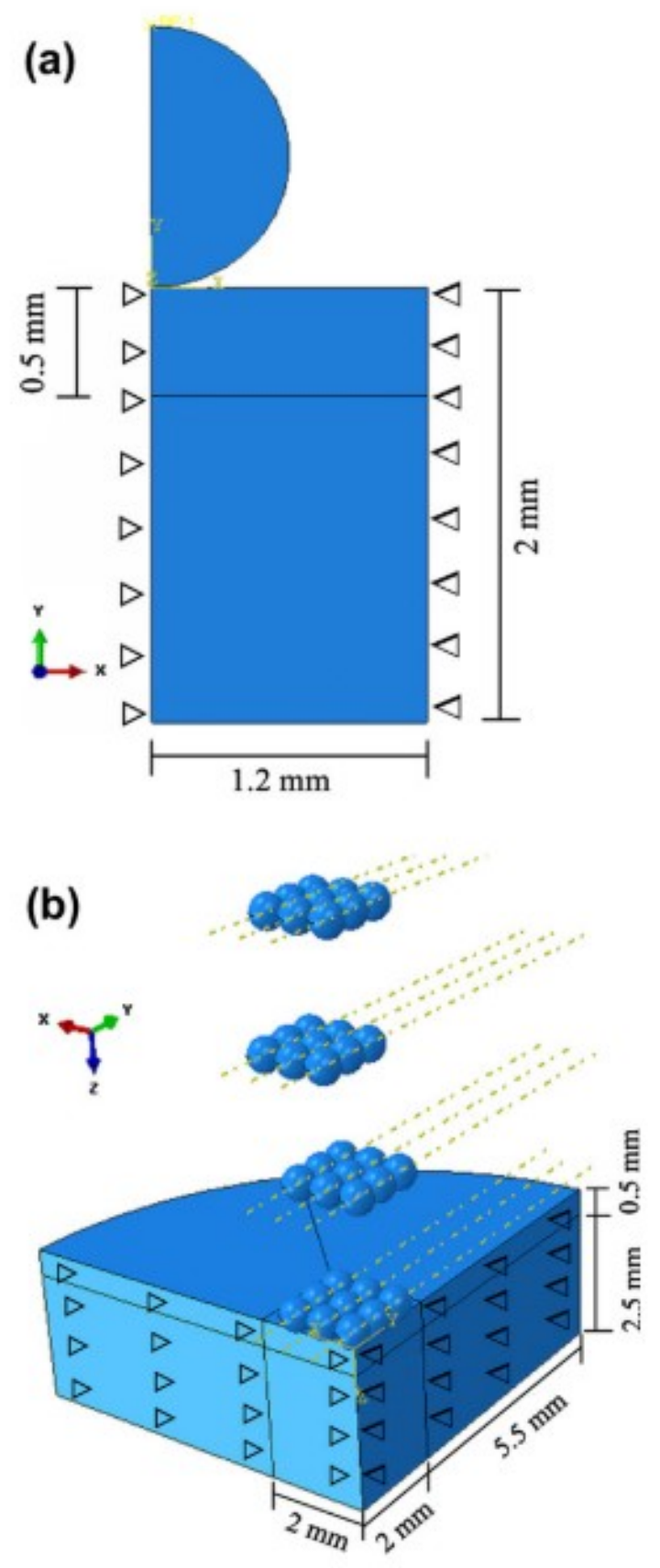

Figure 2-17 Simulation of shot peening: (a) 2D FEA model; (b) 3D FEA model [35] 
(a)

S, S11

(Avg: 75\%)
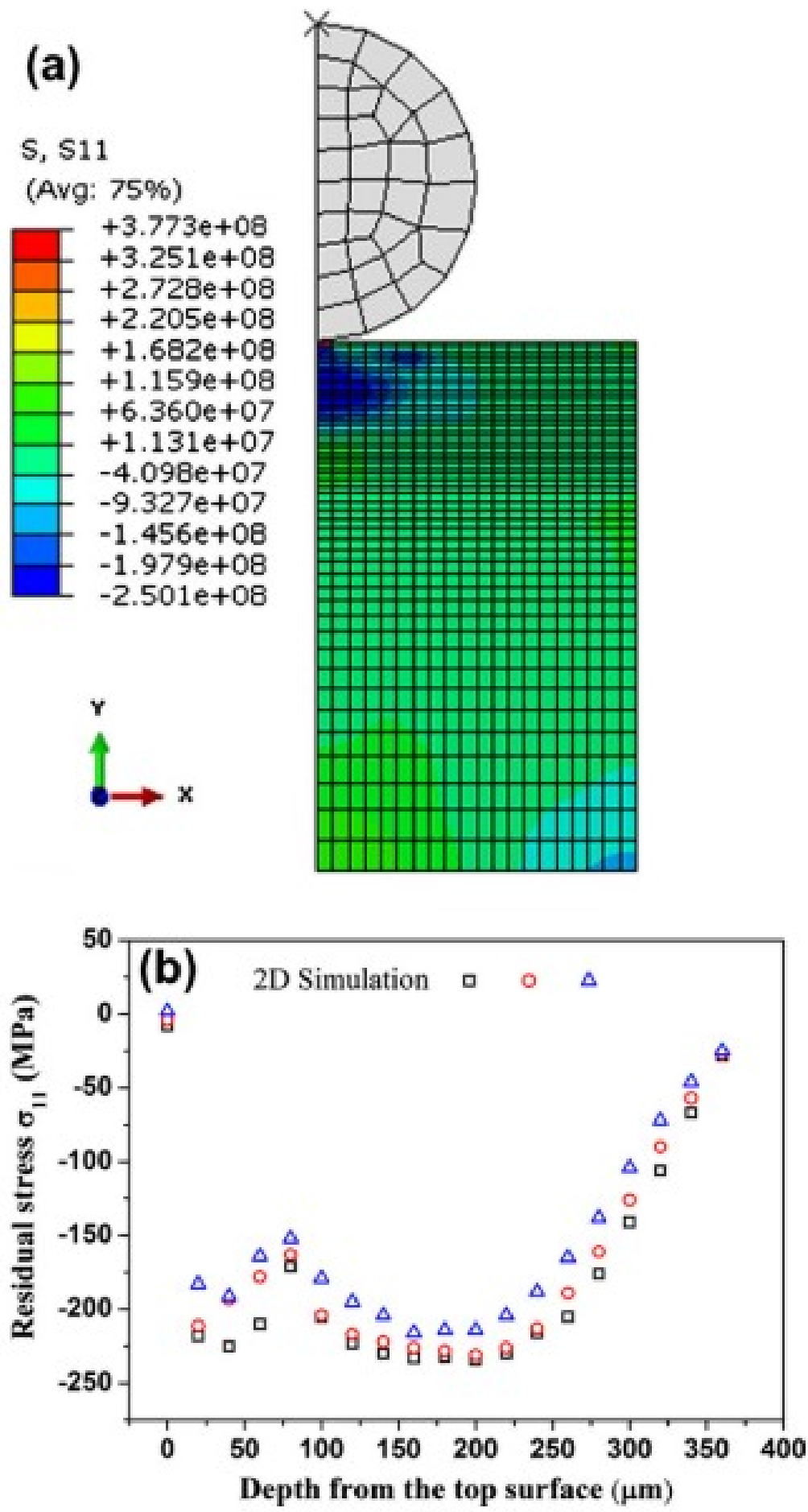

Figure 2-18 FEA simulation results of 2D model: (a) stress contour of $\sigma_{11}$; (b) variation of residual stress $\boldsymbol{\sigma}_{\mathbf{1 1}}$ along the depth from top surface [35] 


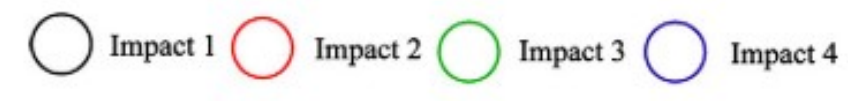

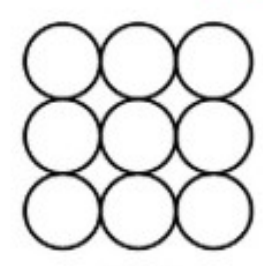

$25 \%$

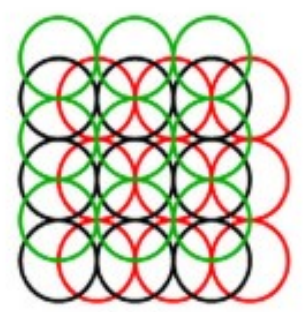

$75 \%$

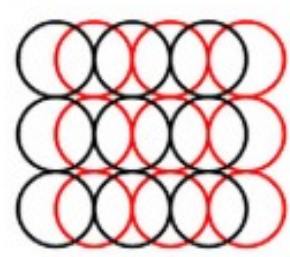

$50 \%$

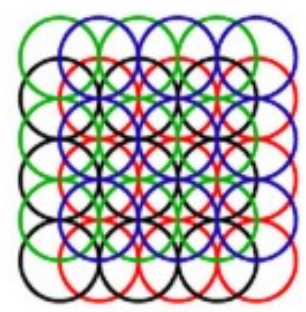

$100 \%$

Figure 2-19 Coverage rates of shot peening with different impacts [35]

(a)

S, S11

(Avg: 75\%)

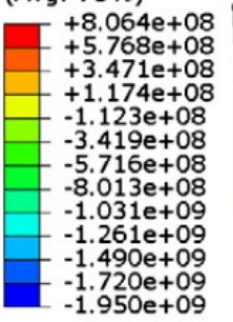

$-1.950 \mathrm{e}+09$

${ }^{x} \int^{x}$

(b)

S, S11
(Avg: $75 \%$ )

$+8.064 e+08$

$+5.768 \mathrm{e}+08$

$+3.471 \mathrm{e}+08$

$+1.174 \mathrm{e}+08$

$-1.123 e+08$

$-3.419 e+08$

$-8.013 e+08$

$-1.031 \mathrm{e}+09$

$1.261 \mathrm{e}+09$

$-1.490 \mathrm{e}+09$

$-1.720 \mathrm{e}+09$

$1.950 \mathrm{e}+09$
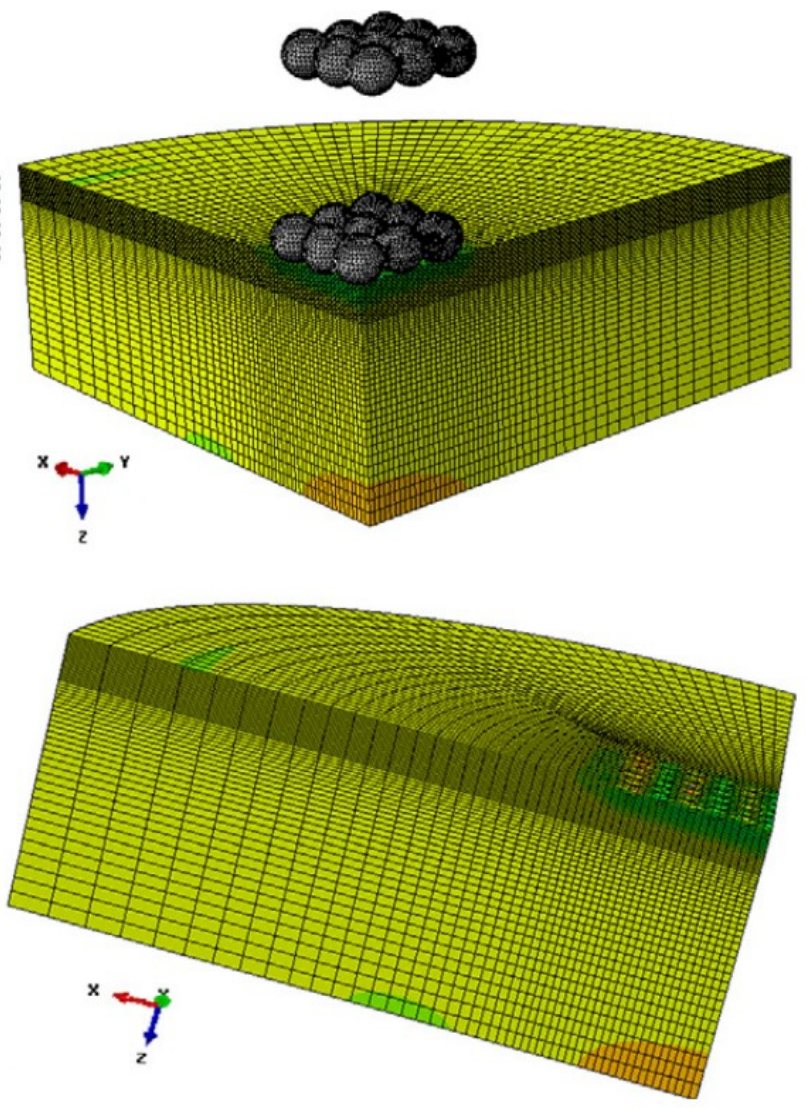

Figure 2-20 Simulation results of 3D model: (a) stress contour of $\boldsymbol{\sigma}_{\mathbf{1 1}}$; (b) contour of deformed surface after shot peening [35] 


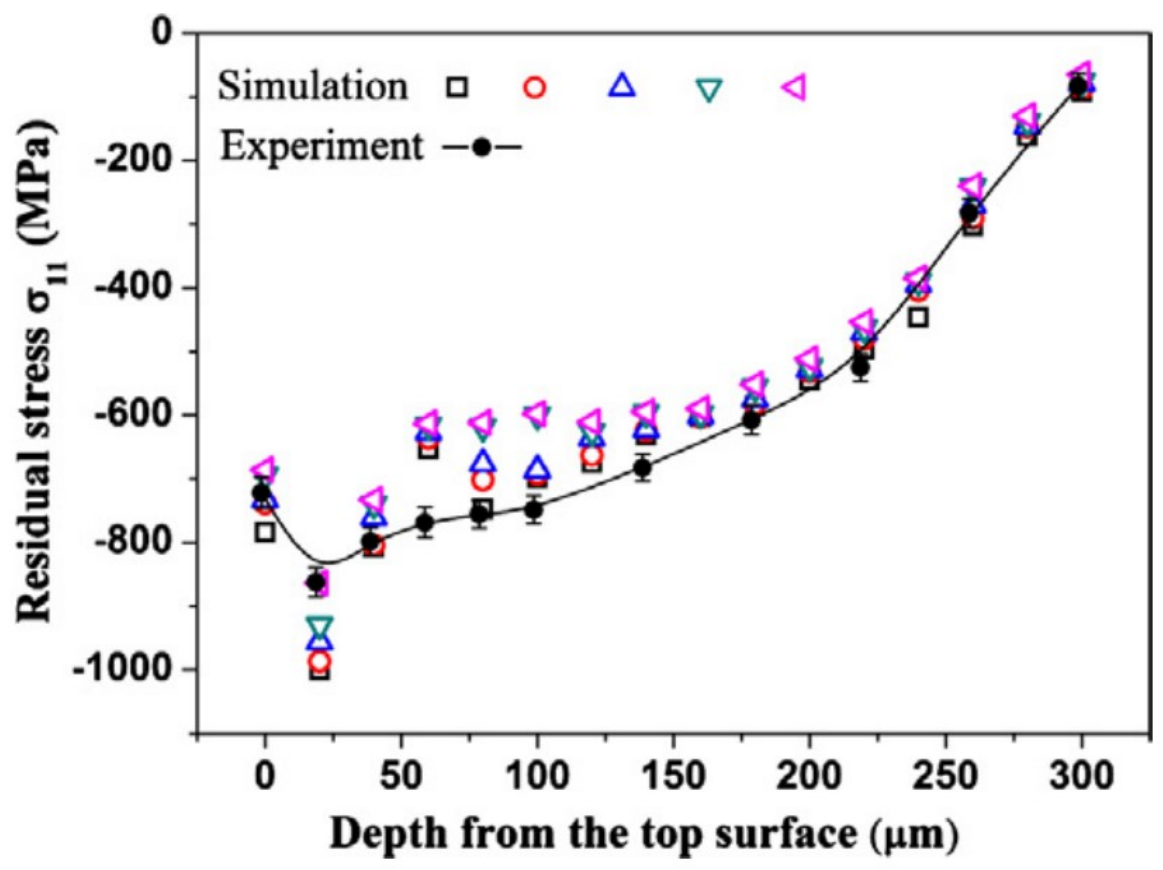

Figure 2-21 Variations of residual stress $\boldsymbol{\sigma}_{\mathbf{1 1}}$ in 3D model along the depth from top surface and experiment results measured by X-ray method [35] 


\subsubsection{Random Shot Peening FEA Model}

A random shot peening FEA model was created for fitting practical shot peening process, as shown in Figure 2-22. This model simulated 20 to 200 peening shot impact on the target surface. The peened area was divided into four parts A11, A10, A01 and A00. The contours of displacement in the depth direction of the surface layer, Von Mises stress and stress $\sigma_{11}$ in $x$ direction after 200 impacts are shown in Figure 2-23, Figure 2-24 and Figure 2-25, respectively. The average residual stresses due to 20 to 200 peening impacts are illustrated in Figure 2-26 [36].

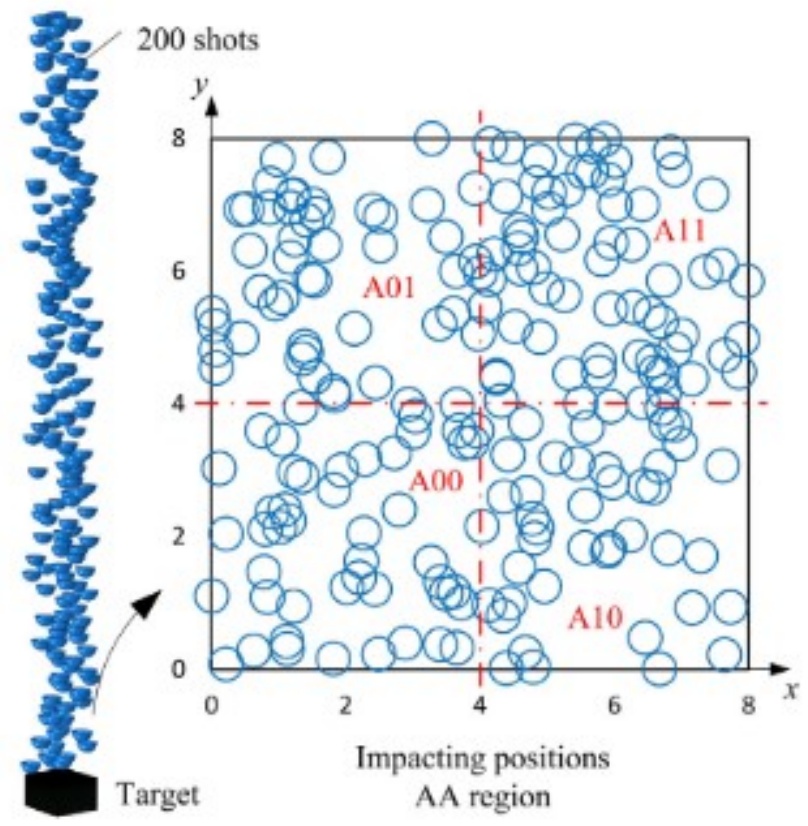

Figure 2-22 FEA model with two hundred shots impacting target surface at random positions [36] 

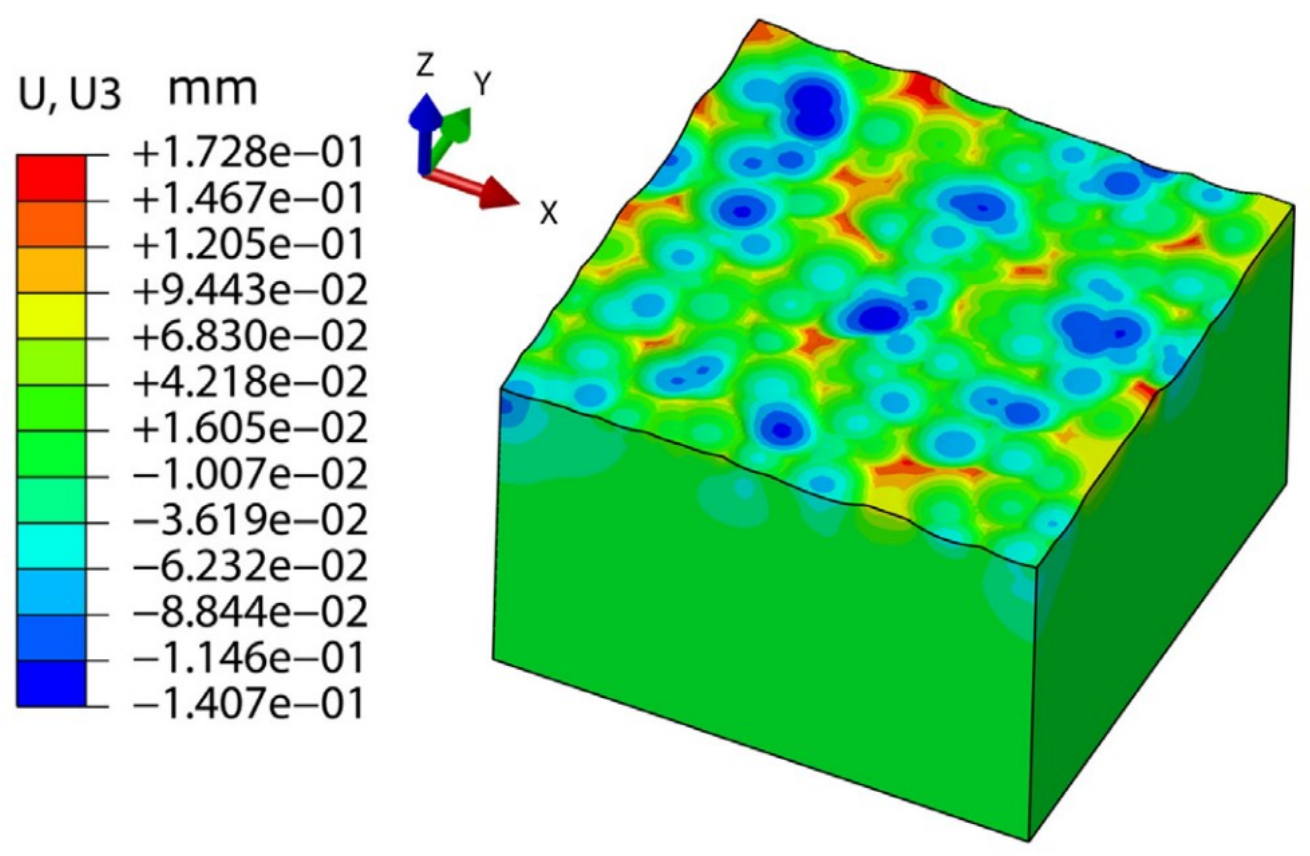

Figure 2-23 Contour of displacement in depth direction of target surface due to 200 impacts [36]

\section{S, Mises}

(Avg: 75\%)
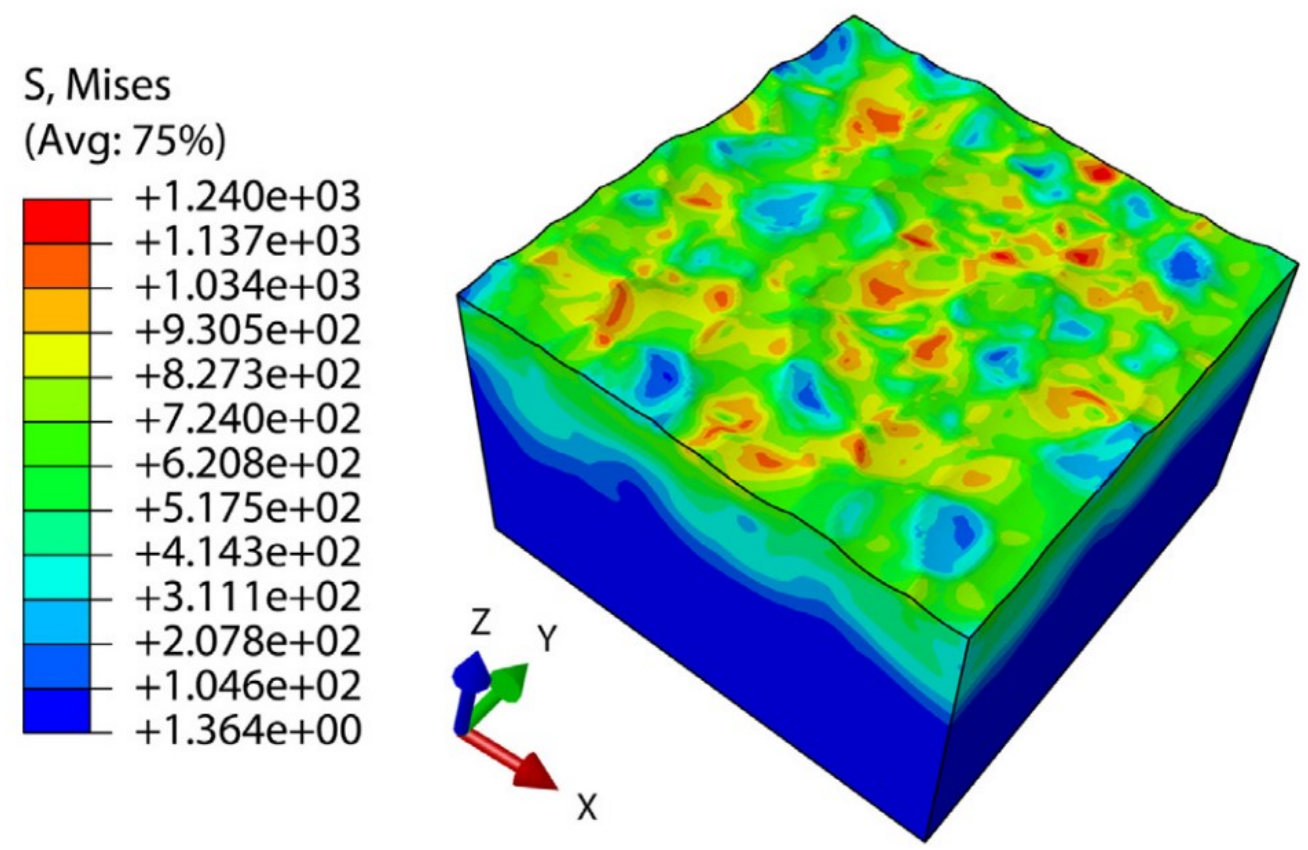

Figure 2-24 Contour of Von Mises stress due to 200 impacts within whole peening region [36] 
S, S11

(Avg: 75\%)
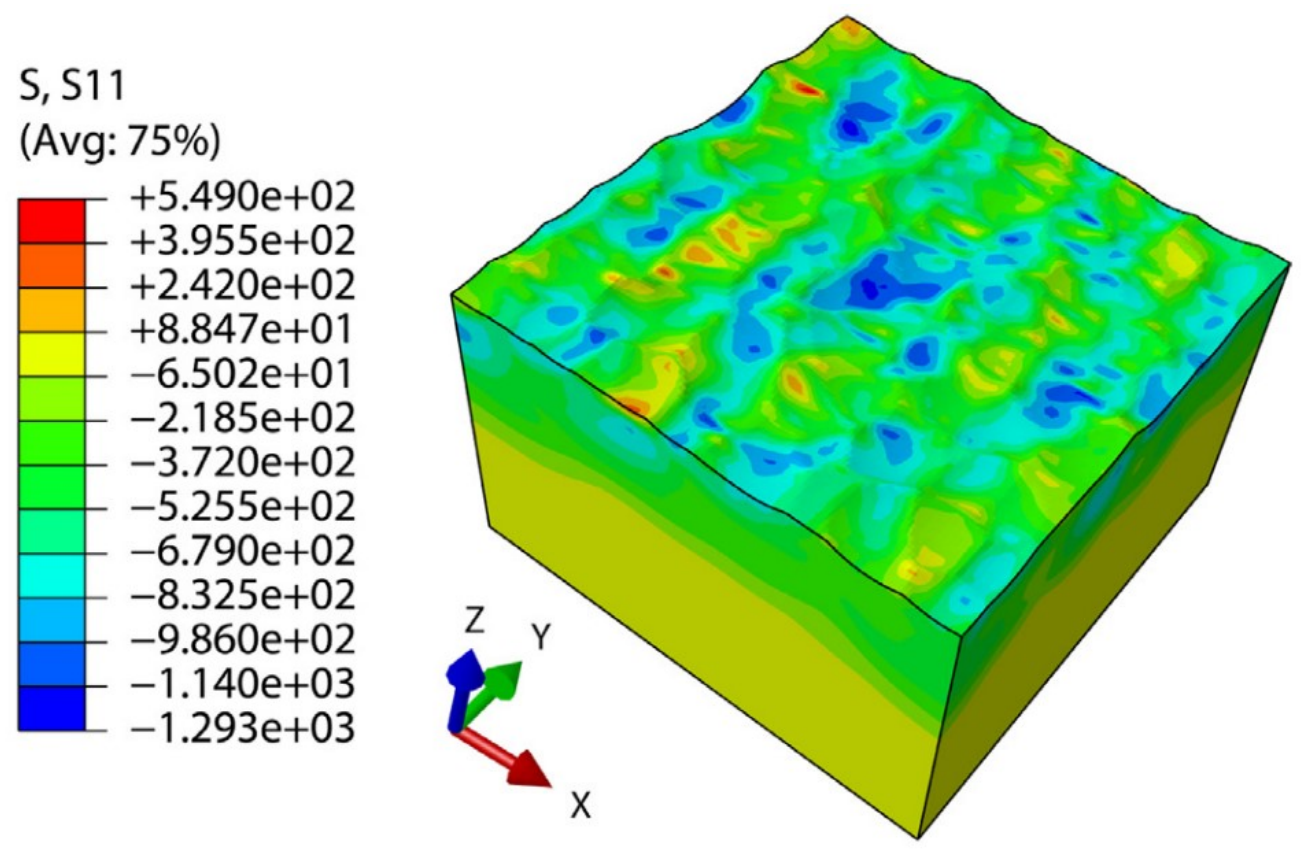

Figure 2-25 Contour of stress $\boldsymbol{\sigma}_{\mathbf{1 1}}$ in $x$ direction due to 200 impacts within whole peening region [36]

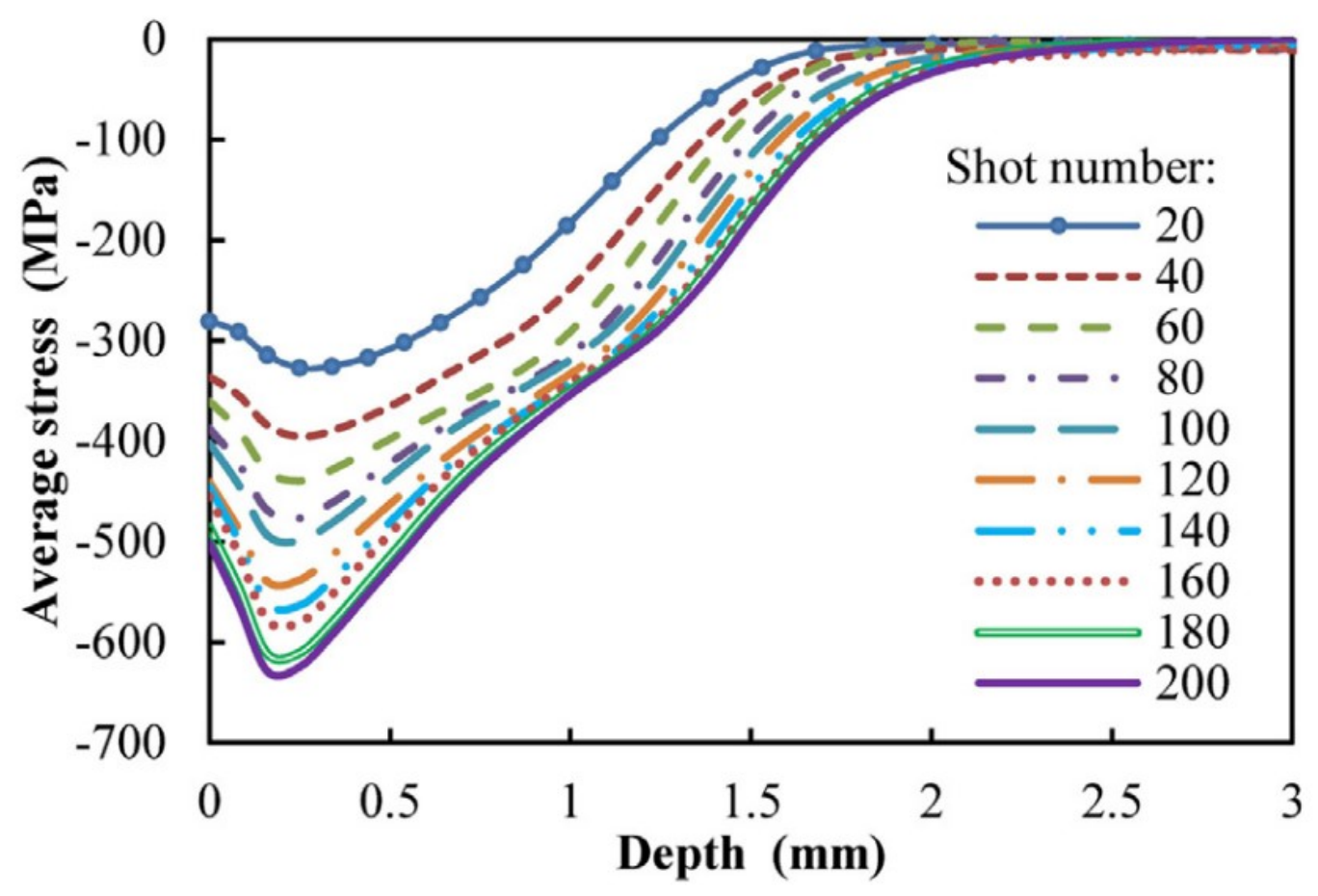

Figure 2-26 Average stress within peened region versus peening shot number [36] 


\subsubsection{Peening Angle and Shot Diameter Models}

To better simulate shot peening process and represent actual peening condition, a 3D FEA model was constructed by Murugaratnam for analyzing the effect of peening angle and shot diameter on the residual stress distribution in the peened surface layer, as shown in Figure 2-27. This model simulated the peening process on a surface using four different shot diameters at two peening angles, $90^{\circ}$ and $35^{\circ}$. The red circle in Figure 2-28 was the shot peening simulation area and the midpoint of the red circle was the measured point. The residual stress distributions in depth direction $Y$ from top surface were determined for the peening with the four shot diameters at the two peening angles, are shown in Figure 2-29 and Figure 2-30. The residual stress values and depths for the case of peening angle $35^{\circ}$ were found lower than that for the case of peening angle $90^{\circ}$. Larger peening shot diameter can cause higher residual stress in the peened surface, but the depth of residual stress was not significantly affected by peening shot diameter [37].

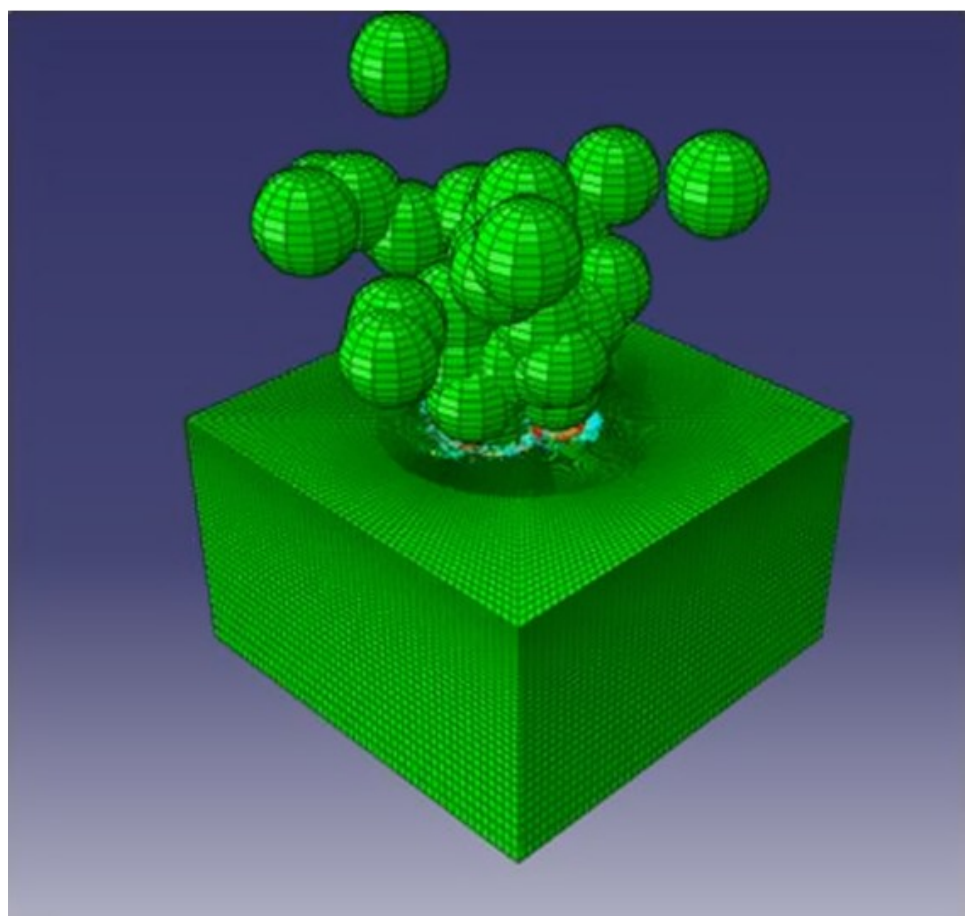

Figure 2-27 FEA model for multiple shot impact using Abaqus package [37] 


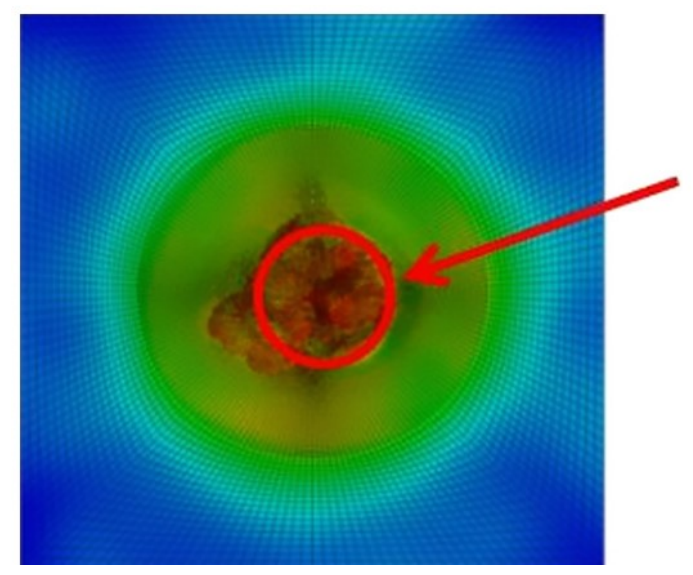

Minimum area

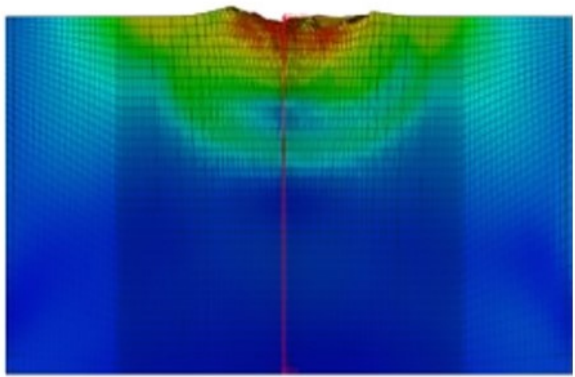

Figure 2-28 Peened surface showing the simulation area of FEA model [37]

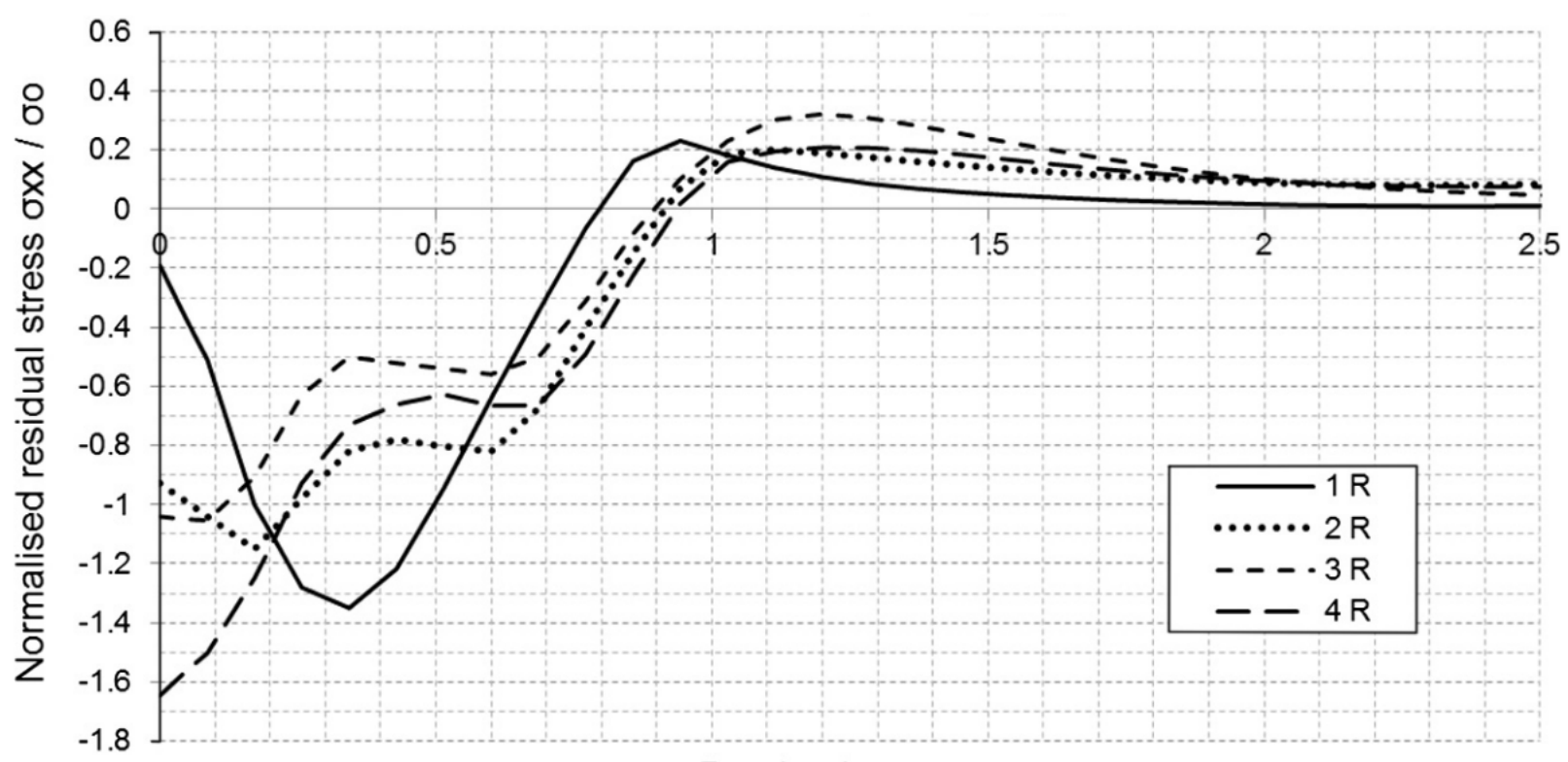

Depth y in $\mathrm{mm}$

Figure 2-29 Residual stress variation in depth direction $Y$ from top surface peened at angle $90^{\circ}$ ( $R$ represnts different peening shot diameters) [37] 


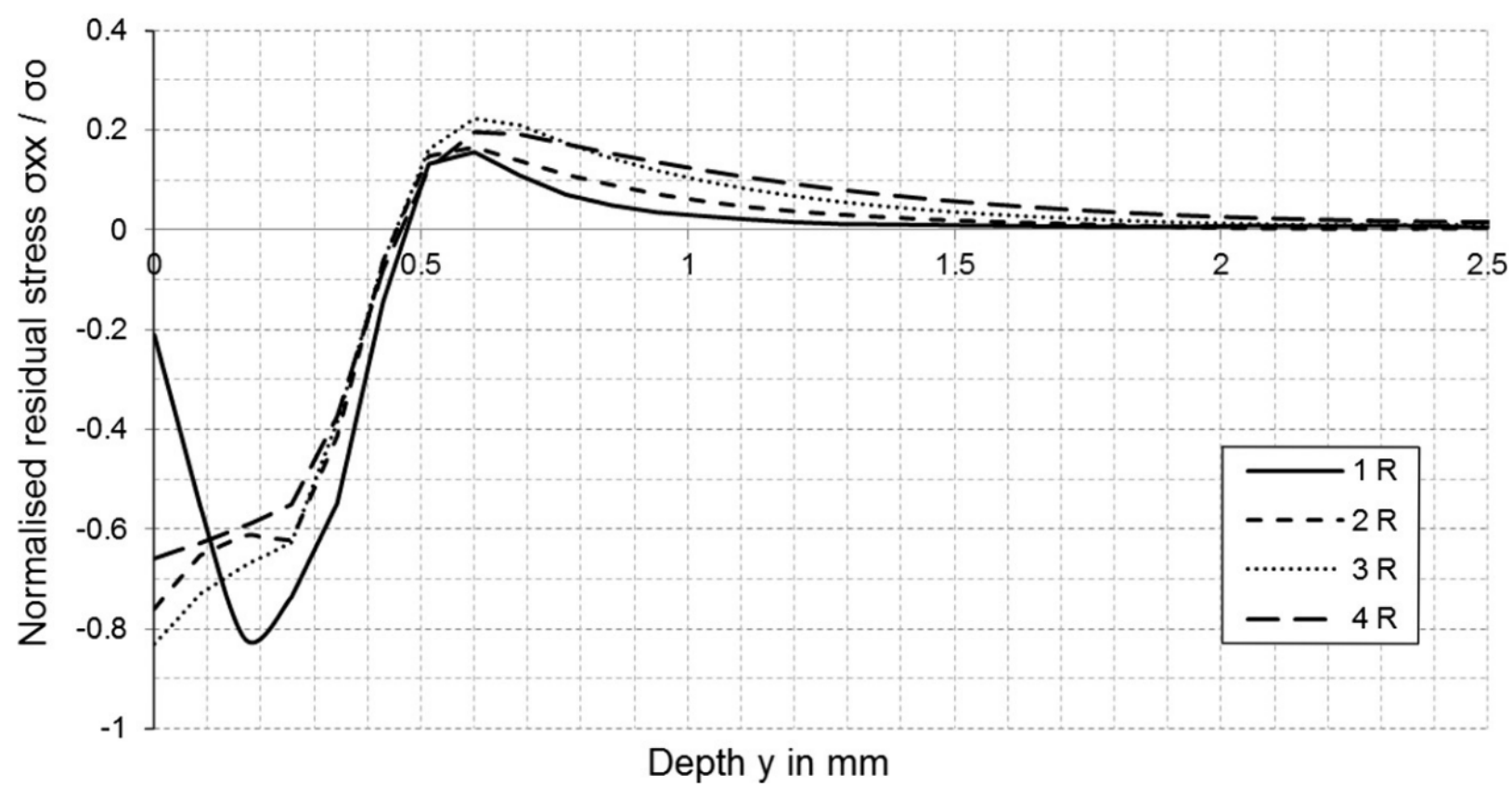

Figure 2-30 Residual stress variation in depth from topsurface peened at angle $35^{\circ}(R$ represnts different peening shot diameters) [37] 


\subsubsection{Peening Process Thermal Effect Model}

For analyzing shot peening process on_carbon steel SAE 1070 with thermal effect involved, a 3D random representative volume $(\mathrm{RV})$ model was developed. It was further expended to three subcategories: rectangular RV (RRV), square RV (SRV) and circular RC (CRV), as shown in Figure 2-31. For the precision of simulation and analysis, the influence of model size, shape of collision area, and temperature rise were all considered in these models. In addition, these models set a new infinite element gap region between the impact region and the boundary to prevent the stress reflection at the boundary of the model. Hence, the influence of the boundary on the shot peening results was eliminated [38].

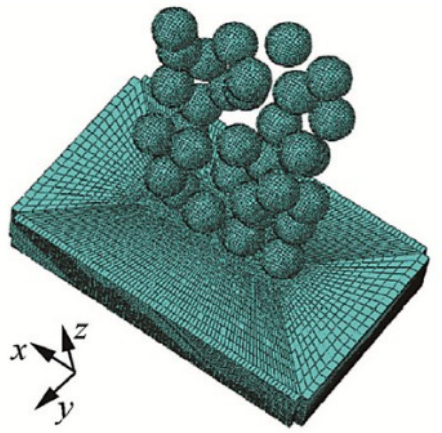

(a) RRV

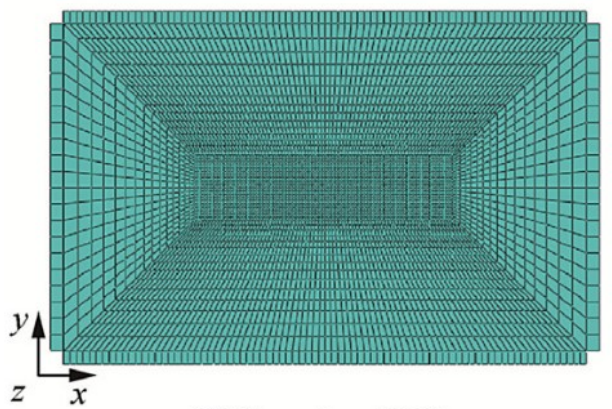

(d) Top view RRV

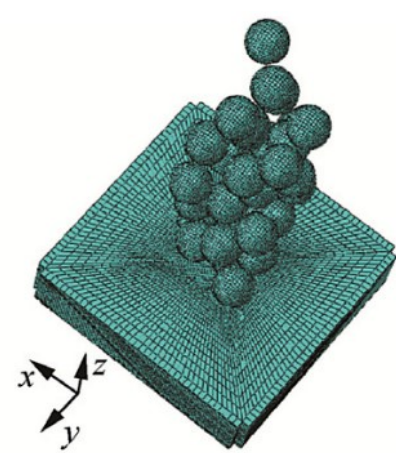

(b) SRV

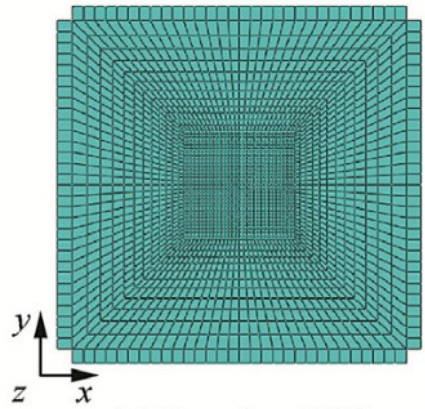

(e) Top view SRV

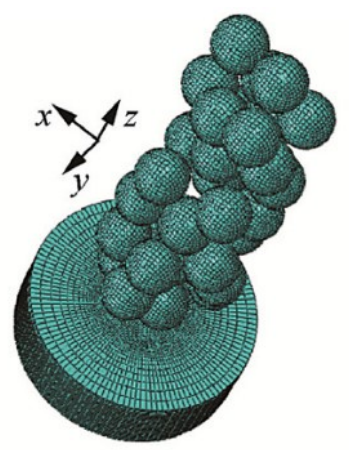

(c) CRV

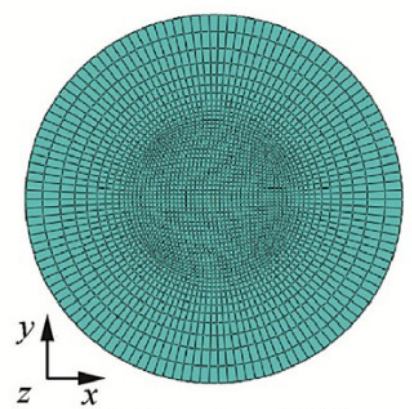

(f) Top view CRV

Figure 2-31 Three random RV FEA meshed models [38] 
In consideration of the thermal effect in shot peening process on the surface performance, the FEA simulation employed Johnson Cook's model which used the plastic property of target material to cover the traditional stress and strain relationship. The simulation results with and without the thermal effect included are shown in Figure 2-32, revealing that the surface residual stress (SRS) varied with the impact number in unit area (N/A). Although shot peening is called "cold work", the thermal softening of the target surface may reduce the residual stresses. Therefore, in the case of a long-time shot peening or overshot peening, the influence of thermal softening on the surface performance should be considered [38]. This model shows that the correct material property data of target surface can increase the accrucy of FEA simulation.

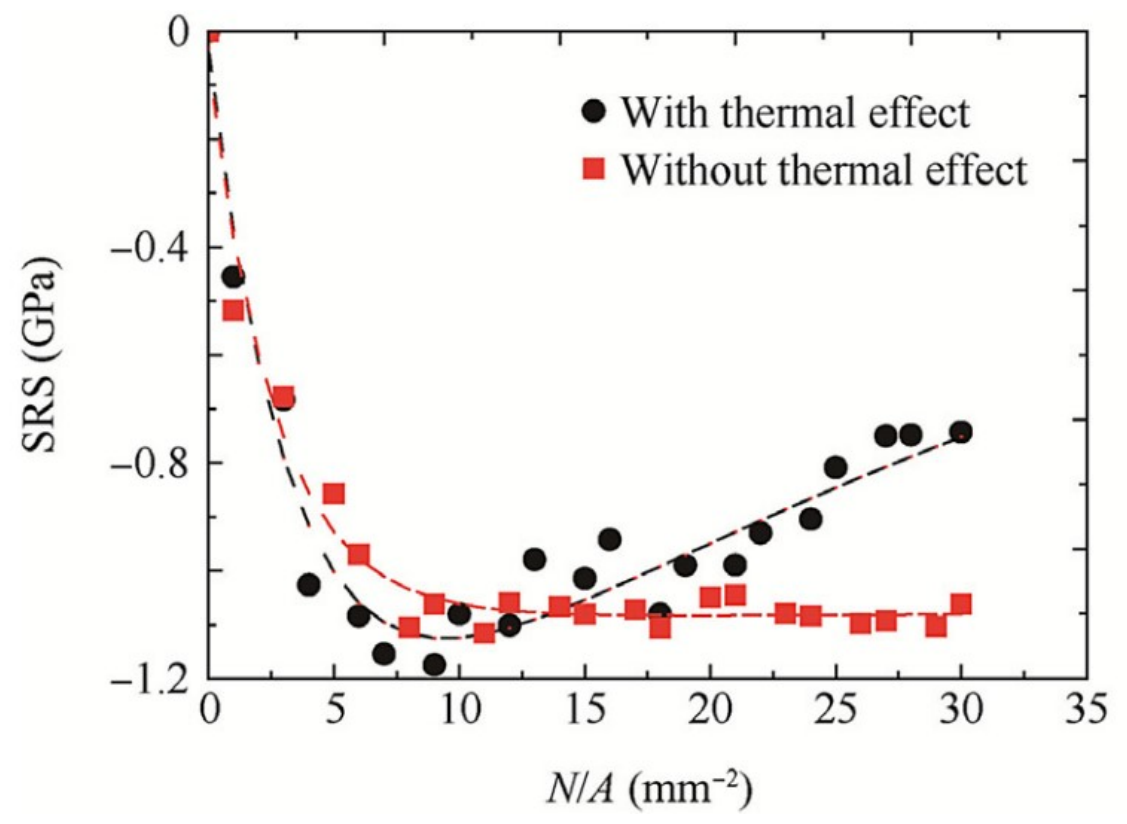

Figure 2-32 Comparison of FEA simulation results with and without thermal effect included [38] 


\section{Chapter 3 Experimental Details}

\subsection{Flange Pin and Peening Shot Materials}

\subsubsection{HY-TUF Steel}

The flange pins of Safran are made from HY-TUF Vac Melt or AMS 6425 steel which is a common aircraft steel with the chemical composition given in Table 3-1.

Table 3-1 Chemical composition (wt\%) of AMS 6425 (HY-TUF steel)

\begin{tabular}{|c|c|c|c|c|c|c|}
\hline Fe & C & Cr & Mo & Si & Mn & Ni \\
\hline Balance & 0.25 & 0.30 & 0.45 & 1.60 & 1.40 & 1.80 \\
\hline
\end{tabular}

This type of steel combines relatively high impact strength with low notch sensitivity and good ductility. Compared with other common aircraft steel such as AISI 4340, 300M, AF 1410 and AerMet 100, HY-TUF steel does not have many advantages because of low constituent of carbon and no cobalt or other alloying additives. However, because of its long-term serving in the industry and advanced surface treatments such as shot peening, this material is still a popular choice in such applications. The final product of this steel has experienced three heat treatment processes: (1) Normalizing of HY-TUF steel is performed at $927^{\circ} \mathrm{C}\left(1700^{\circ} \mathrm{F}\right)$ for $1 \mathrm{hr}$, and then air-cooling. (2) Solution treating of HY-TUF steel is conducted at $871^{\circ} \mathrm{C}\left(1600^{\circ} \mathrm{F}\right)$ for $1 \mathrm{hr}$, then oil-quenching. (3) Tempering of HY-TUF steel is made at $260^{\circ} \mathrm{C}$ for $4 \mathrm{hr}$, and then air-cooling. These heat treatments are applied on HY-TUF steel to achieve the mechanical properties listed in Table 3-2. The microstructure of HY-TUF steel under scanning electron microscopy (SEM) in Figure 3-1 shows fully martensitic phase, which has lamellar and needle-like crystalline structure, and that 
under transmission electron microscopy (TEM) in Figure 3-2 shows retained austenite (R.A) and $\eta$-carbide particles vary in size from $\sim 200$ to $300 \mathrm{~nm}[39]-[41]$.

Table 3-2 Mechanical properties of HY-TUF steel [39]

\begin{tabular}{|c|c|}
\hline Property & HY-TUF steel \\
\hline UTS, MPa & 1575 \\
\hline Yield stress, $\mathrm{MPa}$ & 1400 \\
\hline Hardness, $\mathrm{R}_{\mathrm{C}}$ & 47 \\
\hline Elongation, \% & 13 \\
\hline $\mathrm{K}_{\mathrm{IC}}, \mathrm{ksi} \sqrt{\mathrm{in}}$ & 109 \\
\hline Elastic modulus, $\mathrm{GPa}$ & 200 \\
\hline Modulus of rigidity, $\mathrm{GPa}$ & 76 \\
\hline Poisson's ratio & 0.32 \\
\hline
\end{tabular}

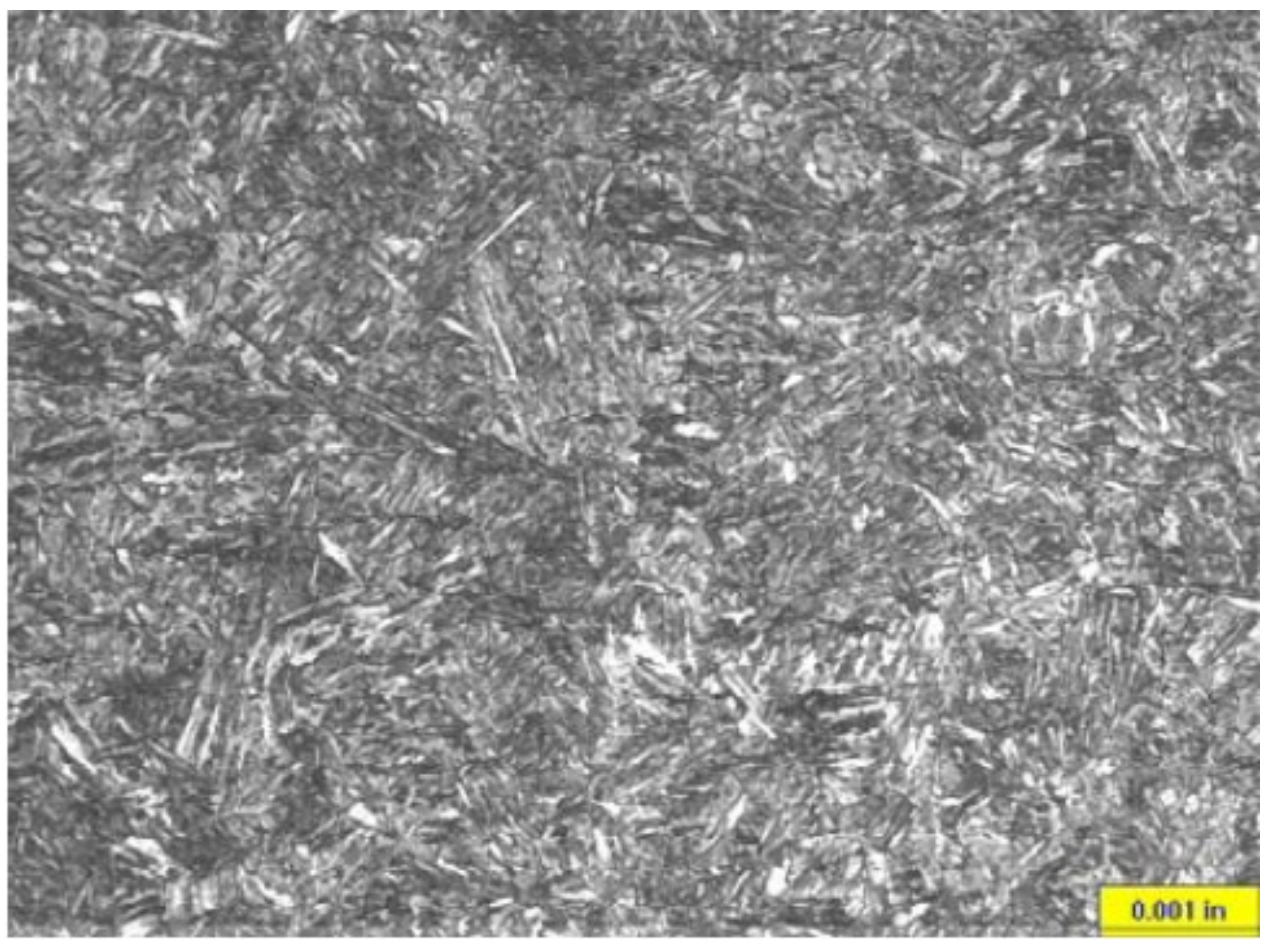

Figure 3-1 SEM micrograph of HY-TUF steel [40] 


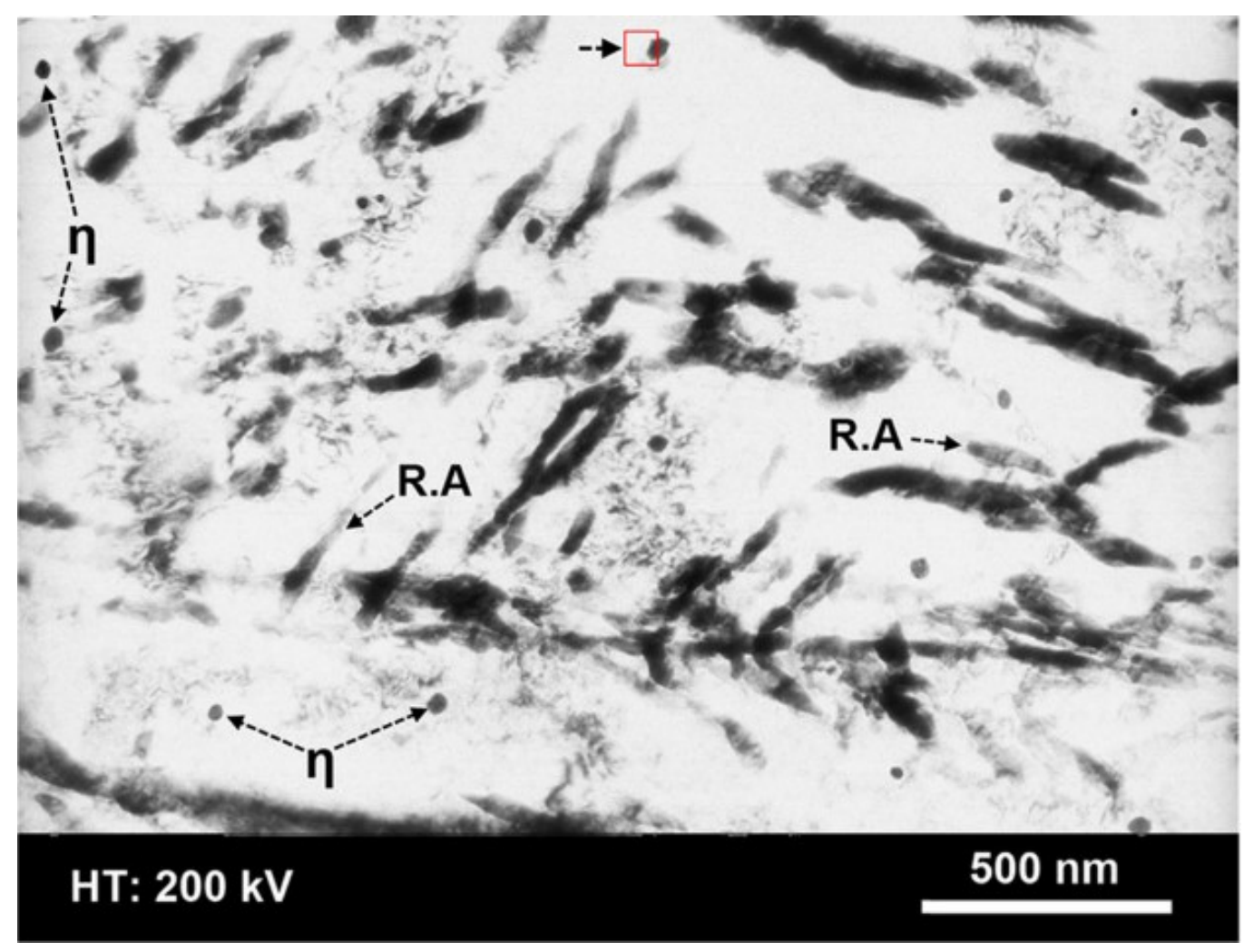

Figure 3-2 TEM micrograph of HY-TUF steel [41] 


\subsubsection{Zirshot-ZC600 Ceramic}

Instead of using traditional steel shots, the flange pins were impacted with ceramic shots (ZirShot-ZC600) to gain higher hardness. Zirshot-ZC600, shown in Figure 3-3, is a ceramic peening shot which contains $60 \%$ to $70 \% \mathrm{ZrO}_{2}, 28 \%$ to $33 \% \mathrm{SiO}_{2}$ and less than $10 \% \mathrm{Al}_{2} \mathrm{O}_{3}$. It has high density $\left(3.85 \mathrm{~g} / \mathrm{cm}^{3}\right)$ and high hardness (HRC70), while the hardness of traditional steel shot (AMS 2431/1) is only about HRC45 - HRC52 [42], [43].

The deformation strength of ceramic shots is much higher than traditional steel shots, therefore, the pinned surface is expected to be much improved after peening with ceramic shots. Another advantage of using ceramic shots is that the shots can be reused or recycled due to little deformation, as discussed previously.

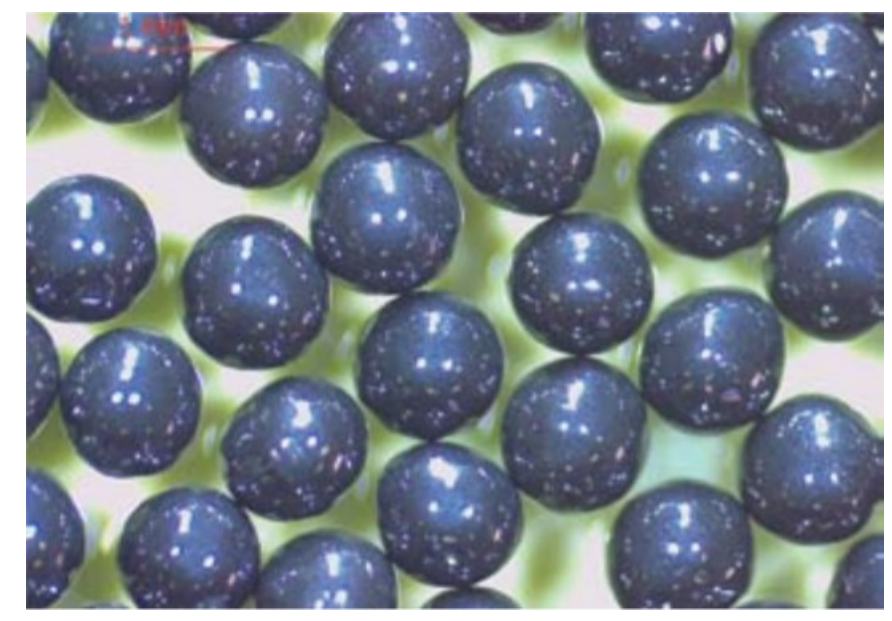

Figure 3-3 Zirshot ceramic peening shot [42] 


\subsection{Flange Pin Specimen for XRD Measurement}

Three identical peened flange pin samples were received from Safran, as shown in Figure 3-4 for one of them. The total length of the flange pin is $130 \mathrm{~mm}$, the thickness of the base is $10 \mathrm{~mm}$ and the length of screw region is $20 \mathrm{~mm}$. The outside diameter and inside diameter of the flange pin are $41 \mathrm{~mm}$ and $31 \mathrm{~mm}$, respectively. These pins are made of AMS 6425 (HY-TUF Steel) with hardness $\sim$ HRC48. They were all peened with ceramic shots (ZirShot-ZC600). The peening process parameters are as follows: peening intensity around $8 \mathrm{~A}$ to $12 \mathrm{~A}$, which is defined by $\mathrm{A}$ type Almen strip, and peening coverage of $100 \%$.

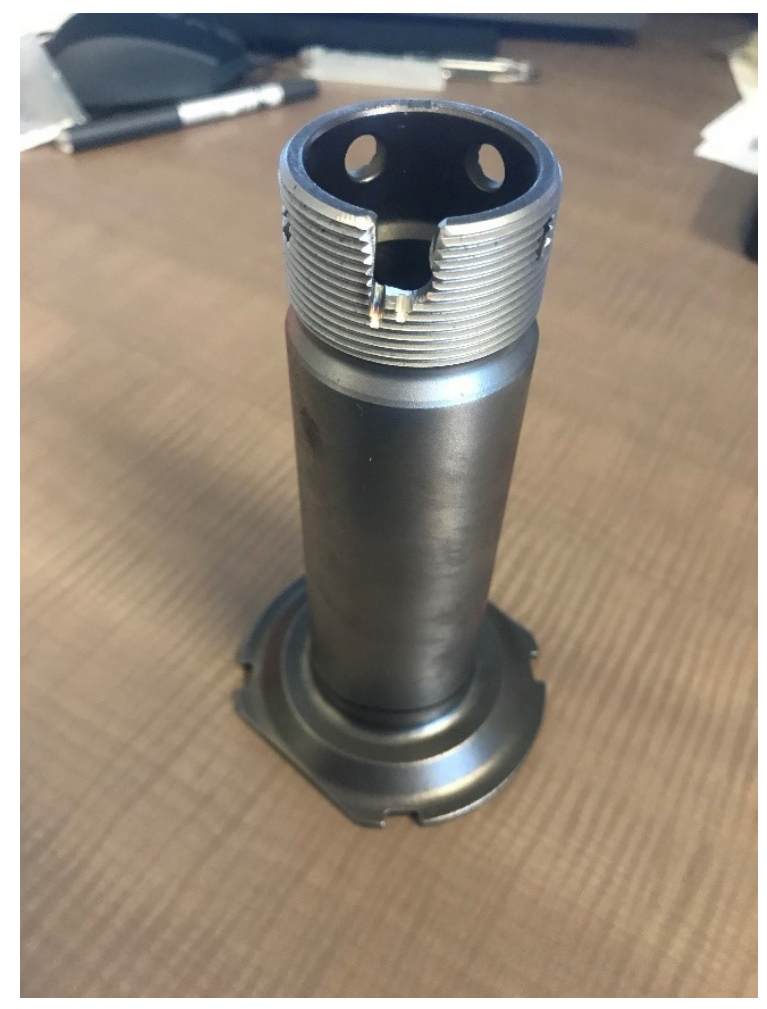

Figure 3-4 Flange pin peened with ceramic shots 
To implement the X-ray measurement, one peened flange pin was cut into four pieces radially, as shown in Figure 3-5. For each piece, X-ray scan was performed on the peened surface at different points or locations, as indicated in Figure 3-6, to determine the residual stresses. The detailed locations for each scan or measurement are schematically summarized in Table 3-3. The X-ray machine is a Rigaku Ultima IV X-ray diffractometer equipped with a $\mathrm{Cu} K \alpha(\lambda=1.54184 \mathrm{~A})$ sealed-tube source and a micro-area stage, shown in Figure 3-7. In total, 13 measurements were made on two pieces of the pin sample with 3 or 4 measurements at each point or location. Due to the size limitation of the XRD machine, some special location and direction on the pin specimens cannot be measured. There are two impossible angles $\left(90^{\circ}\right.$ and $\left.180^{\circ}\right)$ at the top and bottom locations, respectively, where the specimens cannot be rotated with the XRD machine knocking.

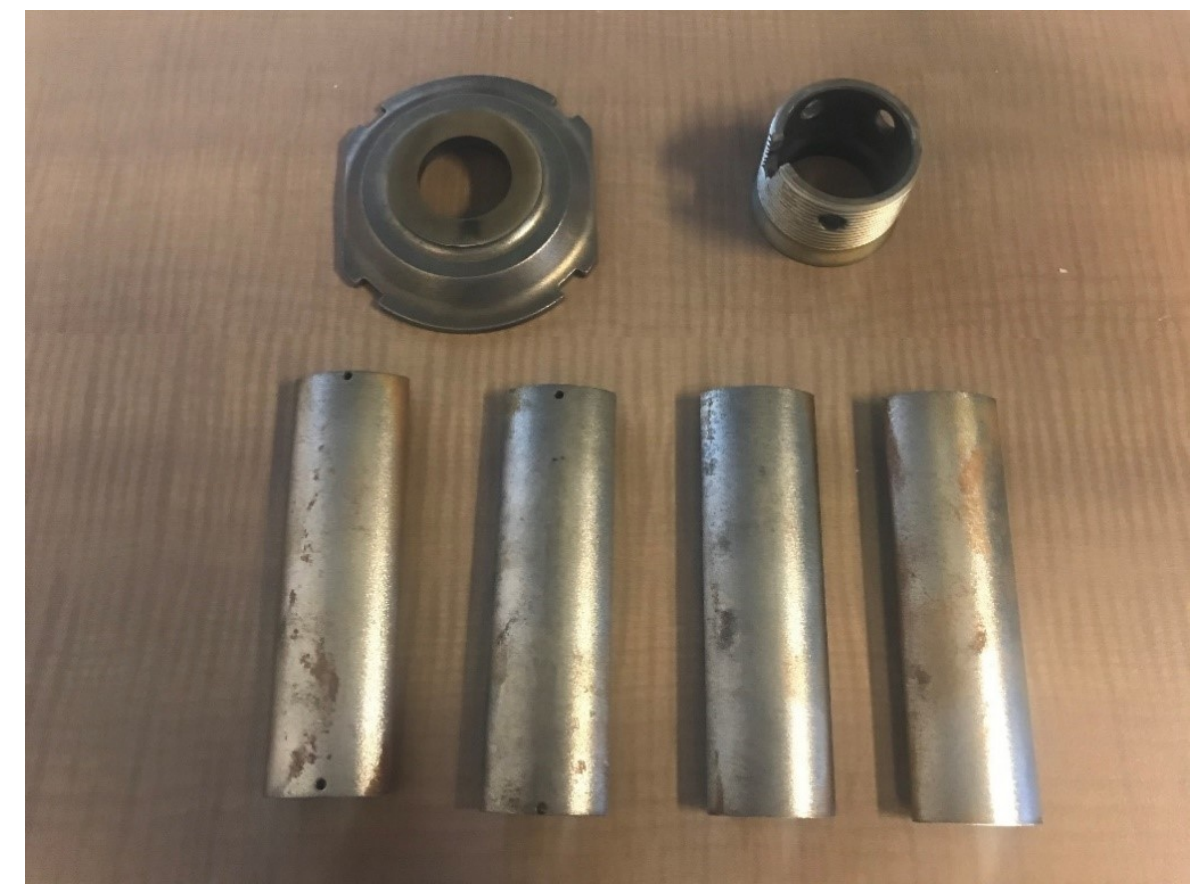

Figure 3-5 Cut flange pin into 4 pieces 


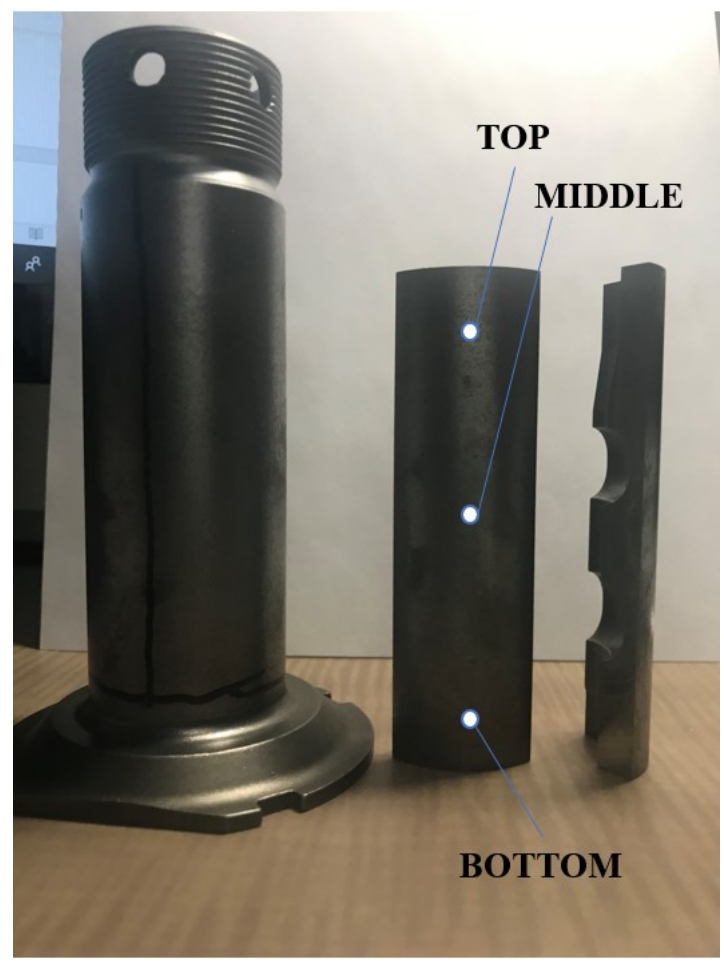

Figure 3-6 Indication of X-ray scan locations on the surface of cut pin

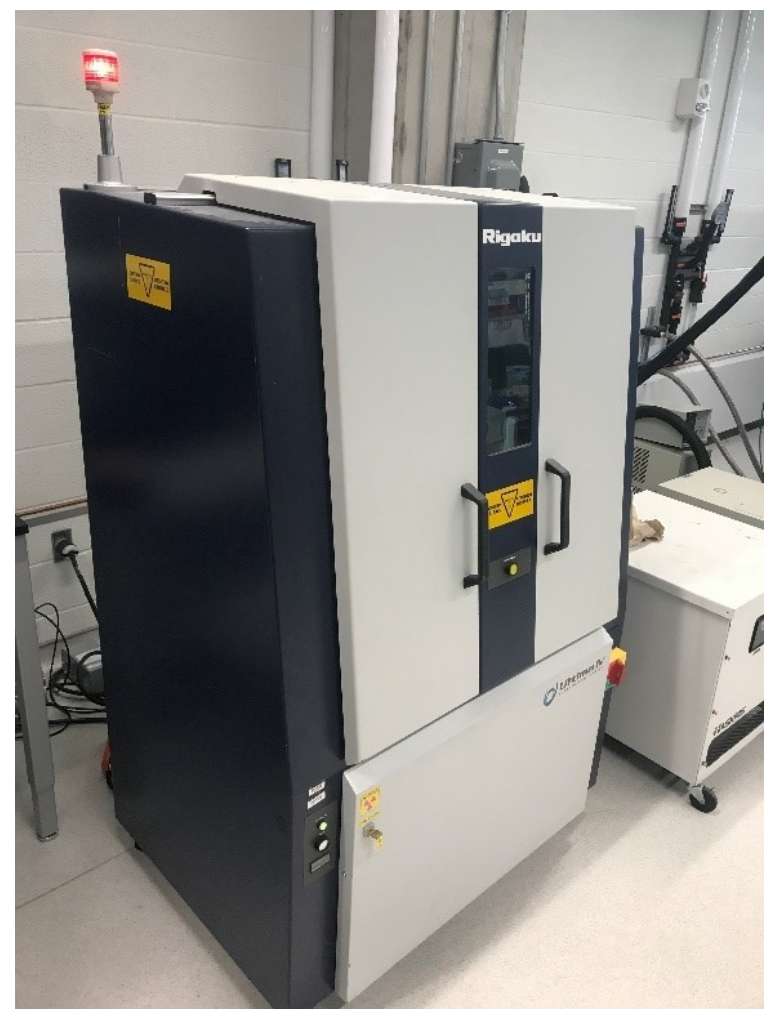

Figure 3-7 Rigaku Ultima IV X-ray Diffractometer 
Table 3-3 Summary of locations on pin specimens for residual stress measurement

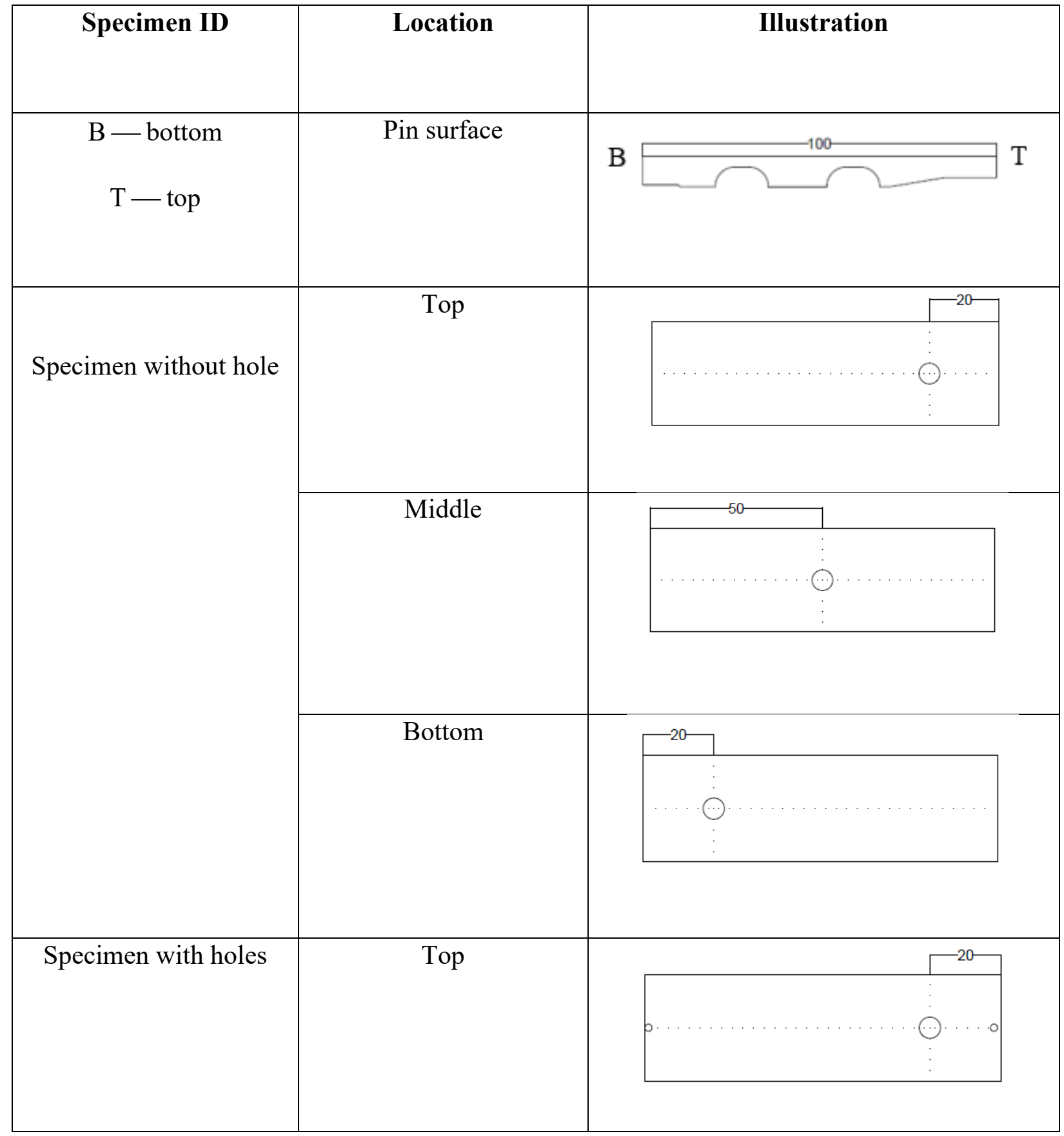




\subsection{XRD Measurement Data}

The X-ray measurement was generally made at four different directions or angles for each location, as illustrated in Figure 3-8, which correspond to the axial or longitudinal stress and circumferential stress in the cylindrical surface of the flange pin, but at some locations, some angles may be impossible due to the limitation of the $\mathrm{X}$-ray machine used, as mentioned previously. The residual stresses in different directions of the pin surface can be obtained with these measurements.

Side view of the specimen

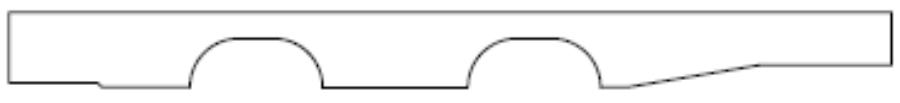

Top view of the specimen surface

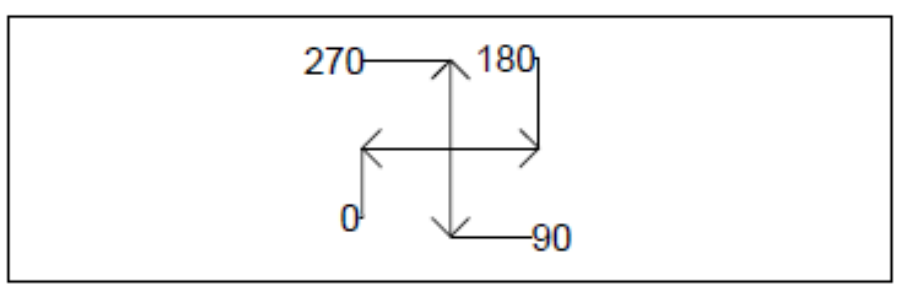

$0^{\circ}$ and $180^{\circ}$ measurements indicate axial or longitudinal stress. $90^{\circ}$ and $270^{\circ}$ measurements indicate circumferential or hoop stress.

Figure 3-8 Illustration of X-ray measurement angles or scan directions

At each measurement direction $\emptyset$, five inter-atomic spacing values $\left(D_{\emptyset, \psi}\right)$, corresponding to five different measurement angles $(\psi)$ were determined and recorded. Five different measurements can be fitted into a primary line, with the $x$-axis represents $\sin ^{2} \psi$ and the $y$-axis represents $\frac{D_{\phi, \psi}-D_{0}}{D_{0}}$ of Eq 2-10. The raw data from the X-ray measurement at the top of the specimen without hole at $0^{\circ}$ scan direction are present in Figure 3-9, the others are reported in Appendix A. 


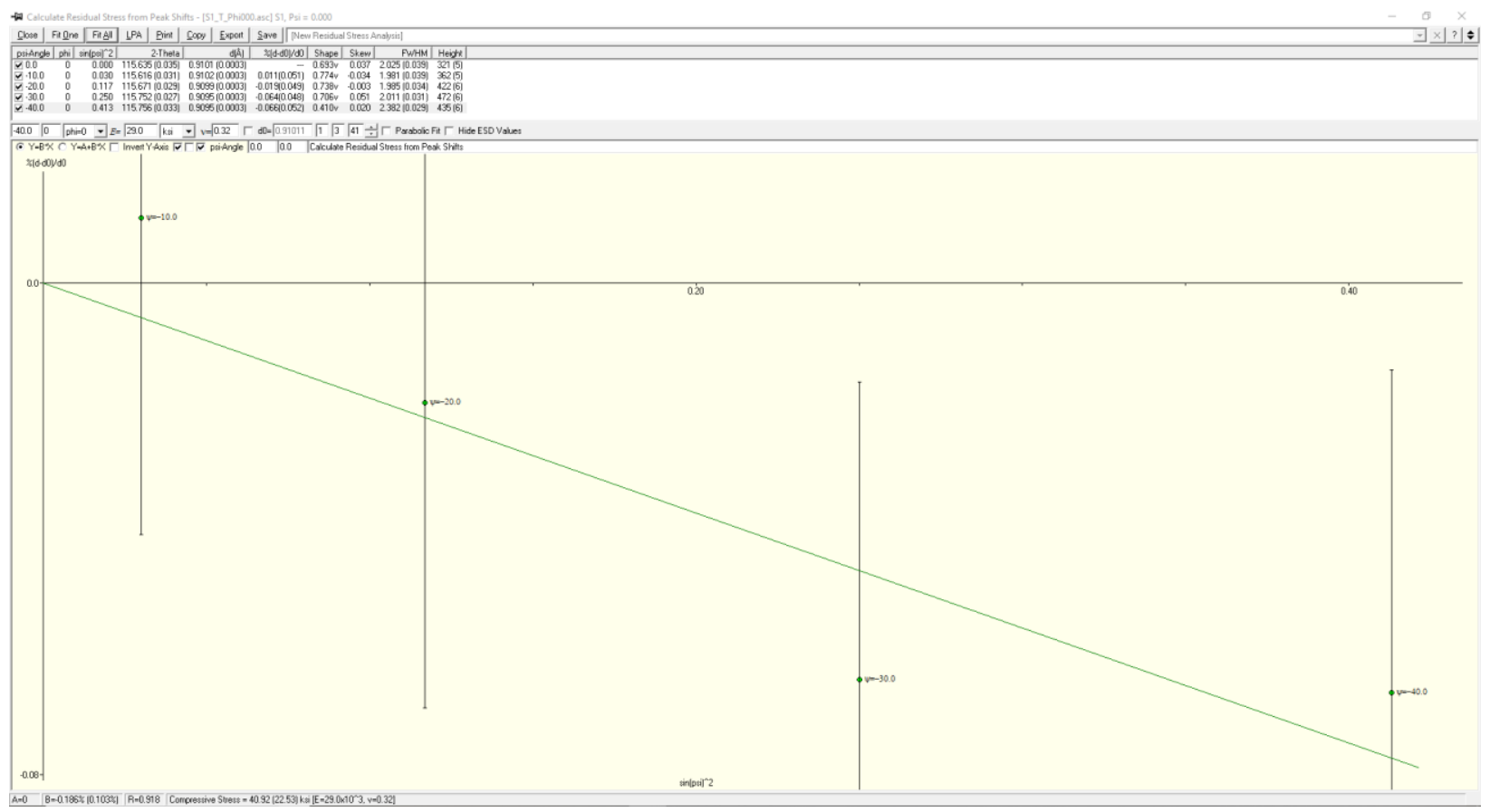

Figure 3-9 XRD measurement data for the top of specimen without hole at $0^{\circ}$ scan 


\subsection{XRD Data Analysis}

The X-ray machine, Rigaku Ultima IV X-ray diffractometer, is equipped with the residual stress computation software. Thus, the raw data from each measurement can be automatically converted to the residual stress value using this software. It was found that both longitudinal and circumferential stress were compressive. The average longitudinal and circumferential residual stress values are reported in Table 3-4, evidently, longitudinal stress and circumferential stress are not equal and the latter is much greater than the former in magnitude. All results of residual stress at different locations and directions on the flange pin are presented in Table 3-5. The residual stress values were obtained from the fitting line of five measurements, as shown in Figure 3-9 and Appendix A. The coefficient of determination $R^{2}$ represents the error of the measurements and the $R^{2}$ values are also reported in Table 3-5. It is demonstrated that the average longitudinal stress is -298.7 MPa and the average circumferential stress is -786.9 MPa. Apparently, the residual stress in circumferential direction is greater than that in longitudinal direction.

Table 3-4 Average residual stress results

\begin{tabular}{|c|c|c|}
\hline Unit & Longitudinal Stress & Circumferential Stress \\
\hline MPa & -298.7 & -786.9 \\
\hline Standard Deviation & 57.8 & 57.3 \\
\hline
\end{tabular}


Table 3-5 Summary of residual stress results for peened flange pin

\begin{tabular}{|c|c|c|c|c|}
\hline Specimen ID & Location & Direction $\varphi$ & $\begin{array}{l}\text { Residual Stress } \\
\text { (MPa) }\end{array}$ & $\begin{array}{c}\text { Coefficient of } \\
\text { Determination } R^{2}\end{array}$ \\
\hline Non-hole specimen & Middle & $\begin{array}{c}0^{\circ} \\
90^{\circ} \\
180^{\circ} \\
270^{\circ} \\
0^{\circ} \\
90^{\circ} \\
180^{\circ} \\
270^{\circ} \\
0^{\circ} \\
90^{\circ} \\
180^{\circ} \\
270^{\circ}\end{array}$ & $\begin{array}{l}-282.13 \\
-313.23 \\
-793.24 \\
-348.74 \\
-775.32 \\
-689.41 \\
-337.43 \\
-865.43 \\
-166.16\end{array}$ & $\begin{array}{l}0.843 \\
0.845 \\
0.986 \\
0.960 \\
0.988 \\
0.966 \\
0.980 \\
0.854 \\
0.931 \\
0.867 \\
\end{array}$ \\
\hline With hole specimen & Top & $\begin{array}{c}0^{\circ} \\
90^{\circ} \\
180^{\circ} \\
270^{\circ}\end{array}$ & $\underbrace{-293.23}_{-810.96}$ & $\begin{array}{c}0.835 \\
0.992 \\
0.955\end{array}$ \\
\hline & & this angl & imited by the & machine. \\
\hline
\end{tabular}




\subsection{Microstructural Examination}

To investigate the influence of the ceramic shot peening on the microstructure of the pin surface, the radial section of the specimen was polished and examined with SEM, the images are shown in Error! Reference source not found.. In general, there is not much difference in microstructure over $\mathrm{t}$ he section, but it can be observed that the shot peening created some pores in the surface layer. 


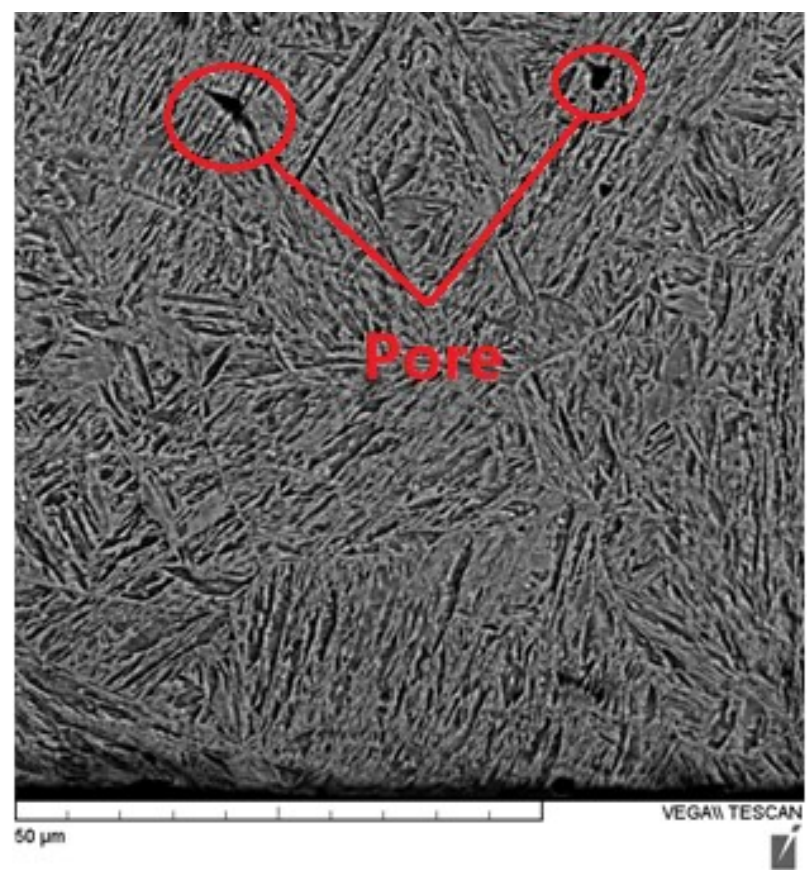

(a)

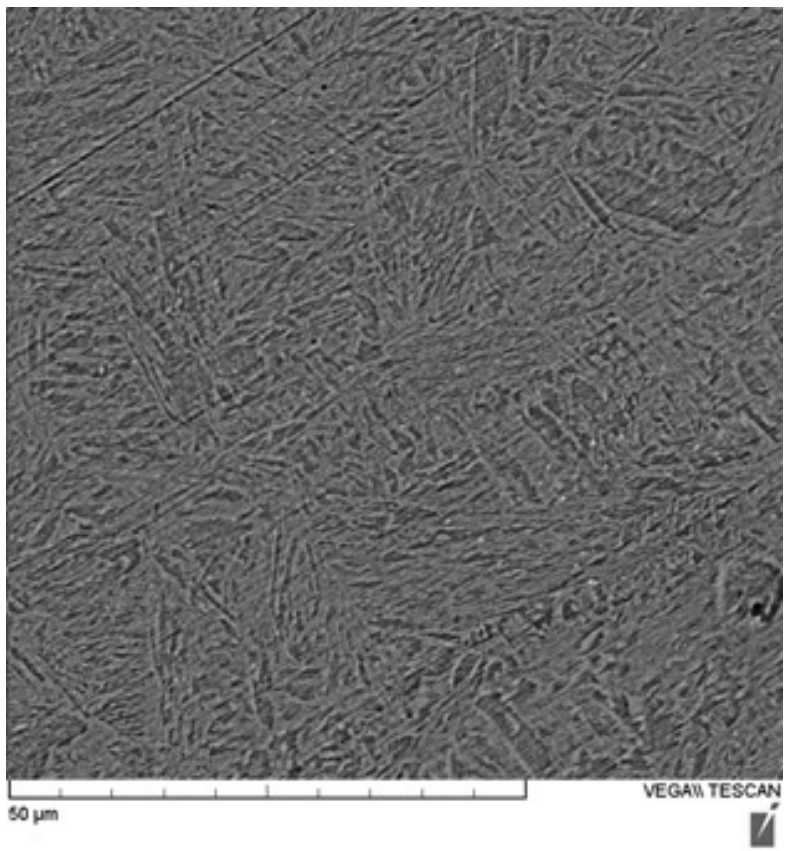

(b)

Figure 3-10 SEM microstructure (a) near peened surface of flange pin; (b) far from the peened surface of flange pin 


\section{Chapter 4 FEA Simulation of Shot Peening on Flange Pin}

Experimental determination of residual stress has certain limitations due to the capacity of the testing machines or instruments, as discussed previously. For example, XRD technique can only measure the residual stresses at the peened surface. If the stress distribution within a certain depth of the peened surface layer is required, experimental methods exhibit deficiency. Differently, FEA simulation can functionally overcome the drawbacks of the experimental means. It enables various complex geometry to be investigated and is also able to determine the stresses in any direction at any depth from the target surface.

In this research, in addition to experimental determination of the residual stresses in the surface of the peened flange pin using XRD, FEA simulation study was also conducted, with a threedimensional model constructed representing the cylindrical target or peened flange pin surface having a certain depth or thickness. The peening of the target surface by the ceramic shots was simulated as a continuous flow of the shots impacting the surface at a set rate. However, it should be pointed out that this simulation cannot provide the results of the residual stresses exactly representing the real case of the peened flange pin from Safran, because the peening process parameters such as shot flow rate, duration of peening, detailed properties of the ceramic shot, etc. are deemed to be commercial secret of Safran and are not provided for this study, while these parameters are the necessary input of the FEA simulation and influence the residual stress results significantly. As a result, it is impossible to reasonably compare the FEA simulation results with the XRD measurements, due to lack of the real peening process parameters for the flange pin.

On the other hand, although the present FEA simulation may not accurately compute the residual stresses in the peened flange pin, it does provide valuable results to Safran and other shot peening industries. First, no research has been reported in literature for shot peening on curved (cylindrical) 
surfaces like flange pins. Second, the present simulation uses random multiple shots peening model with the shot flow rate being a model variable, which enables determining the residual stress profile under any designated peening conditions. In other words, as long as the real peening process parameters are available, the residual stresses in the flange pin at any depth of the surface can be accurately predicted using this model.

Additionally, for further investigation of the interaction between peening shot and target surface during peening process, FEA simulation in this study is also performed for flat target surface subjected to shot peening at various impact angles and target surface with different curvature radii, thus to determine the residual stress distribution in the surface layer under these different shot peening angles and surface geometry conditions. These studies are aimed to provide Safran company and relevant industries the guideline for designing the peening process which can achieve optimal residual stress profile for a given surface geometry.

\subsection{Material Data for FEA Model}

\subsubsection{Material Data of Flange Pin}

The whole FEA model for the peening flange pin can be divided into two parts, target surface and peening shot. The target surface material is HY-TUF steel which has the density of $7.77 \times 10^{3} \mathrm{~kg} / \mathrm{m}^{3}$. The Young's modulus and Poisson's ratio of HY-TUF steel are $206 \mathrm{GPa}$ and 0.32 , respectively. In consideration of both elastic and plastic deformation as well as work hardening, the properties of HY-TUF steel input to the FEA model need to include the entire stress and strain curve (elastic and plastic region). The stress and strain curve of HY-TUF steel, plotted from the data extracted from a tensile test, is present in 


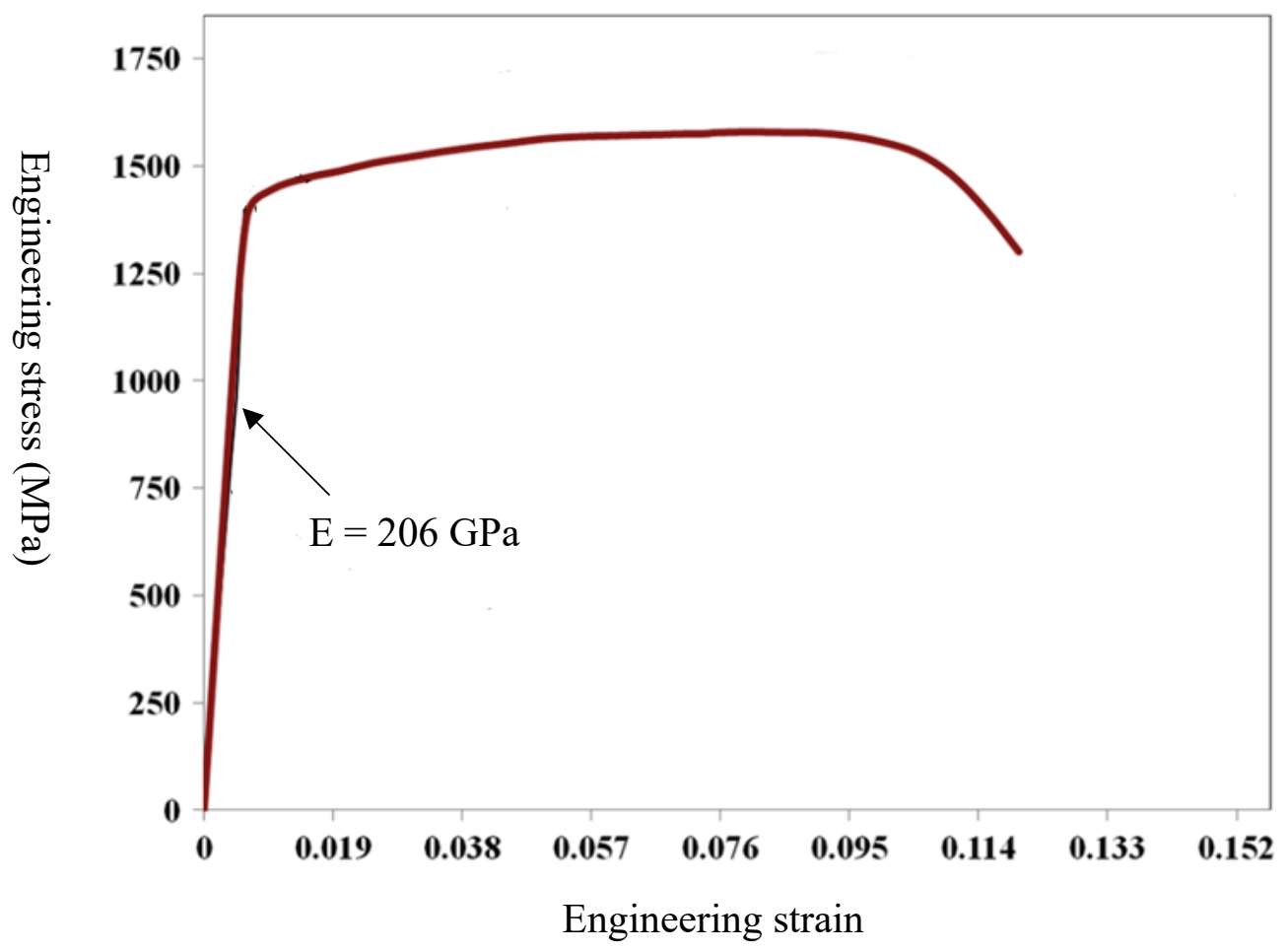

Figure 4-1 Stress-strain curve of HY-TUF steel [41]

According to the stress and strain relation, the plastic strain of HY-TUF steel can be calculated as

$$
\begin{gathered}
\varepsilon_{E}=\frac{\sigma}{E} \\
\varepsilon_{P}=\varepsilon_{T}-\varepsilon_{E}
\end{gathered}
$$

where $\varepsilon_{E}$ is the elastic strain, $\sigma$ is stress, $E$ is the Young's modulus, $\varepsilon_{T}$ is total strain and $\varepsilon_{P}$ the plastic strain. The total strain, plastic strain and stress data of HY-TUF steel are summarized in Table 4-1. The yield stress of HY-TUF steel is about $1400 \mathrm{MPa}$. 
Table 4-1 Tensile test data of HY-TUF steel

\begin{tabular}{c|c|c|c}
\hline & Strain & $\begin{array}{c}\text { Stress } \\
(\mathrm{MPa})\end{array}$ & Plastic Strain \\
\hline \multirow{4}{*}{ Elastic } & 0 & 0 & \\
Deformation & 0.00122 & 250 & \\
& 0.00241 & 500 & \\
& 0.00344 & 750 & \\
& 0.00463 & 1000 & \\
\hline \multirow{5}{*}{ Plastic } & 0.00567 & 1250 & \\
\hline \multirow{5}{*}{ Deformation } & 0.00685 & 1400 & 0.000 \\
& 0.01070 & 1450 & 0.004 \\
& 0.01618 & 1475 & 0.009 \\
& 0.02240 & 1500 & 0.015 \\
& 0.04506 & 1550 & 0.038 \\
& 0.07098 & 1575 & 0.063 \\
& 0.09601 & 1569 & 0.088 \\
& 0.10342 & 1541 & 0.096 \\
& 0.10993 & 1482 & 0.103 \\
& 0.11541 & 1390 & 0.109 \\
& 0.12000 & 1300 & 0.114 \\
\hline
\end{tabular}

\subsubsection{Material Data of Shot}

The ceramic shot used in this research is ZirShot-ZC600 with the chemical composition given in Chapter 3. The density of the ceramic shot is $3.85 \times 10^{3} \mathrm{~kg} / \mathrm{m}^{3}$. The Young's modulus and Poisson's ratio of the ceramic shot are $393 \mathrm{GPa}$ and 0.27 , respectively. The yield stress of the ceramic shot is about $4000 \mathrm{MPa}$. Since the yield stress of the ceramic shot material is much higher than that of HY-TUF steel, the deformation of the shot should be much less than that of the flange pin target under the shot peening. Also, ceramic is brittle and displays little plastic deformation. Therefore, the ceramic shot is deemed to deform elastically only in the FEA simulation. 


\subsection{FEA Geometric Model}

\subsubsection{Flange Pin Model}

Based on the dimensions of the flange pin from Safran, for saving simulation running time, a sector segment with $4 \mathrm{~mm}$ length (in the longitudinal direction of the flange pin) and $2 \mathrm{~mm}$ depth (in the radial direction from the flange pin surface) and $10^{\circ}$ angle (in the circumferential direction of the flange pin cross-section) is modelled, where the curvature radius of the segment top surface is $20.5 \mathrm{~mm}$, as shown in Figure 4-2, to simulate the stress and strain behavior of the flange pin under shot peening. In this model, the $x$-axis is the circumferential direction, the $y$-axis is the radial direction, and the $z$-axis is the longitudinal or axial direction on the flange pin specimen.

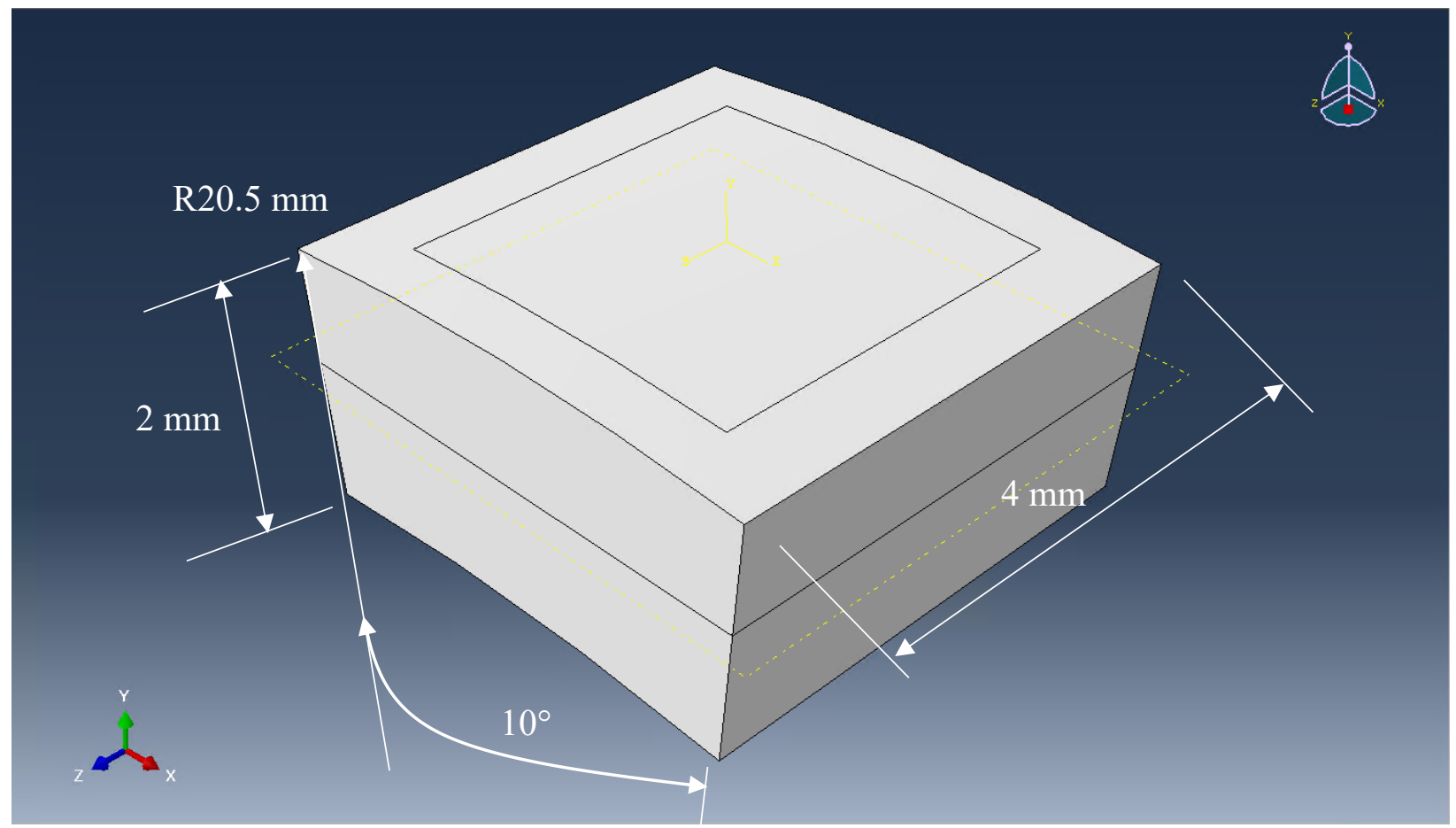

Figure 4-2 FEM geometric model of target surface part 
The meshing density in the central region of the model, where shots are impacting, is higher than that in the corner region, as shown in Figure 4-3, to ensure the accuracy of the residual stress results, meanwhile to save computation time.

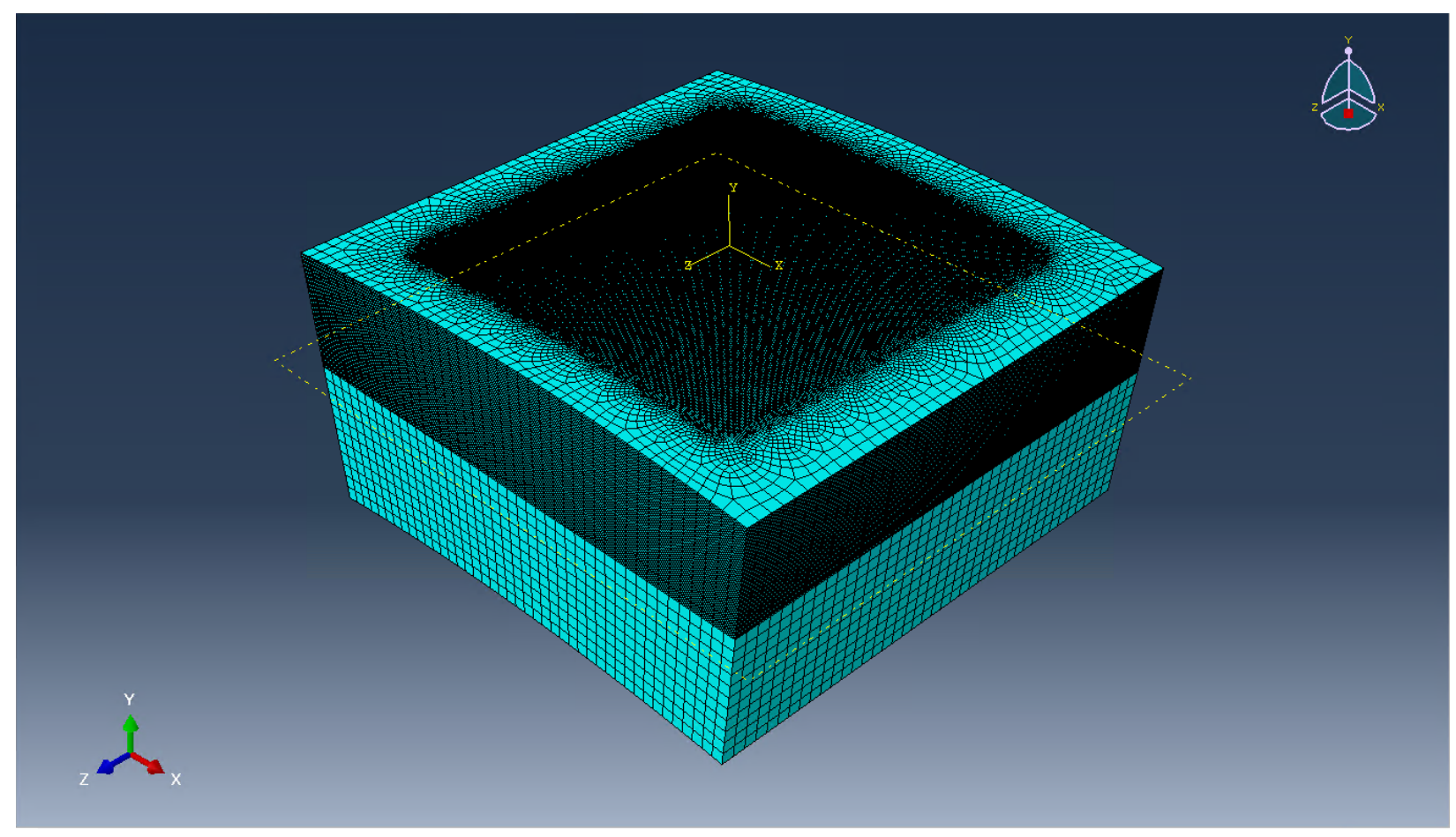

Figure 4-3 Meshed FEM model of target surface part 


\subsubsection{Geometric Model of Shot}

Although the real peening process proceeded with a continuous flow of shots impacting on the surface at a set rate, in this simulation within the target area of the FEA model, it is assumed that shots are impacting on the pin surface one by one at random, that is, the shots are impacting on the target surface successively; the following shot is coming in contact with the target surface when the prior shot has left the surface. For each shot, the FEA geometric model is a sphere ball in shape with a radius of $0.365 \mathrm{~mm}$, as shown in Figure 4-4, which is the average radius of ZirShot-ZC600 shots used for peening the flange pin.

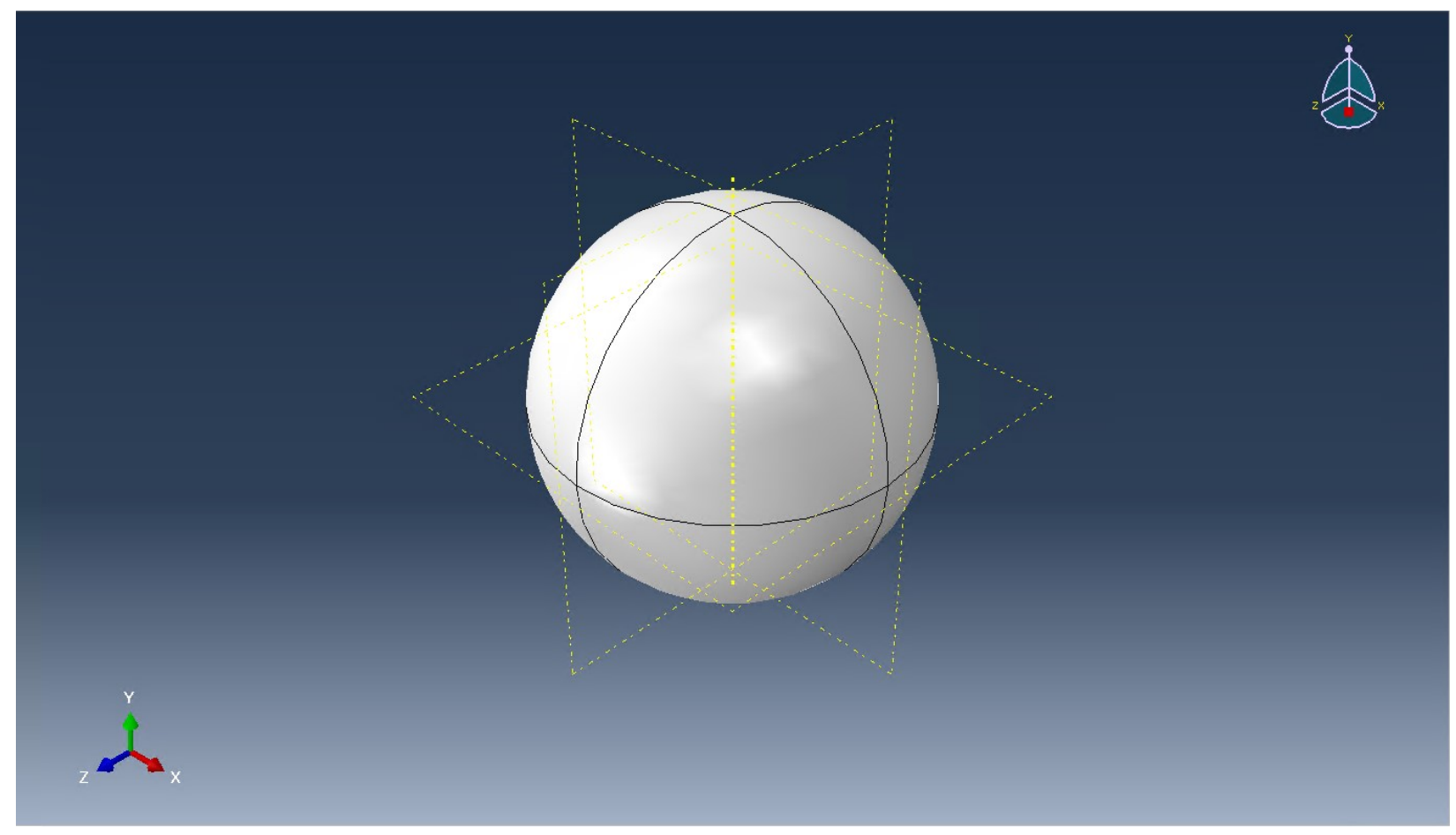

Figure 4-4 FEM geometric model of ceramic peening shot

The meshed ceramic shot model is shown in Figure 4-5. Since the deformation of the shot would be much smaller than that of the flange pin target during the peening and the stress/strain behavior of the shots is not the main concern in this research, uniform meshing is used for the peening shot. 


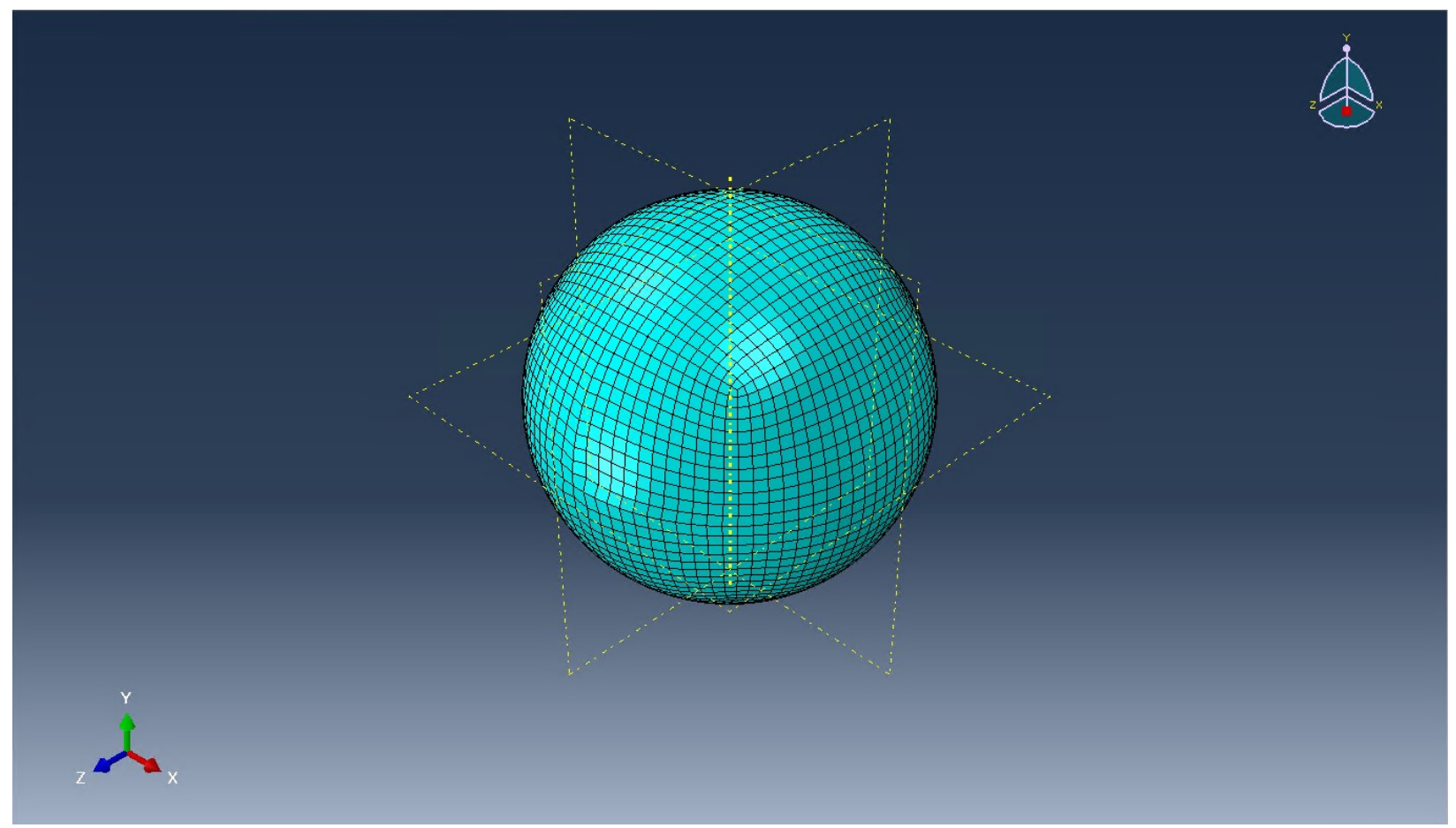

Figure 4-5 Meshed FEM model of ceramic peening shot 


\subsubsection{Single Shot and Target Surface Assembly Model}

In order to determine the peened area on the target surface by one shot impact, the assembly model with a single shot impacting on the target surface is constructed, as shown in Figure 4-6. In this model, using the center of the target as the origin establishes a cylindrical coordinate system. Then, building boundary conditions make all the surfaces (except top surface or peening surface) of the target stationary in their normal direction. Finally, the shot is assumed to impact the target surface at the center of the model along the longitudinal direction of the cylindrical segment at an angle of $45^{\circ}$ with the target surface. The shot impact velocity is set to be $60 \mathrm{~m} / \mathrm{s}$, which corresponds to the $y$ and $z$ components of $-42.4 \mathrm{~m} / \mathrm{s}$ and $42.4 \mathrm{~m} / \mathrm{s}$ respectively, as illustrated in Figure 4-7.

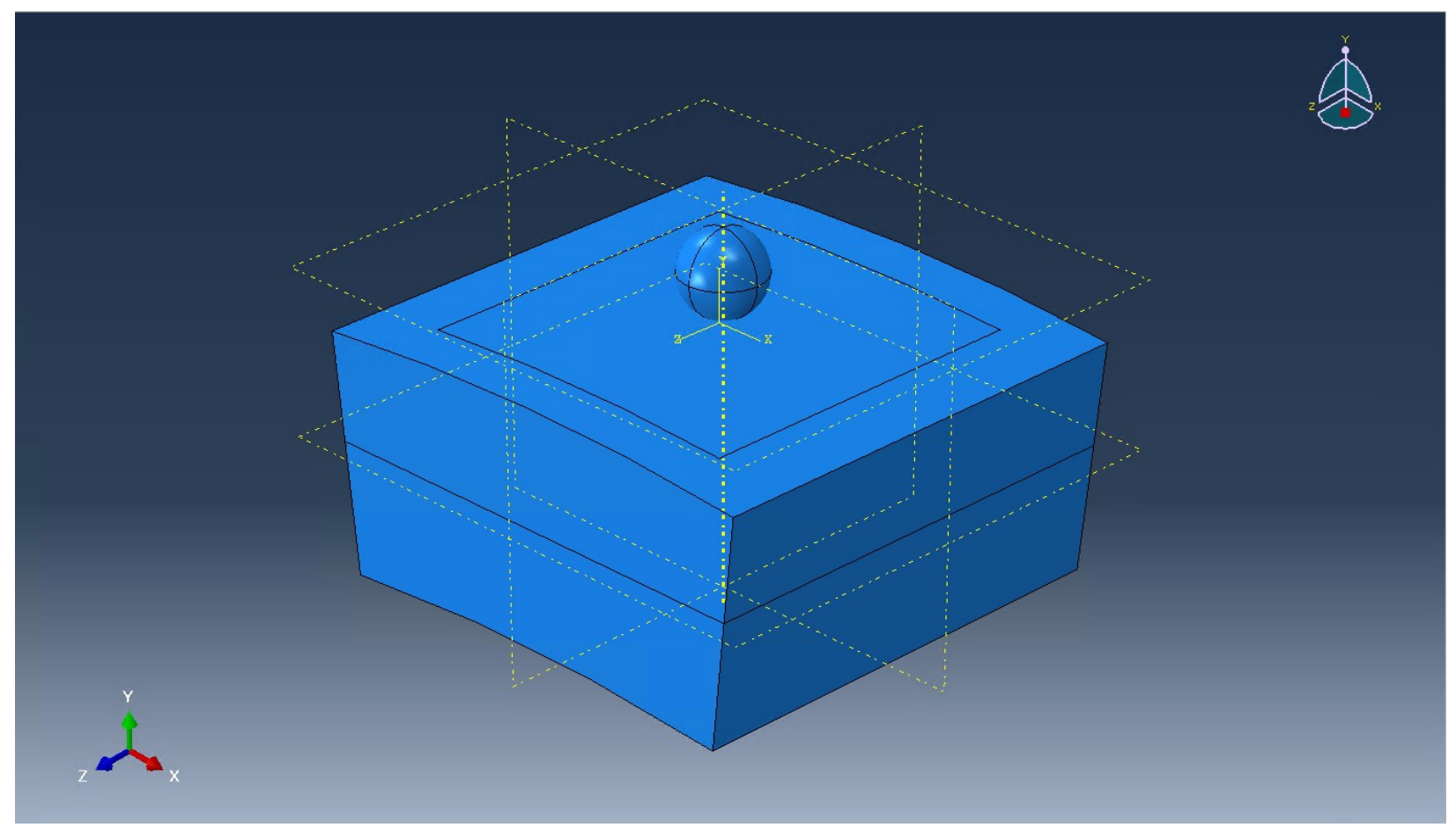

Figure 4-6 FEM single ball and target assembly model 


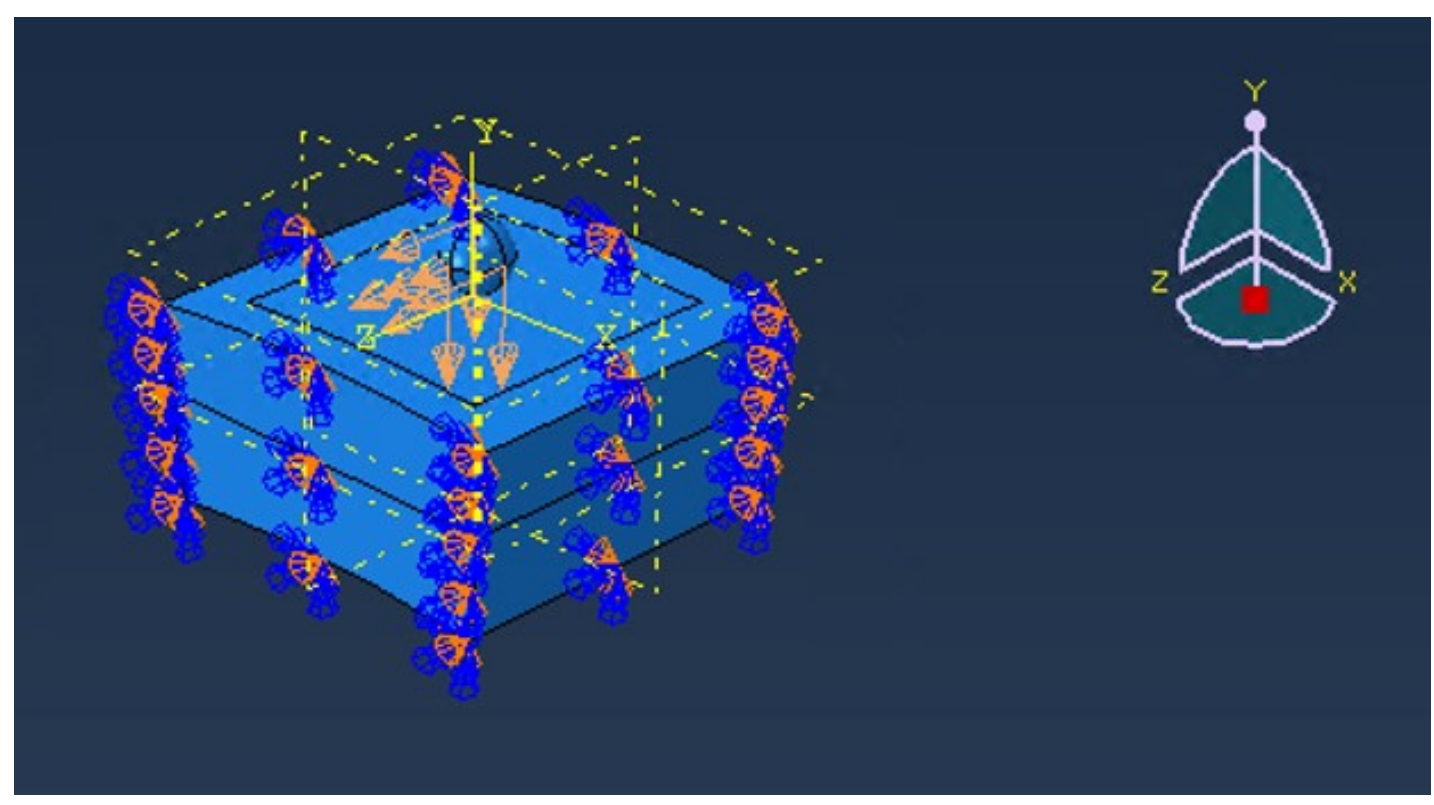

Figure 4-7 Boundary conditions and preload of FEM single shot model 


\subsubsection{Convergence Test}

Generally, higher mesh density offers better simulation accuracy. However, finer mesh causes increasing of freedom degrees of the model, which will result in a large amount of calculation time and computer memory space. Therefore, a compromise between solution accuracy and calculation time is reached by conducting a convergence test on the single shot model. Eleven different meshing sizes from $0.05 \mathrm{~mm}$ to $0.011 \mathrm{~mm}$ are used in the test. Figure $4-8$ illustrates the convergence behavior of the model with varying mesh size, with respect to the maximum Von Mises stress residing in the peened surface after the shot has left. It is shown that the residual stress increases with mesh size until the mesh size is down to $0.014 \mathrm{~mm}$, then the stress becomes nearly constant. Finally, a conservative estimation of mesh size $0.0125 \mathrm{~mm}$ is used in this simulation study.

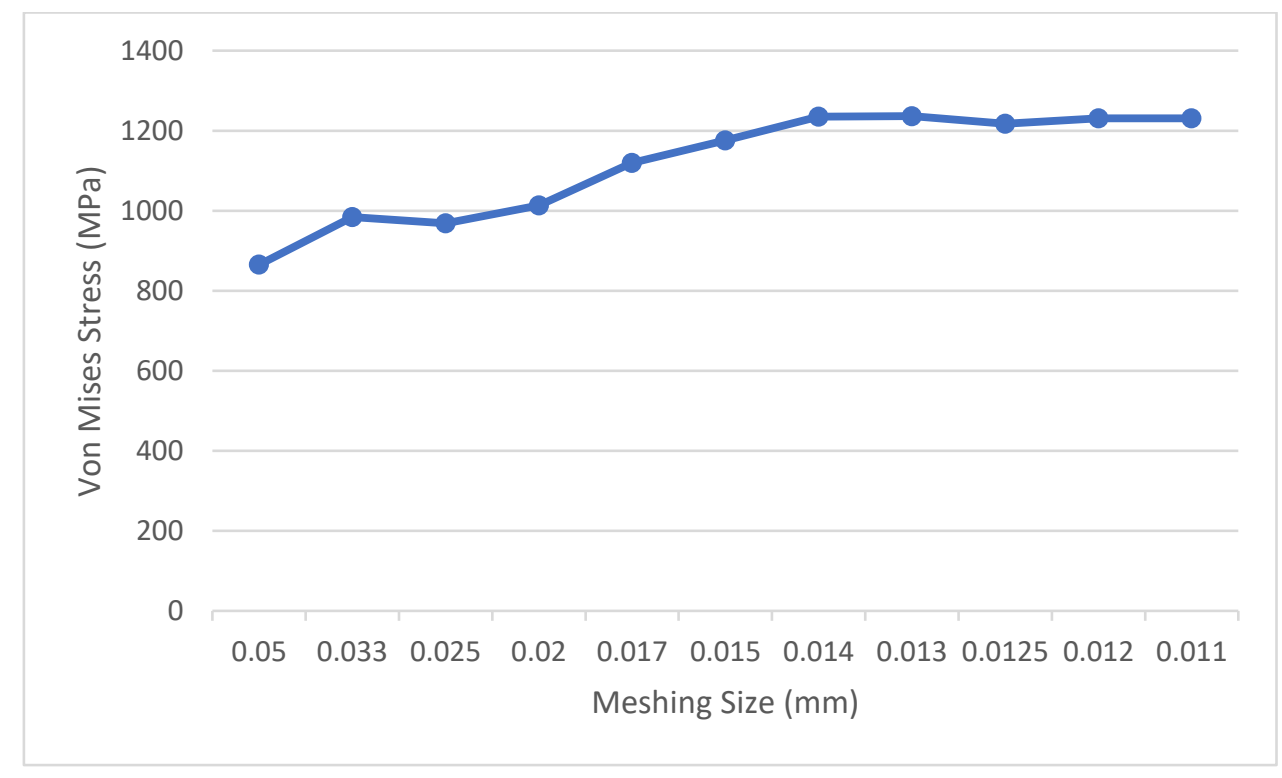

Figure 4-8 Maximum Von Mises stress versus meshing size 


\subsubsection{Single Shot Impact Aera}

For calculating the peening shot number based on shot peening coverage of multiple shot peening mode, the area of single shot impact needs to be determined. In terms of the concept of shot peening coverage [18], the impact area should be the region where plastic deformation has taken place on the target surface due to peening. Then, assuming the impact area is a circle, the diameter of the circle can be determined in the cross-section at the center of the deformed model by measuring the deformed region $d$ on the target surface after the shot has left, which represents the plastic deformations or residual deformations, associated with the residual stresses generated, as shown in Figure 4-9. It is measured $d=0.26 \mathrm{~mm}$, thus the impact area is calculated to be $\pi r^{2}$ where the radius $r=0.13 \mathrm{~mm}$.

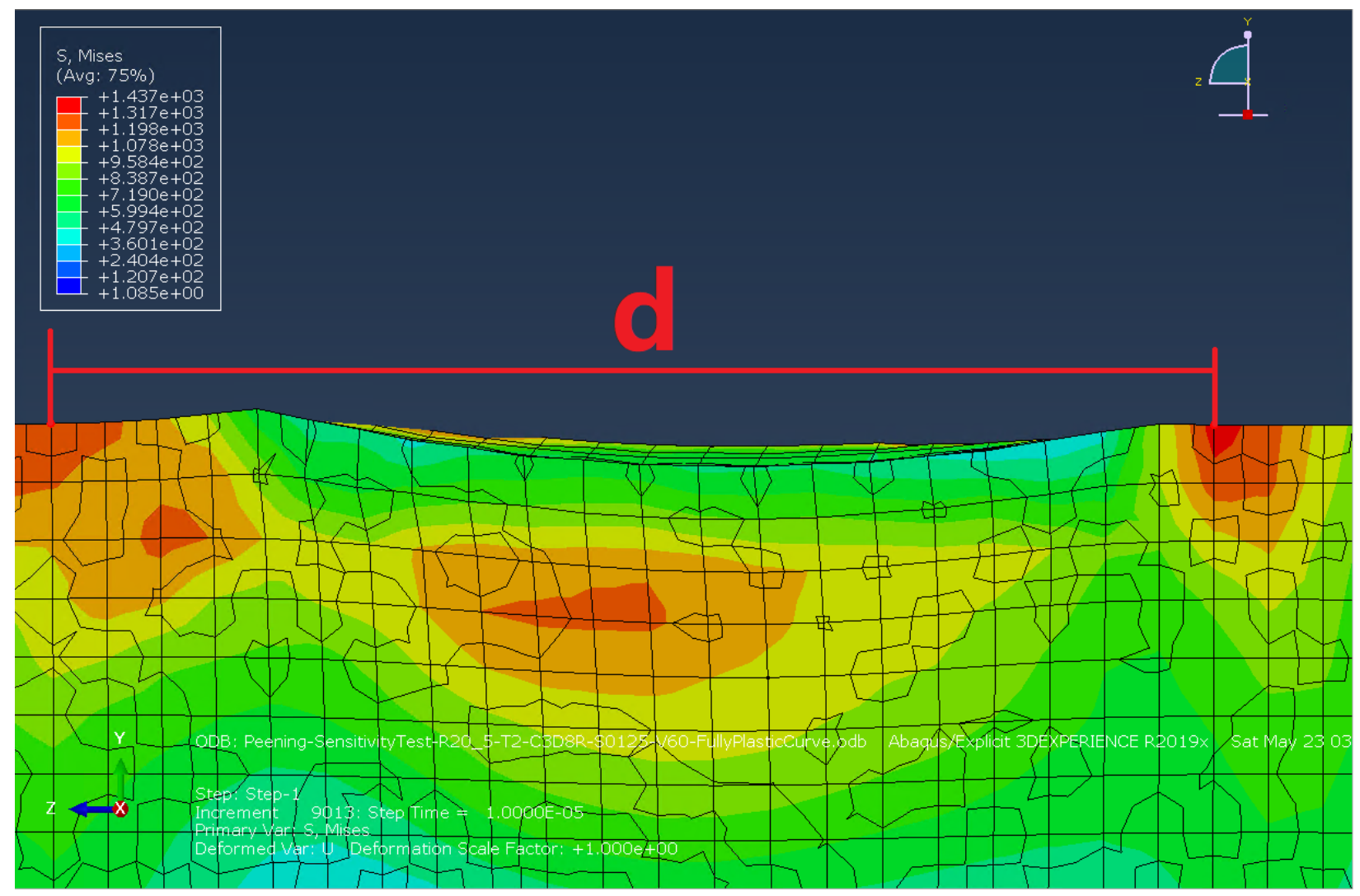

Figure 4-9 Cross-section of deformed model showing plastic or residual deformations of target surface due to single shot peening 


\subsection{Multiple Shot Peening Model}

\subsubsection{Peening Shot Number}

To build a multiple shot peening model, first, it is necessary to calculate the number of peening shots used according to the coverage equation (Eq 2-1). In the equation, $r$ is the radius of each shot impact, thus, the peened area $A_{I}$ by each shot impact can be expressed as

$$
A_{I}=\pi r^{2}
$$

The parameter $R$ in Eq 2-1 is the number of shots that impact the workpiece per unit area per unit time, and $t$ is the time during which the impressions are being created. Thus, the number $N_{U}$ of shots in the unit area is calculated as

$$
N_{U}=R \times t
$$

Then the number $N_{U}$ of shots in the unit area can be calculated as

$$
N_{U}=\frac{\ln (1-C)}{-A_{I}}
$$

Furthermore, the simulation area $A_{S}$ is defined in the FEA model, which is within a circle with the radius $r_{S}$. This area defines the impact region of the shots, that is, all shots will fall into this area only.

$$
A_{S}=\pi r_{S}^{2}
$$

Finally, the number $N_{S}$ of shots in the simulation area can be calculated as

$$
N_{S}=\frac{\ln (1-C)}{-A_{I}} \times A_{S}
$$




\subsubsection{Peening Shot Velocity}

To determine the peening shot velocity, the angle between the target surface and peening shot incidence must be defined, which is termed peening angle $\theta_{P}$, as illustrated in Figure 4-10. Then when the peening shot velocity $V_{P}$ is set, the fractional velocity of peening shot in $\mathrm{z}\left(V_{z}\right)$ and $\mathrm{y}\left(V_{Y}\right)$ direction can be calculated as

$$
\begin{aligned}
& V_{z}=V_{P} \times \cos \left(\theta_{P}\right) \\
& V_{Y}=V_{P} \times \sin \left(\theta_{P}\right)
\end{aligned}
$$

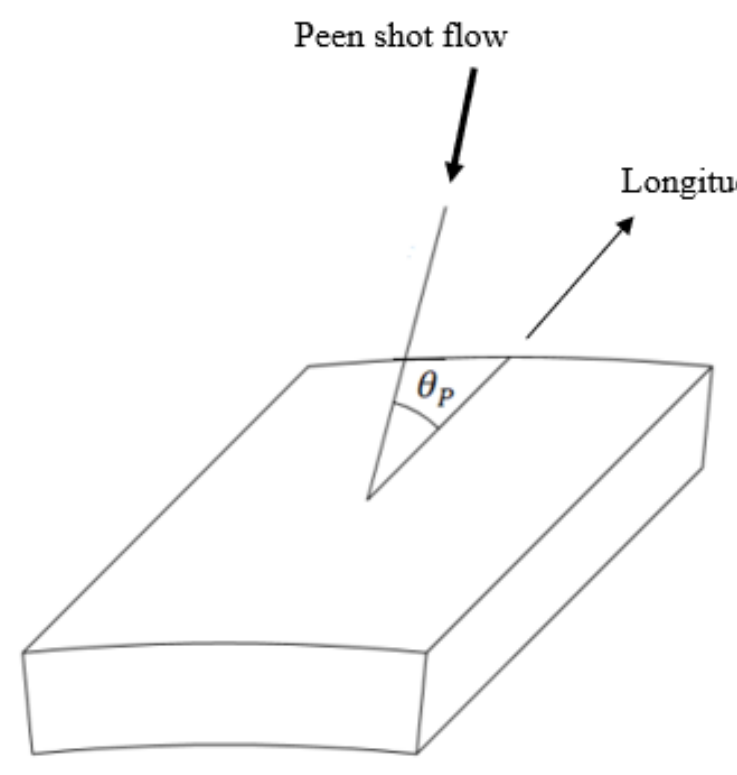

(a)

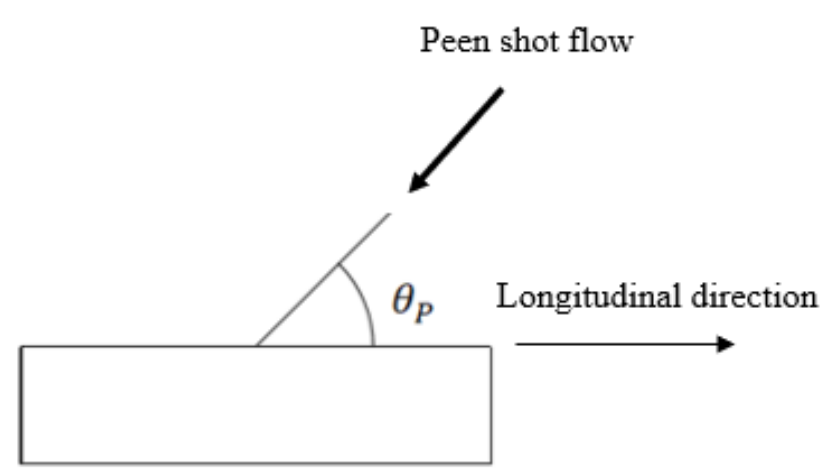

(b)

Figure 4-10 Schematic diagram showing the impact angle of peening shot flow: (a) 3D view; (b) section view 


\subsubsection{Impact Interval}

In the FEA model, the time interval $T_{I}$ between two consecutive peening shots is chosen to be $5 e^{-6}$ seconds which was suggested by other researchers and used in their studies [44], then the distance interval in the $z$-direction $D_{I_{Z}}$ and $y$-direction $D_{I_{Y}}$ can be calculated as

$$
\begin{aligned}
& D_{I_{Z}}=V_{z} \times T_{I} \\
& D_{I_{Y}}=V_{Y} \times T_{I}
\end{aligned}
$$

\subsubsection{Peening Shot Location}

Based on the simulation results of the single shot model, the radius of the peened area by one shot impact is $0.13 \mathrm{~mm}$. Considering that in the actual shot peening process, the shot peening coverage hardly reached $100 \%$, therefore, the $C$ value, calculated from Eq $2-1$, is reasonably 0.98 rather than 1. Using Eq 4-2, Eq 4-3 and Eq 4-11, the shot flow is generated randomly within a circle area of $0.4 \mathrm{~mm}$ radius in the central region of the target surface of the FEA model using the MATLAB program given below. It gives that in total thirty-seven shots will be used in each simulation run. The impact locations of each shot on the target surface, generated by the MATLAB program, are reported in Appendix B.

close all

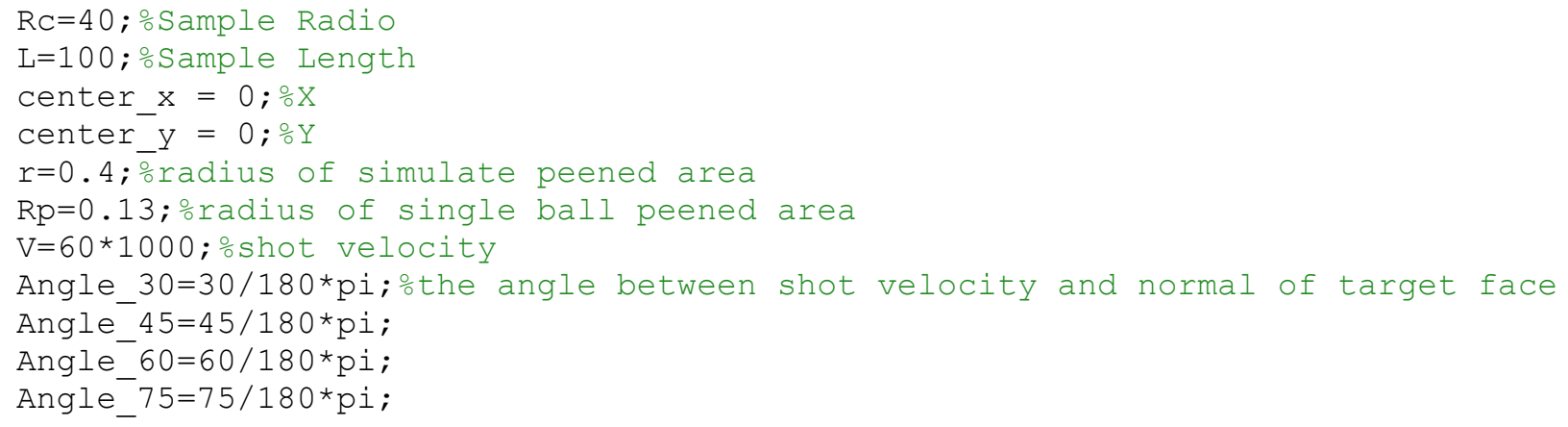


Angle $90=90 / 180 *$ pi ;

$\mathrm{V}$ Z $3 \overline{0}=\mathrm{V}^{\star} \cos ($ Angle 30 ); VVelocity $\mathrm{X}$ Direction

V_Y_30 $=V^{*} \sin ($ Angle_30); $\%$ Velocity_Y_Direction

$\mathrm{V}^{-} \mathrm{Z}^{-} 45=\mathrm{V} * \cos ($ Angle_45);

$\mathrm{V}_{-}^{-} \mathrm{Y}_{-}^{-} 45=\mathrm{V} * \sin ($ Angle_45);

$V^{-} Z^{-}-60=V^{*} \cos ($ Angle_60);

$\mathrm{V}-\mathrm{Y}-60=\mathrm{V} * \sin ($ Angle_60);

$\mathrm{V}^{-} \mathrm{Z}^{-} 75=\mathrm{V}{ }^{*} \cos \left(\right.$ Angle $\left.\mathrm{e}^{-} 75\right)$;

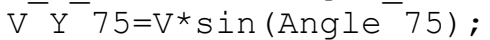

V_Z_ $90=V^{*} \cos ($ Angle_90);

$\mathrm{V}_{-}^{-}{ }^{-}-90=\mathrm{V} * \sin ($ Angle_ 90$)$;

Area $=\mathrm{pi}{ }^{*} 2{ }^{*} \mathrm{Rc}{ }^{*} \mathrm{~L} ; \%$ Sample Surface Area

area $=\mathrm{pi}^{*} \mathrm{Rp}^{\wedge} 2$; $\circ$ single ball peened area

simulation_area $=\mathrm{pi}{ }^{*}{ }^{*}$ r;

Coverage $=0.98$;

$\mathrm{ABC}=\log (0.02)$;

$\mathrm{ABCD}=$ simulation_area/area*ABC/4;

○Coverage $=1-\exp (-$ area* $\mathrm{RT}) ; \%$ Coverage

$\%-\exp (-$ area* RT $)=$ Coverage -1 ;

oexp $(-$ area* $\mathrm{RT})=1$-Coverage;

o-area ${ }^{\mathrm{RT}}=\log (1$-Coverage $)$;

$\circ \mathrm{RT}=-\log (1$-Coverage $) /($-area $)$;

ㅇT/area $=(1$-Coverage $) /(-$ area $) /$ area;

dot_number $=[\log (1-$ Coverage $)] /(-$ area $) *$ simulation_area;

dot_number_1=round (dot_number);

T I=5E-06; $\circ$ Time Interval

D_I_Y_30=V_Y_30*T_I; $\circ$ Distance_Interval

D I X $30=V$ Z $30 * T$ I ;

D_I Y $-45=\mathrm{V}^{-} \mathrm{Y}^{-} 45 * \mathrm{~T}^{-} \mathrm{I}$;

$\mathrm{D}^{-} \mathrm{I}^{-} \mathrm{X}^{-} 45=\mathrm{V}^{-} \mathrm{Z}^{-} 45 * \mathrm{~T}$ I;

$\mathrm{D}^{-} \mathrm{I}^{-} \mathrm{Y}-60=\mathrm{V}^{-} \mathrm{Y}^{-} 60 * \mathrm{~T}^{-} \mathrm{I}$;

$\mathrm{D}^{-} \mathrm{I}^{-} \mathrm{X}-60=\mathrm{V} \mathrm{Z}^{-} 60 * \mathrm{~T}-\mathrm{I}$;

$\mathrm{D}^{-}{ }^{-} \mathrm{Y}^{-} 75=\mathrm{V}^{-} \mathrm{Y}^{-} 75 * \mathrm{~T}^{-} \mathrm{I}$;

$\mathrm{D}^{-} \mathrm{I}^{-} \mathrm{X}^{-} 75=\mathrm{V}^{-} \mathrm{Z}^{-} 75 * \mathrm{~T}^{-} \mathrm{I}$;

D_I_Y ${ }^{-} 90=V^{-} \mathrm{Y}^{-} 90 * \mathrm{~T}^{-} \mathrm{I}$;

D_I_X_90 ${ }^{-}{ }^{-}{ }^{-}{ }^{-}-90 * \mathrm{~T}_{-}^{-}{ }^{-}$;

\footnotetext{
odot_number_1=round(total_number_1*simulation_area/Area); $\%$ shot number in simulation àrea

dot_number_2=dot_number_1*2; $\circ$ shot number in simulation area

dot_number_3=dot_number_1*3; $\%$ shot number in simulation area

$\mathrm{TT}_{-} \overline{1}=\left(\right.$ dot_number_1+1)*T_ $\mathrm{I}_{\text {; }}$

$\mathrm{t}=0: \mathrm{pi} / 100: 2{ }^{*} \mathrm{pi}$

$x=r^{*} \cos (t)+$ center_x;

$y=r^{*} \sin (t)+$ center_y;
} 


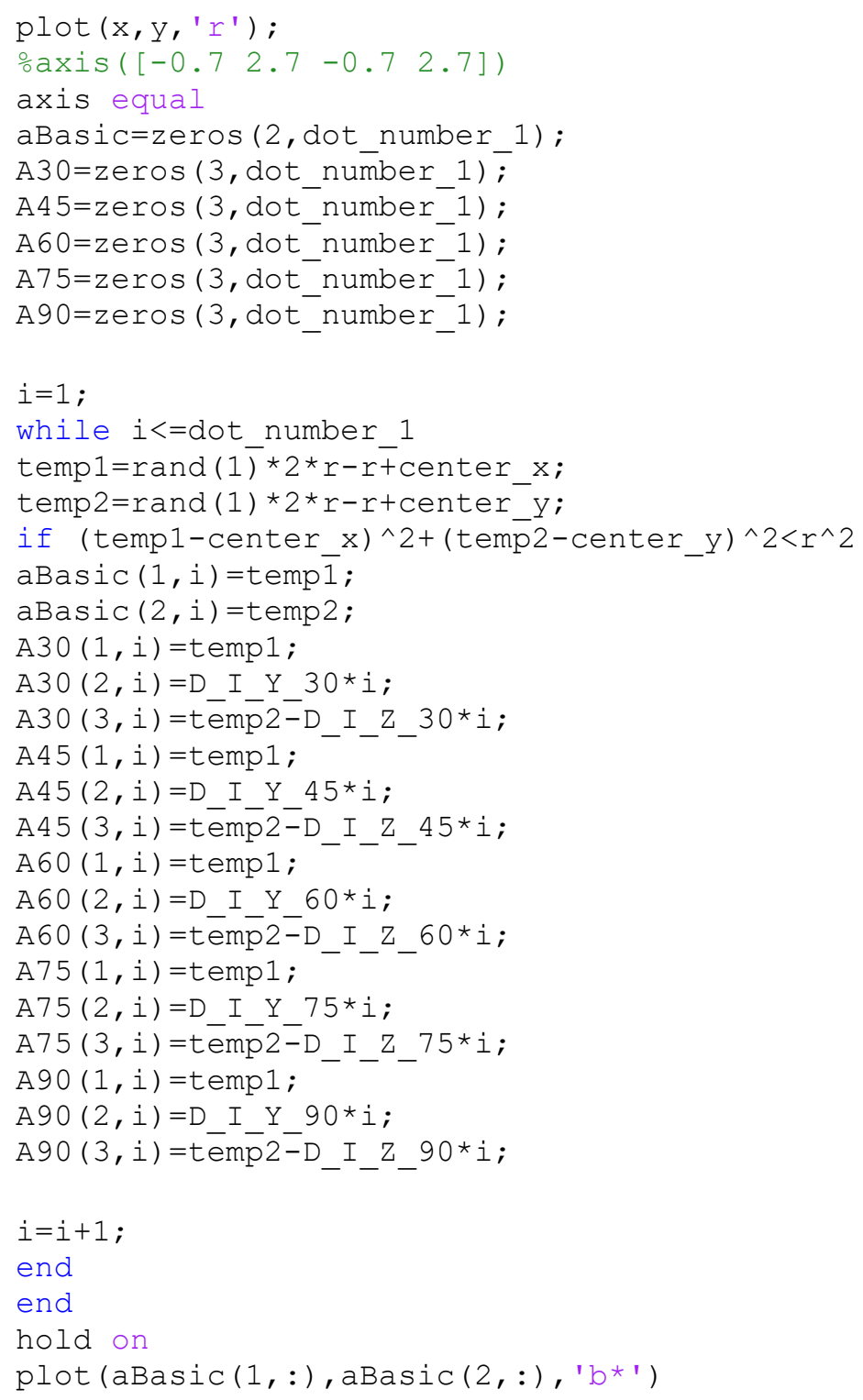




\subsection{Multiple Shot Peening of Flange Pin}

\subsubsection{Target Surface and Shot Flow Assembly Model}

For simulating the actual shot peening process of the flange pin, a multiple shot peening model is created, as shown in Figure 4-11. The target surface model and boundary conditions are the same as for single shot peening; the shot flow model and setting are described in the previous section. After the peening process is completed in the simulation, the peened surface is analyzed in stress and strain behavior.

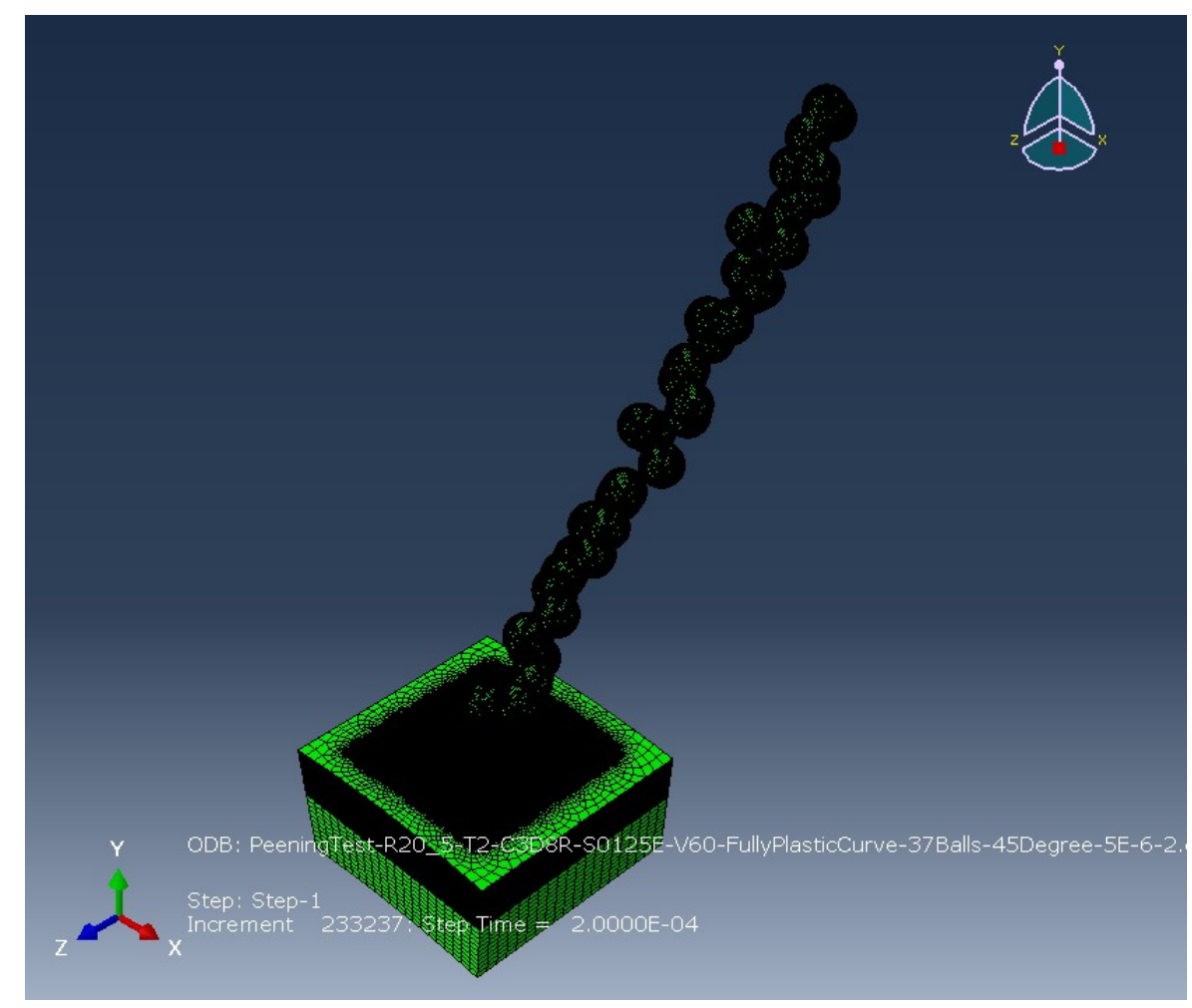

Figure 4-11 FEA model for simulating real peening process of flange pin 


\subsubsection{Residual Stress Profiles}

The stresses in various directions such as longitudinal or axial, circumferential and radial direction are examined in the longitudinal section through the center of the model. Figure 4-12 shows the Von Mises stress distribution in the peened surface layer. The area marked with a red circle indicates the central region of the peened surface, which is affected the most by shot peening, therefore, the following stress analyses are focused on this area.

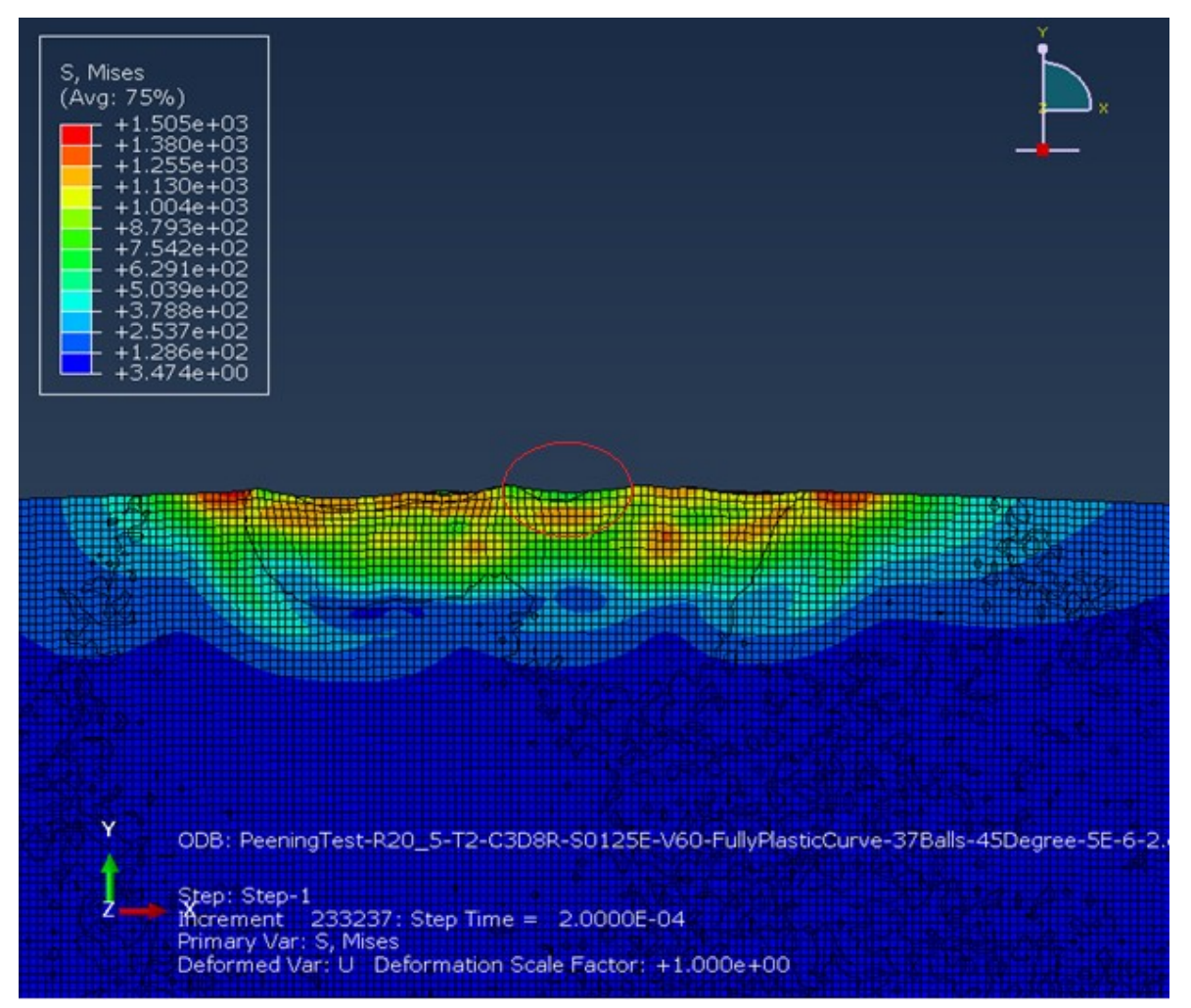

Figure 4-12 Longitudinal section of peened surface layer of flange pin showing Von Mises stress distribution 
First, in correspondence to the X-ray measurements described in Chapter 3, the longitudinal and circumferential stress in the peened surface layer are examined. As shown in Figure 4-13, the longitudinal stresses in the surface layer are all compressive although the stress varies in magnitude within the layer. Red area shows positive residual stress (tensile stress) and blue area shows negative residual stress (compressive stress). On the surface at the center of the peened area, the longitudinal stress is $-291.4 \mathrm{MPa}$.

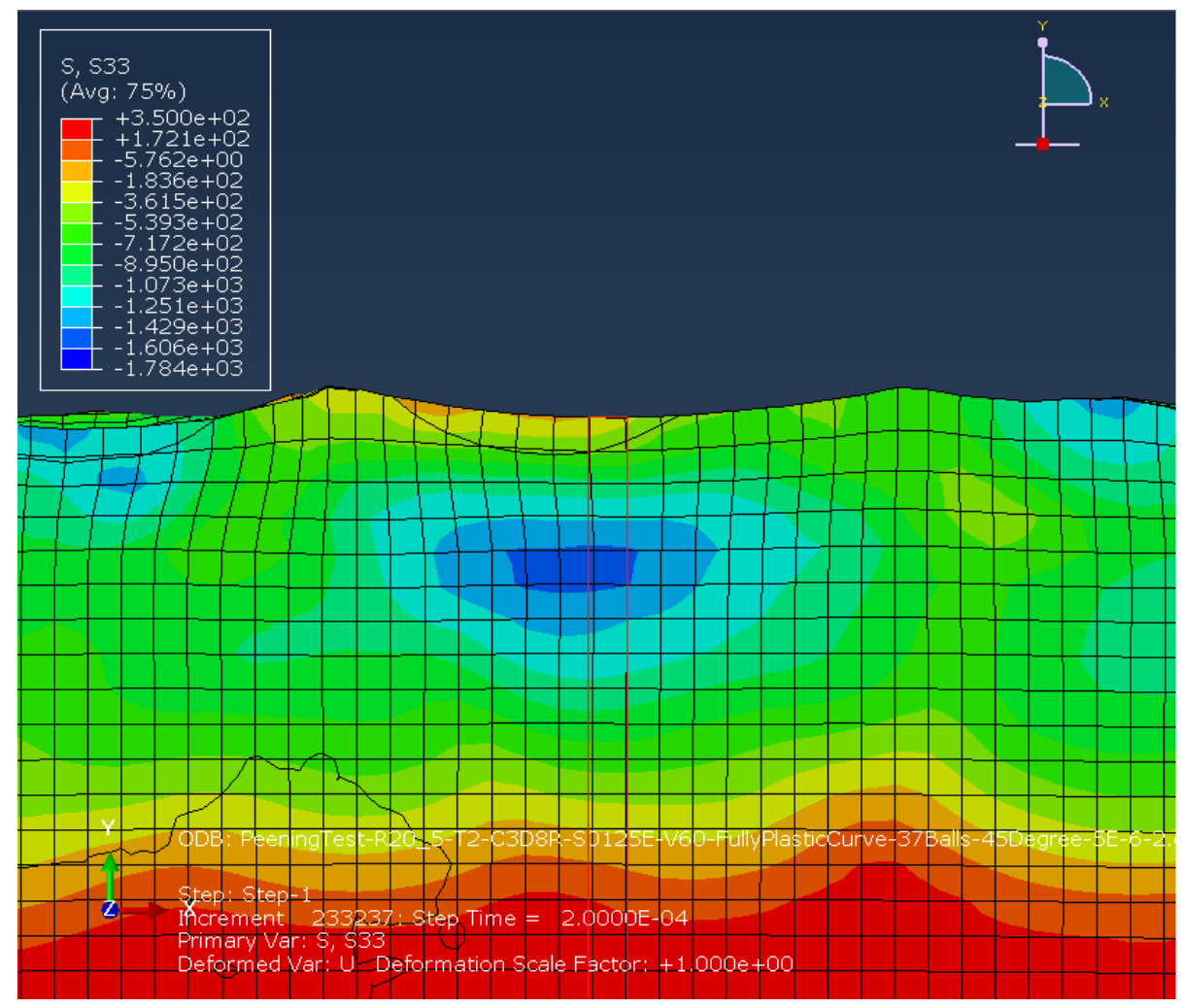

Figure 4-13 Longitudinal stress profile in the central area of peened surface simulating actual peening process of flange pin

Figure 4-14 shows the circumferential stress distribution in the surface layer under multiple shot peening of the flange pin. The circumferential stresses are also all compressive in the surface layer and vary in magnitude within the layer. On the surface at the center of the peened area, the circumferential stress is $-768.5 \mathrm{MPa}$. 


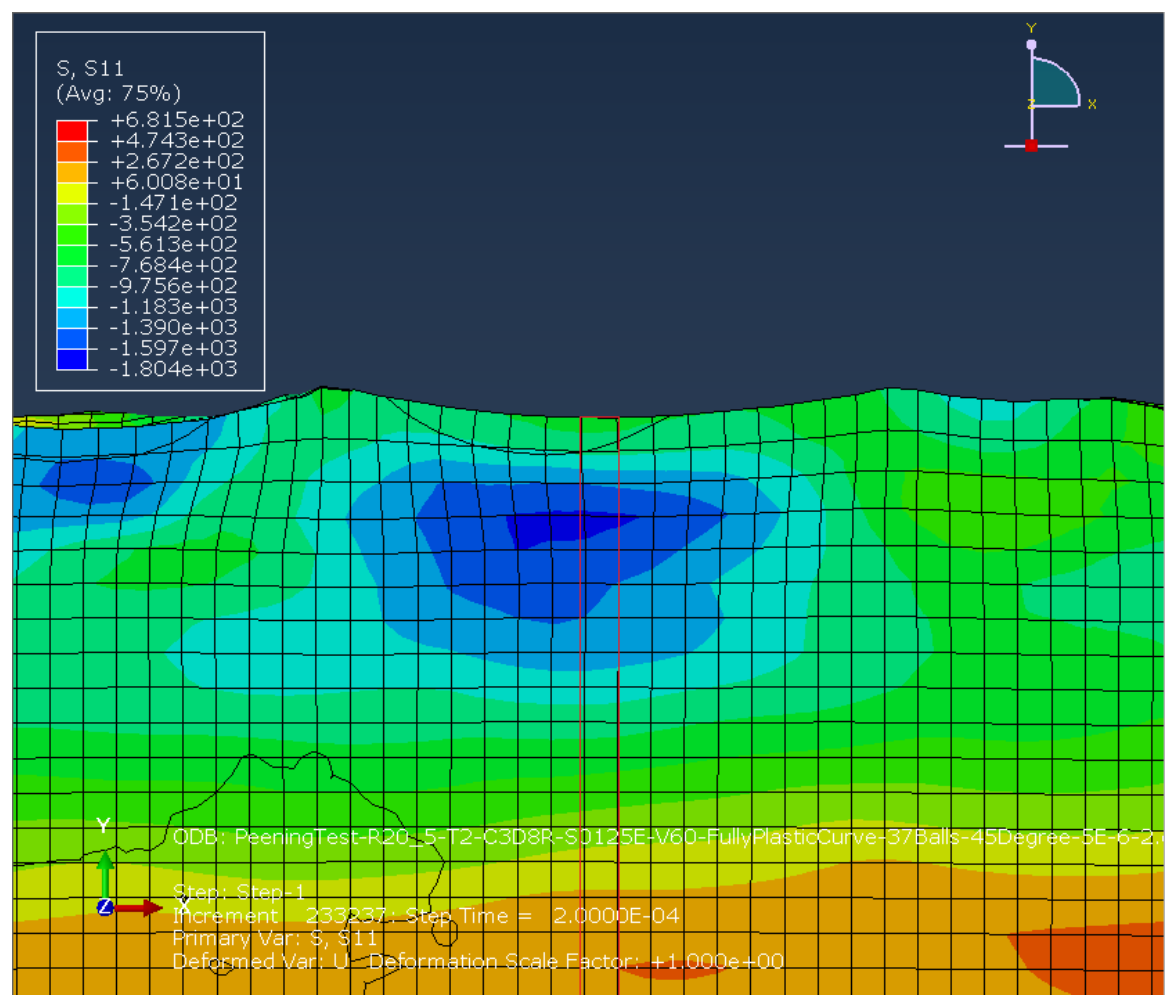

Figure 4-14 Circumferential stress profile in the central area of peened surface simulating actual peening process of flange pin

As reported in Table 3-4, the longitudinal or axial stress and circumferential stress on the peened surface of the flange pin determined from the X-ray measurements are -298.7 MPa and -786.9, respectively. It is noted that although the real peening process parameters of the flange pin are not known and the FEA simulation uses the suggested data in literature, the FEA simulation results are very close to the experimental data. Consistently, the peening process did generate compressive stresses, which are expected and will favor the fatigue resistance of the flange pin. It is also revealed that the circumferential stress is more than double greater than the longitudinal stress in magnitude. 
Since the X-ray method can only measure residual stresses at the surface of the flange pin, the radial stress cannot be determined by the X-ray measurement. However, the FEA simulation uses a 3D model, which allows to determine stresses also in radial direction in addition to longitudinal and circumferential direction. As shown in Figure 4-15, the radial stresses are also all compressive in the surface layer and vary in magnitude within the layer. On the surface at the center of the peened area, the radial stress is about -50 MPa. Compared to longitudinal and circumferential stresses, the radial stresses are relatively low in the peened surface.

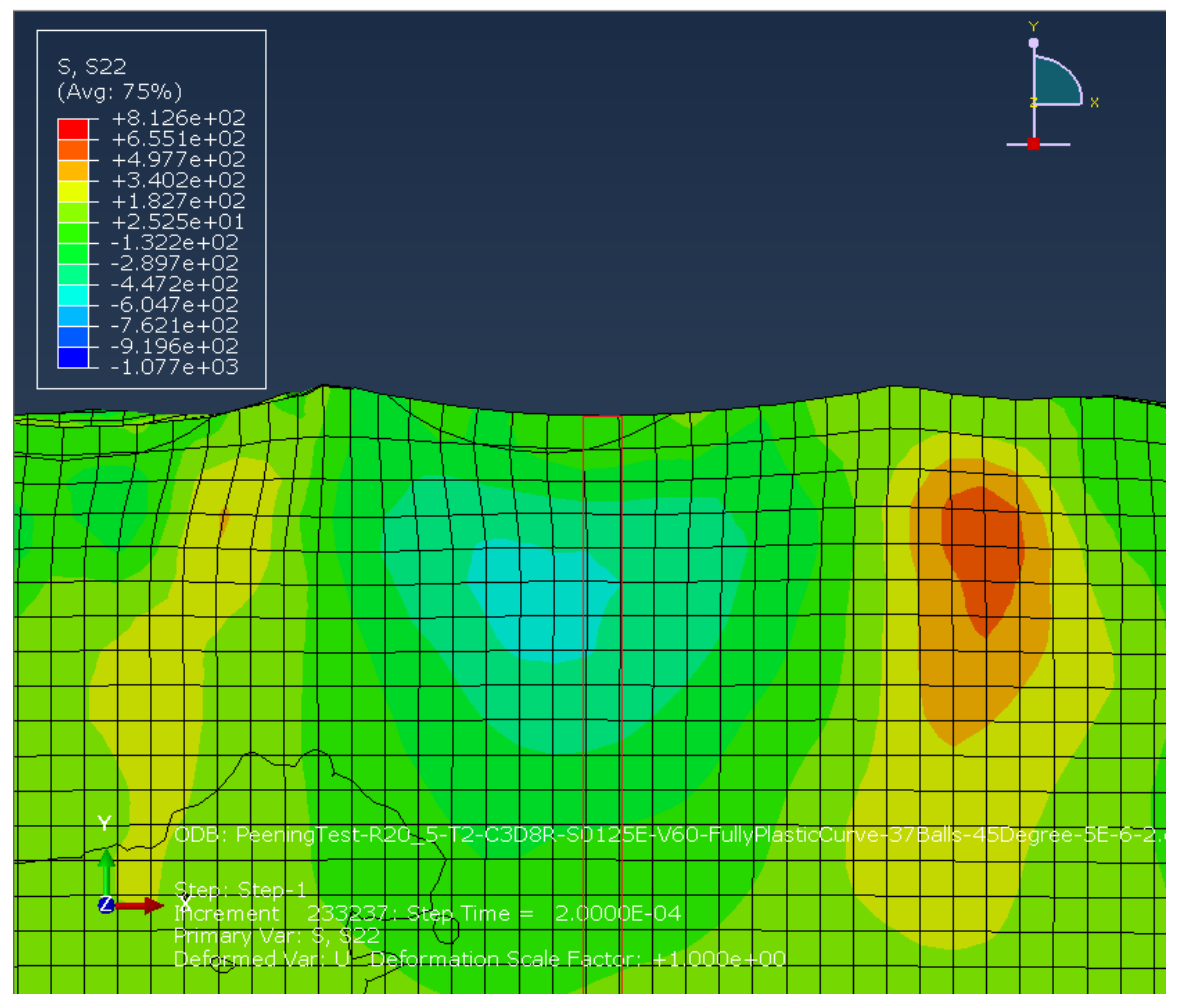

Figure 4-15 Radial stress profile in the central area of peened surface simulating actual peening process of flange pin 
Moreover, it is important to concern Von Mises stress when studying the stress and strain behavior of materials or structures because it governs the yielding of the material for a structure subjected to a complex stress condition, according to the Shear - Strain Energy Theory of material failure criterion. Therefore, the Von Mises stress distribution in the peened surface layer of the flange pin is also examined. As presented in Figure 4-16 nonuniform Von Mises stress profile is observed within the surface layer, with the maximum value reaches $1505 \mathrm{MPa}$ in some region in the sublayer (area in red). The yield strength of the flange pin material (HY-TUF steel) is about $1400 \mathrm{MPa}$, as reported in Table 3-2. Thus, based on the Von Mises failure criterion or Shear - Strain Energy Theory, local yielding has occurred in some regions where the Von Mises stress is greater than the yield strength of HY-TUF steel (1400 MPa). In other words, plastic deformation has taken place locally in the peened flange pin, which corresponds to the strain hardening behavior of the peened surface layer.

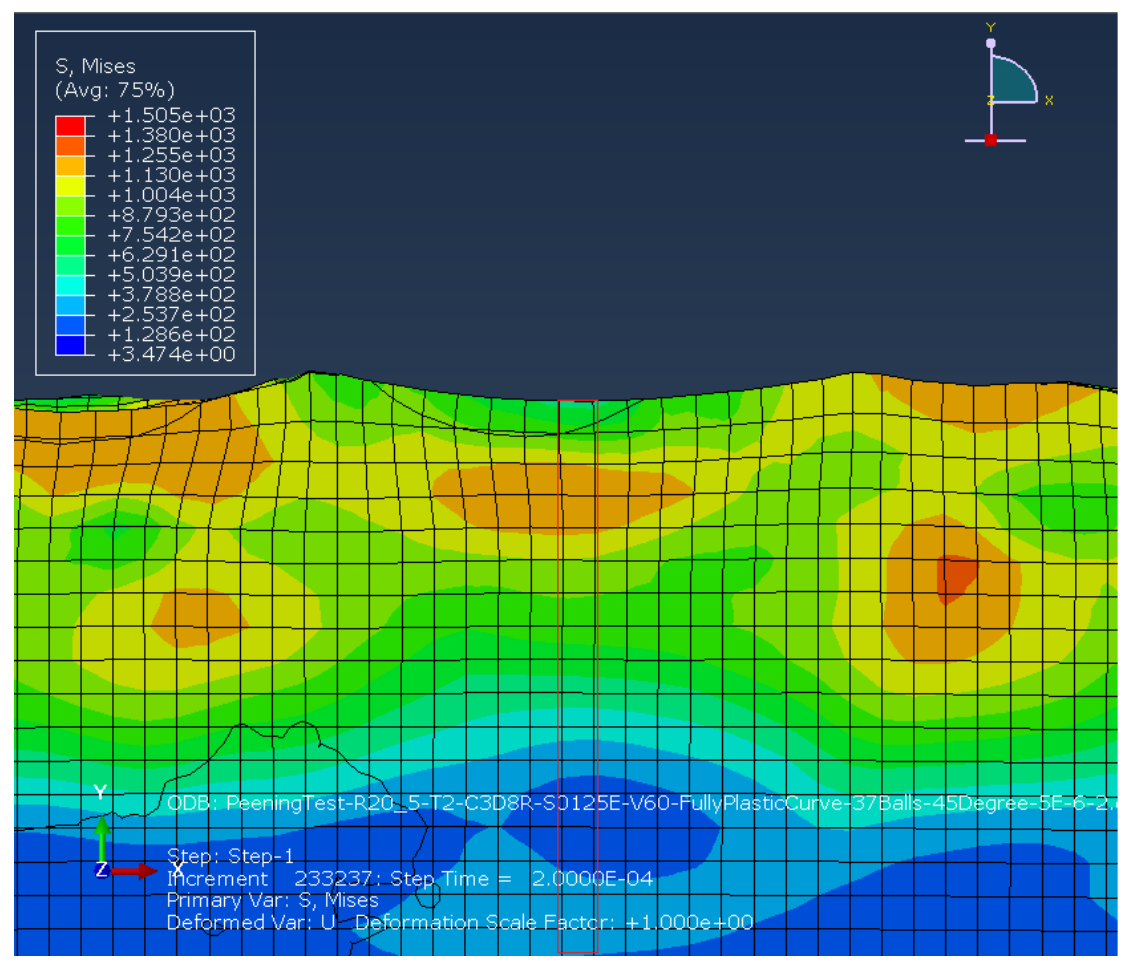

Figure 4-16 Von Mises stress distribution in the central area of peened surface simulating actual peening process of flange pin 
Furthermore, as indicated above, the residual stresses appear nonuniform within the peened surface layer of the flange pin. For the longitudinal, circumferential, and radial stress, the maximum compressive stress all occurs at subsurface, not on the top surface. For better demonstration, the variations of the longitudinal, circumferential, radial and Von Mises stress at the center of the peened surface model, where the target surface is affected the most by the shot peening, along the depth from the top surface are plotted together in Figure 4-17. The following characteristics of the residual stresses in the peened surface can be observed. First, in the region near the surface the longitudinal, circumferential and radial stress are all compressive, but at a depth about $0.18 \mathrm{~mm}$, these stresses become tensile. This means that under the peening shot flow condition in the FEA simulation, the hardened layer thickness of the flange pin is about $0.18 \mathrm{~mm}$. Second, the maximum compressive stresses in longitudinal, circumferential and radial direction all do not occur at the top surface, but take place at the subsurface in a depth about $0.05 \mathrm{~mm}$. Third, at the pin surface the circumferential stress is greater than the longitudinal and radial stress in magnitude, but below a layer around $0.05 \mathrm{~mm}$ in depth where the maximum compressive stresses occur, the circumferential and longitudinal stress are almost the same. Overall, the radial stress is much lower than circumferential and longitudinal stress in magnitude. Fourth, the maximum Von Mises coincides with the maximum circumferential, longitudinal, and radial stress, taking place at the subsurface $0.05 \mathrm{~mm}$ in depth. Finally, for all residual stresses, the variation in magnitude trend follows increasing initially until reaching a maximum value, and then decreasing to nearly zero. This variation behavior of the residual stresses conforms to the essence of peening surface treatment that only the surface layer is affected by the shot peening and the substrate remains unchanged. 


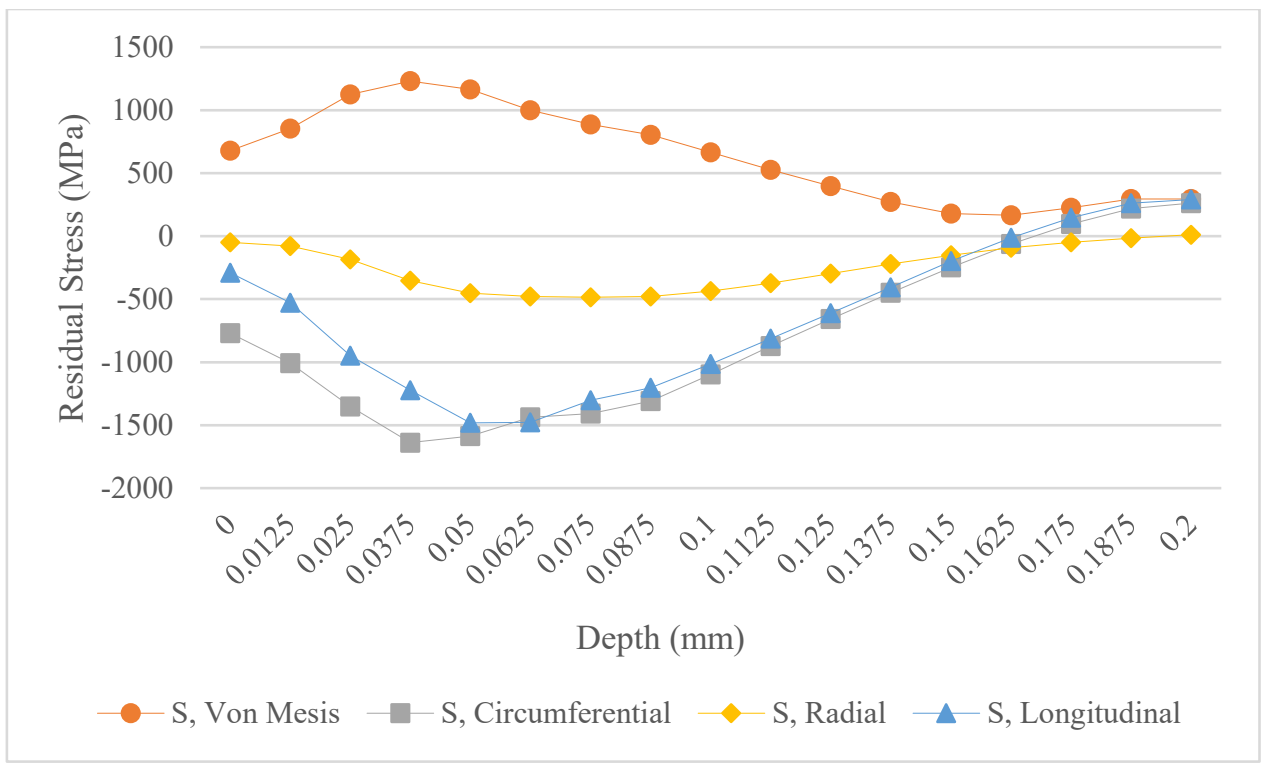

Figure 4-17 Variations of residual stresses in depth of peened flange pin surface

\subsection{Variation of Target Surface Curvature}

\subsubsection{Target Surface Curvature Model}

In order to help Safran gain more understanding of the residual stresses in the flange pin resulting from shot peening, further FEA simulation is performed on the target surface with variable curvature, because Safran has various sizes of flange pin and the radius of the pin may influence the residual stress behavior in the peened flange pin. In this simulation, the FEA model is created with the curvature radius of target surface varying from $10 \mathrm{~mm}$ to infinite (flat surface). The models with the curvature radius of $10 \mathrm{~mm}$ and infinite are shown in Figure 4-18. The boundary conditions of the target surface models are the same as for the model of actual flange pin peening, discussed above. The shot flow is also set to be $60 \mathrm{~m} / \mathrm{s}$ in this simulation, but it impacts the target surface normally, that is, the peening angle $\theta_{P}=90^{\circ}$. 


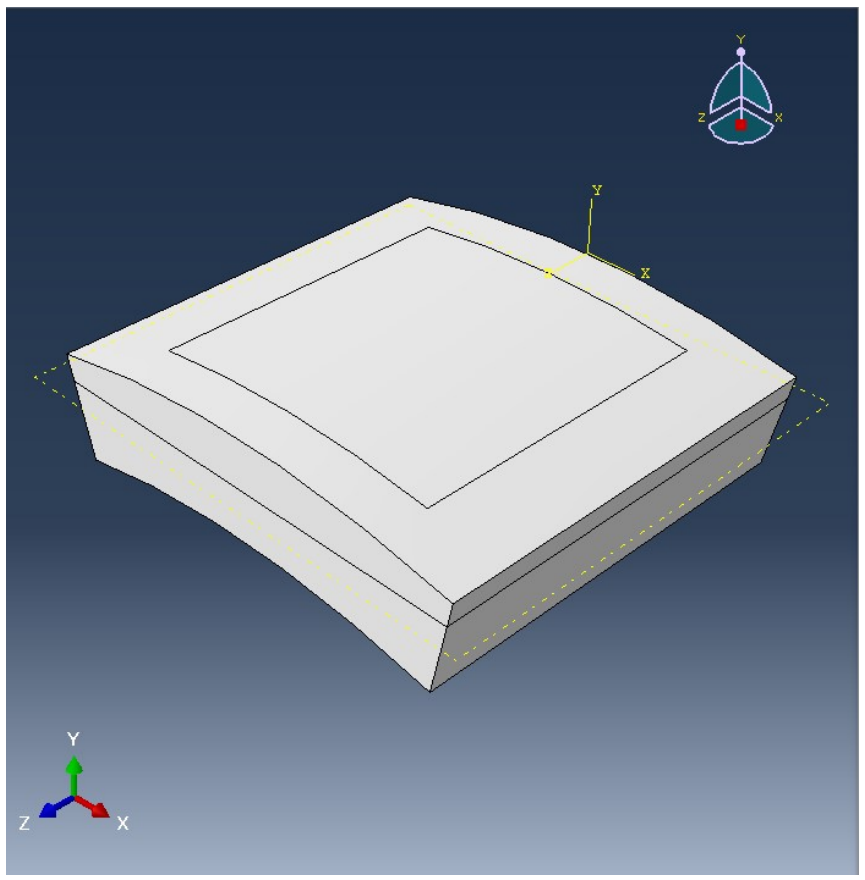

(a)

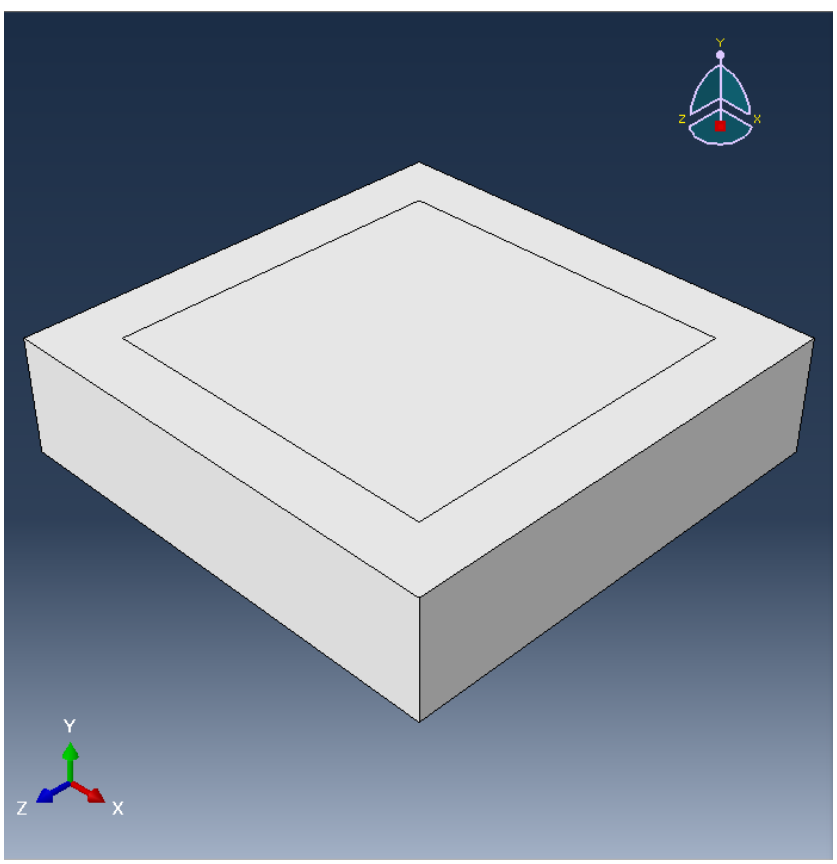

(b)

Figure 4-18 Target surface curvature model: (a) curvature radius of $10 \mathrm{~mm}$; (b) infinite curvature radius (flat surface) 


\subsubsection{Residual Stress Profiles in Peened Surface with Small Curvature Radius}

Figure 4-19 presents the FEA simulation results of the residual stresses in the peened surface with curvature radius of $10 \mathrm{~mm}$. Overall, the longitudinal, circumferential, and radial stress all appear compressive in the surface layer and have nonuniform distributions. The Von Mises stress profile is shown in Figure 4-20. Similarly, the variations of the longitudinal, circumferential, radial and Von Mises stress at the center of the peened surface model along the depth from the top surface are plotted together in Figure 4-21. It is shown that through the whole depth of the surface layer the circumferential stress is slightly greater than the longitudinal stress in magnitude, and both are much greater than the radial stress. Also, the maximum compressive stresses in the three directions all occur at a depth around $0.0625 \mathrm{~mm}$, but in this case the maximum Von Mises stress does not coincide with the same location.

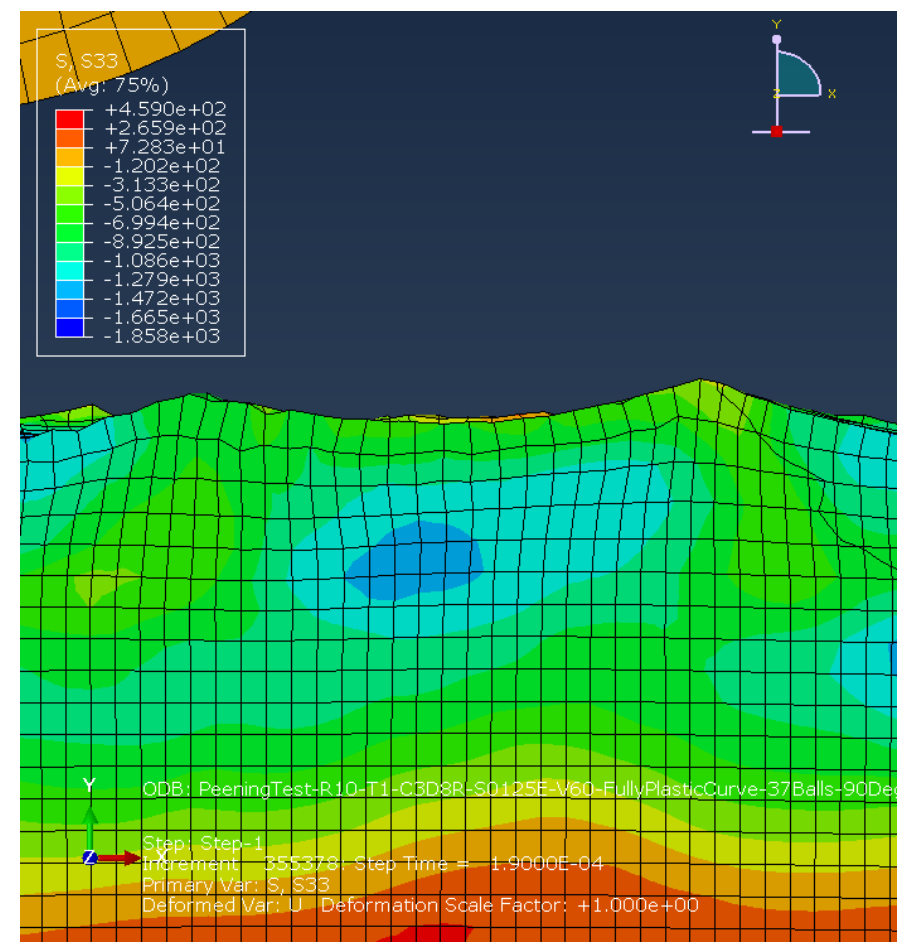

(a) 


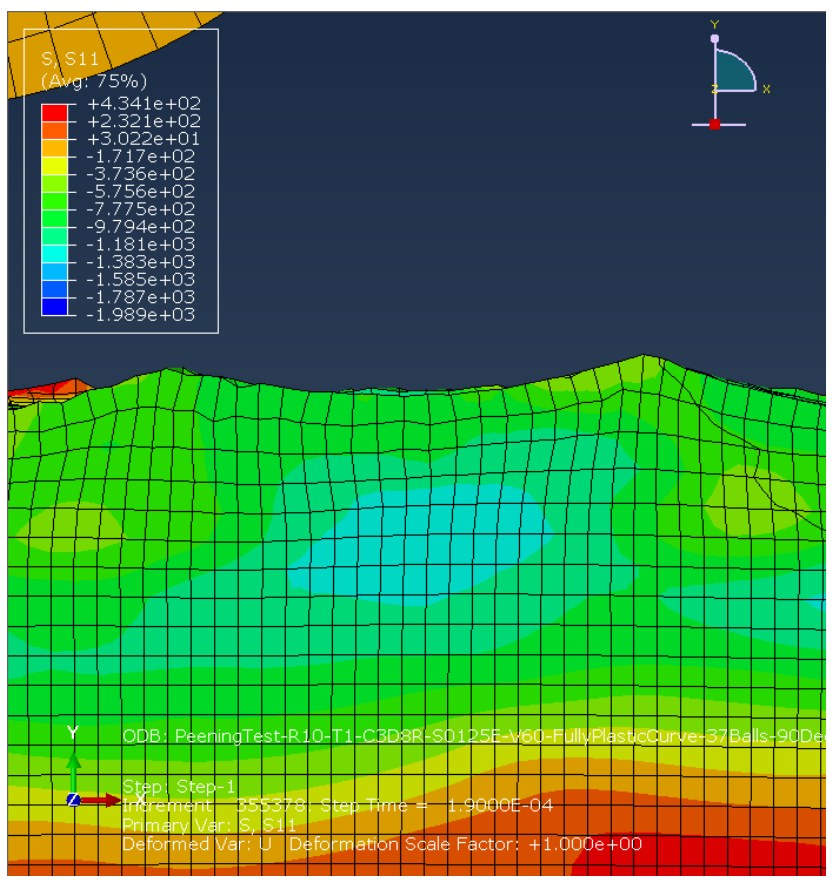

(b)

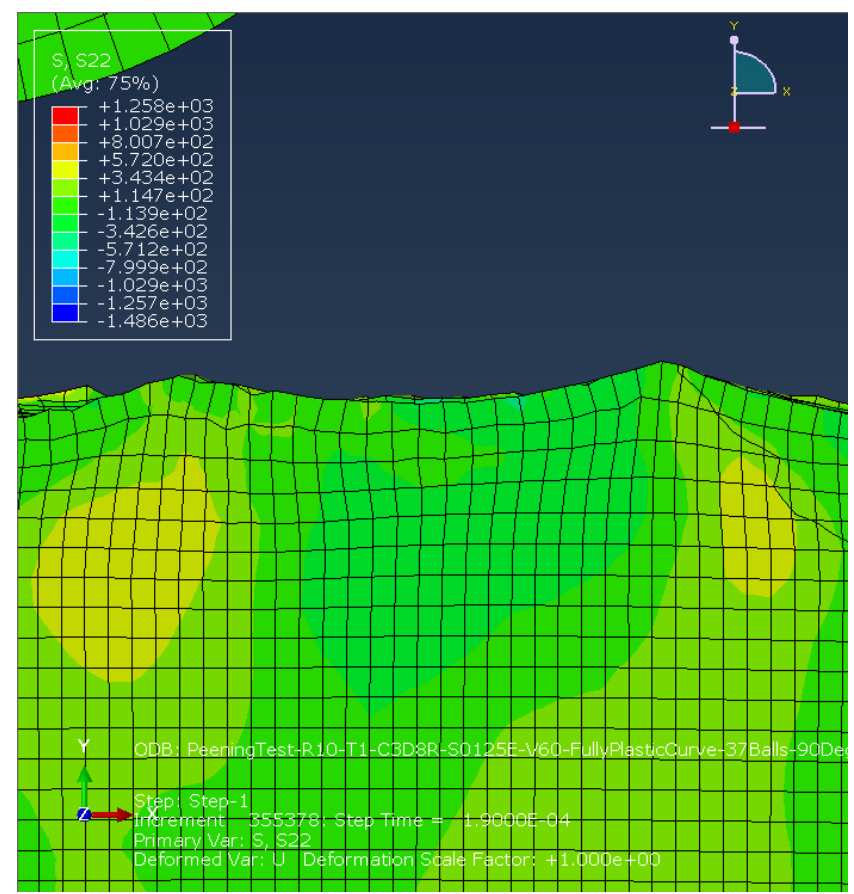

(c)

Figure 4-19 Residual stress profile in peened surface with curvature radius of $10 \mathrm{~mm}$ : (a) longitudinal stress; (b) circumferential stress; (c) radial stress 


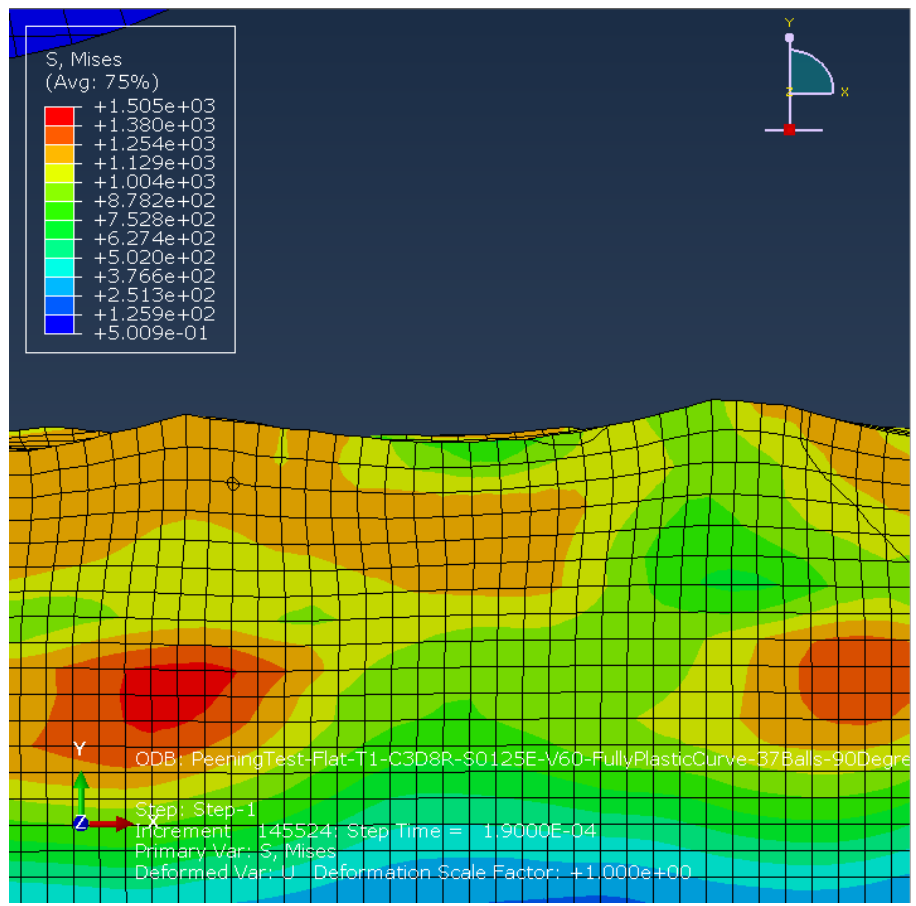

Figure 4-20 Von Mises stress profile in peened surface with curvature radius of $10 \mathrm{~mm}$

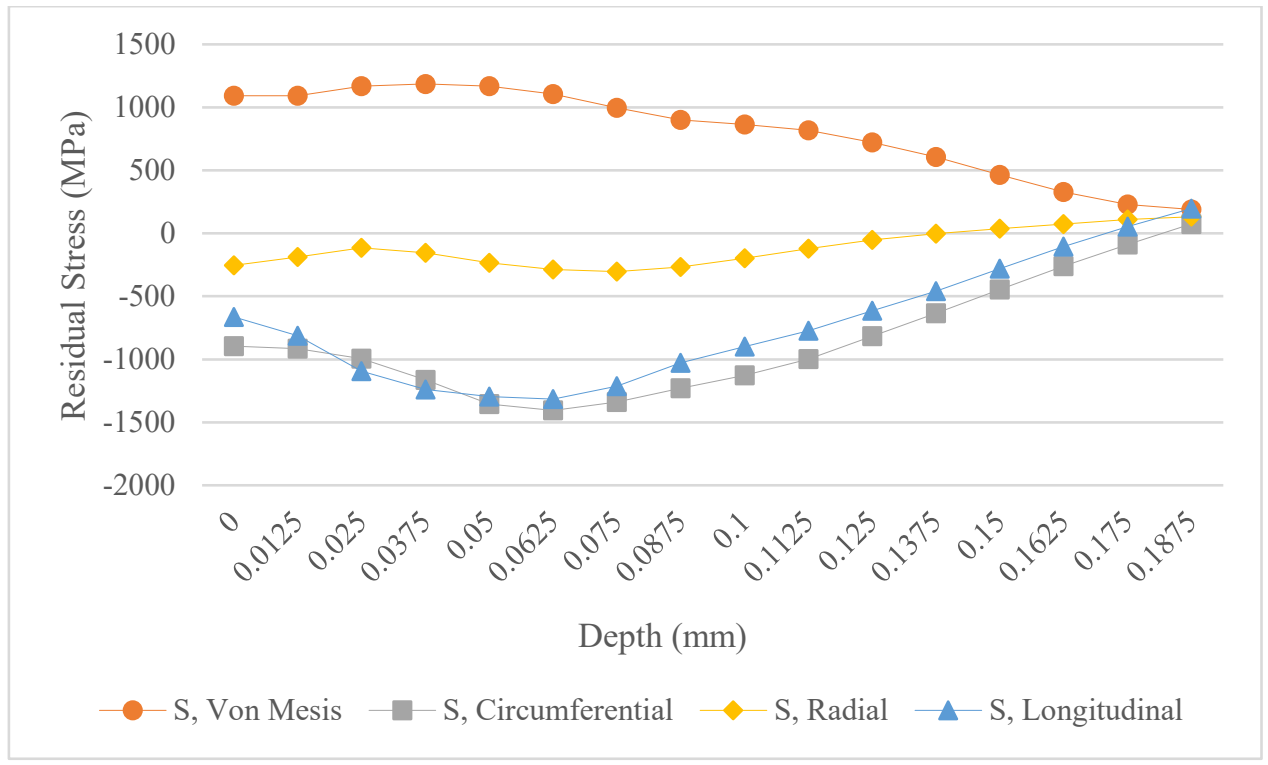

Figure 4-21 Variations of residual stresses in depth of peened surface with curvature radius of $10 \mathrm{~mm}$ 


\subsubsection{Residual Stress Profiles in Peened Surface with Infinite Curvature Radius}

When the curvature radius is infinite, the target surface becomes flat. Figure 4-22 presents the FEA simulation results of the residual stresses in the peened surface with infinite curvature radius. It is shown that although there is large difference in curvature between the flat surface and the surface with small curvature radius $(10 \mathrm{~mm})$, the residual stress behavior does not change significantly. The Von Mises stress profile is shown in Figure 4-23. The variations of the longitudinal, circumferential, radial and Von Mises stress at the center of the peened surface model along the depth from the top surface are plotted together in Figure 4-24. At the surface, the longitudinal and circumferential stress are about $-500 \mathrm{MPa}$ and $-750 \mathrm{MPa}$, respectively. The radial stress is much lower and less than $100 \mathrm{MPa}$. Compared to the target surface with curvature radius of $10 \mathrm{~mm}$, which has the longitudinal and circumferential stress about -700 MPa and -900 MPa, respectively, at the center point of the surface, the extreme case (flat surface) results in reduced longitudinal and circumferential stress at the top surface. However, the maximum longitudinal and circumferential stress in magnitude which occur at the subsurface of the flat surface are about -1500 MPa and $1510 \mathrm{MPa}$, respectively, showing higher than that (about -1470 MPa and -1480 MPa) of the target surface with curvature radius of $10 \mathrm{~mm}$. Also, the extreme geometry (flat surface) causes the locations of maximum compressive stresses moving down in depth from $0.07 \mathrm{~mm}$ (for the target surface with curvature radius of $10 \mathrm{~mm}$ ) to $0.075 \mathrm{~mm}$. 


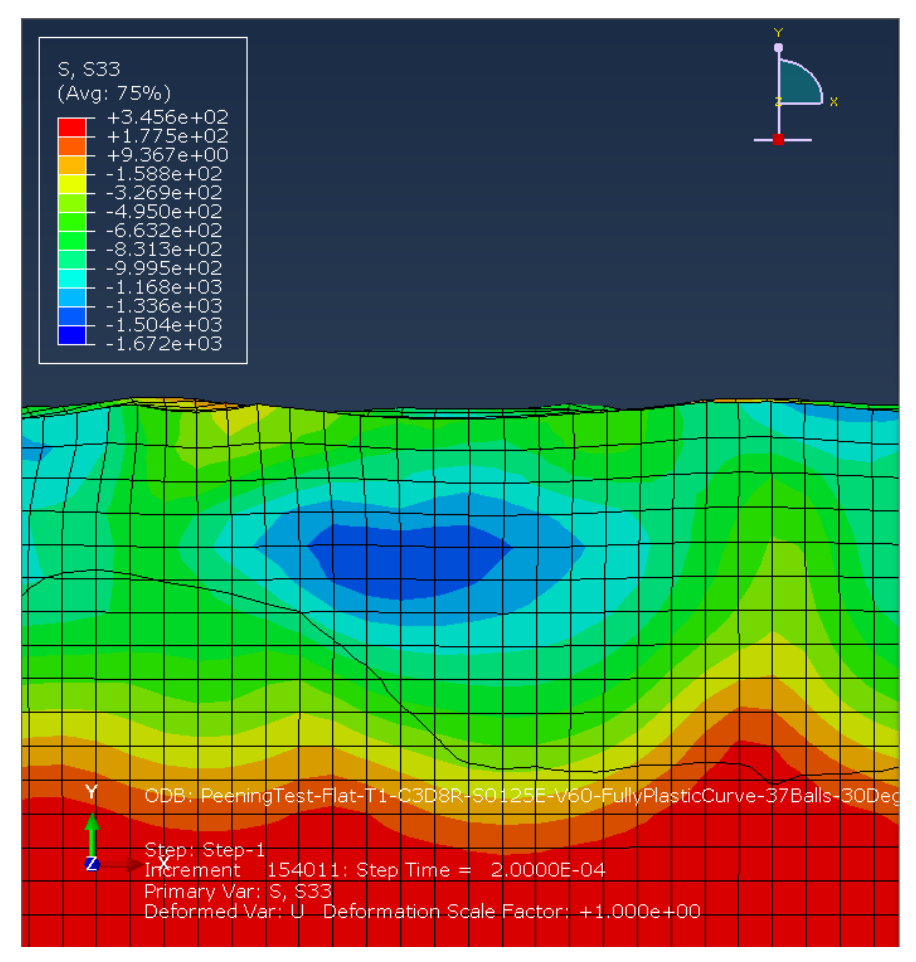

(a)

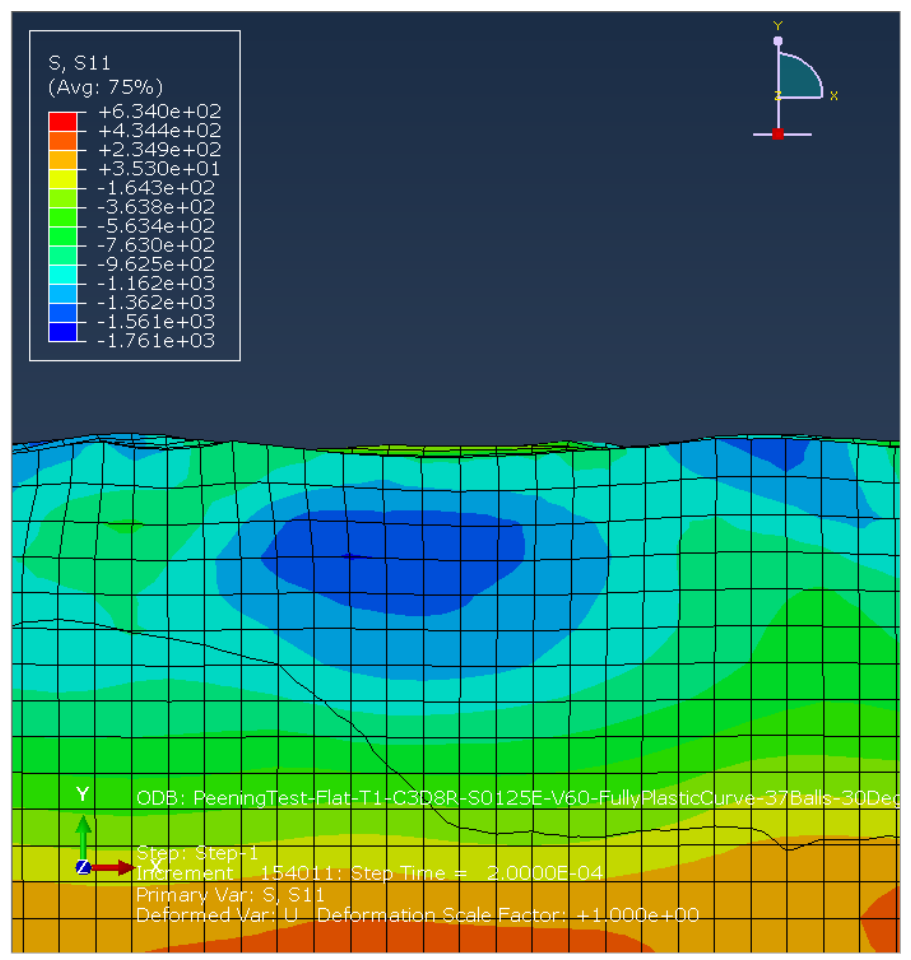

(b) 


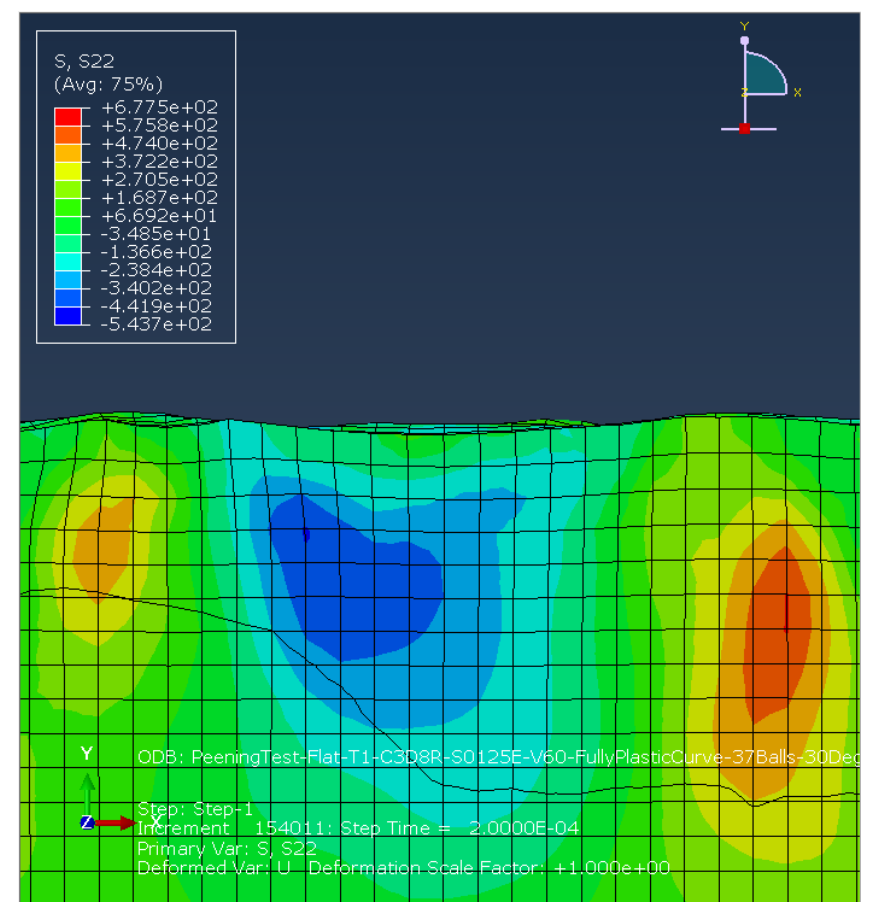

(c)

Figure 4-22 Residual stress profile in peened surface with infinite curvature radius: (a) longitudinal stress; (b) circumferential stress; (c) radial stress

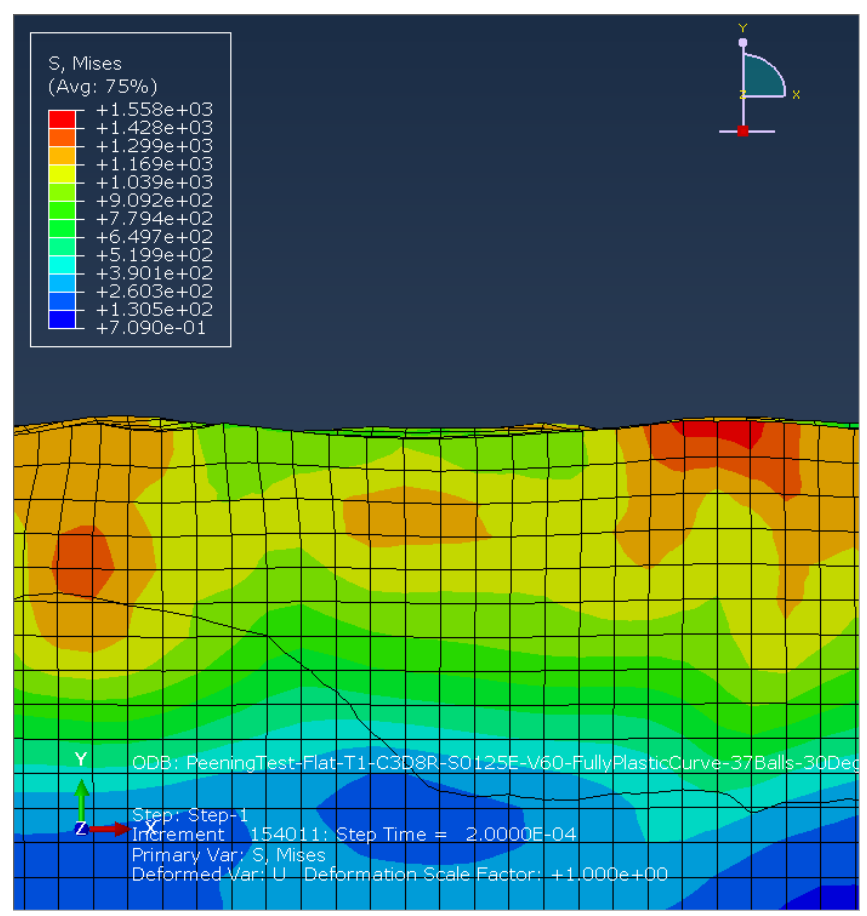

Figure 4-23 Von Mises stress profile in peened surface with infinite curvature radius 


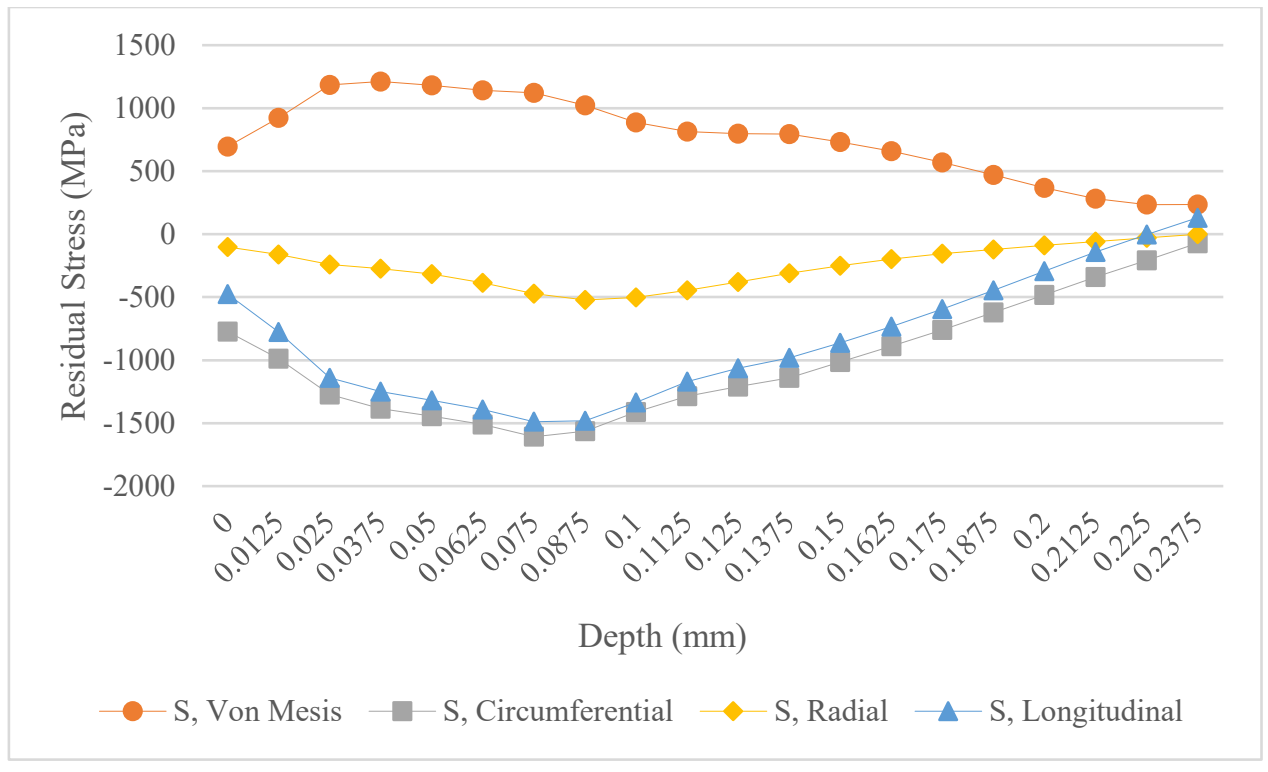

Figure 4-24 Variations of residual stresses in depth of peened surface with infinite curvature radius 


\subsubsection{Effects of Surface Curvature on Residual Stress Profiles}

The FEA simulation models and the associated results of residual stresses in the peened surface having other surface curvature radii $(20 \mathrm{~mm}, 30 \mathrm{~mm}, 40 \mathrm{~mm}$ and $50 \mathrm{~mm}$ ) are presented in Appendix C. To illustrate the influence of target surface curvature on the residual stress profiles in the surface layer due to shot peening, the residual stress variations in depth of the peened surface with different curvature radii are plotted together in Figure 4-25. It is noted that although the location of the maximum compressive stresses for all surface curvature cases is within a small range (between $0.0625 \mathrm{~mm}$ and $0.0875 \mathrm{~mm}$ ), it does vary from surface to surface with different curvatures. In the deeper layer below this location the residual stresses in longitudinal, circumferential, and radial direction all increase in magnitude with decreasing the surface curvature or increasing the surface curvature radius. However, in the top layer of the surface no evident relationship between the residual stress and target surface curvature can be identified. At the top surface, as discussed above, the magnitudes of longitudinal and circumferential stress of the flat surface are smaller than that of the surface with curvature radius of $10 \mathrm{~mm}$, but just beneath the top surface, this relation does not apply. The explanation for this randomness can be that at the top surface the direct impact action of the shot flow causes stress concentration there, which results in computational inaccuracy of the FEA simulation. On the other hand, the maximum compressive stresses at the subsurface more reasonably reflect the true stress behavior of the peened surface, thus they are the main concern in this study. 


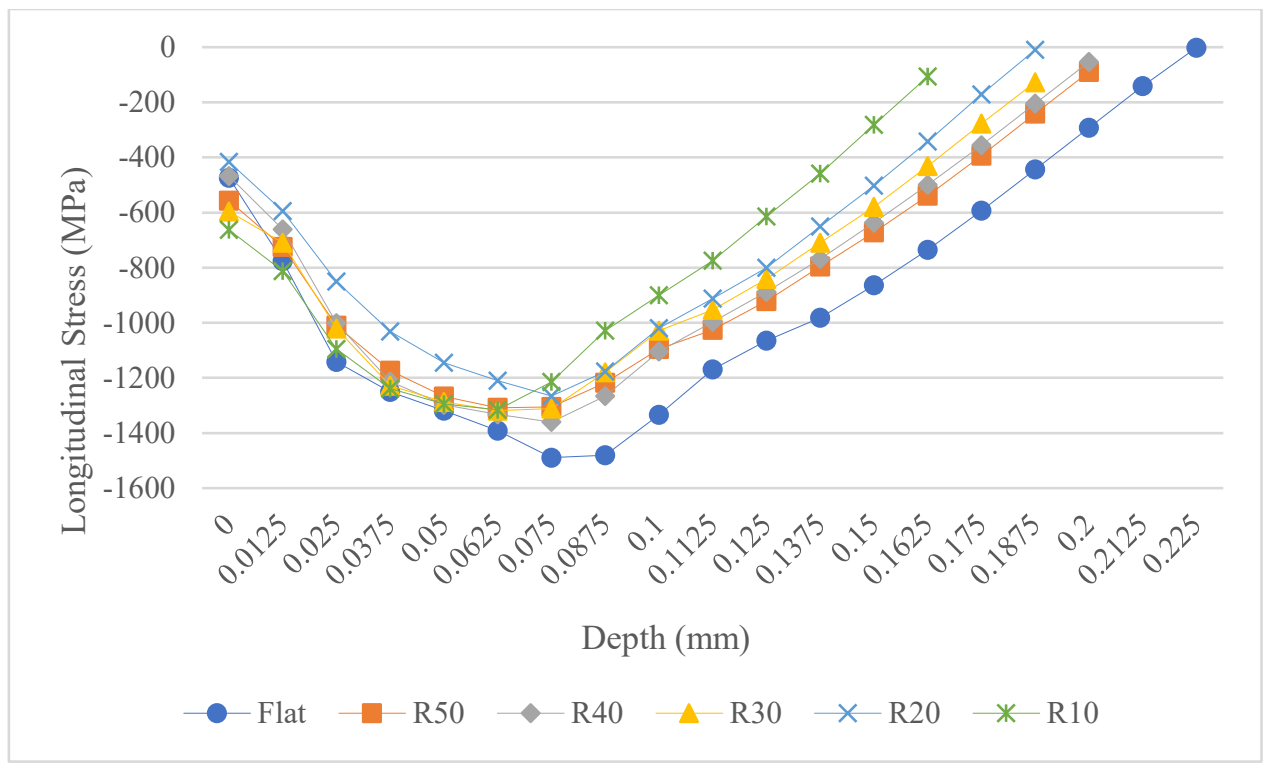

(a)

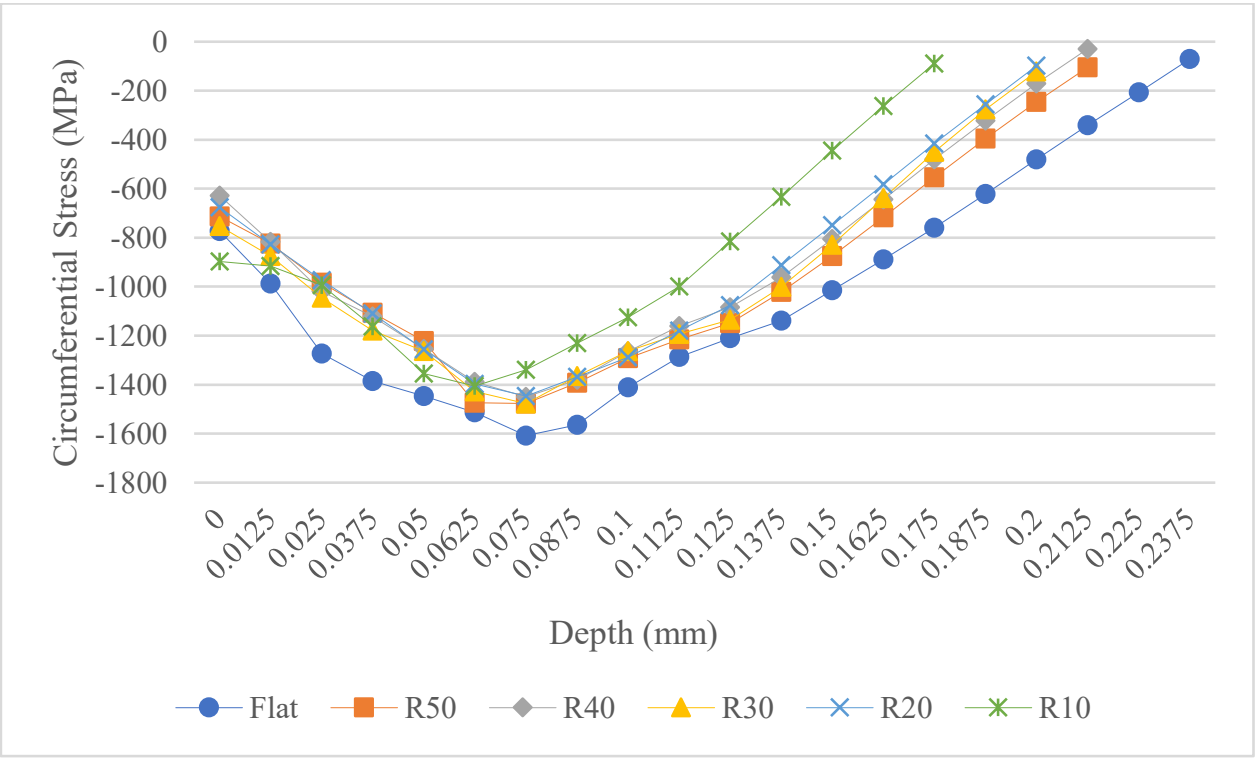

(b) 


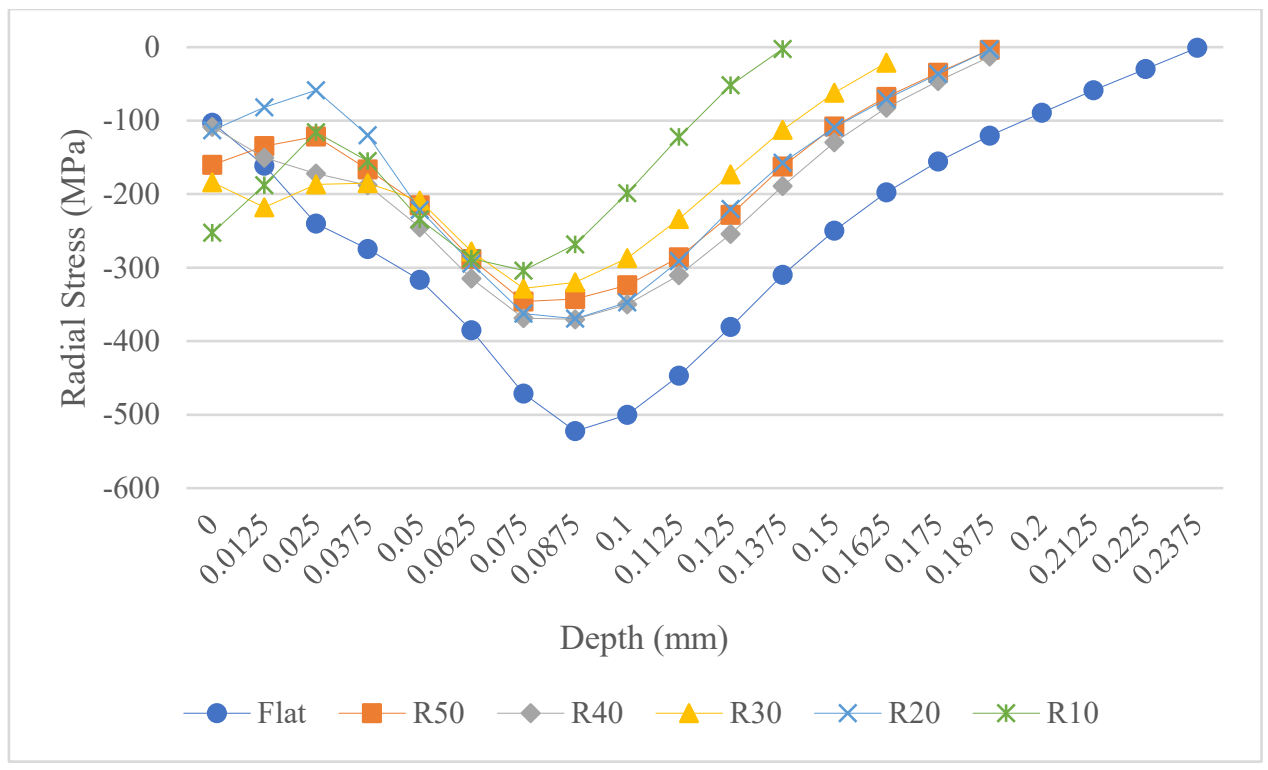

(c)

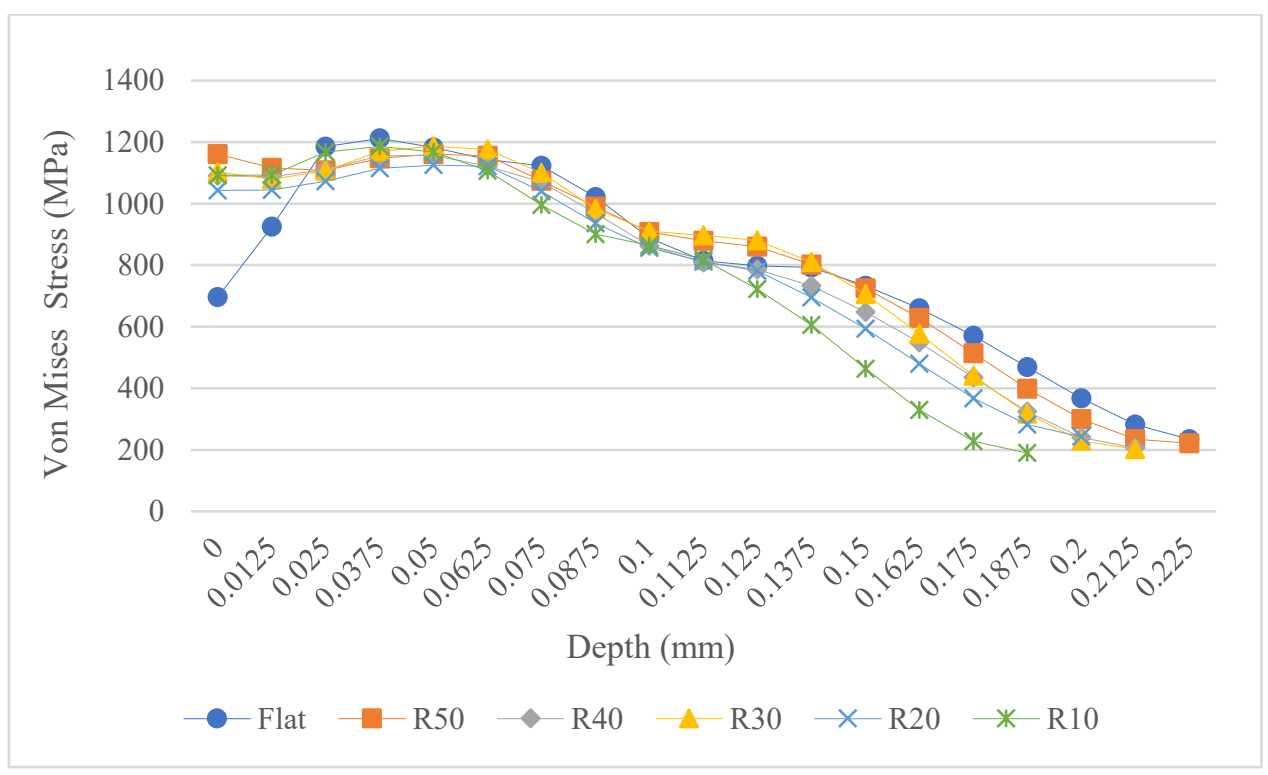

(d)

Figure 4-25 Comparison of residual stresses in target surface with different curvatures: (a) longitudinal stress; (b) circumferential stress; (c) radial stress; (d) Von Mises stress 
For better understanding of the effect of surface curvature on the maximum residual stresses in the peened surface, the maximum residual stress values and their occurrence locations for the peened surface with different curvatures are illustrated in Figure 4-26. It is shown that although the maximum residual stresses in longitudinal, circumferential and radial direction vary with the surface curvature, they do not exhibit direct relations. However, it is evident that the residual stresses in flat surface are larger in magnitude, as seen in Figure 4-27 (a). Similarly, the location of the maximum residual stresses varies between $0.0625 \mathrm{~mm}$ and $0.0875 \mathrm{~mm}$ for different surface curvature cases, but it does not exhibit a direct relation to the surface curvature. 


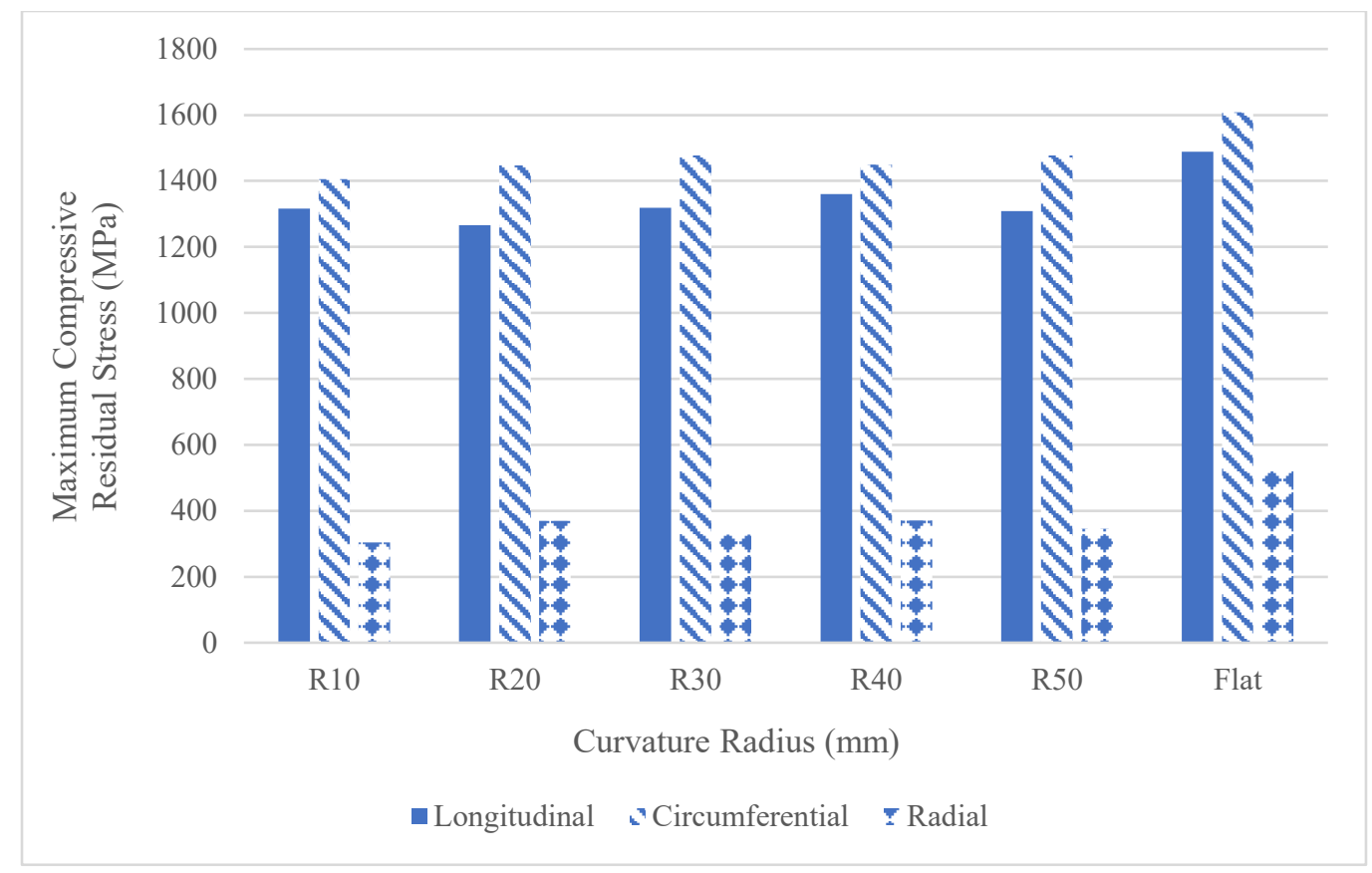

(a)

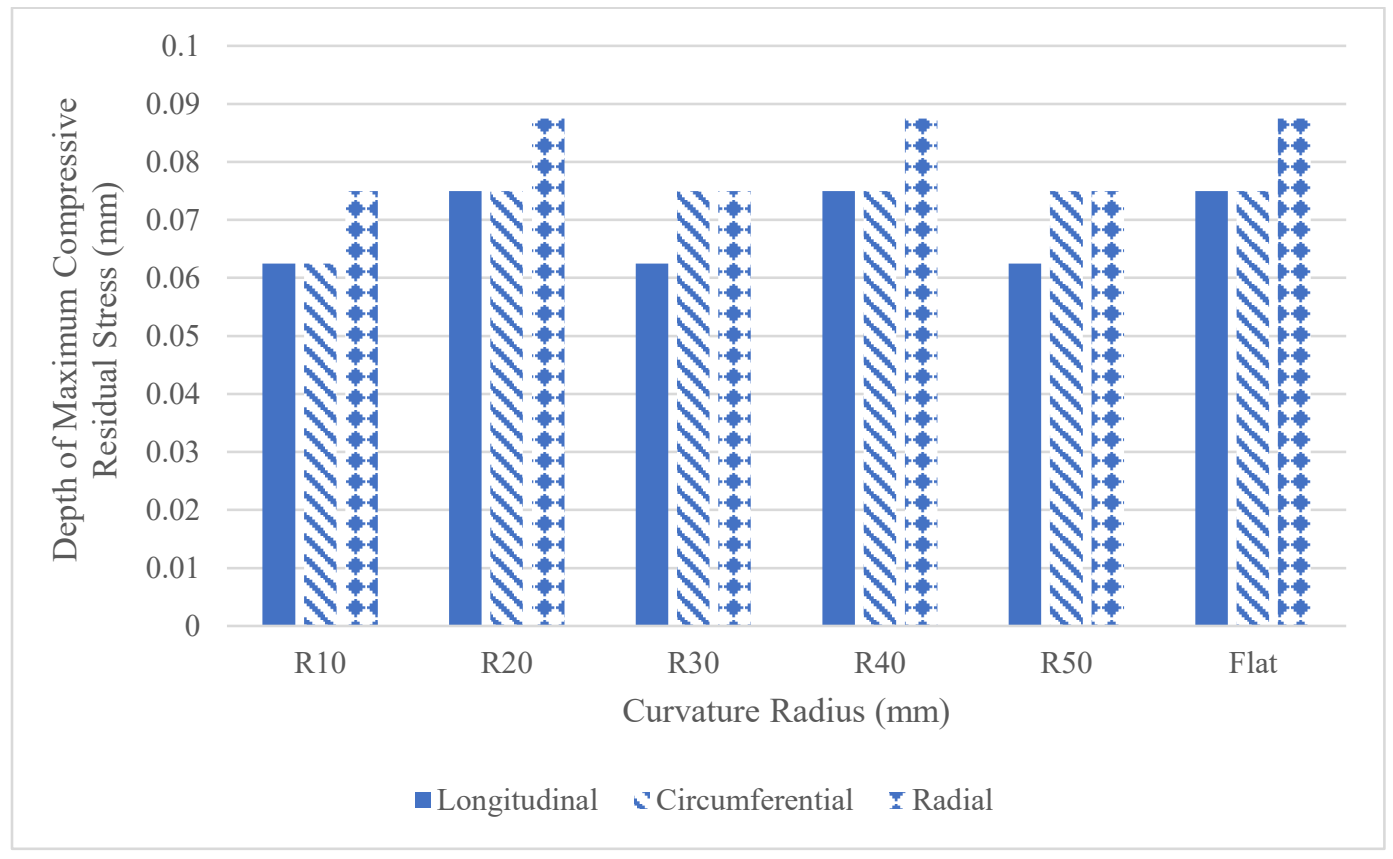

(b)

Figure 4-26 Comparison of maximum residual stresses in target surface with different curvatures: (a) magnitude; (b) location 


\subsection{Variation of Shot Peening Angle}

\subsubsection{Shot Peening Angle Model}

As a key parameter in shot peening process, shot peening angle is supposed to play an important in influencing the residual stress behavior of the peened surface. To confirm this hypothesis, the FEA simulation is also made on a flat target surface subjected to shot flow load at different peening angles $\left(\theta_{P}\right)$ from $30^{\circ}$ to $90^{\circ}$. The FEA models for the maximum and minimum impact angle cases are presented in Figure 4-27. The FEA target surface model for the peening angle simulation study is shown in Figure 4-28, with the boundary conditions used the same as for the curved surface models described previously. The velocity of peening shots is also set to be $60 \mathrm{~m} / \mathrm{s}$.

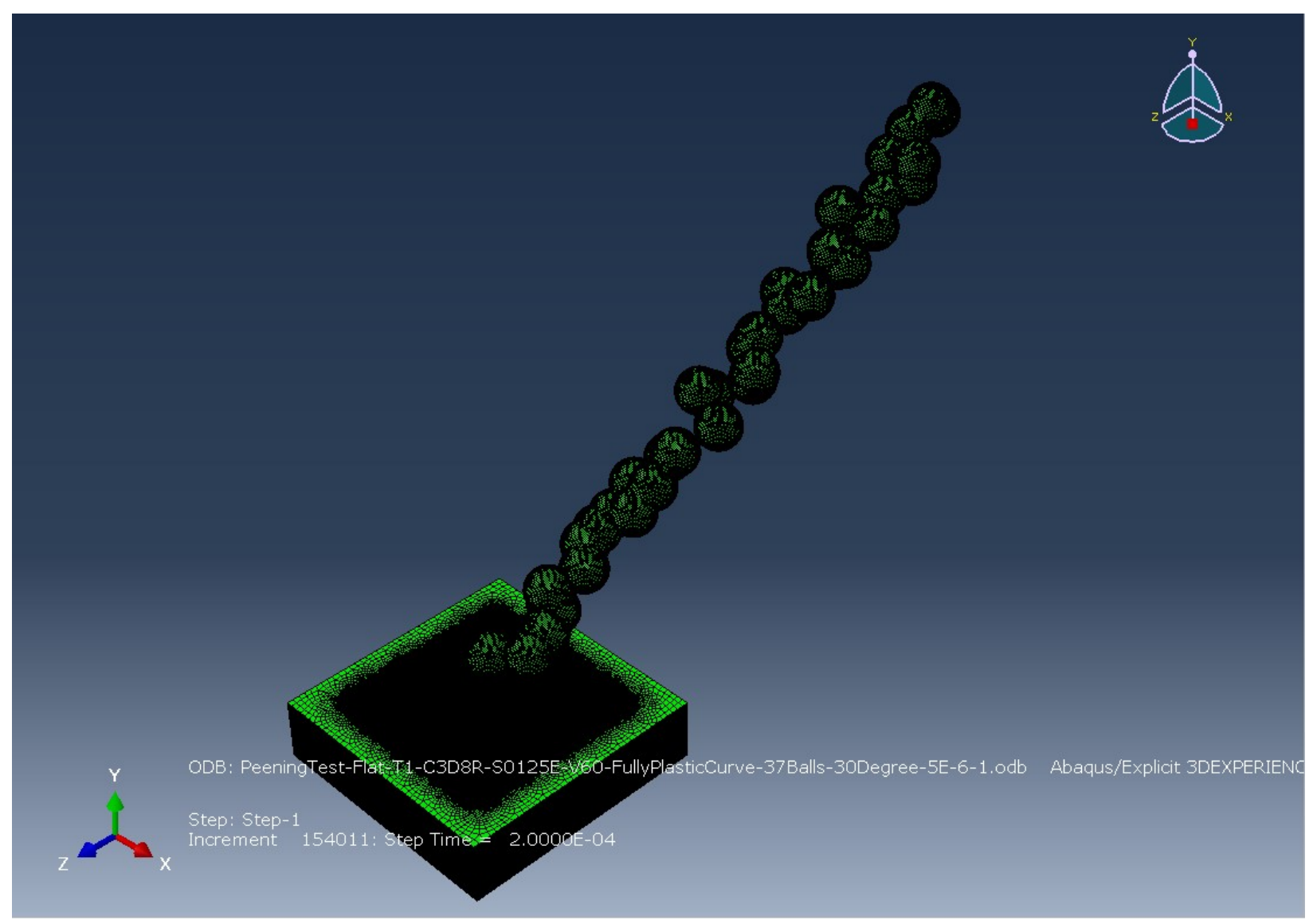




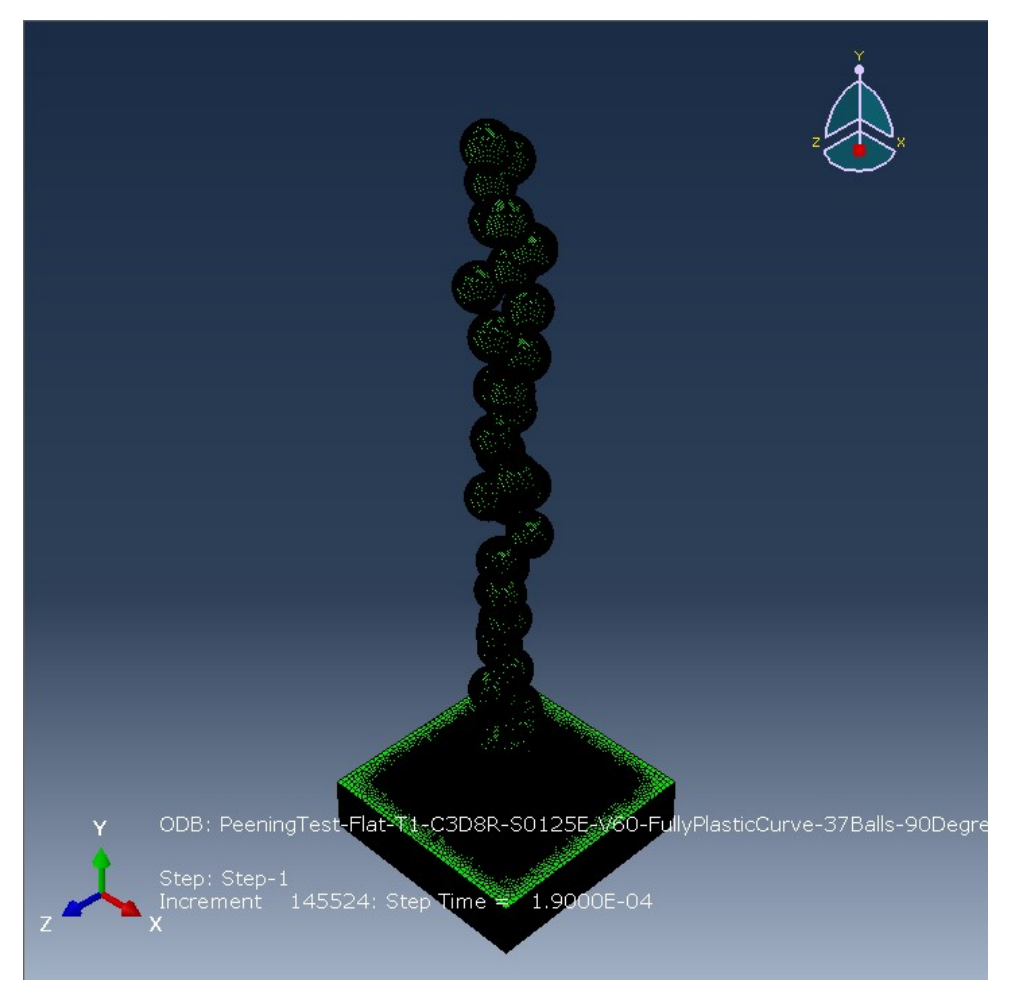

(b)

Figure 4-27 FEA shot peening angle model: (a) $30^{\circ}$ impact; (b) $90^{\circ}$ impact

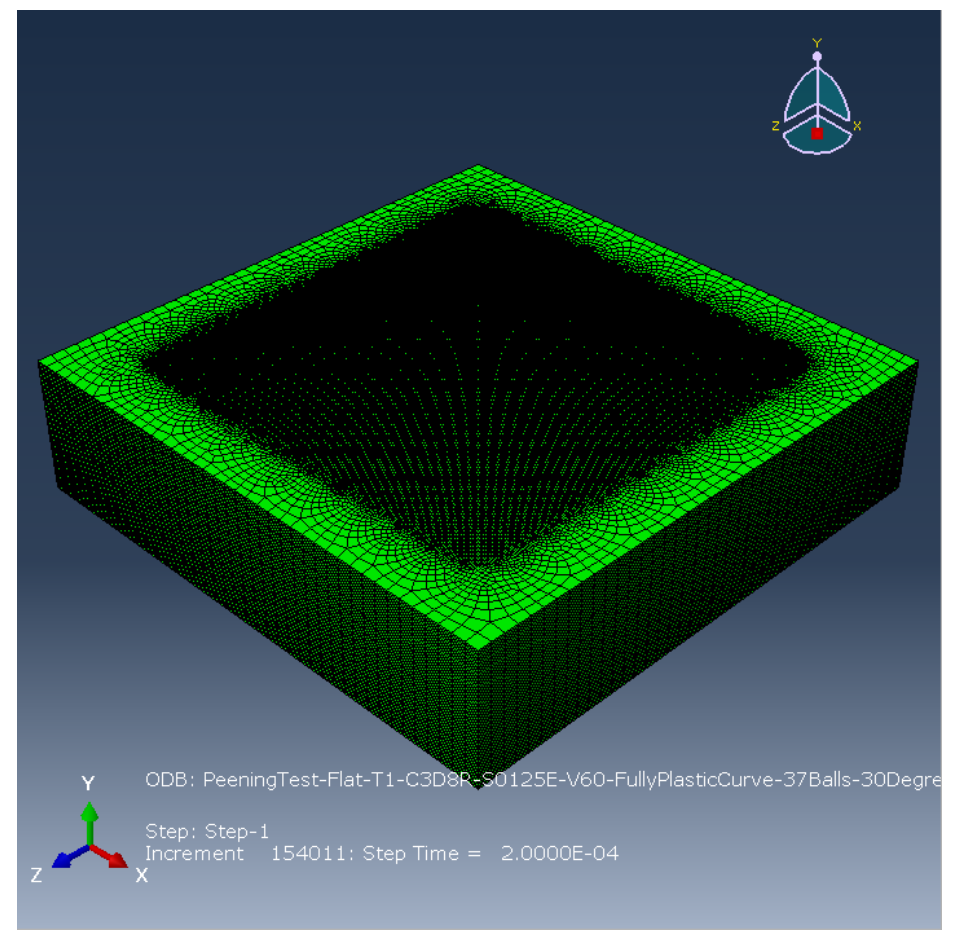

Figure 4-28 FEA flat target surface model for shot peening angle simulation study 


\subsubsection{Residual Stress Profiles in Target Surface Peened at $30^{\circ}$ Angle}

Figure 4-29 presents the FEA simulation results of the residual stresses in the flat surface peened at $30^{\circ}$ angle. Similar to the cases analyzed previously, the longitudinal, circumferential and radial stress are all generally compressive in the surface layer. Some tensile stresses observed at the top surface layer should be a result of stress concentration, as discussed previously. The Von Mises stress profile is presented in Figure 4-30, showing that some regions of the surface layer have experienced plastic deformation because the Von Mises stress values are greater than $1400 \mathrm{MPa}$ which is the yield strength of the target surface material (HY-TUF steel). For better presentation of the FEA simulation results, the variations of the longitudinal, circumferential and radial stress as well as the Von Mises stress at the center of the peened surface model along the depth from the top surface are plotted together in Figure 4-31. It is shown that the location of the maximum compressive stresses is about $0.05 \mathrm{~mm}$ from the top surface in depth. The circumferential stress is greater than the longitudinal stress in magnitude in the top surface layer and both are greater than the radial stress in magnitude, but in the deeper layer (below the location of the maximum compressive stresses), the circumferential and longitudinal stress are very close. The maximum Von Mises occurs at the subsurface in a depth about $0.025 \mathrm{~mm}$. 


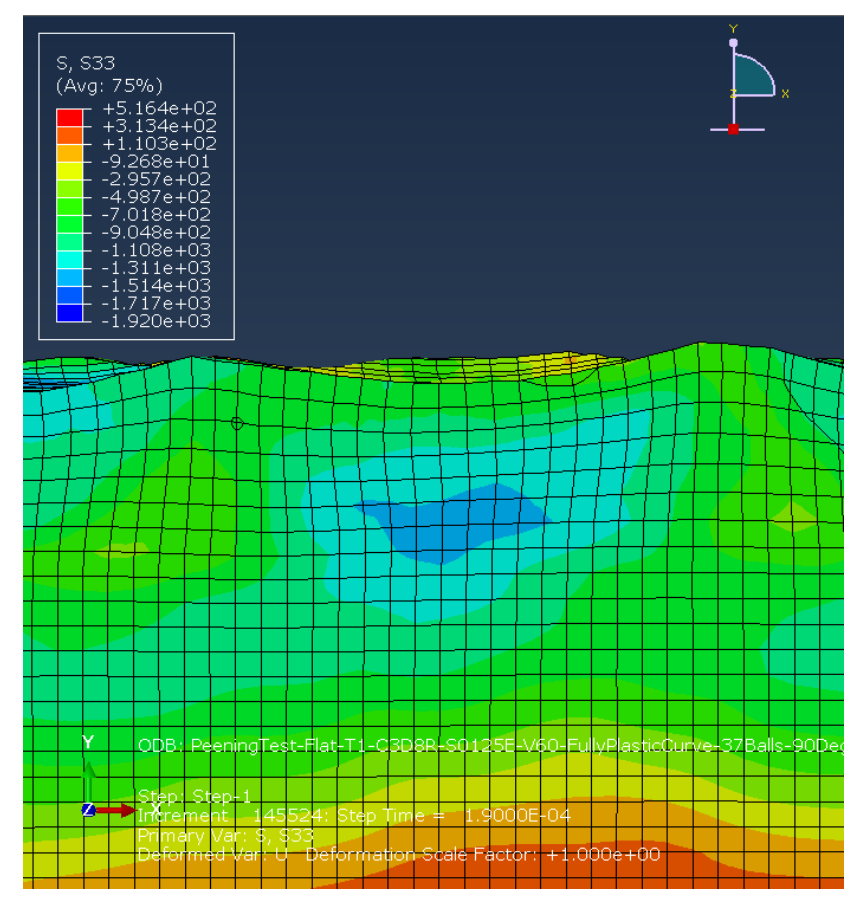

(a)

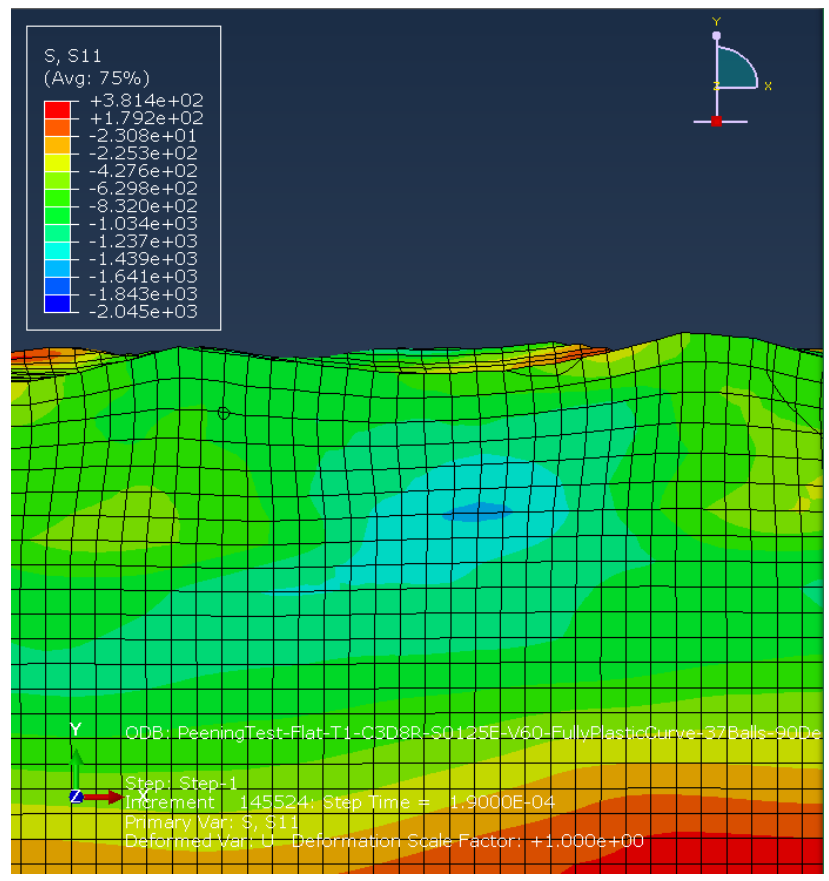

(b) 


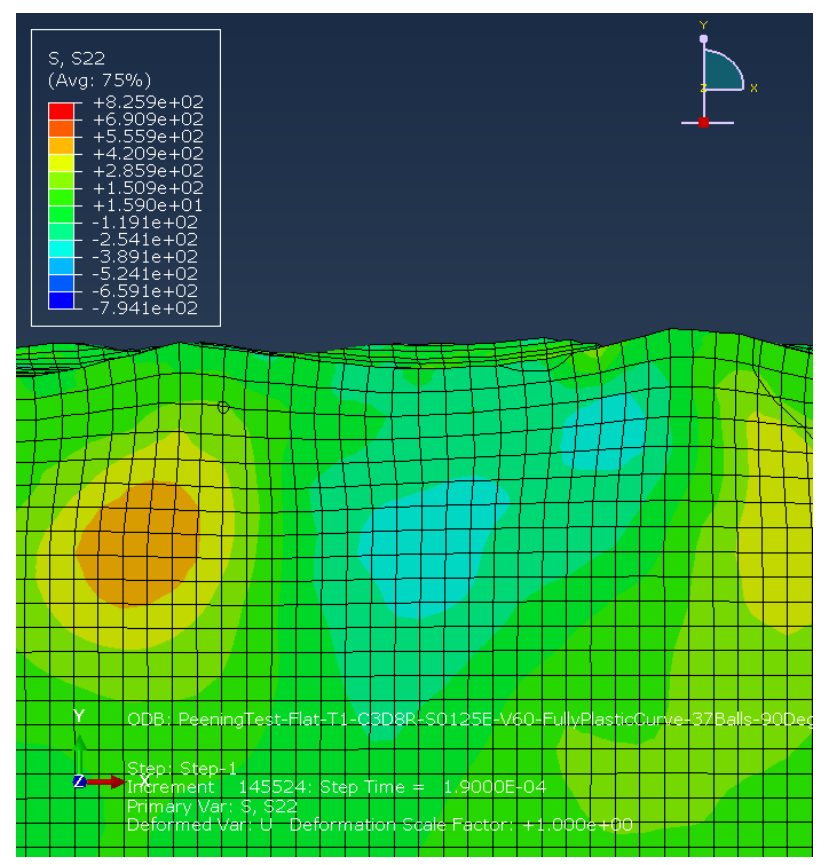

(c)

Figure 4-29 Residual stress profile in peened surface by $30^{\circ}$ angle impact:

(a) longitudinal stress; (b) circumferential stress; (c) radial stress

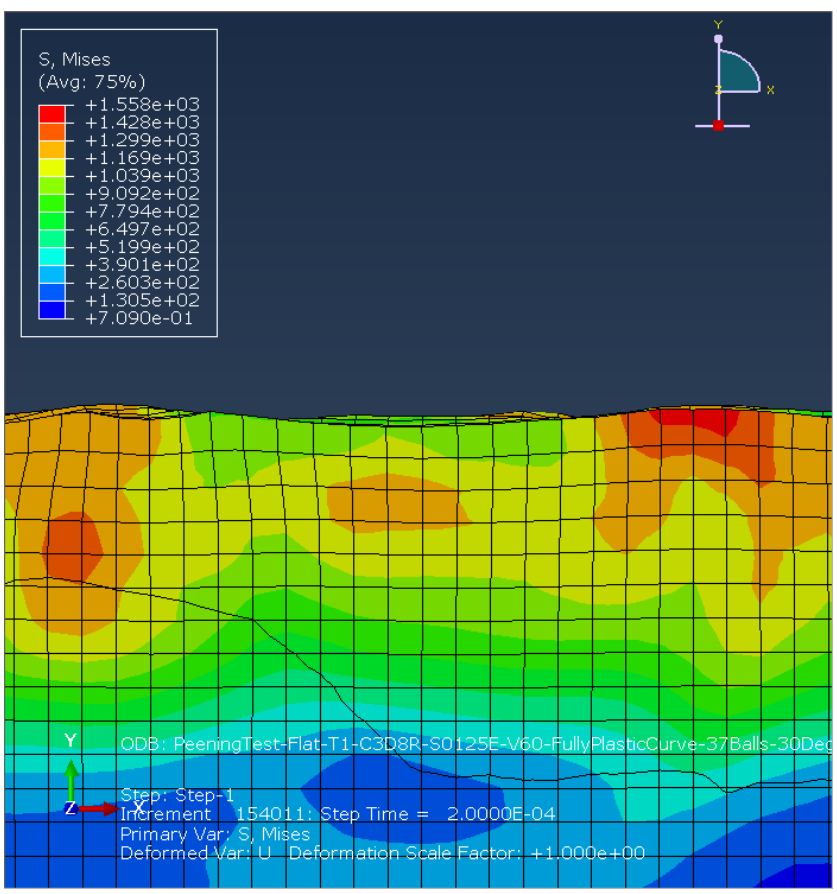

Figure 4-30 Von Mises stress profile in peened surface by $30^{\circ}$ angle impact 


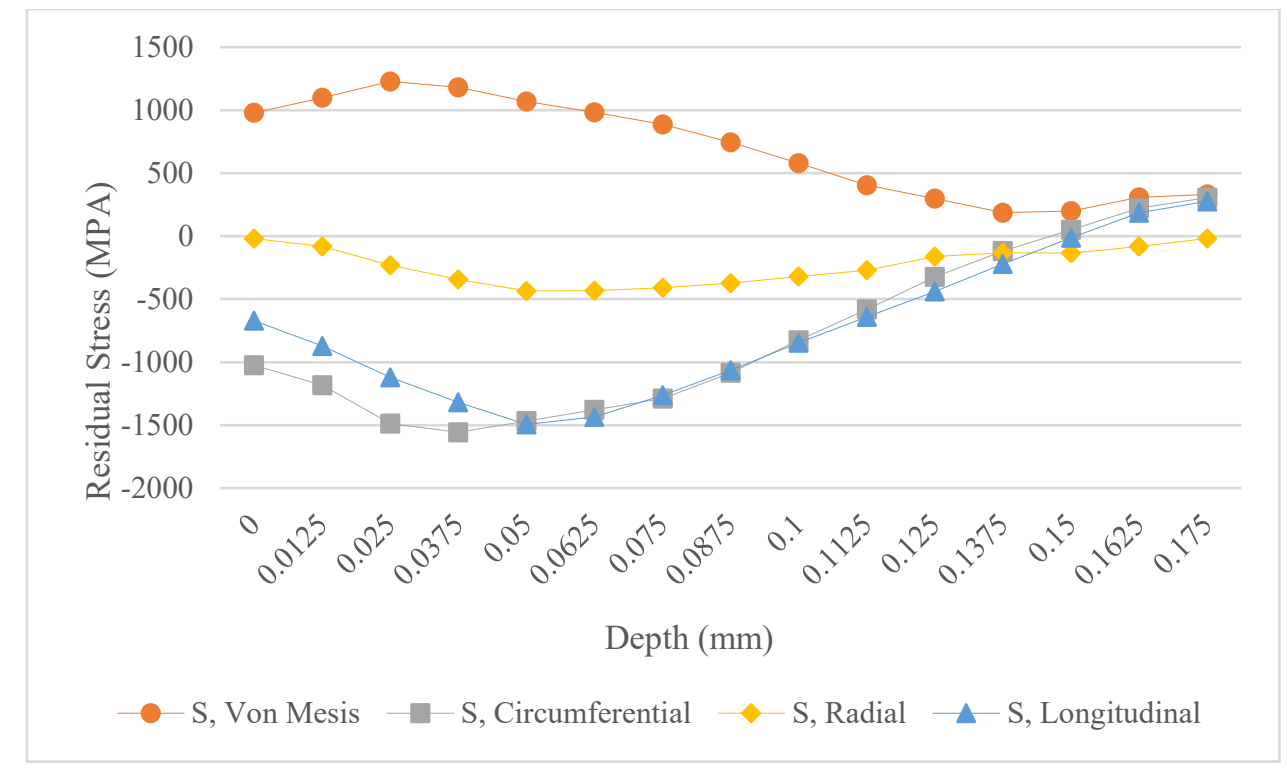

Figure 4-31 Variations of residual stresses in depth of peened surface by $30^{\circ}$ angle impact 


\subsubsection{Effects of Peening Angle on Residual Stress Profiles}

For the case of flat surface peened normally or at $90^{\circ}$ angle, the FEA simulation is exactly same as that of the surface with infinite curvature radius, which has been studied in the previous section. The FEA models and associated simulation results for the flat surface peened at other angles $\left(45^{\circ}\right.$, $60^{\circ}$ and $75^{\circ}$ ) are presented in Appendix D.

To examine the effect of shot peening angle on the residual stress profiles in the surface layer, the residual stress variations in depth from the target surface peened at different angles are plotted together in Figure 4-32. It is noted that the location of the maximum compressive stresses varies obviously with peening angle, but the variation is within a small range. Below this range in depth, the longitudinal, circumferential, radial and Von Mises stress all generally increase in magnitude with peening angle. However, at the top layer of the surface, no evident relationship between the residual stress and peening angle is identified. As discussed for surface curvature influence on the residual stresses, at the top surface the direct impingement of the shot flow generates stress concentration there, which leads to computational inaccuracy of the FEA simulation. 


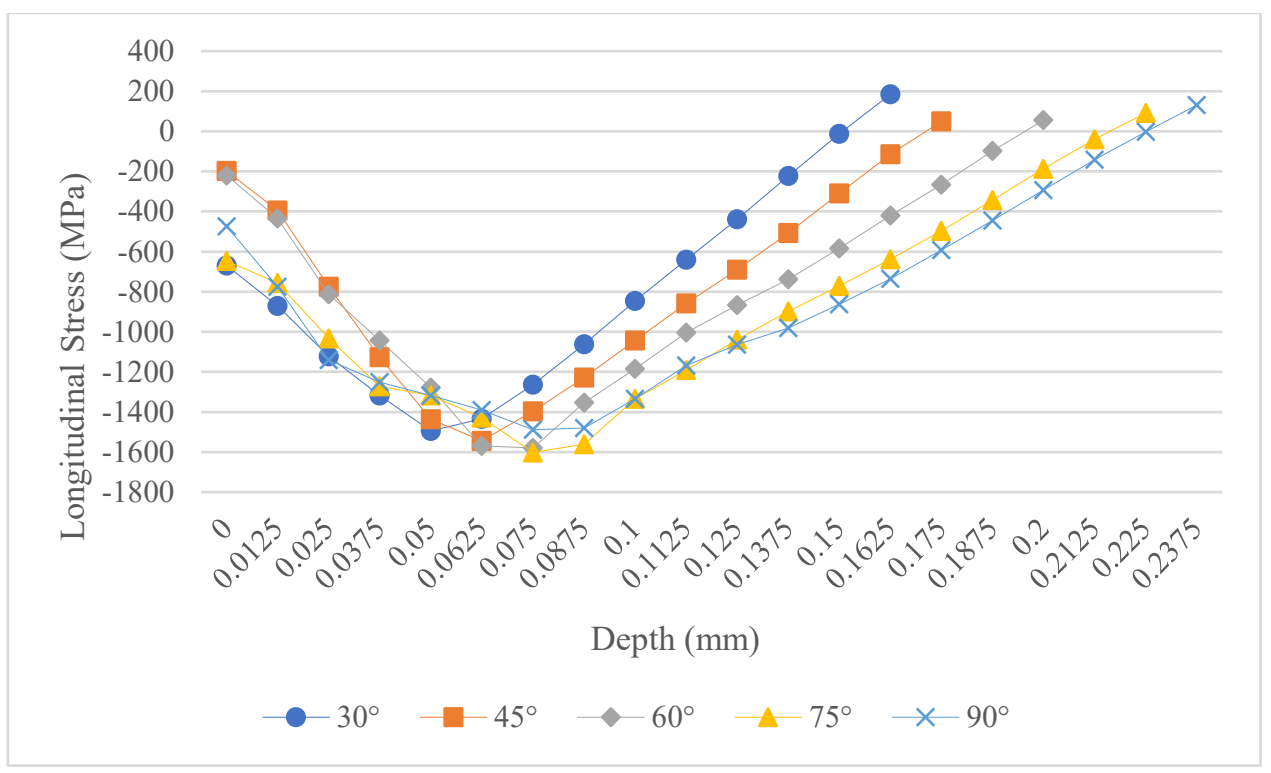

(a)

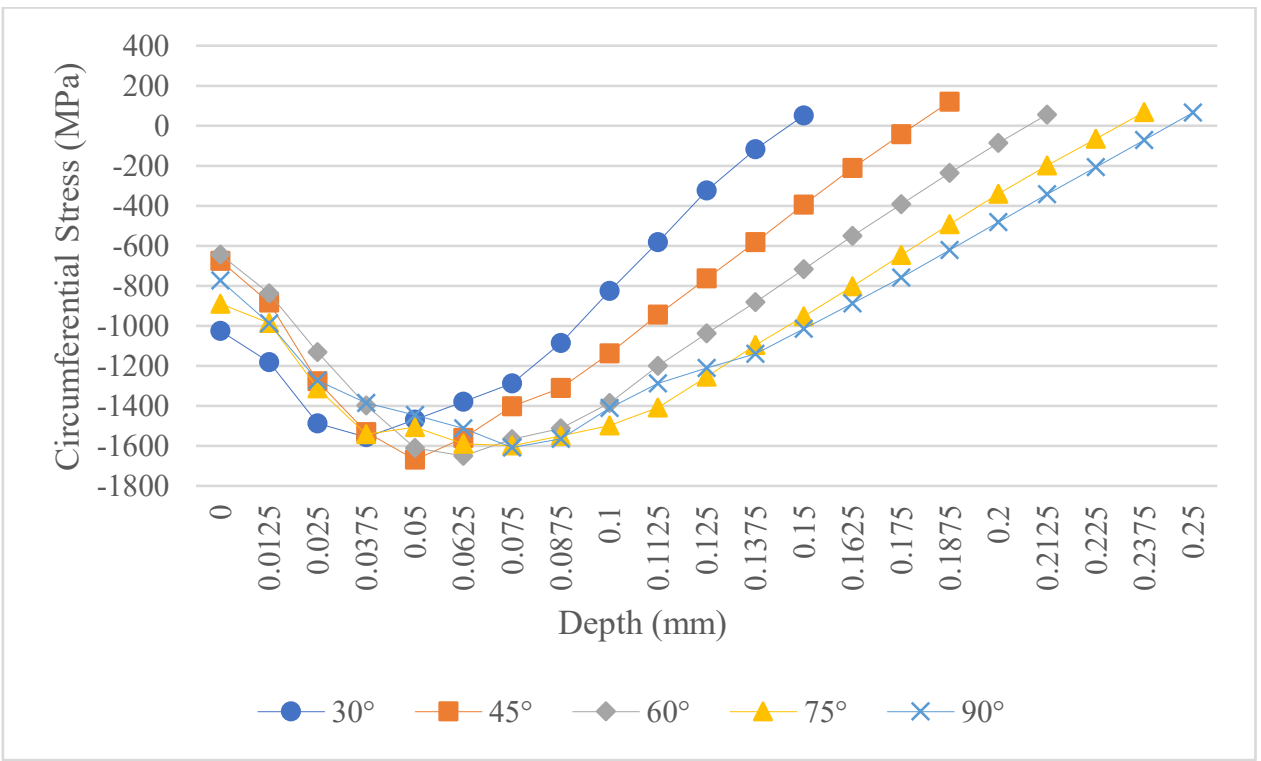

(b) 


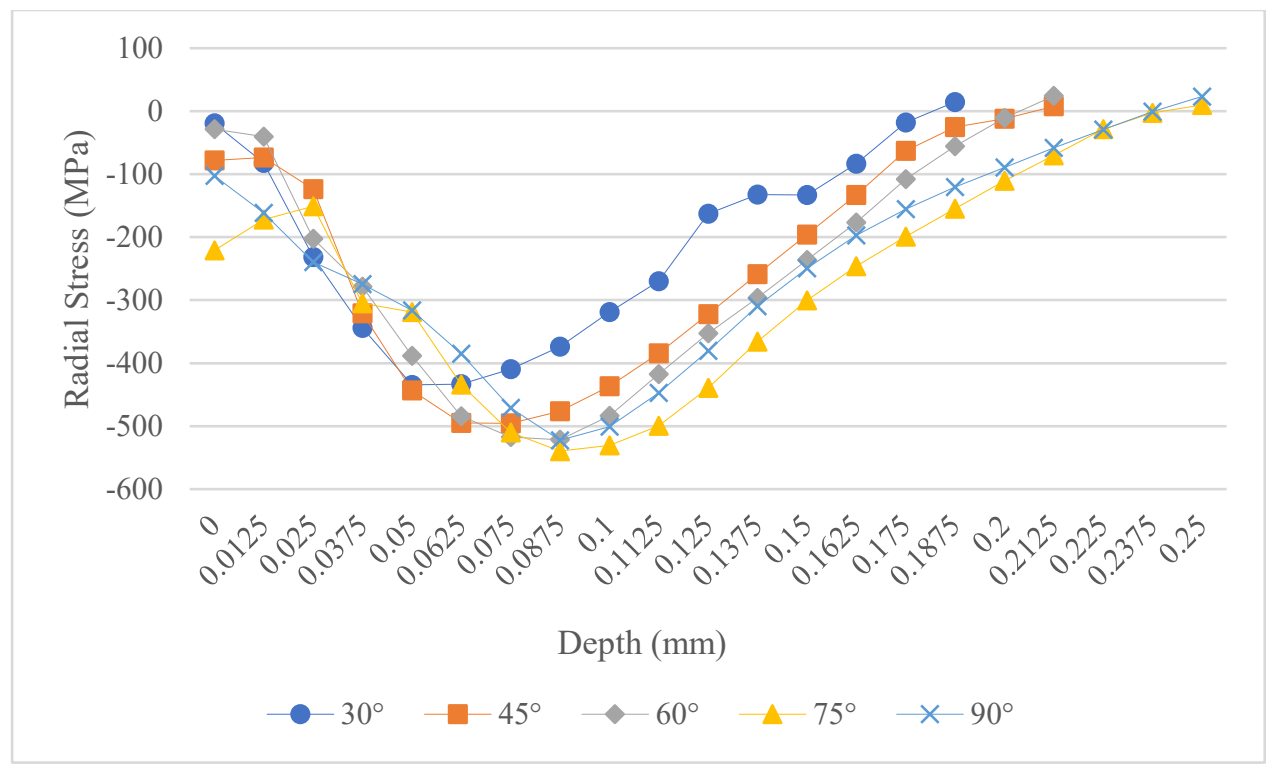

(c)

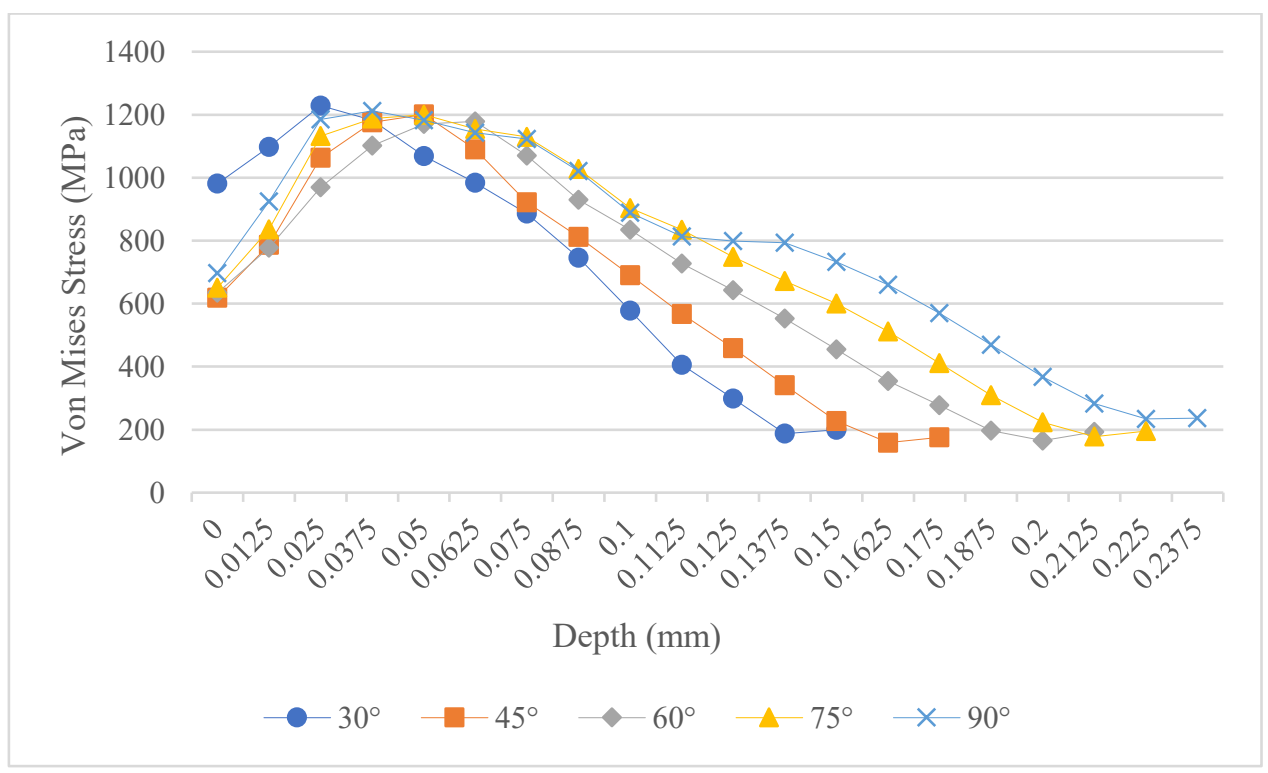

(d)

Figure 4-32 Comparison of residual stresses in target surface peened at different angles: (a) longitudinal stress; (b) circumferential stress; (c) radial stress; (d) Von Mises stress 
Furthermore, detailed analyses are made in the maximum residual stresses versus peening angle, by presenting the maximum residual stress values and their occurrence locations against peening angle using histogram in Figure 4-33. It is noted that although the maximum residual stresses in longitudinal, circumferential and radial direction vary with peening angle, no direct relation between them can be identified, as seen in Figure 4-34 (a). However, it can be suggested that with increasing peening angle the location of the maximum residual stresses moves down in depth from the peened surface, according to Figure 4-34 (b). The location of the maximum residual stresses varies between $0.0375 \mathrm{~mm}$ and $0.0875 \mathrm{~mm}$ for different peening angles.

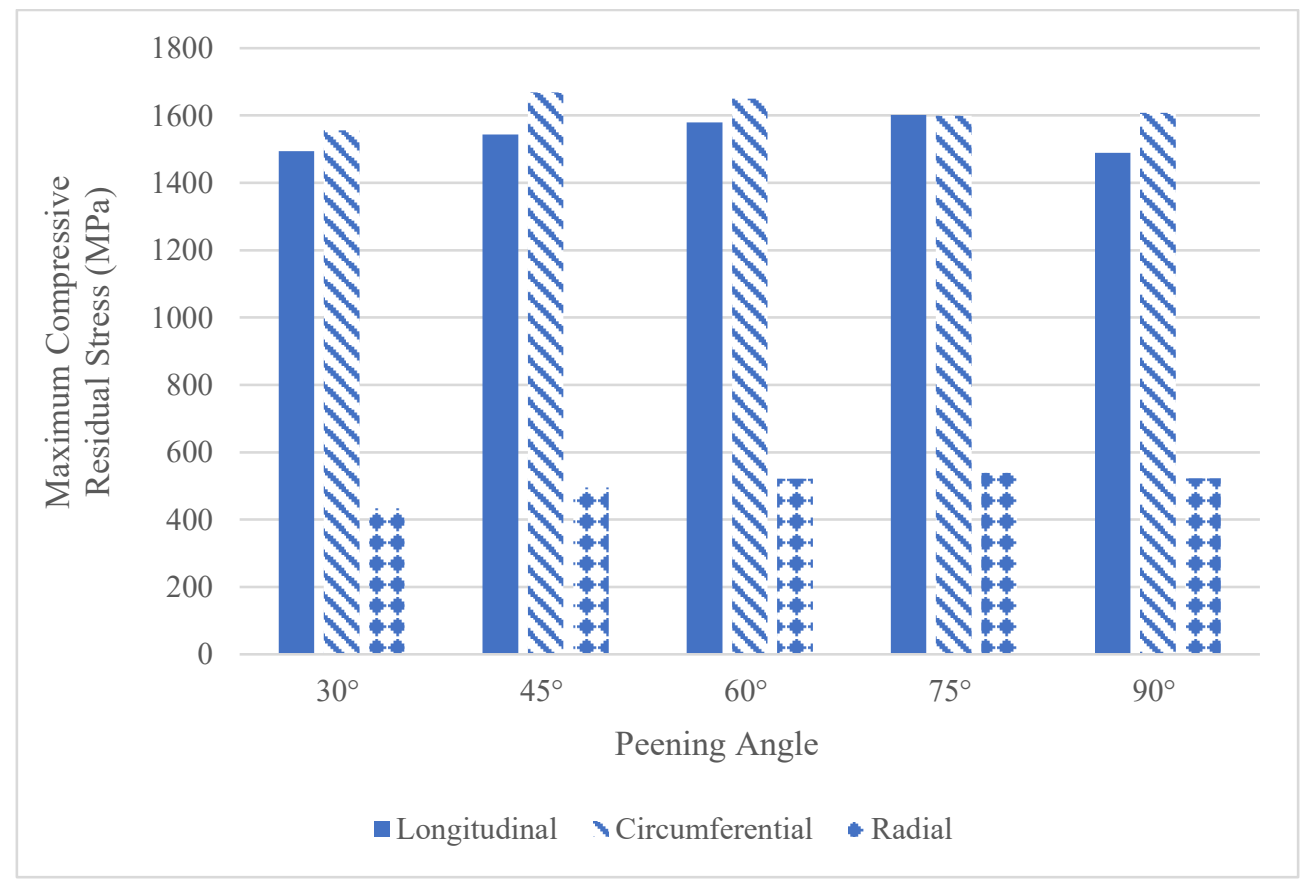

(a) 


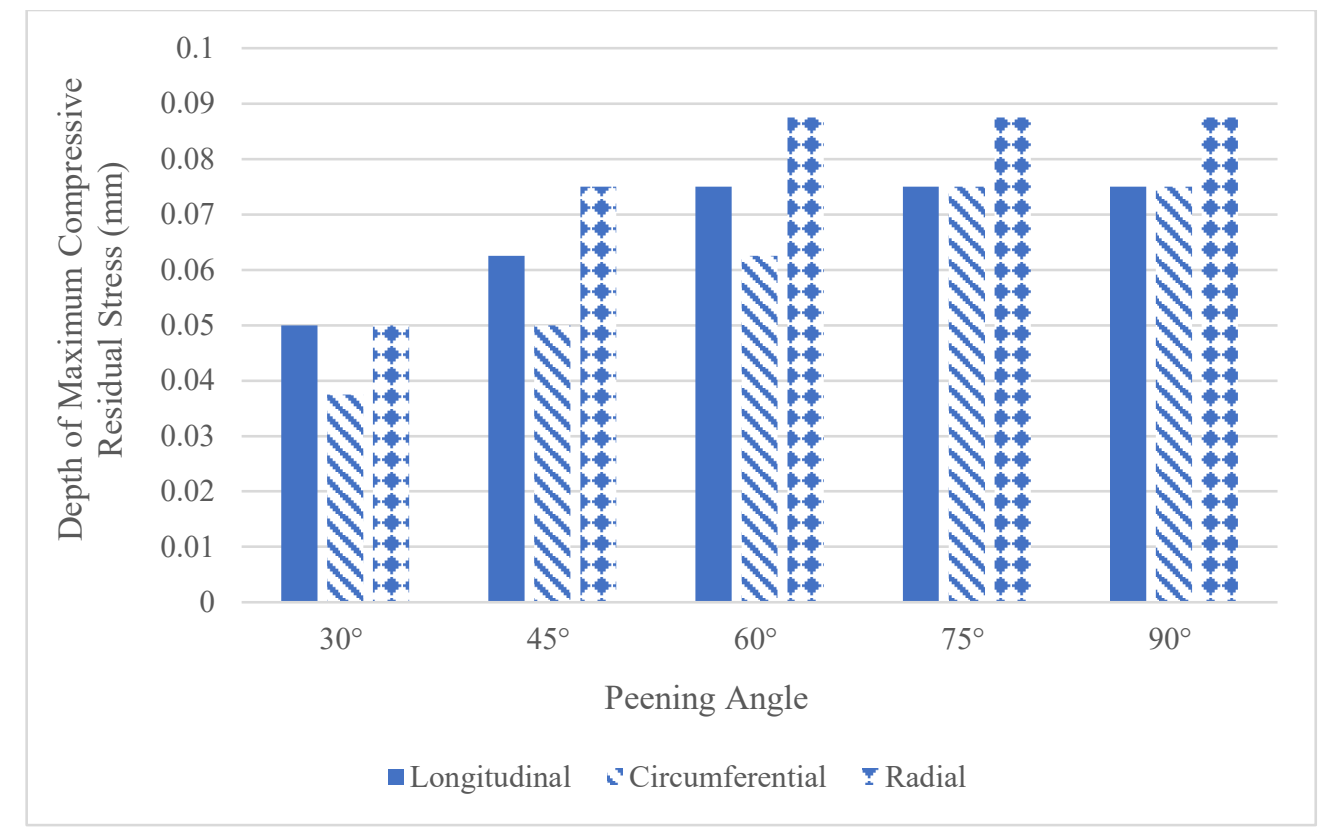

(b)

Figure 4-33 Comparison of maximum residual stresses in target surface peened at different angles: (a) magnitude; (b) location 


\section{Chapter 5 Conclusions and Future work}

\subsection{Summary of the Present Research}

Safran provided the HY-TUF steel flange pin peened with ZirShot-ZC600 ceramic shots. The peened pin was first cut in four specimens and then XRD scan was performed at different locations of the specimen surface to determine the residual stresses. The XRD scan was conducted in the longitudinal and circumferential direction of the flange pin at each location. The XRD measurement data were analyzed using the residual stress computation software built in the Rigaku Ultima IV X-ray diffractometer.

Meanwhile, FEA simulation study was carried out to simulate the shot peening process on the flange pin of Safran. First, a FEA model of the target surface with one shot peening was created to determine the impact area by one shot, which would be used to calculate the shot number of multiple shot peening flow in terms of peening coverage. The material parameters of HY-TUF steel and ZirShot-ZC600 ceramic shot for the FEA model were determined based on the basic material properties of the steel and ceramic. Second, a multiple shot peening flow model was built for the flange pin peened with ZirShot-ZC600 ceramic shots. The shot flow locations on the target surface were generated randomly utilizing the MATLAB program. In this simulation, the longitudinal, circumferential and radial stress as well as Von Mises stress in the peened surface of the flange pin were analyzed, with the focus on the maximum residual stresses and the variations of the residual stresses along the depth of the surface layer.

Finally, the effects of target surface curvature and shot peening angle on the residual stress profile in the peened surface were investigated with FEA simulation. The FEA models of the target surface with different curvature radii from $10 \mathrm{~mm}$ to infinite (flat surface) and the FEA models of a flat 
target surface peened at different angles were constructed. The simulation results were analyzed, mainly concerned with the influence of the target surface curvature and shot peening angle on the maximum residual stress and its location in the peened surface.

\subsection{Conclusions from the Present Research}

From the experimental measurements using XRD technique of the residual stresses in the flange pin peened with ZirShot-ZC600 ceramic shots, the FEA simulations of the peening process and computation of the residual stress results generated, the following conclusions can be derived from the present research.

1. XRD technique is an effective approach for determining the residual stress in a peened surface, even the surface with a curvature like the flange pin in cylindrical shape, but this experimental method is limited to residual stress measurement at the surface only, not in depth, therefore, the radial stress in the peened pin cannot be measured by XRD technique.

2. The residual stresses in longitudinal and circumferential direction are all compressive, determined by the XRD measurements. From the residual stress data of XRD measurements summarized in Table 3-5, both the longitudinal stress (at $0^{\circ}$ and $180^{\circ}$ ) and the circumferential stress (at $90^{\circ}$ and $270^{\circ}$ ) are not uniform over the pin surface. At different locations of the pin surface, the values of the longitudinal and circumferential stress vary, which implies that the pin surface was not peened uniformly. However, the variation is not significant overall, the average longitudinal and circumferential stress at the peened pin surface are about -298.7 MPa and -786.9 MPa, respectively. Due to surface curvature and peening angle effects, the longitudinal and circumferential stress are not equal in magnitude; the latter is more than two times greater than the former. 
3. FEA simulation, as the most popular numerical approach in analyzing stress and strain of loaded structures, exhibits excellent ability in the residual stress analysis of the peened flange pin. Compared with the XRD measurement, the FEA simulation can compute the residual stress not only in longitudinal and circumferential direction, but also in radial direction. The most important is that FEA simulation can also compute the residual stress in different depths of the peened surface layer.

4. Consistent with the experimental XRD measurement results, the residual stresses in the peened pin are all compressive, confirmed by the FEA simulations. The circumferential stress is greater than the longitudinal stress and both are much greater than the radial stress.

5. Although the FEA simulation of the flange pin peened with ZirShot-ZC600 ceramic shots was performed not using the exactly same process parameters as in the real peening process due to the confidential consideration of Safran, for example, shot flow velocity and peening duration, the residual stress results from the XRD measurement and FEA simulation at the peened surface of the flange pin are very close (XRD: longitudinal stress -298.7 MPa and circumferential stress 786.9 MPa; FEA: longitudinal stress -291.4 MPa and circumferential stress 768.5 MPa). This implies that the peening process parameters used in the FEA model, which were suggested in literature, are very similar to that used in the real peening process of the flange pin.

6. The FEA simulation results reveal that the residual stresses in the peened pin surface are not uniform over the surface and in depth. In the examination of the central position of the peened surface where the surface is affected the most by the shot peening, it is found that the residual stresses increase in magnitude along the depth from the top surface layer until reaching the maximum at subsurface, and then decrease in magnitude down to zero in more 
depth. The locations of the maximum residual stresses are about $0.05 \mathrm{~mm}$ in depth from the top surface of the peened flange pin.

7. The Von Mises stress also varies within the peened surface layer, with the maximum value appearing at the subsurface about $0.0375 \mathrm{~mm}$ from the top surface. According to the material failure criterion of Shear - Strain Energy Theory, local yielding occurs in some regions of the surface layer where the Von Mises stress is greater than the yield strength of HY-TUF steel (1400 MPa), with plastic deformation taking place, which corresponds to the work hardening behavior of the peened surface.

8. The FEA simulations reveal that target surface curvature and shot peening angle do influence the residual stress profile of the peened surface, but no direct relations between them can be identified. However, it can be suggested that the maximum residual stresses in flat surface are greater than that in the surface with curvature and with increasing peening angle the location of the maximum residual stresses moves down in depth of the peened surface layer.

\subsection{Significant Contributions of the Present Research}

Although many studies have been carried out in shot peening process and the residual stresses of peened surface, the target surfaces are all flat, as reported in literature. The present research first experimentally and numerically analyzes the residual stresses in the peened surface with curvature, in particular, the influence of target surface curvature on the residual stress profile of the peened surface is revealed. This outcome of the research provides Safran and other relevant industries the guidance of peening process design for a given surface geometry, towards optimal residual stress distribution in the peened surface layer. 
Safran first time used ZirShot-ZC600 ceramic shots to peen their flange pins and is in urgent need for understanding the residual stress behavior in the peened pins. The present research effectively measured the residual stresses in longitudinal and circumferential direction of the flange pin using $\mathrm{XRD}$ and the results are proven valid by the repeatability of the measurement data at multiple locations of the pin surface. The FEA simulations help further understand the variations of the residual stress in depth of the surface layer, in particular, the maximum residual stress and its location.

\subsection{Future Work of the Project}

As indicated in this thesis, XRD technique can only measure residual stresses at a surface, therefore, in order to investigate the residual stresses at subsurface, especially, the maximum residual stress, the pin specimen surface should be removed via electrochemical corrosion,

As discussed in Chapter 2, shot peening on the surface of a metal component is aimed to generate compressive stresses in the surface layer so as to enhance the fatigue resistance of the component. Therefore, it is necessary to perform fatigue test on the peened flange pin in comparison with the intact flange pin. 


\section{References}

[1] A. Hebborn, "A380 Landing Gear and Systems - The Feet of the Plane," Lect. HAW Hambg., no. June, 2008.

[2] H. Kumar, S. Singh, and P. Kumar, "Modified Shot Peening Processes - a Review," Int. J. Eng. Sci. Emerg. Technol., vol. 5, no. 1, pp. 12-19, 2009.

[3] G. S. Was and R. M. Pelloux, "Effect of Shot Peening Methods on the Fatigue of Alloy 7075-T6,” Proceedings, First Int. Conf. Shot Peen., pp. 445-451, 1981.

[4] Y. F. Al-Obaid, "Shot Peening Mechanics: Experimental and Theoretical Analysis," Mech. Mater., vol. 19, no. 2-3, pp. 251-260, 1995.

[5] A. Sandá, V. García Navas, and O. Gonzalo, "Surface state of Inconel 718 ultrasonic shot peened: Effect of processing time, material and quantity of shot balls and distance from radiating surface to sample," Mater. Des., vol. 32, no. 4, pp. 2213-2220, 2011.

[6] G. F. Bush, J. O. Almen, L. A. Danse, and J. P. Heiss, "How, When and by Whom Was Mechanical Prestressing Discovered," Bienn. Meet. Div, no. 20, p. 11, 1962.

[7] F. Mohs, "Mohs Scale of Mineral Hardness," 1812.

[8] P. E. Cary, "History of Shot Peening," in In 1st international conference on shot peening, Paris, France, 1982, pp. 23-28.

[9] Surface Rolling and Other Methods for Mechanical Prestressing of Metals, J-811. SAE International, 1962.

[10] G. Schiavone, J. Murray, S. Smith, M. P. Y. Desmulliez, A. R. Mount, and A. J. Walton, 
"A Wafer Mapping Technique for Residual Stress in Surface Micromachined Films," $J$. Micromechanics Microengineering, vol. 26, no. 9, pp. 1-12, 2016.

[11] G. H. Farrahi, J. L. Lebrijn, and D. Couratin, "Effect of Shot Peening on Residual Stress and Fatigue Life of a Spring Steel," Fatigue Fract. Eng. Mater. Struct., vol. 18, no. 2, pp. 211-220, 1995.

[12] J. Champaigne, "Shot Peening Overview," Electron. Inc, 2001.

[13] D. A. Hills, R. B. Waterhouse, and B. Noble, "An Analysis of Shot Peening," Strain Anal, vol. 18, no. 2, pp. 95-100, 1983.

[14] Y. F. Al-Obaid, "A Rudimentary Analysis of Improving Fatigue Life of Metals by ShotPeening," J. Appl. Mech. Trans. ASME, vol. 57, no. 2, pp. 307-312, 1990.

[15] J. Pritchard, "Overview of Landing Gear Dynamics," J. Aircr., vol. 38, no. 1, pp. 130-137, 2001.

[16] S. Bagheri and M. Guagliano, "Review of Shot Peening Processes to Obtain Nanocrystalline Surfaces in Metal Alloys," Surf. Eng., vol. 25, no. 1, pp. 3-14, 2009.

[17] I. Altenberger, B. Scholtes, U. Martin, and H. Oettel, Cyclic Deformation and Near Surface Microstructures of Shot Peened or Deep Rolled Austenitic Stainless Steel AISI 304, vol. 264, no. 1-2. 1999.

[18] D. Kirk and M. Y. Abyaneh, "Theoretical Basis of Shot Peening Coverage Control," Shot Peen., vol. 9, no. 2, pp. 28-30, 1995.

[19] Q. X. Xia, Z. C. Chen, X. Q. Cheng, and X. F. Sheng, "Calculation Method of Shot Peening Coverage Based on Area Computation for Random Finite Element Model,” 2013 Int. Conf. 
Mech. Autom. Eng., no. 2, pp. 22-25, 2013.

[20] J. Cammett, "Shot Peening Coverage- the Real Deal," vol. 21, no. 3, pp. 10-13, 2007.

[21] P. S. Prevey and J. T. Cammett, "The Effect of Shot Peening Coverage on Residual Stress, Cold Work and Fatigue in a Ni-Cr-Mo Low Alloy Steel,” Proc. Int. Conf. Shot Peen., pp. 295-304, 2006.

[22] M. Guagliano, "Relating Almen Intensity to Residual Stresses Induced by Shot Peening: a Numerical Approach,”J. Mater. Process. Technol., vol. 110, no. 3, pp. 277-286, 2001.

[23] Y. B. Guo, A. W. Warren, and F. Hashimoto, "The Basic Relationships between Residual Stress, White Layer, and Fatigue Life of Hard Turned and Ground Surfaces in Rolling Contact," CIRP J. Manuf. Sci. Technol., vol. 2, no. 2, pp. 129-134, 2010.

[24] R. B. Waterhouse, "The Effect of Residual Stress Induced by Shot-Peening on Fatigue Crack Propagation in Two High Strength Aluminium Alloys," Fatigue Fract. Eng. Mater. Struct., vol. 10, no. 4, pp. 261-272, 1987.

[25] J. C. Kim, S. K. Cheong, and H. Noguchi, "Residual Stress Relaxation and Low- and Highcycle Fatigue Behavior of Shot-Peened Medium-Carbon Steel,” Int. J. Fatigue, vol. 56, pp. 114-122, 2013.

[26] I. Nikitin, B. Scholtes, H. J. Maier, and I. Altenberger, "High Temperature Fatigue Behavior and Residual Stress Stability of Laser-Shock Peened and Deep Rolled Austenitic Steel AISI 304," Scr. Mater., vol. 50, no. 10, pp. 1345-1350, 2004.

[27] D. Lohe, K.-H. Lang, and O. Vöhringer, "Residual Stresses and Fatigue Behaviour," Handb. Residual Stress Deform. Steel, pp. 11-26, 2002. 
[28] N. S. Rossini, M. Dassisti, K. Y. Benyounis, and A. G. Olabi, "Methods of Measuring Residual Stresses in Components,” Mater. Des., vol. 35, pp. 572-588, 2012.

[29] N. Tebedge, G. Alpsten, and L. Tall, "Residual-stress Measurement by the Sectioning Method," Exp. Mech., vol. 13, no. 2, pp. 88-96, 1973.

[30] R. C. Spoorenberg, H. H. Snijder, and J. C. D. Hoenderkamp, "Experimental Investigation of Residual Stresses in Roller Bent Wide Flange Steel Sections," J. Constr. Steel Res., vol. 66, no. 6, pp. 737-747, 2010.

[31] M. G. Bateman et al., "Measurement of Residual Stress in Thick Section Composite Laminates Using the Deep-Hole Method," Int. J. Mech. Sci., vol. 47, no. 11, pp. 1718-1739, 2005.

[32] P. S. Prevéy, "X-Ray Diffraction Residual Stress Techniques," ASM Handb., vol. 10, pp. $380-392,1986$.

[33] V. Hauk and H. Behnken, Structural and Residual Stress Analysis by Nondestructive Methods. 1997.

[34] A. Levers and A. Prior, "Finite Element Analysis of Shot Peening," J. Mater. Process. Technol., vol. 80-81, pp. 304-308, 1998.

[35] L. Xie, J. Zhang, C. Xiong, L. Wu, C. Jiang, and W. Lu, "Investigation on Experiments and Numerical Modelling of the Residual Stress Distribution in Deformed Surface Layer of Ti6Al-4V after Shot Peening,” Mater. Des., vol. 41, pp. 314-318, 2012.

[36] X. Xiao, X. Tong, Y. Liu, R. Zhao, G. Gao, and Y. Li, "Prediction of Shot Peen Forming Effects with Single and Repeated Impacts,” Int. J. Mech. Sci., vol. 137, pp. 182-194, 2018. 
[37] K. Murugaratnam, S. Utili, and N. Petrinic, "A Combined DEM-FEM Numerical Method for Shot Peening Parameter Optimisation," Adv. Eng. Softw., vol. 79, pp. 13-26, 2015.

[38] D. HU et al., "A Unifying Approach in Simulating the Shot Peening Process Ssing a 3D Random Representative Volume Finite Element Model,” Chinese J. Aeronaut., vol. 30, no. 4, pp. 1592-1602, 2017.

[39] Metallic Materials Properties Development and Standardization (MMPDS-012). Federal Aviation Administration, 2003.

[40] E. U. Lee, R. Taylor, C. Lei, and H. C. Sanders, “Aircraft Steels,” 2009.

[41] A. Zare, H. Mansouri, and S. R. Hosseini, "Effect of Deep Cryogenic Treatment on the Microstructure and Mechanical Properties of HY-TUF Steel," Metallogr. Microstruct. Anal., vol. 4, no. 3, pp. 169-177, 2015.

[42] S. Launches, "Saint-Gobain Launches High-Density Ceramic Peening Shot : Zirshot HDC," pp. 20-22, 2017.

[43] “Zirshot Technical Data Sheet," 2012.

[44] R. Purohit, C. S. Verma, R. S. Rana, R. Dwivedi, and S. Dwivedi, "Simulation of Shot Peening Process,” Mater. Today Proc., vol. 4, no. 2, pp. 1244-1251, 2017. 


\section{Appendix A}

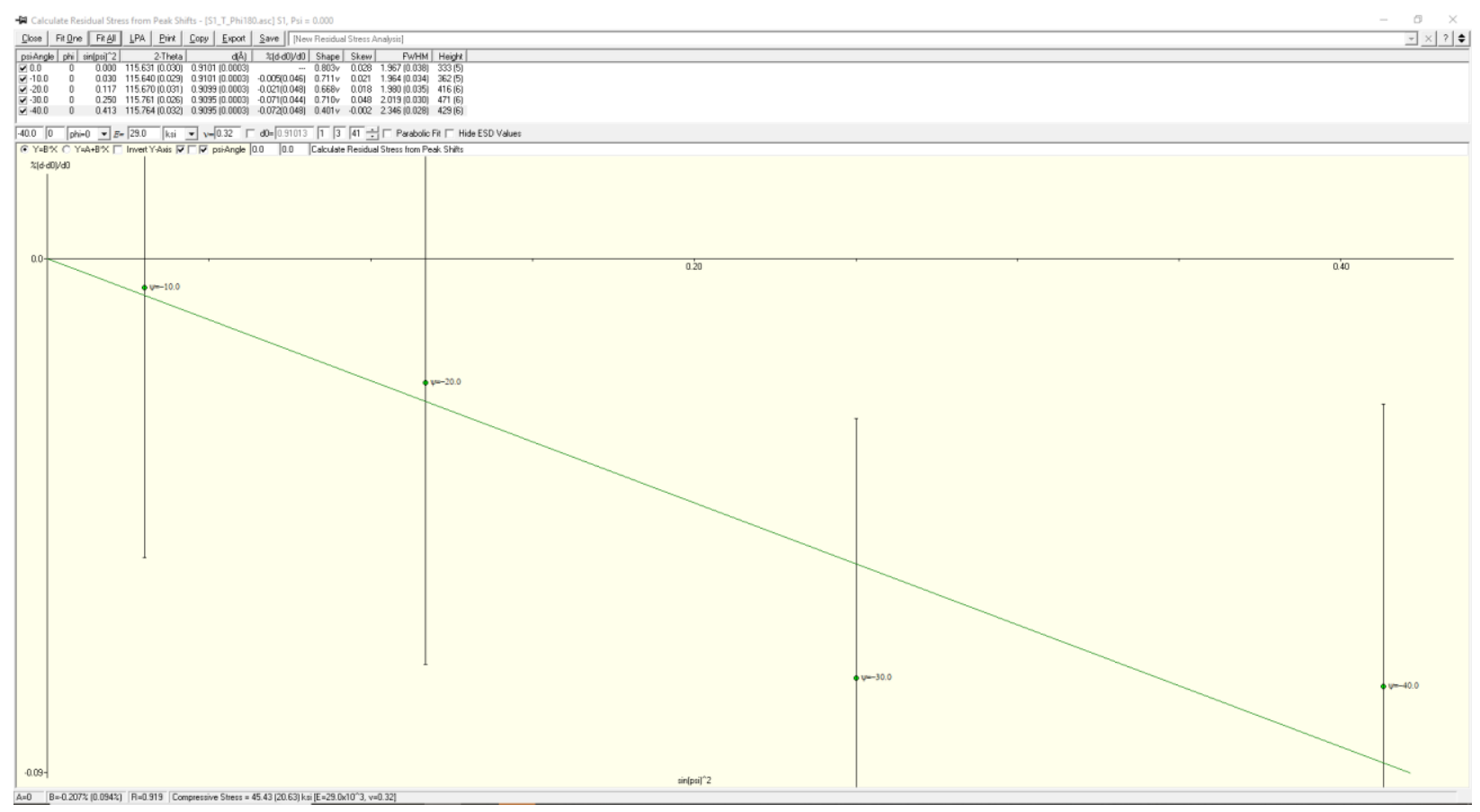

Figure AP-1 XRD measurement data for the top of specimen without hole at $180^{\circ}$ scan

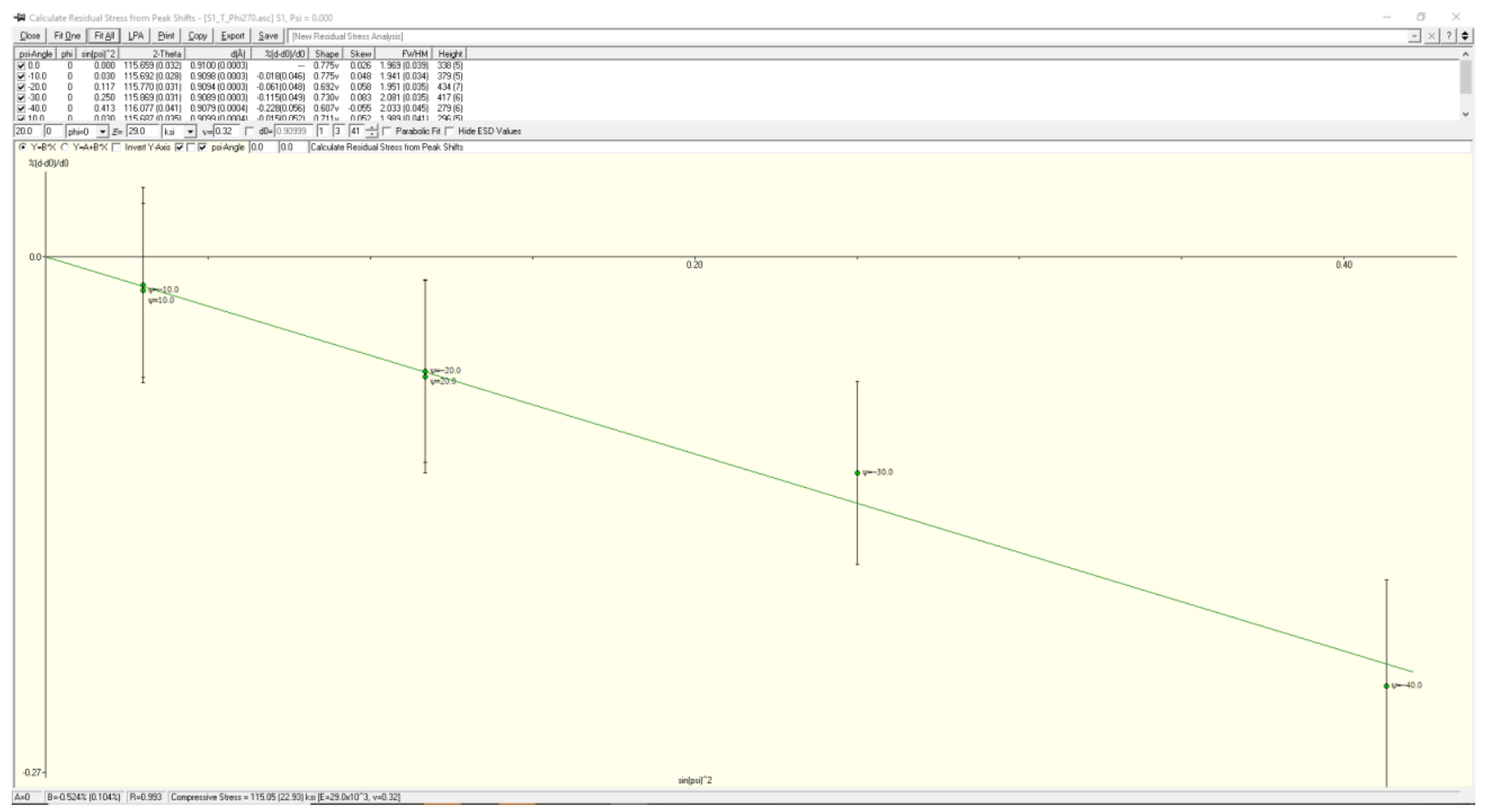

Figure AP-2 XRD measurement data for the top of specimen without hole at $270^{\circ}$ scan 


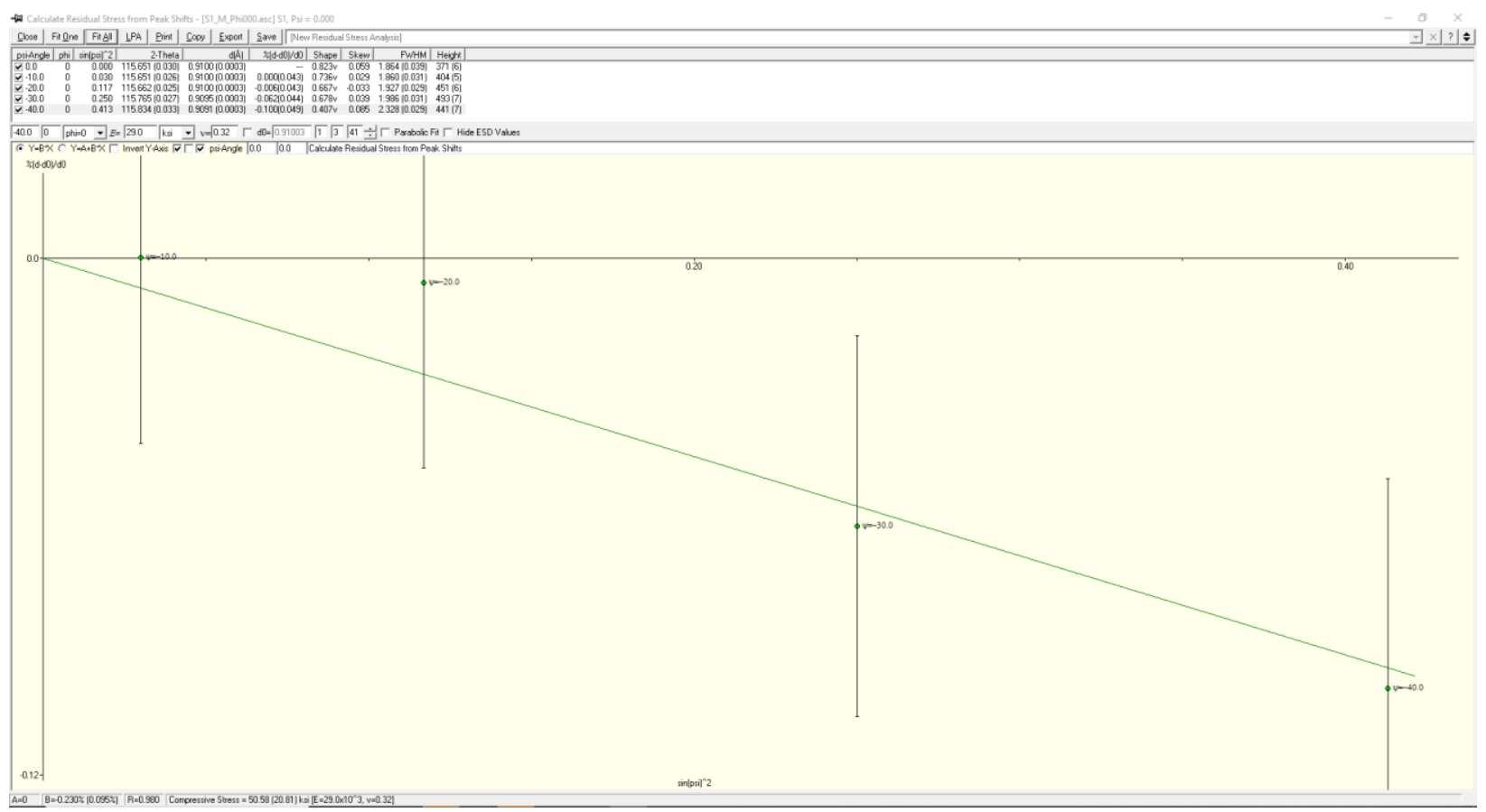

Figure AP-3 XRD measurement data for the middle of specimen without hole at $0^{\circ}$ scan

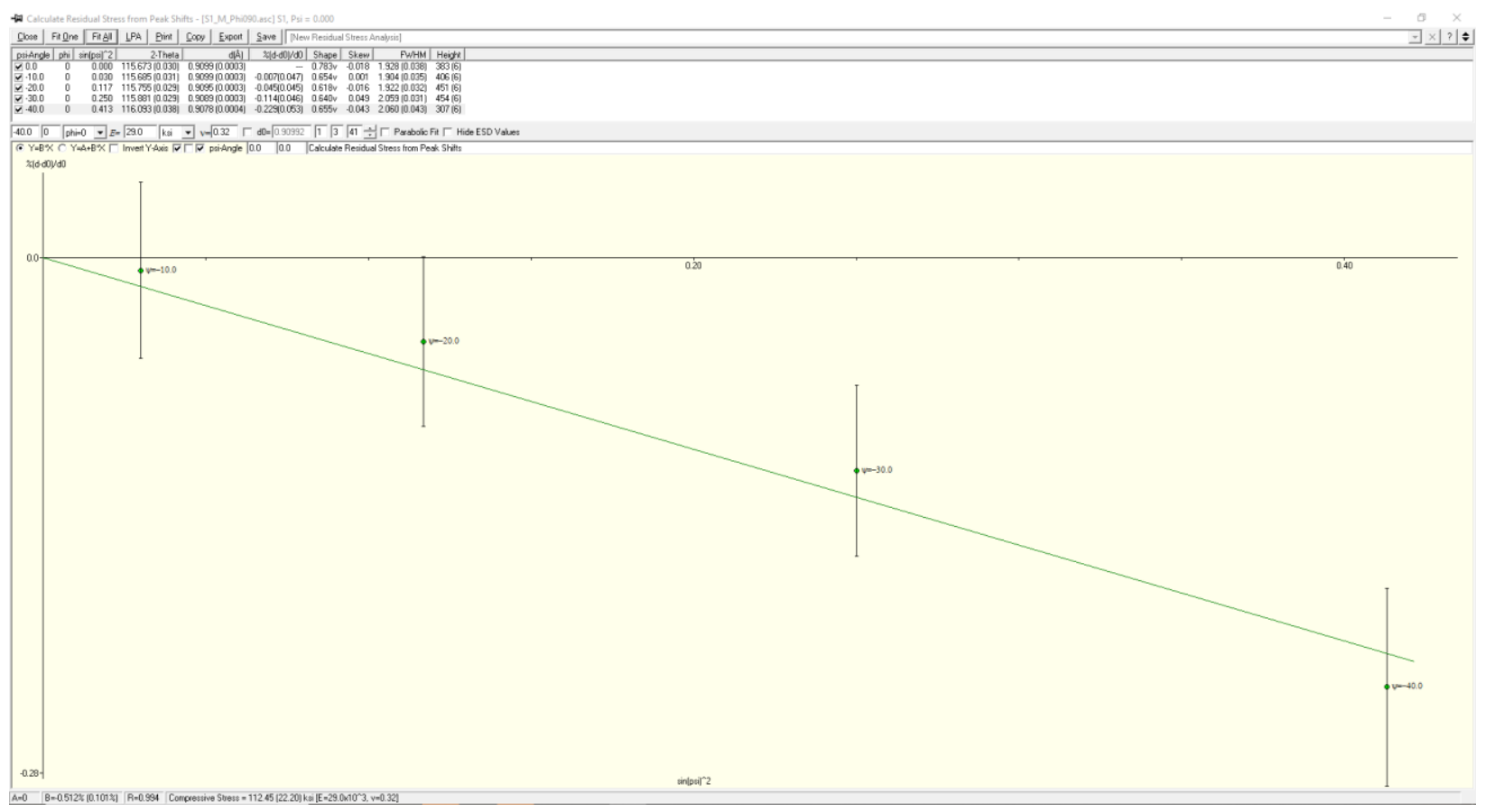

Figure AP-4 XRD measurement data for the middle of specimen without hole at $90^{\circ}$ scan 


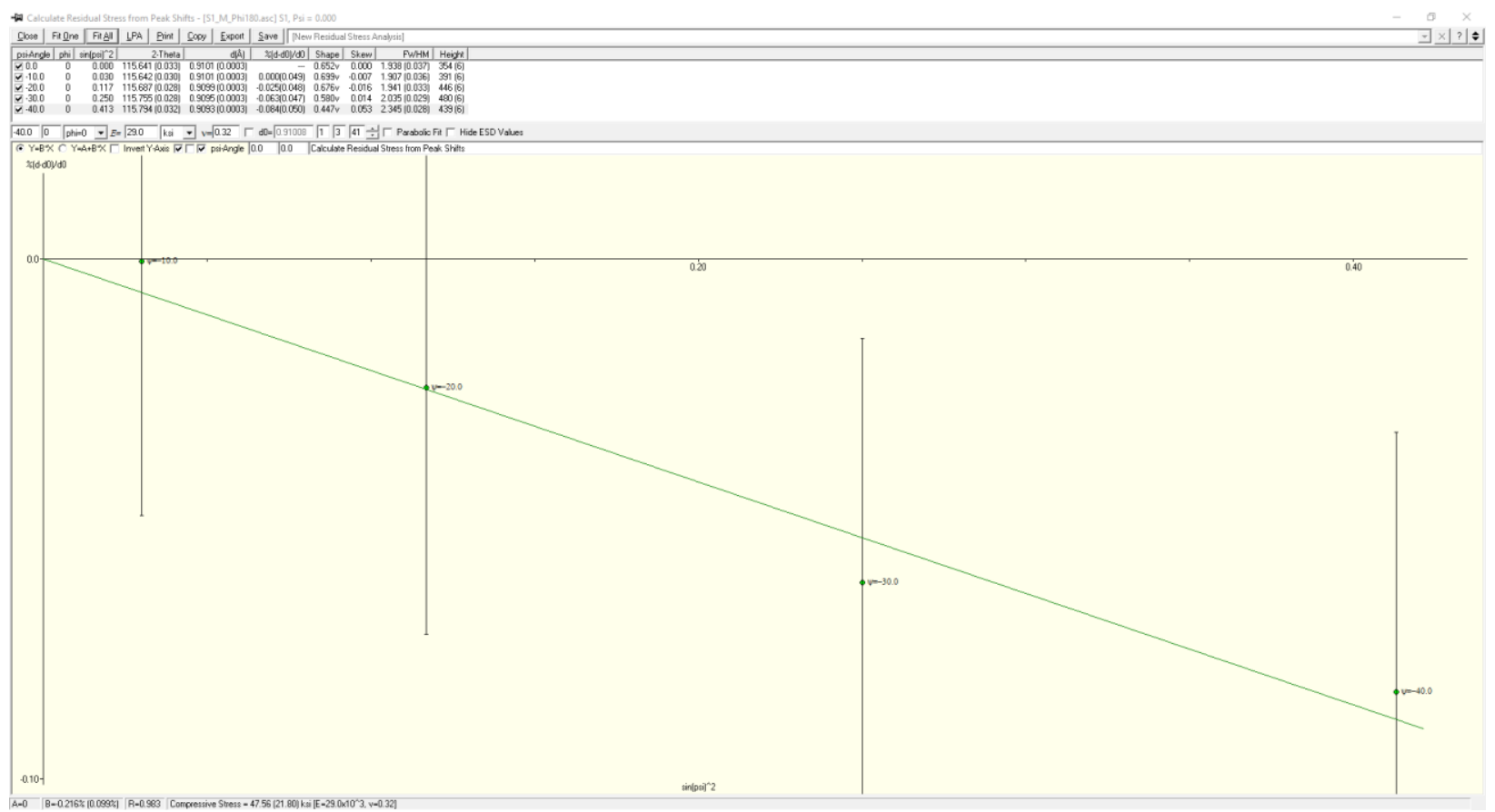

Figure AP-5 XRD measurement data for the middle of specimen without hole at $180^{\circ}$ scan

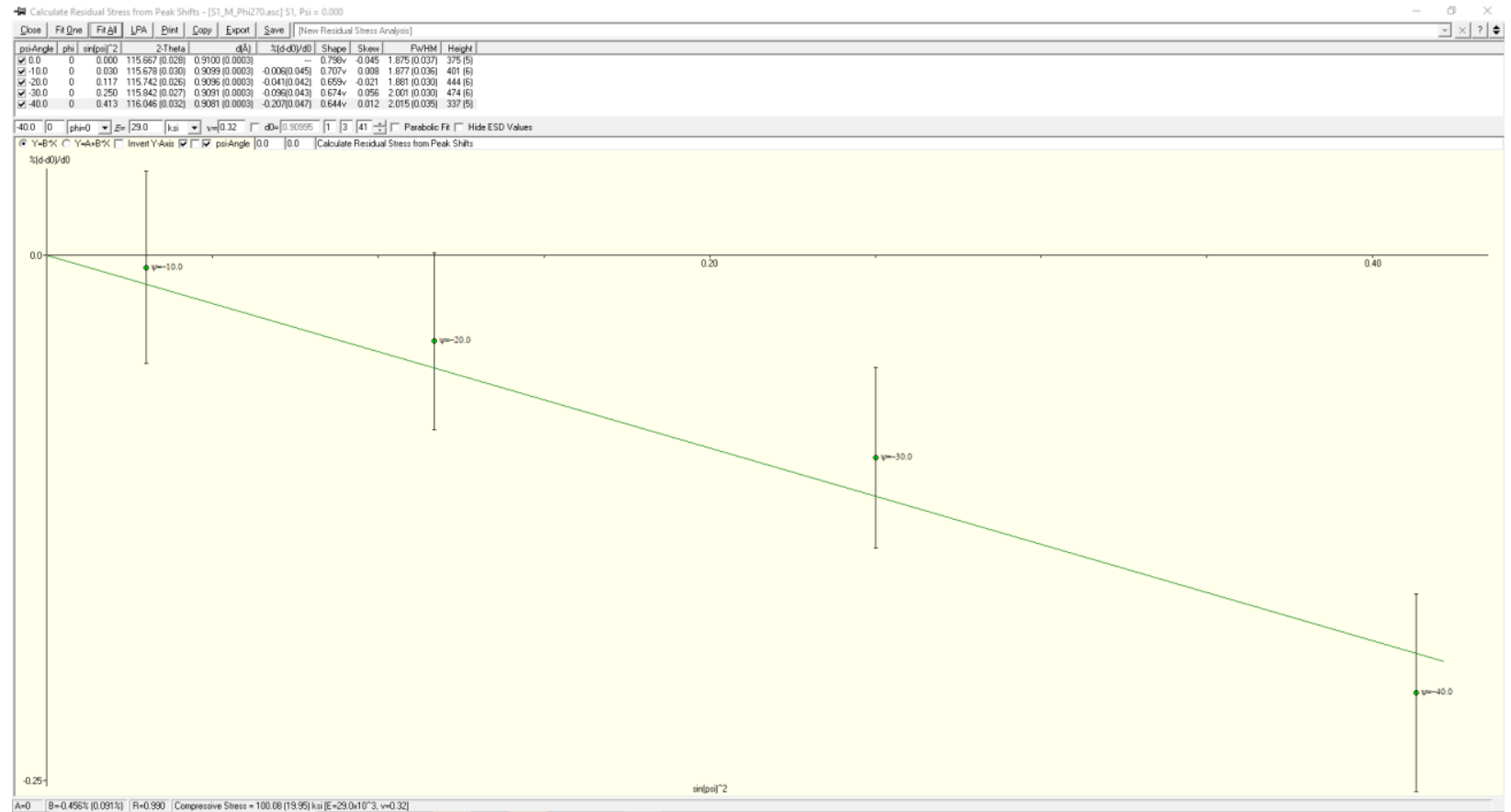

Figure AP-6 XRD measurement data for the middle of specimen without hole at $270^{\circ}$ scan 


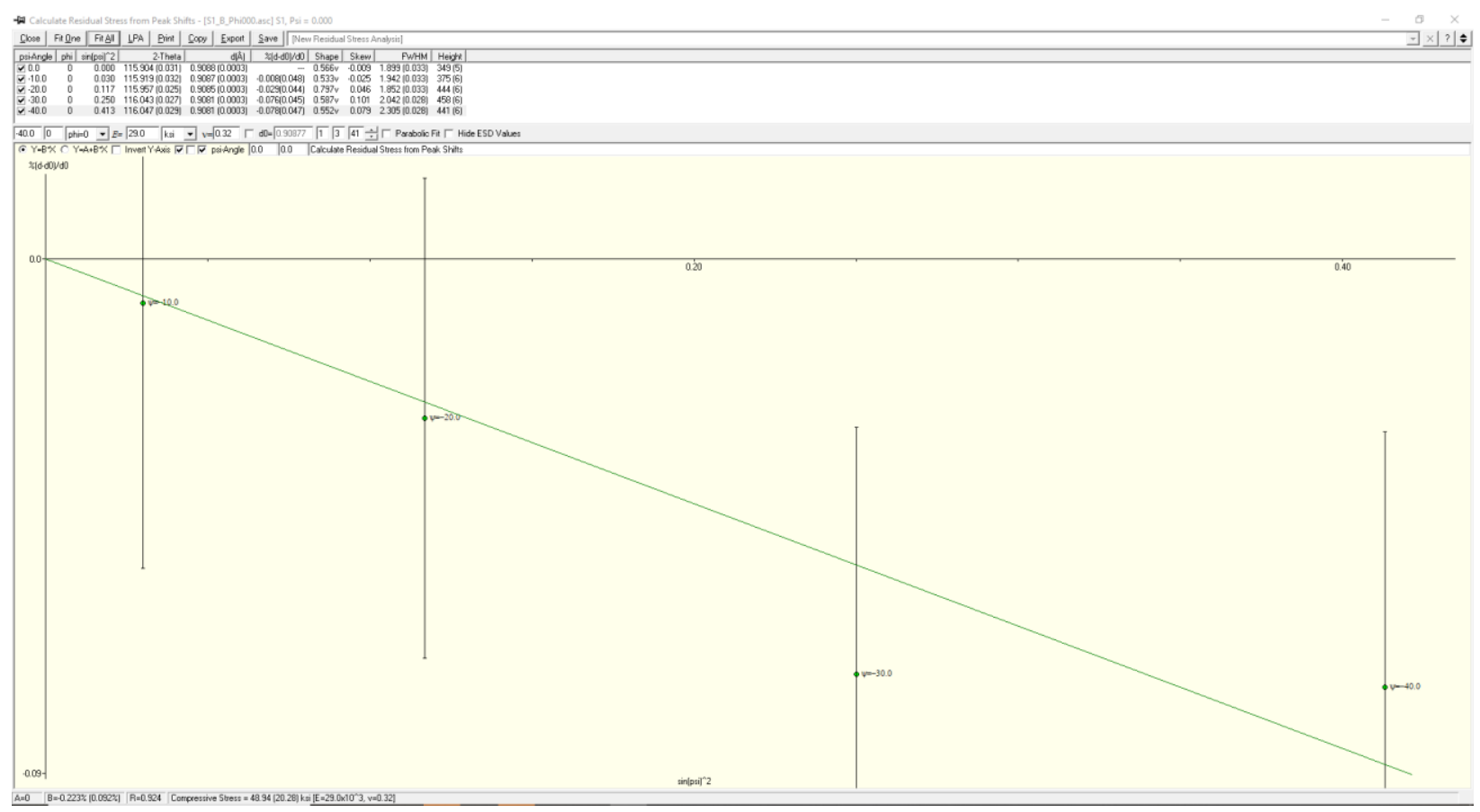

Figure AP-7 XRD measurement data for the bottom of specimen without hole at $0^{\circ}$ scan

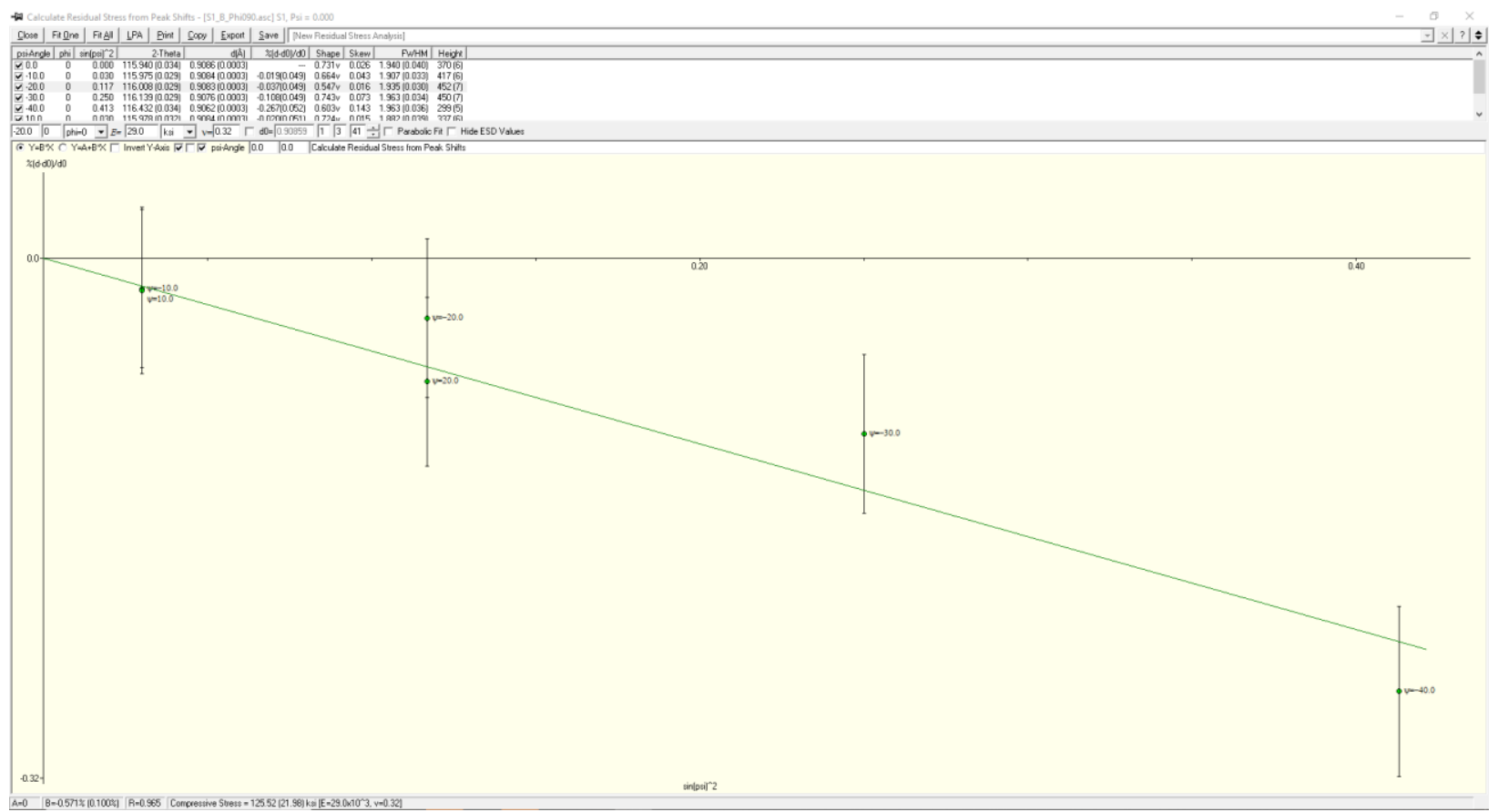

Figure AP-8 XRD measurement data for the bottom of specimen without hole at $90^{\circ}$ scan 


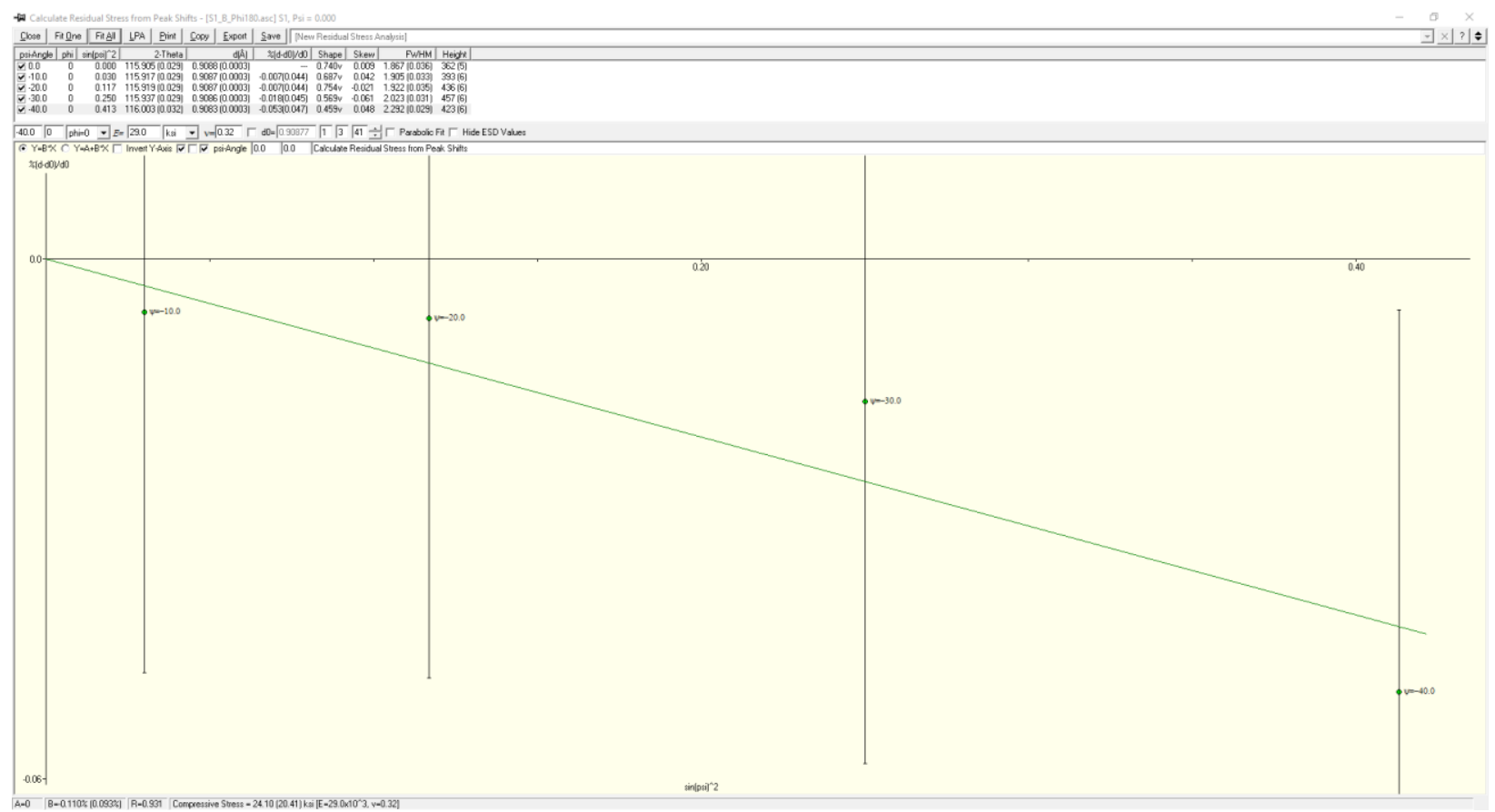

Figure AP-9 XRD measurement data for the bottom of specimen without hole at $180^{\circ}$ scan

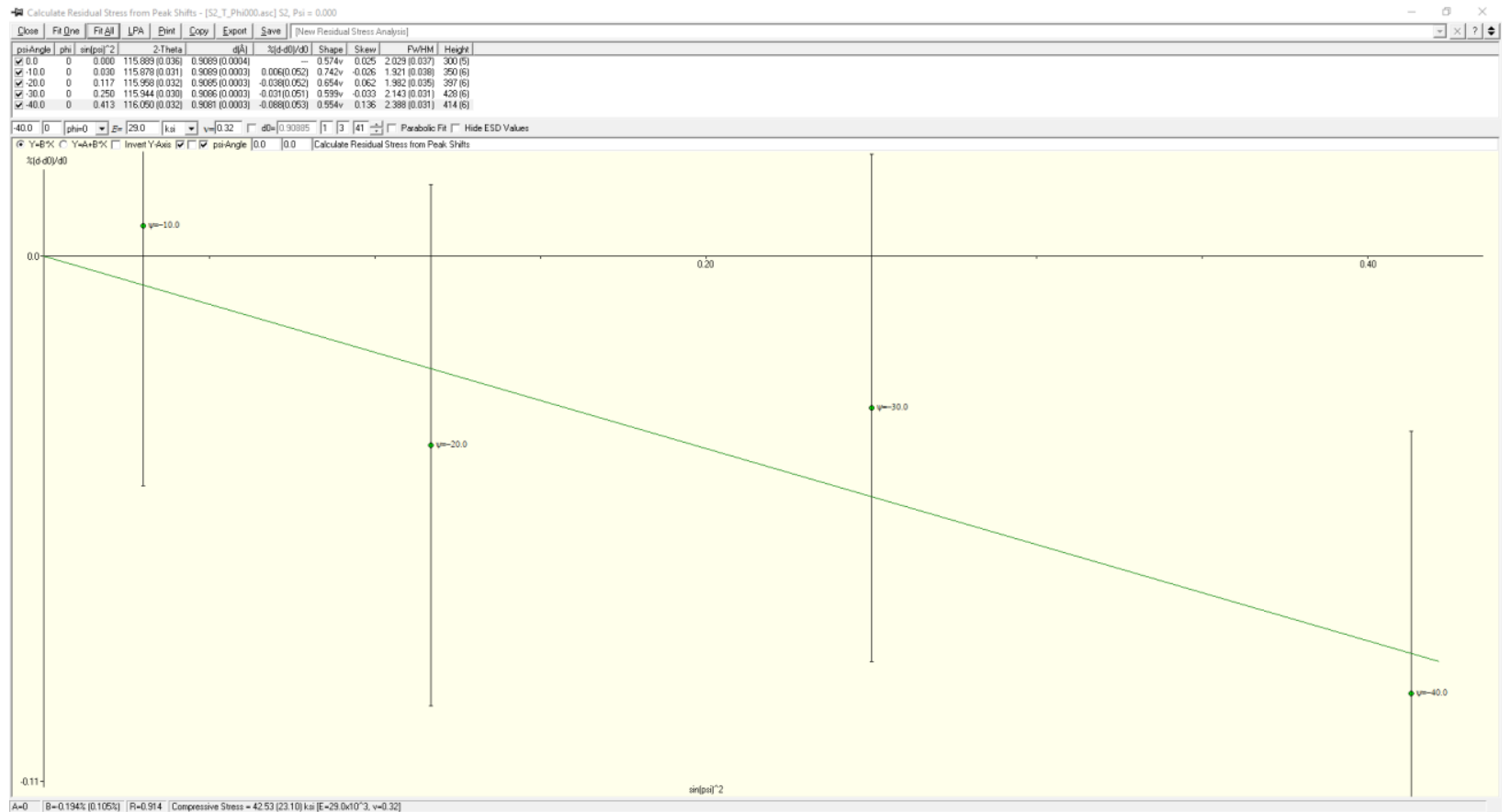

Figure AP-10 XRD measurement data for the top of specimen with holes at $0^{\circ}$ scan 


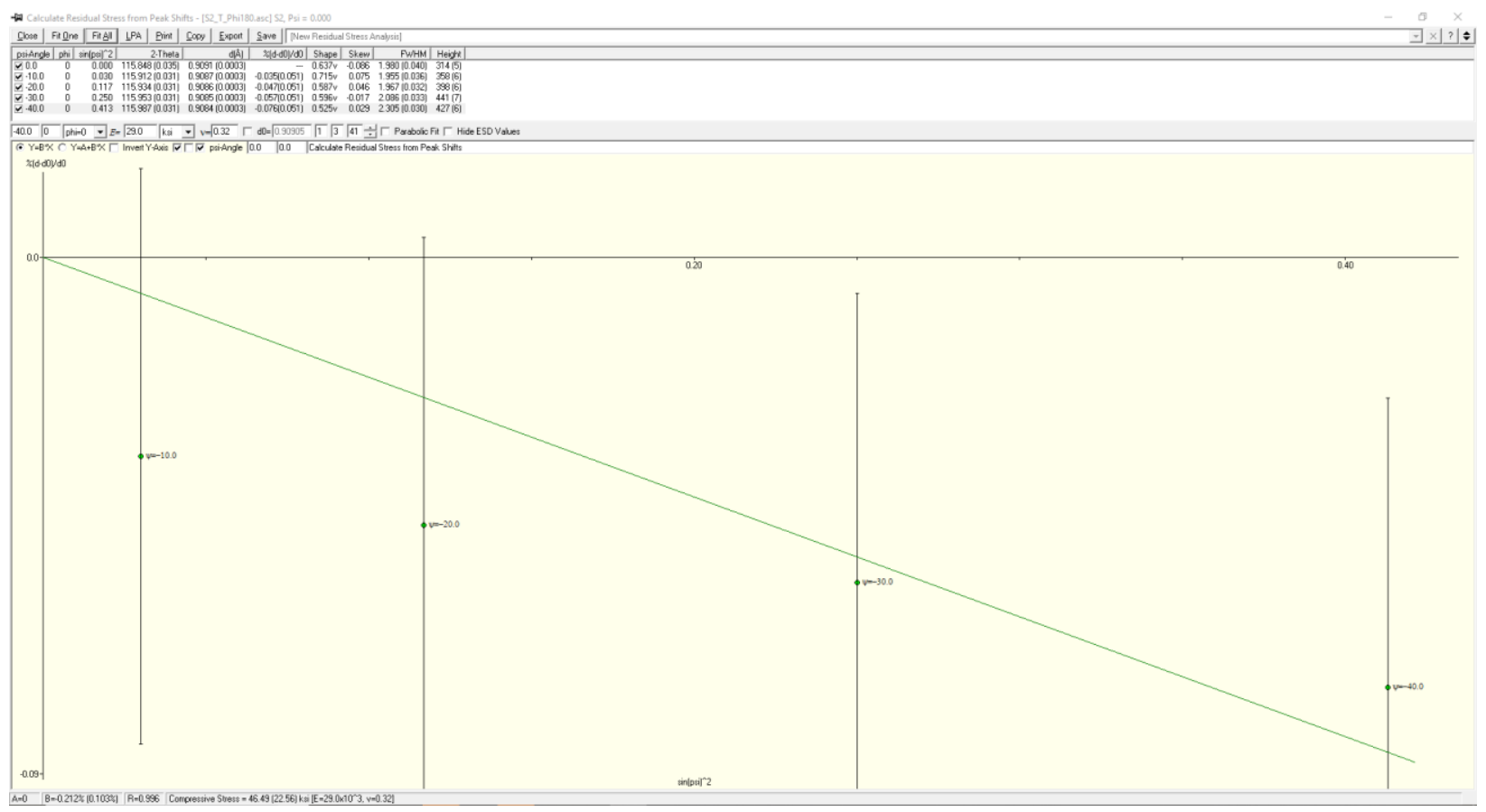

Figure AP-11 XRD measurement data for the top of specimen with holes at $180^{\circ}$ scan

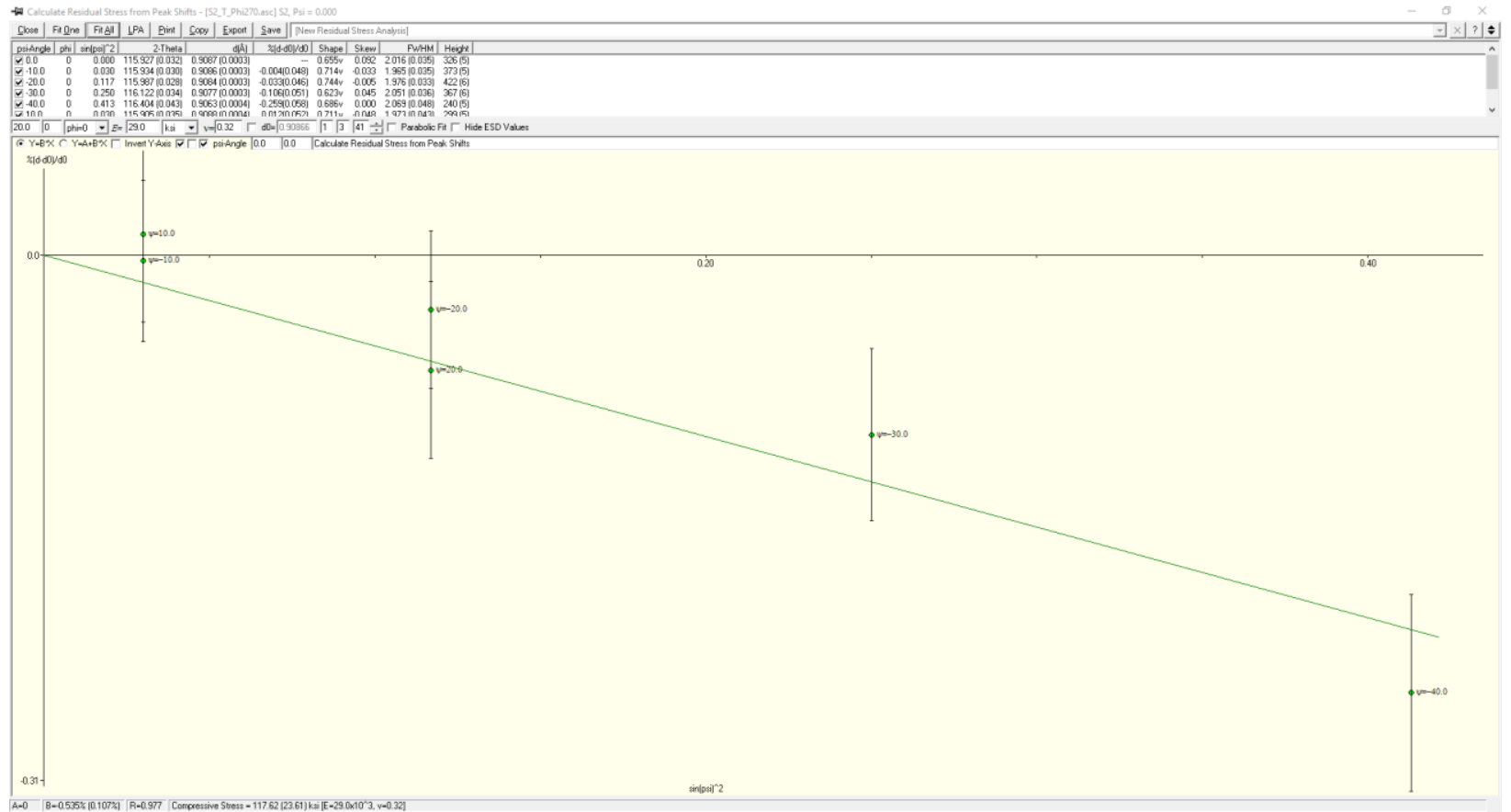

Figure AP-12 XRD measurement data for the top of specimen with holes at $270^{\circ}$ scan 


\section{Appendix B}

Table AP-1 Peening shot locations on the target surface of flange pin

\begin{tabular}{c|c|c}
\hline & $\mathrm{X}$ & $\mathrm{Z}$ \\
\hline 1 & -0.30012 & -0.08272 \\
2 & 0.244691 & -0.08582 \\
3 & 0.176776 & -0.18845 \\
4 & 0.05302 & -0.26047 \\
5 & -0.03848 & -0.00099 \\
6 & -0.0714 & 0.266944 \\
7 & 0.069608 & -0.03765 \\
8 & -0.19664 & -0.05758 \\
9 & -0.1801 & -0.02256 \\
10 & -0.14597 & -0.05029 \\
11 & 0.177975 & 0.128938 \\
12 & -0.18219 & 0.009048 \\
13 & 0.22902 & 0.300059 \\
14 & 0.0317 & 0.038405 \\
15 & 0.161877 & 0.290214 \\
16 & 0.295315 & -0.20243 \\
17 & -0.2197 & -0.30476 \\
18 & -0.23804 & 0.136344 \\
19 & 0.263427 & -0.16598 \\
20 & 0.307844 & 0.096583 \\
21 & -0.01701 & 0.101686 \\
22 & -0.00285 & 0.222724 \\
23 & -0.05163 & -0.17013 \\
24 & -0.25829 & -0.09069 \\
25 & 0.262234 & 0.189956 \\
26 & 0.104142 & -0.28748 \\
27 & 0.342792 & 0.015776 \\
28 & 0.115066 & 0.362178 \\
29 & 0.256089 & -0.1801 \\
30 & -0.28376 & 0.266797 \\
31 & 0.056445 & -0.06515 \\
32 & 0.260517 & -0.23515 \\
33 & -0.28264 & -0.07003 \\
34 & 0.273154 & 0.255607 \\
35 & -0.31788 & -0.03232 \\
36 & -0.19176 & -0.23962 \\
\hline & -0.20361 & 0.146486 \\
\hline & & \\
\hline
\end{tabular}


Table AP-2 Peening shot locations for $30^{\circ}$ peening angle model

\begin{tabular}{c|c|c|c}
\hline & $\mathrm{X}$ & $\mathrm{Y}$ & $\mathrm{Z}$ \\
\hline 1 & -0.30012 & 0.15 & -0.34253 \\
2 & 0.244691 & 0.3 & -0.60543 \\
3 & 0.176776 & 0.45 & -0.96787 \\
4 & 0.05302 & 0.6 & -1.2997 \\
5 & -0.03848 & 0.75 & -1.30003 \\
6 & -0.0714 & 0.9 & -1.2919 \\
7 & 0.069608 & 1.05 & -1.8563 \\
8 & -0.19664 & 1.2 & -2.13604 \\
9 & -0.1801 & 1.35 & -2.36083 \\
10 & -0.14597 & 1.5 & -2.64836 \\
11 & 0.177975 & 1.65 & -2.72895 \\
12 & -0.18219 & 1.8 & -3.10864 \\
13 & 0.22902 & 1.95 & -3.07744 \\
14 & 0.0317 & 2.1 & -3.5989 \\
15 & 0.161877 & 2.25 & -3.6069 \\
16 & 0.295315 & 2.4 & -4.35935 \\
17 & -0.2197 & 2.55 & -4.72149 \\
18 & -0.23804 & 2.7 & -4.54019 \\
19 & 0.263427 & 2.85 & -5.10233 \\
20 & 0.307844 & 3 & -5.09957 \\
21 & -0.01701 & 3.15 & -5.35427 \\
22 & -0.00285 & 3.3 & -5.49304 \\
23 & -0.05163 & 3.45 & -6.14571 \\
24 & -0.25829 & 3.6 & -6.32607 \\
25 & 0.262234 & 3.75 & -6.30523 \\
26 & 0.104142 & 3.9 & -7.04248 \\
27 & 0.342792 & 4.05 & -6.99903 \\
28 & 0.115066 & 4.2 & -6.91244 \\
29 & 0.256089 & 4.35 & -7.71452 \\
30 & -0.28376 & 4.5 & -7.52743 \\
31 & 0.056445 & 4.65 & -8.11918 \\
32 & 0.260517 & 4.8 & -8.54899 \\
33 & -0.28264 & 4.95 & -8.64368 \\
34 & 0.273154 & 5.1 & -8.57785 \\
35 & -0.31788 & 5.25 & -9.12559 \\
36 & -0.19176 & 5.4 & -9.5927 \\
37 & -0.20361 & 5.55 & -9.4664 \\
\hline & & & \\
\hline
\end{tabular}


Table AP-3 Peening shot locations for $45^{\circ}$ peening angle model

\begin{tabular}{c|c|c|c}
\hline & $\mathrm{X}$ & $\mathrm{Y}$ & $\mathrm{Z}$ \\
\hline 1 & -0.30012 & 0.212132 & -0.29485 \\
2 & 0.244691 & 0.424264 & -0.51008 \\
3 & 0.176776 & 0.636396 & -0.82485 \\
4 & 0.05302 & 0.848528 & -1.109 \\
5 & -0.03848 & 1.06066 & -1.06165 \\
6 & -0.0714 & 1.272792 & -1.00585 \\
7 & 0.069608 & 1.484924 & -1.52257 \\
8 & -0.19664 & 1.697056 & -1.75464 \\
9 & -0.1801 & 1.909188 & -1.93175 \\
10 & -0.14597 & 2.12132 & -2.17161 \\
11 & 0.177975 & 2.333452 & -2.20451 \\
12 & -0.18219 & 2.545584 & -2.53654 \\
13 & 0.22902 & 2.757716 & -2.45766 \\
14 & 0.0317 & 2.969848 & -2.93144 \\
15 & 0.161877 & 3.181981 & -2.89177 \\
16 & 0.295315 & 3.394113 & -3.59654 \\
17 & -0.2197 & 3.606245 & -3.911 \\
18 & -0.23804 & 3.818377 & -3.68203 \\
19 & 0.263427 & 4.030509 & -4.19649 \\
20 & 0.307844 & 4.242641 & -4.14606 \\
21 & -0.01701 & 4.454773 & -4.35309 \\
22 & -0.00285 & 4.666905 & -4.44418 \\
23 & -0.05163 & 4.879037 & -5.04917 \\
24 & -0.25829 & 5.091169 & -5.18185 \\
25 & 0.262234 & 5.303301 & -5.11334 \\
26 & 0.104142 & 5.515433 & -5.80292 \\
27 & 0.342792 & 5.727565 & -5.71179 \\
28 & 0.115066 & 5.939697 & -5.57752 \\
29 & 0.256089 & 6.151829 & -6.33192 \\
30 & -0.28376 & 6.363961 & -6.09716 \\
31 & 0.056445 & 6.576093 & -6.64124 \\
32 & 0.260517 & 6.788225 & -7.02338 \\
33 & -0.28264 & 7.000357 & -7.07039 \\
34 & 0.273154 & 7.212489 & -6.95688 \\
35 & -0.31788 & 7.424621 & -7.45695 \\
36 & -0.19176 & 7.636753 & -7.87638 \\
37 & -0.20361 & 7.848885 & -7.7024 \\
\hline & & & \\
\hline
\end{tabular}


Table AP-4 Peening shot locations for $60^{\circ}$ peening angle model

\begin{tabular}{c|c|c|c}
\hline & $\mathrm{X}$ & $\mathrm{Y}$ & $\mathrm{Z}$ \\
\hline 1 & -0.30012 & 0.259808 & -0.23272 \\
2 & 0.244691 & 0.519615 & -0.38582 \\
3 & 0.176776 & 0.779423 & -0.63845 \\
4 & 0.05302 & 1.03923 & -0.86047 \\
5 & -0.03848 & 1.299038 & -0.75099 \\
6 & -0.0714 & 1.558846 & -0.63306 \\
7 & 0.069608 & 1.818653 & -1.08765 \\
8 & -0.19664 & 2.078461 & -1.25758 \\
9 & -0.1801 & 2.338269 & -1.37256 \\
10 & -0.14597 & 2.598076 & -1.55029 \\
11 & 0.177975 & 2.857884 & -1.52106 \\
12 & -0.18219 & 3.117691 & -1.79095 \\
13 & 0.22902 & 3.377499 & -1.64994 \\
14 & 0.0317 & 3.637307 & -2.06159 \\
15 & 0.161877 & 3.897114 & -1.95979 \\
16 & 0.295315 & 4.156922 & -2.60243 \\
17 & -0.2197 & 4.41673 & -2.85476 \\
18 & -0.23804 & 4.676537 & -2.56366 \\
19 & 0.263427 & 4.936345 & -3.01598 \\
20 & 0.307844 & 5.196152 & -2.90342 \\
21 & -0.01701 & 5.45596 & -3.04831 \\
22 & -0.00285 & 5.715768 & -3.07728 \\
23 & -0.05163 & 5.975575 & -3.62013 \\
24 & -0.25829 & 6.235383 & -3.69069 \\
25 & 0.262234 & 6.495191 & -3.56004 \\
26 & 0.104142 & 6.754998 & -4.18748 \\
27 & 0.342792 & 7.014806 & -4.03422 \\
28 & 0.115066 & 7.274613 & -3.83782 \\
29 & 0.256089 & 7.534421 & -4.5301 \\
30 & -0.28376 & 7.794229 & -4.2332 \\
31 & 0.056445 & 8.054036 & -4.71515 \\
32 & 0.260517 & 8.313844 & -5.03515 \\
33 & -0.28264 & 8.573651 & -5.02003 \\
34 & 0.273154 & 8.833459 & -4.84439 \\
35 & -0.31788 & 9.093267 & -5.28232 \\
36 & -0.19176 & 9.353074 & -5.63962 \\
37 & -0.20361 & 9.612882 & -5.40351 \\
\hline & & & \\
\hline
\end{tabular}


Table AP-5 Peening shot locations for $75^{\circ}$ peening angle model

\begin{tabular}{c|c|c|c}
\hline & $\mathrm{X}$ & $\mathrm{Y}$ & $\mathrm{Z}$ \\
\hline 1 & -0.30012 & 0.289778 & -0.16037 \\
2 & 0.244691 & 0.579555 & -0.24111 \\
3 & 0.176776 & 0.869333 & -0.42139 \\
4 & 0.05302 & 1.159111 & -0.57105 \\
5 & -0.03848 & 1.448889 & -0.38922 \\
6 & -0.0714 & 1.738666 & -0.19893 \\
7 & 0.069608 & 2.028444 & -0.58117 \\
8 & -0.19664 & 2.318222 & -0.67875 \\
9 & -0.1801 & 2.608 & -0.72137 \\
10 & -0.14597 & 2.897777 & -0.82674 \\
11 & 0.177975 & 3.187555 & -0.72516 \\
12 & -0.18219 & 3.477333 & -0.9227 \\
13 & 0.22902 & 3.767111 & -0.70934 \\
14 & 0.0317 & 4.056888 & -1.04863 \\
15 & 0.161877 & 4.346666 & -0.87447 \\
16 & 0.295315 & 4.636444 & -1.44476 \\
17 & -0.2197 & 4.926222 & -1.62474 \\
18 & -0.23804 & 5.215999 & -1.26128 \\
19 & 0.263427 & 5.505777 & -1.64125 \\
20 & 0.307844 & 5.795555 & -1.45633 \\
21 & -0.01701 & 6.085333 & -1.52887 \\
22 & -0.00285 & 6.37511 & -1.48548 \\
23 & -0.05163 & 6.664888 & -1.95598 \\
24 & -0.25829 & 6.954666 & -1.95418 \\
25 & 0.262234 & 7.244444 & -1.75119 \\
26 & 0.104142 & 7.534221 & -2.30627 \\
27 & 0.342792 & 7.823999 & -2.08066 \\
28 & 0.115066 & 8.113777 & -1.8119 \\
29 & 0.256089 & 8.403555 & -2.43182 \\
30 & -0.28376 & 8.693332 & -2.06257 \\
31 & 0.056445 & 8.98311 & -2.47217 \\
32 & 0.260517 & 9.272888 & -2.71981 \\
33 & -0.28264 & 9.562666 & -2.63234 \\
34 & 0.273154 & 9.852443 & -2.38435 \\
35 & -0.31788 & 10.14222 & -2.74992 \\
36 & -0.19176 & 10.432 & -3.03487 \\
37 & -0.20361 & 10.72178 & -2.72641 \\
\hline & & & \\
\hline
\end{tabular}


Table AP-6 Peening shot locations for $90^{\circ}$ peening angle model

\begin{tabular}{c|c|c|c}
\hline & $\mathrm{X}$ & $\mathrm{Y}$ & $\mathrm{Z}$ \\
\hline 1 & -0.30012 & 0.3 & -0.08272 \\
2 & 0.244691 & 0.6 & -0.08582 \\
3 & 0.176776 & 0.9 & -0.18845 \\
4 & 0.05302 & 1.2 & -0.26047 \\
5 & -0.03848 & 1.5 & -0.00099 \\
6 & -0.0714 & 1.8 & 0.266944 \\
7 & 0.069608 & 2.1 & -0.03765 \\
8 & -0.19664 & 2.4 & -0.05758 \\
9 & -0.1801 & 2.7 & -0.02256 \\
10 & -0.14597 & 3 & -0.05029 \\
11 & 0.177975 & 3.3 & 0.128938 \\
12 & -0.18219 & 3.6 & 0.009048 \\
13 & 0.22902 & 3.9 & 0.300059 \\
14 & 0.0317 & 4.2 & 0.038405 \\
15 & 0.161877 & 4.5 & 0.290214 \\
16 & 0.295315 & 4.8 & -0.20243 \\
17 & -0.2197 & 5.1 & -0.30476 \\
18 & -0.23804 & 5.4 & 0.136344 \\
19 & 0.263427 & 5.7 & -0.16598 \\
20 & 0.307844 & 6 & 0.096583 \\
21 & -0.01701 & 6.3 & 0.101686 \\
22 & -0.00285 & 6.6 & 0.222724 \\
23 & -0.05163 & 6.9 & -0.17013 \\
24 & -0.25829 & 7.2 & -0.09069 \\
25 & 0.262234 & 7.5 & 0.189956 \\
26 & 0.104142 & 7.8 & -0.28748 \\
27 & 0.342792 & 8.1 & 0.015776 \\
28 & 0.115066 & 8.4 & 0.362178 \\
29 & 0.256089 & 8.7 & -0.1801 \\
30 & -0.28376 & 9 & 0.266797 \\
31 & 0.056445 & 9.3 & -0.06515 \\
32 & 0.260517 & 9.6 & -0.23515 \\
33 & -0.28264 & 9.9 & -0.07003 \\
34 & 0.273154 & 10.2 & 0.255607 \\
35 & -0.31788 & 10.5 & -0.03232 \\
36 & -0.19176 & 10.8 & -0.23962 \\
37 & -0.20361 & 11.1 & 0.146486 \\
\hline & & & \\
\hline 1
\end{tabular}




\section{Appendix C}

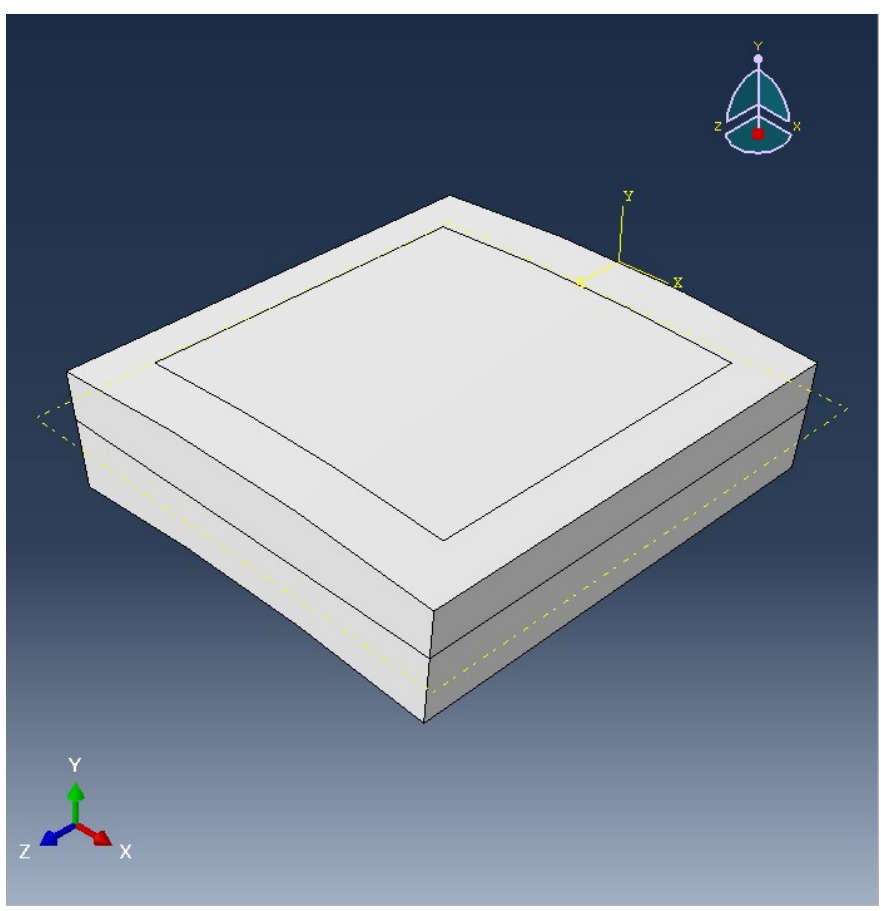

Figure AP-13 FEA model of target surface with curvature radius $20 \mathrm{~mm}$

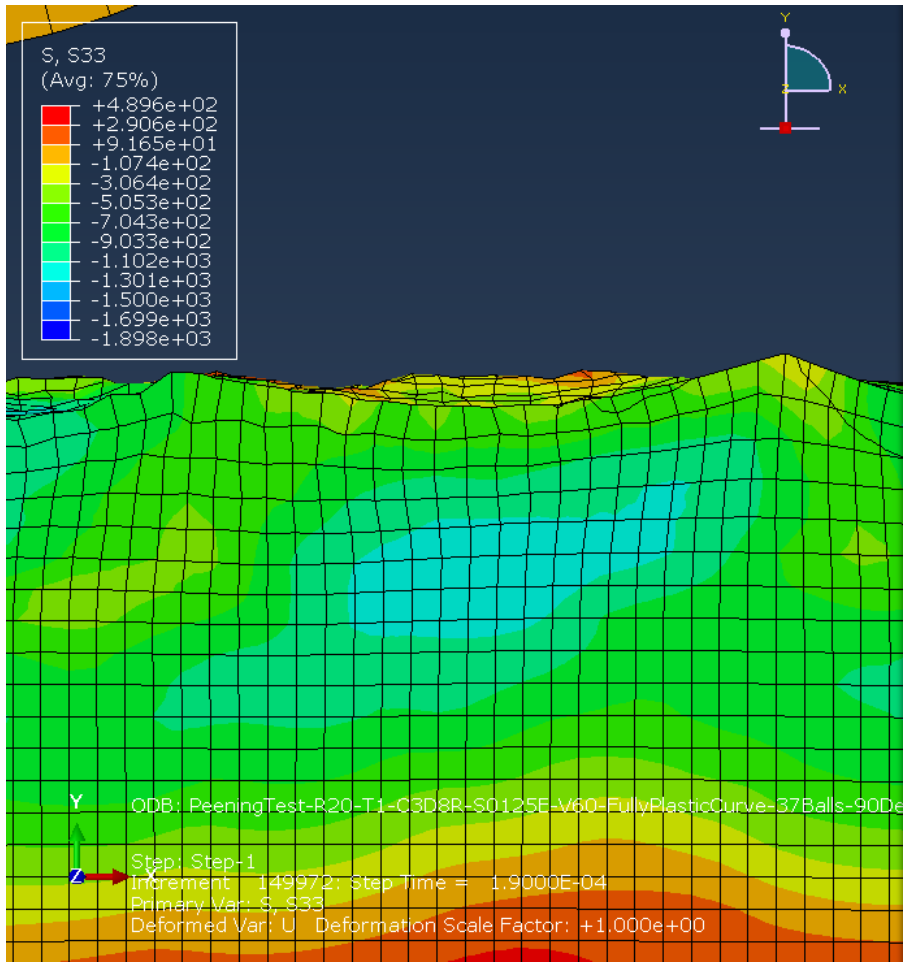

(a) 


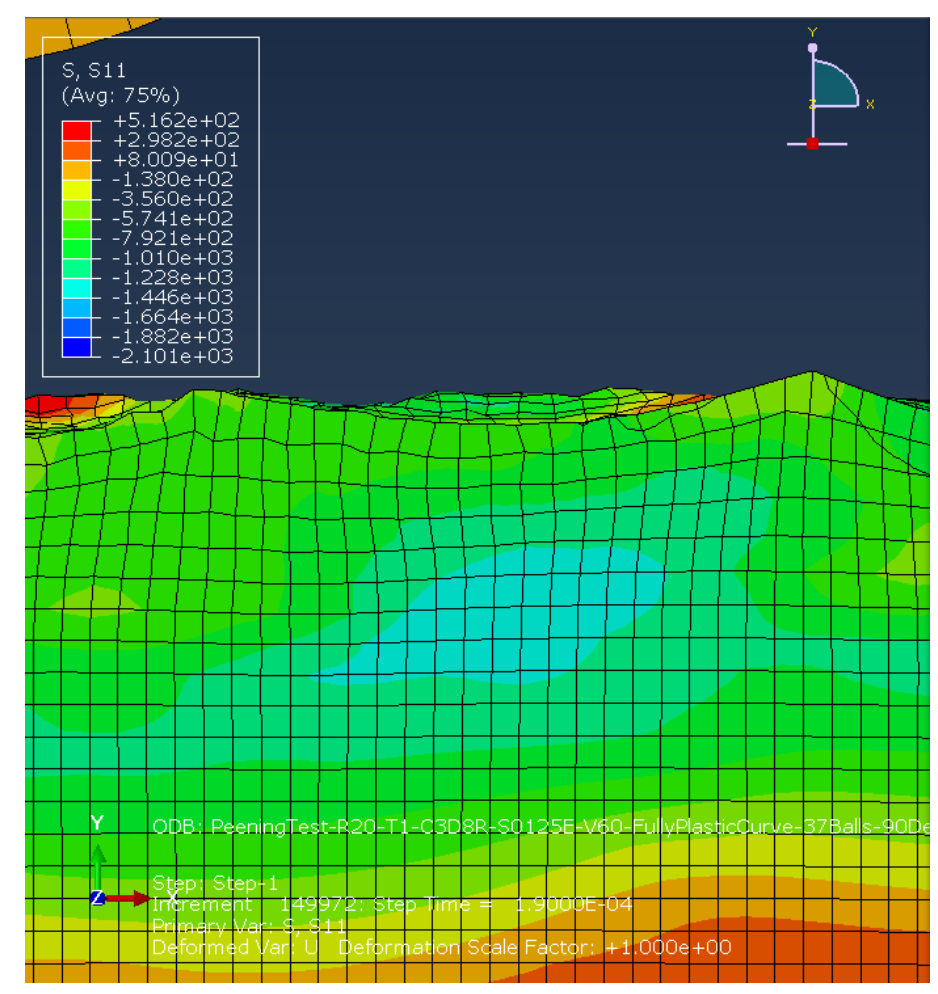

(b)

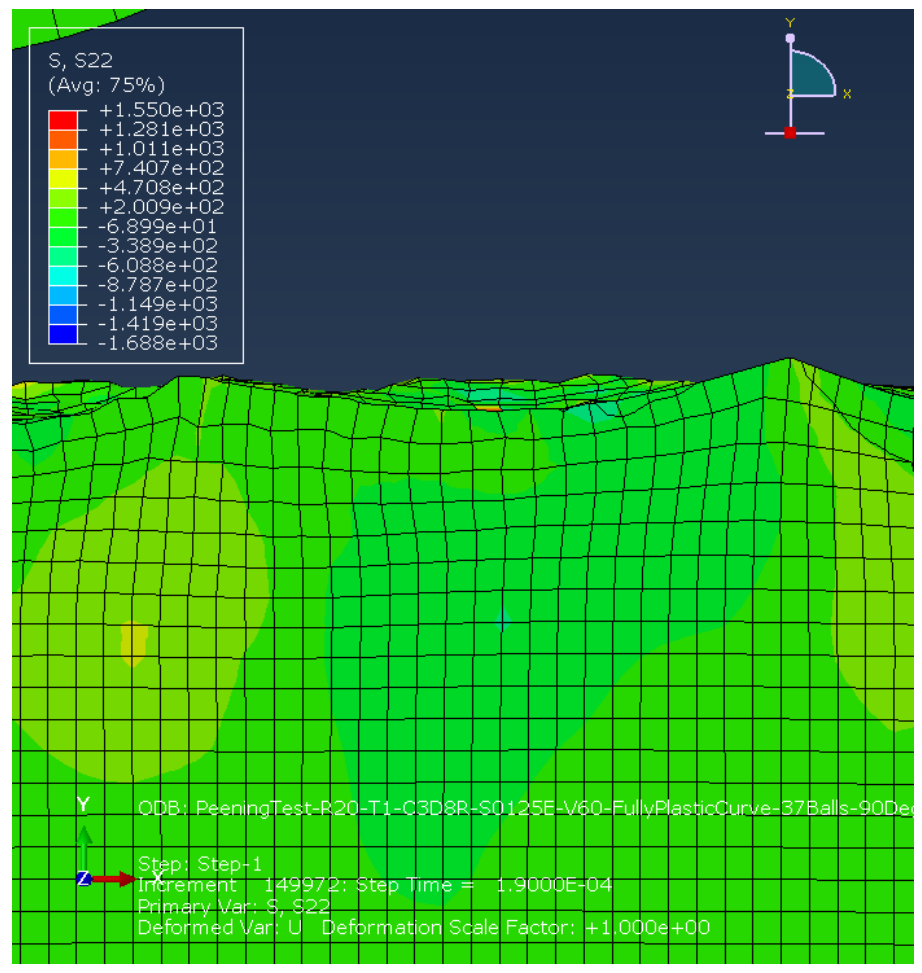

(c) 


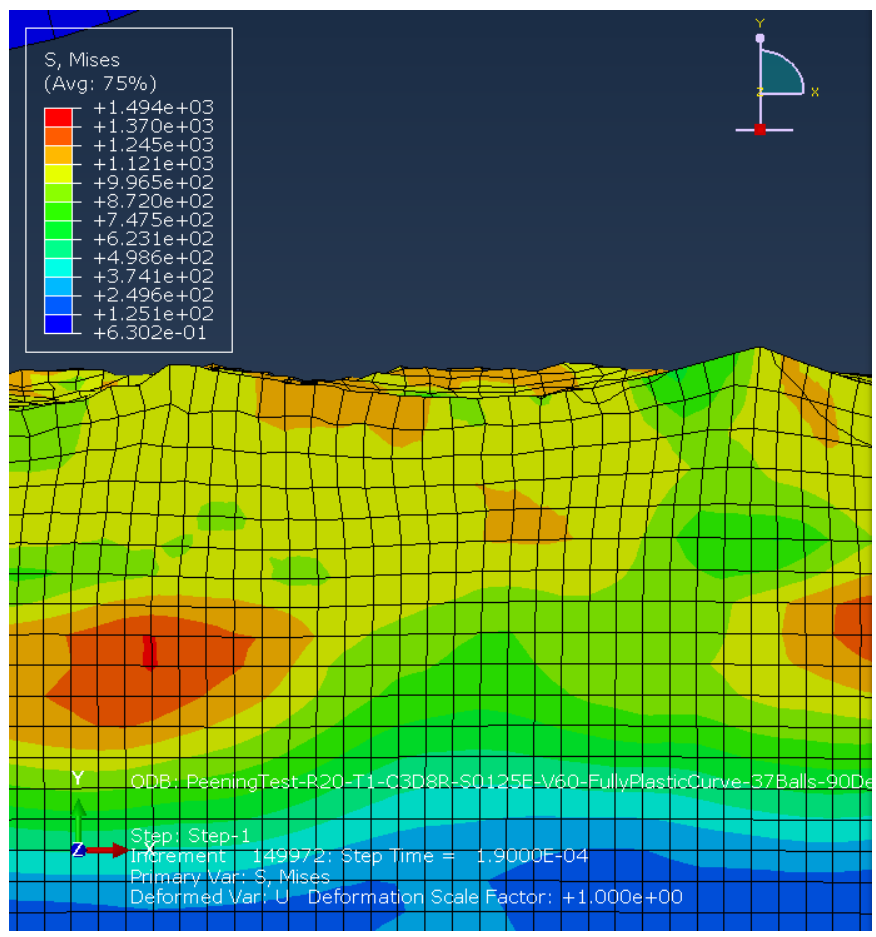

(d)

Figure AP-14 Residual stress profile in peened surface with curvature radius of $20 \mathrm{~mm}$ : (a) longitudinal stress; (b) circumferential stress; (c) radial stress; (d) Von Mises stress

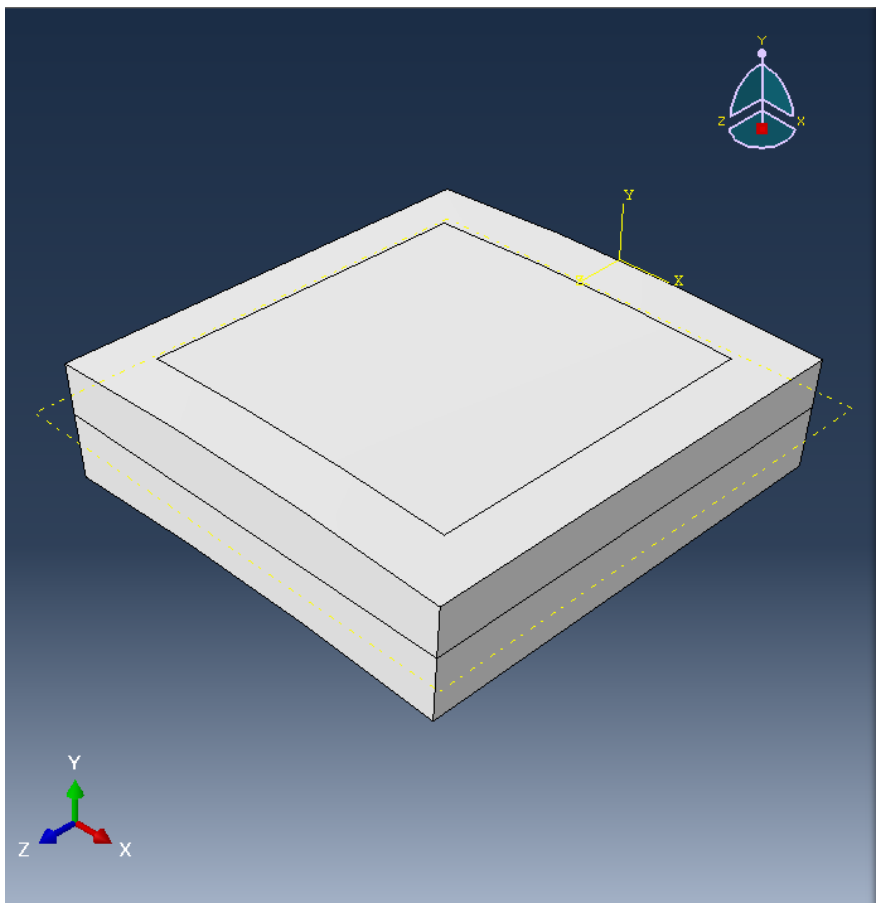

Figure AP-15 FEA model of target surface with curvature radius $30 \mathrm{~mm}$ 


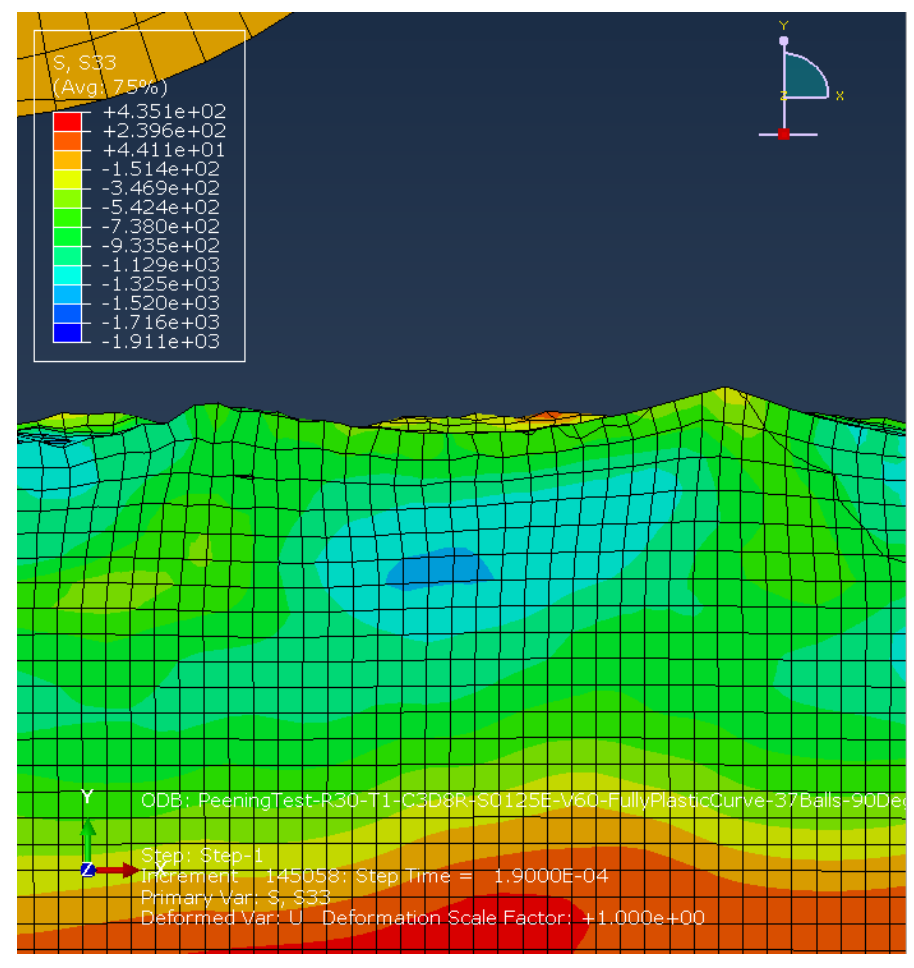

(a)

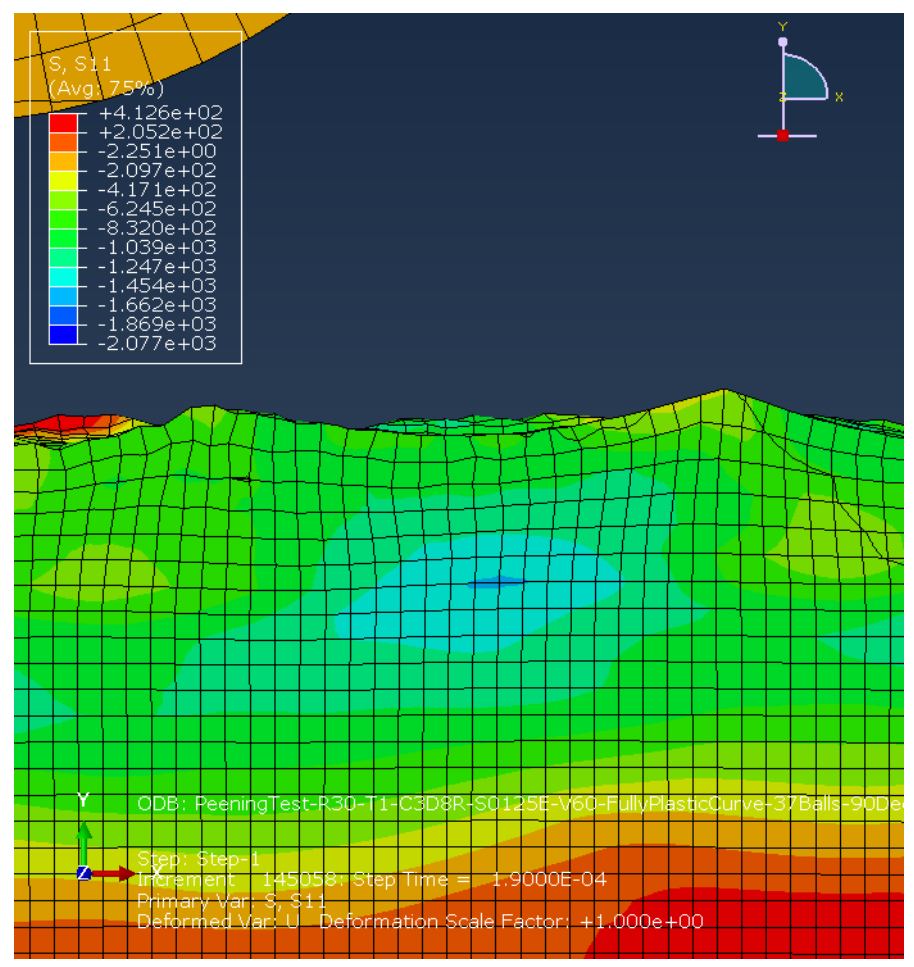

(b)

132 


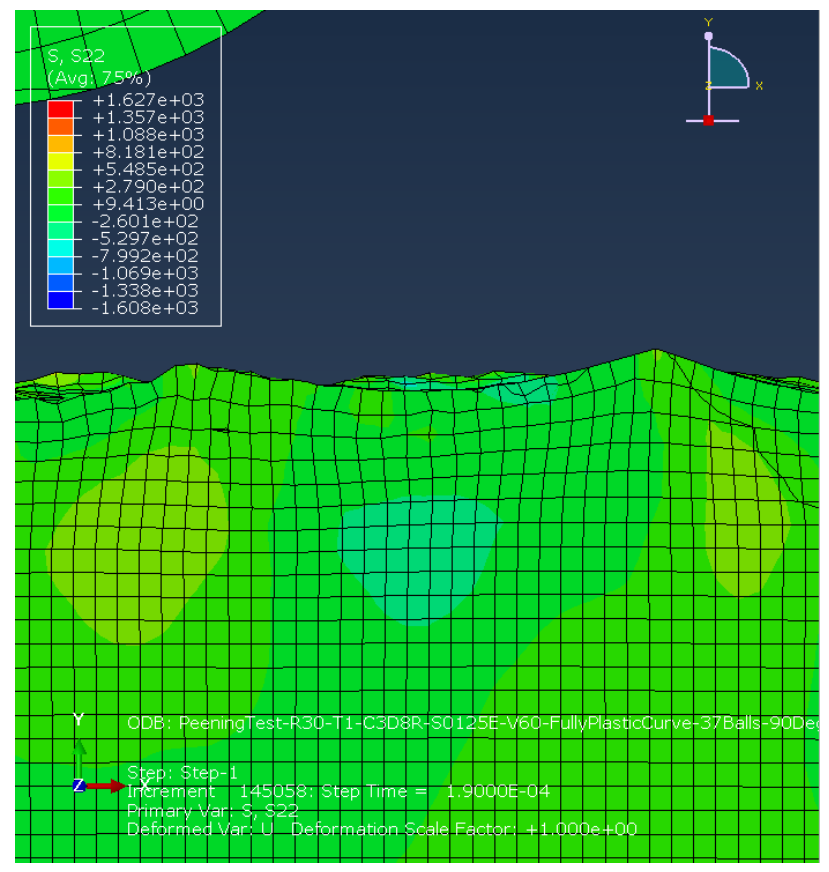

(c)

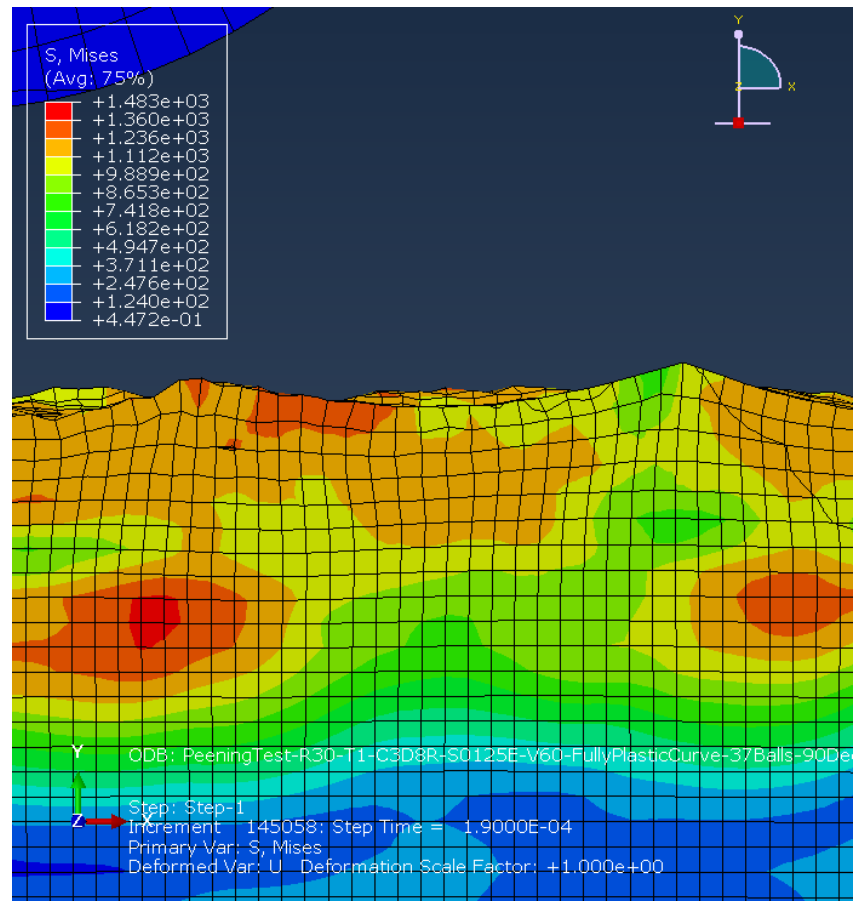

(d)

Figure AP-16 Residual stress profile in peened surface with curvature radius of $30 \mathrm{~mm}$ : (a) longitudinal stress; (b) circumferential stress; (c) radial stress; (d) Von Mises stress 


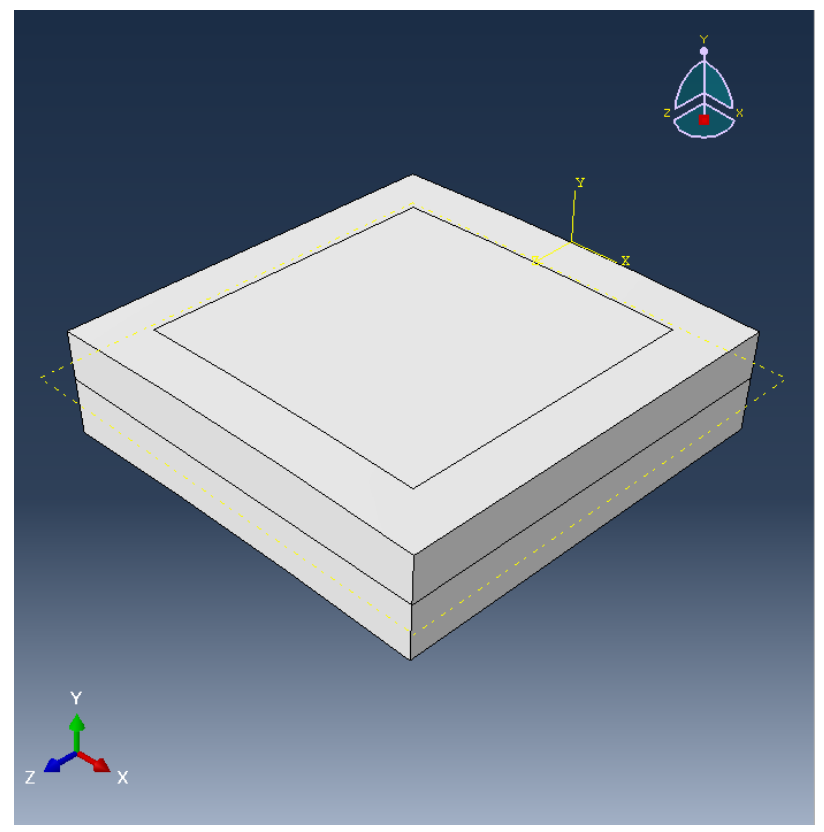

Figure AP-17 FEA model of target surface with curvature radius $40 \mathrm{~mm}$

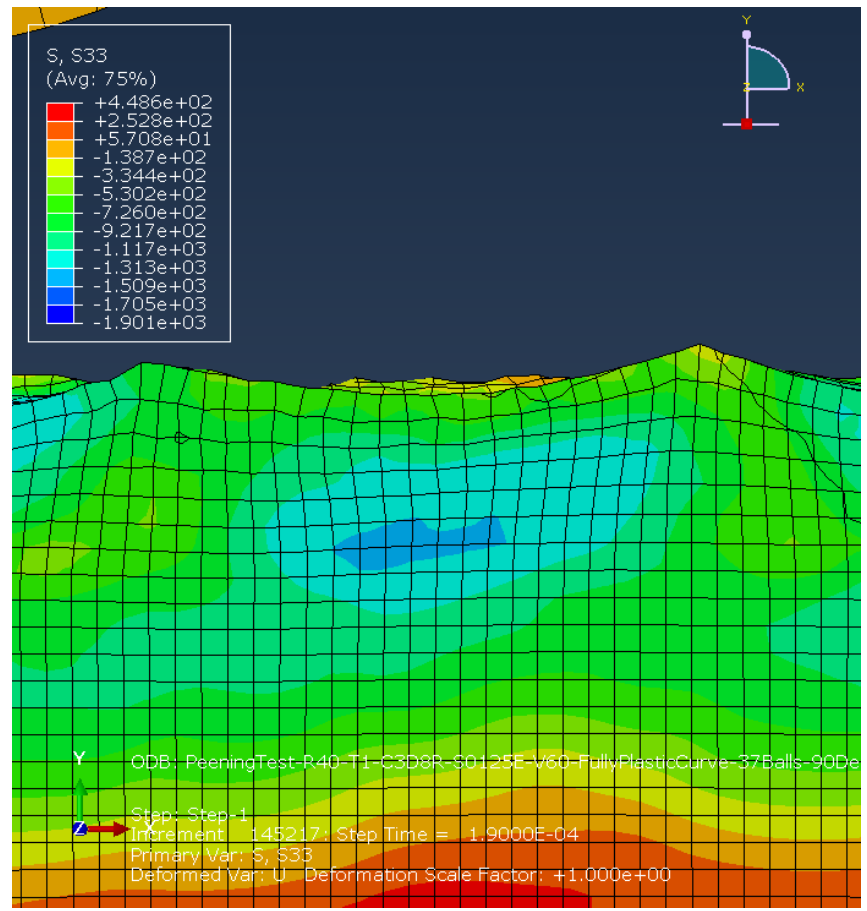

(a) 


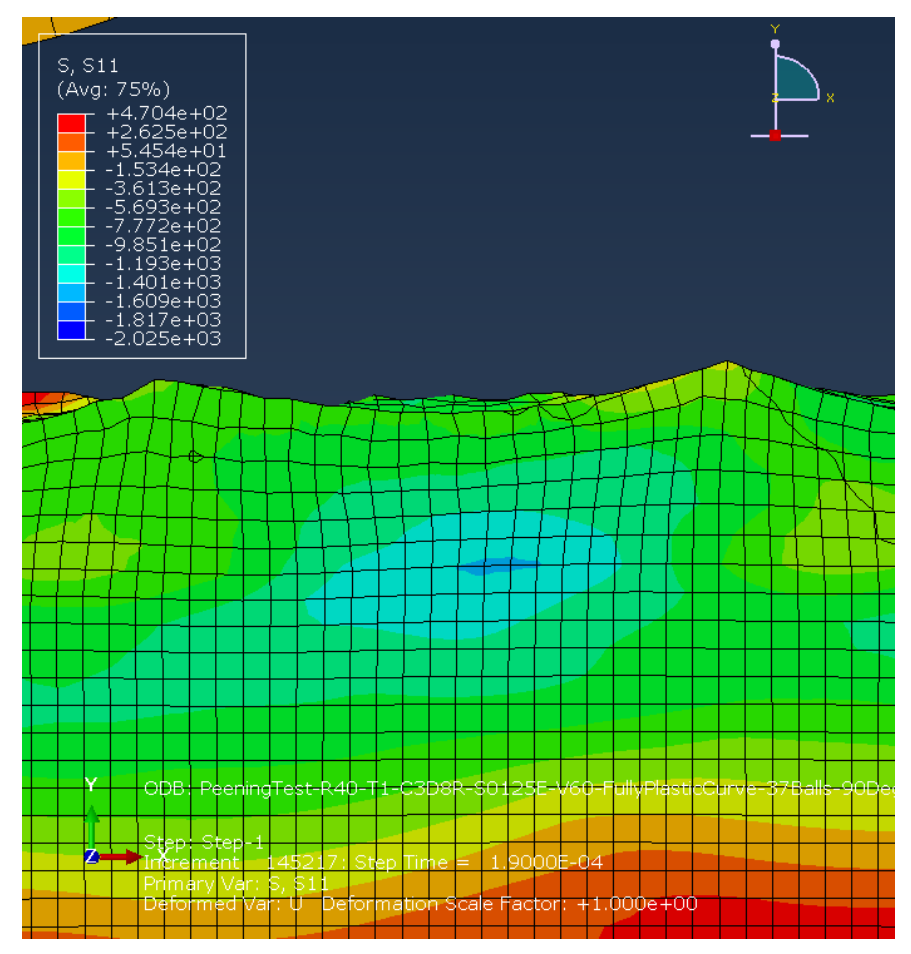

(b)

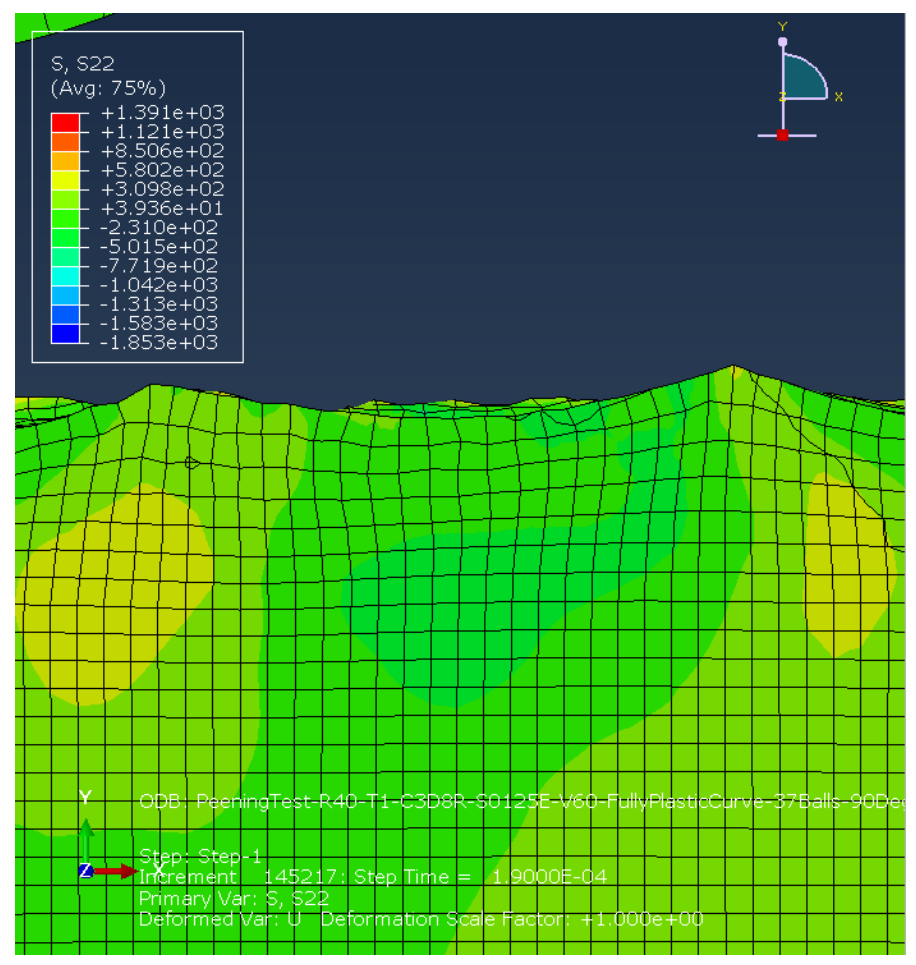

(c) 


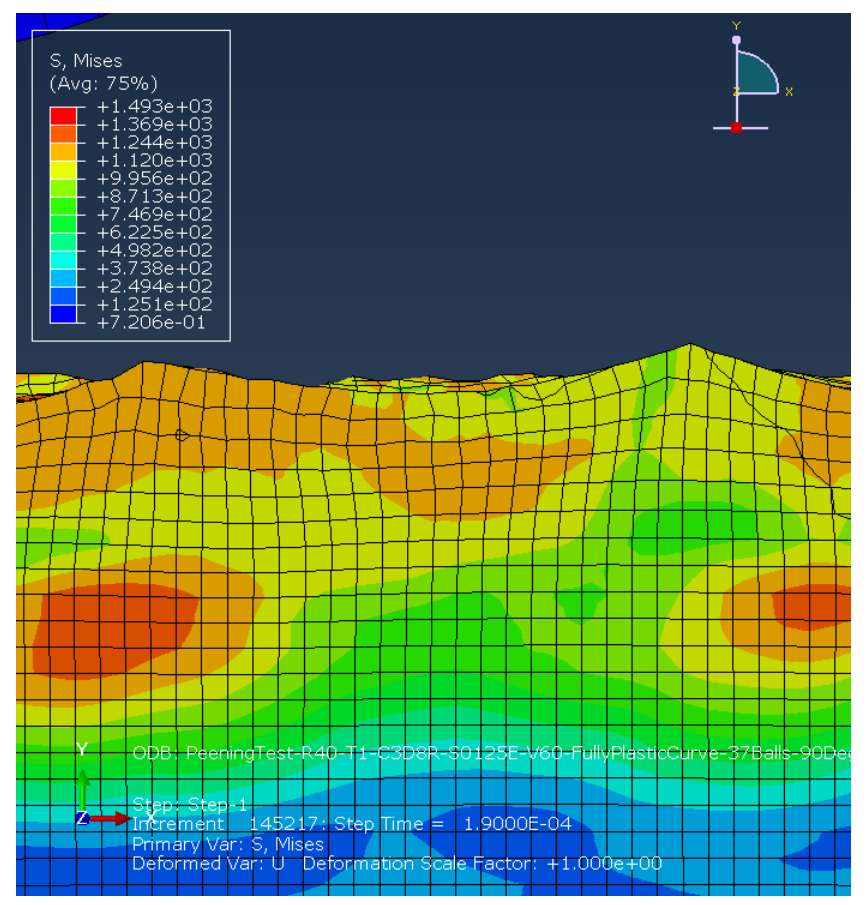

(d)

Figure AP-18 Residual stress profile in peened surface with curvature radius of $40 \mathrm{~mm}$ : (a) longitudinal stress; (b) circumferential stress; (c) radial stress; (d) Von Mises stress

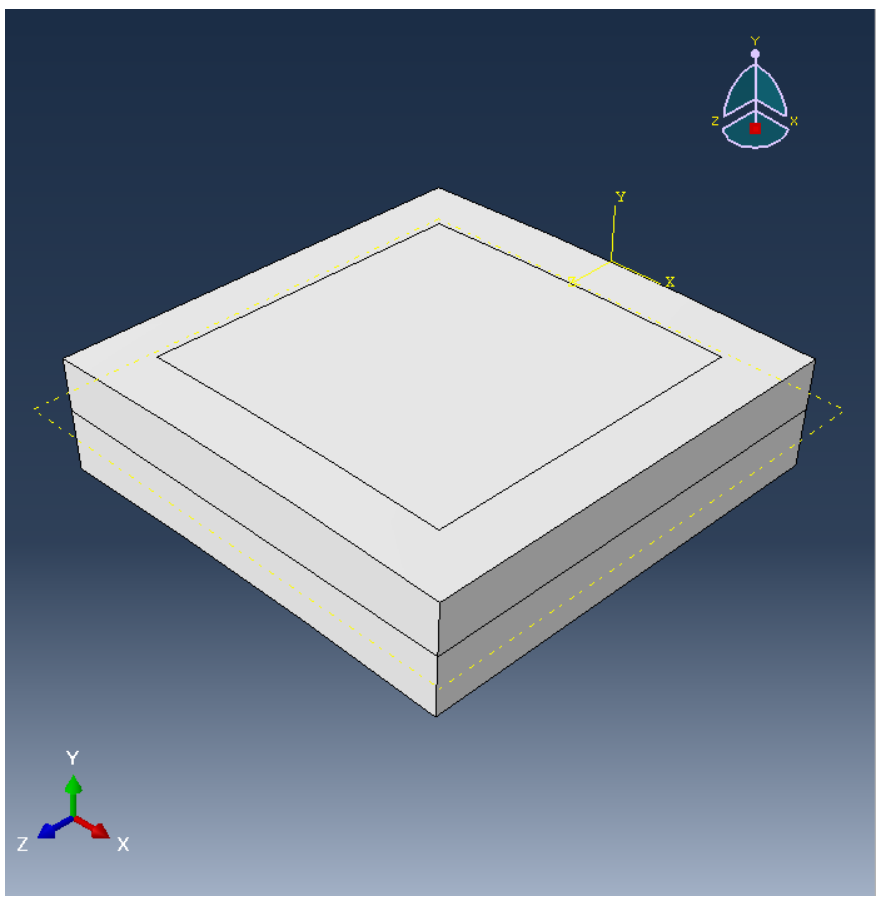

Figure AP-19 FEA model of target surface with curvature radius $50 \mathrm{~mm}$ 


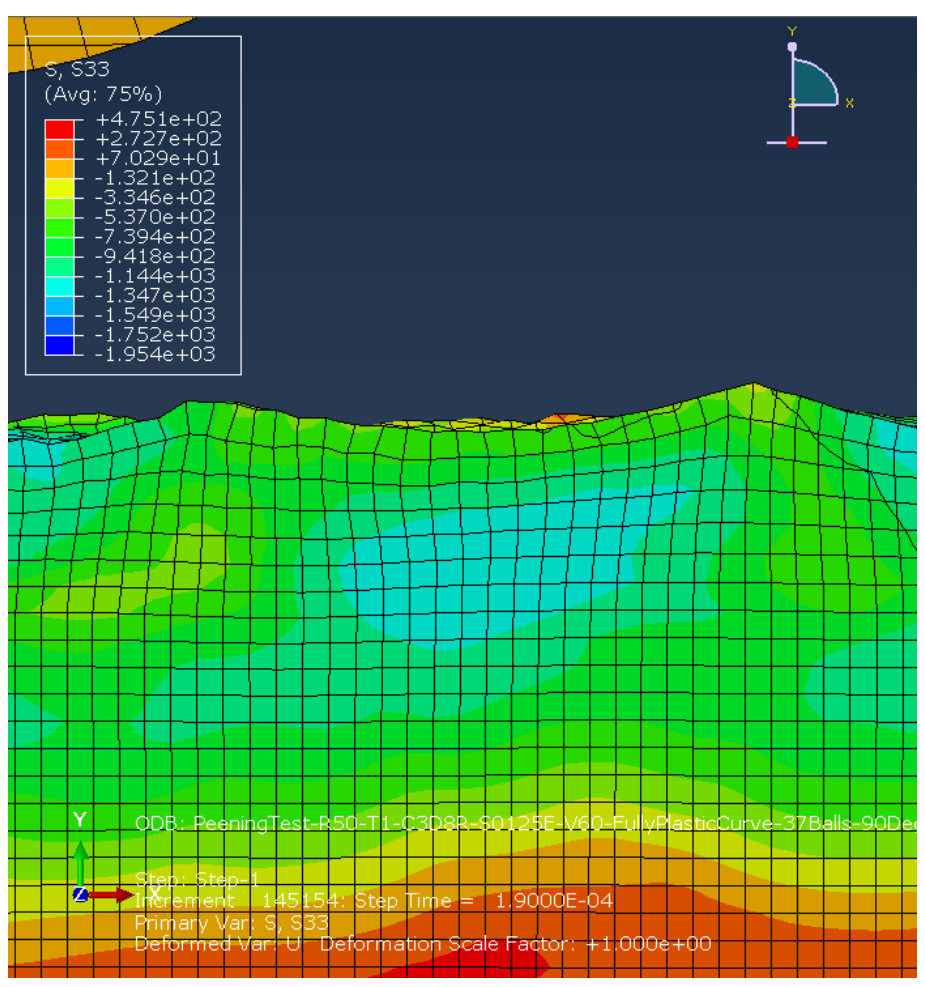

(a)

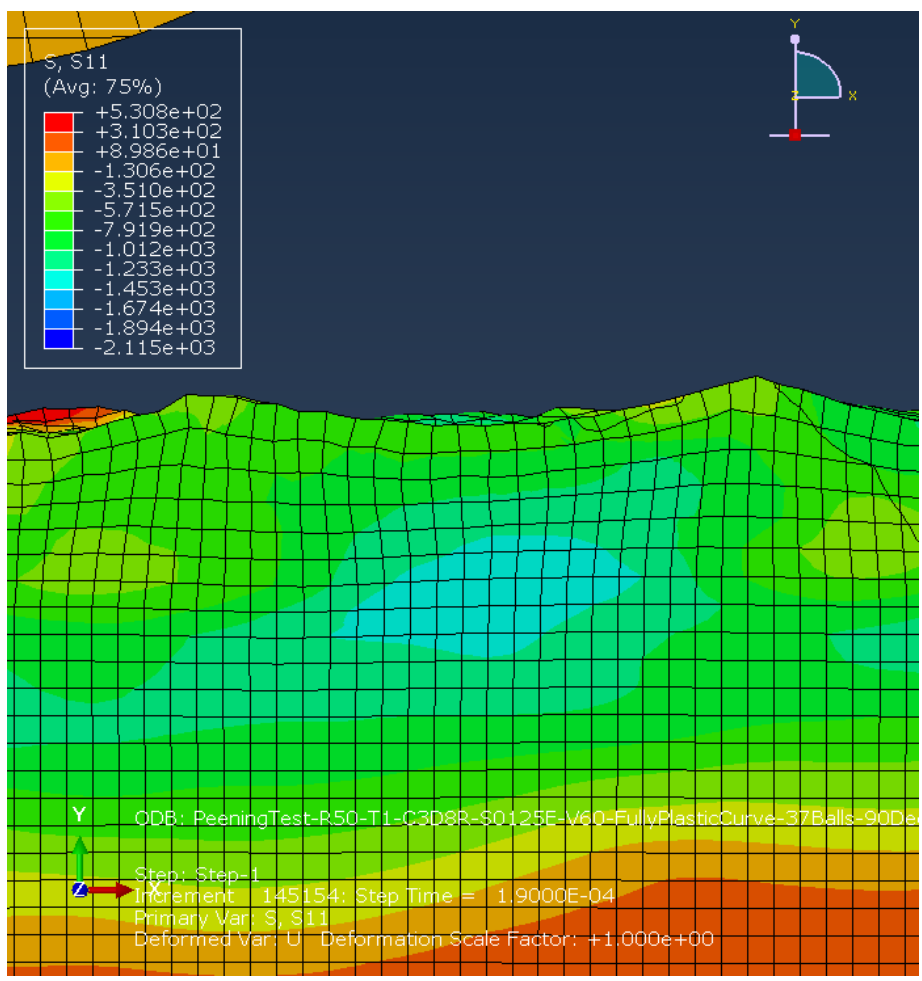

(b) 


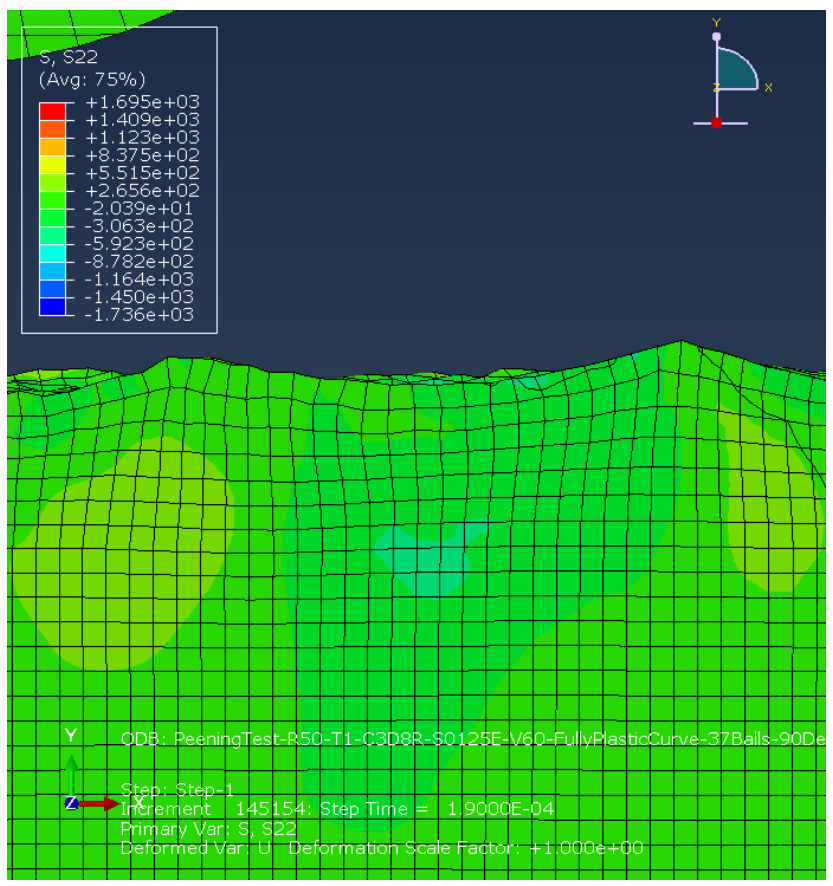

(c)

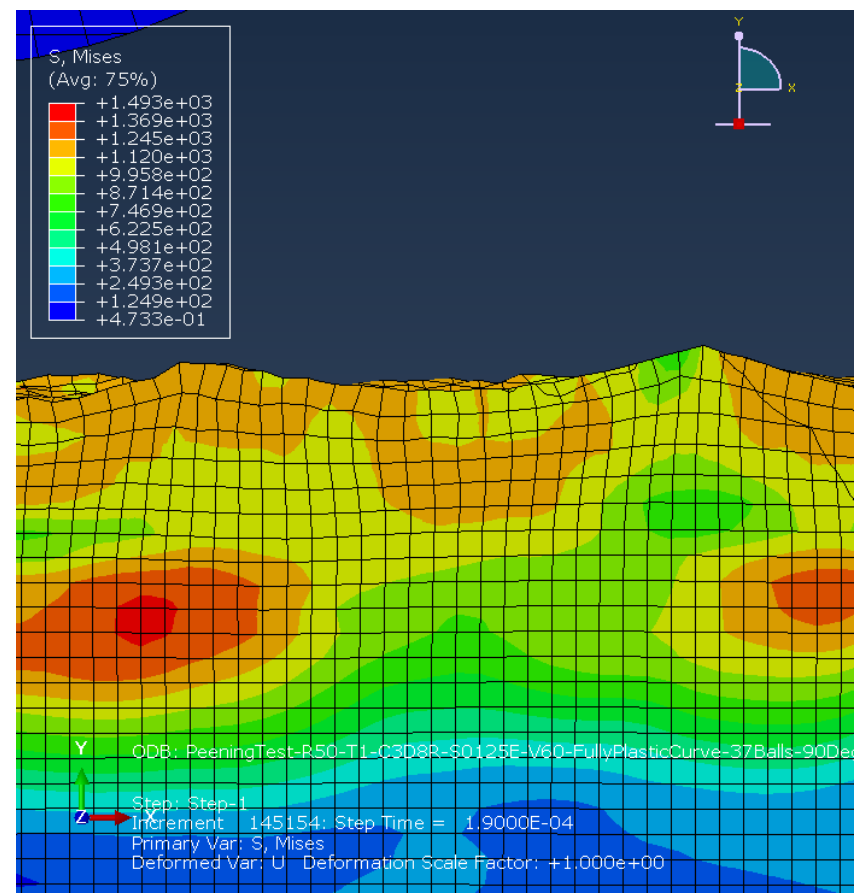

(d)

Figure AP-20 Residual stress profile in peened surface with curvature radius of $50 \mathrm{~mm}$ : (a) longitudinal stress; (b) circumferential stress; (c) radial stress; (d) Von Mises stress 


\section{Appendix D}

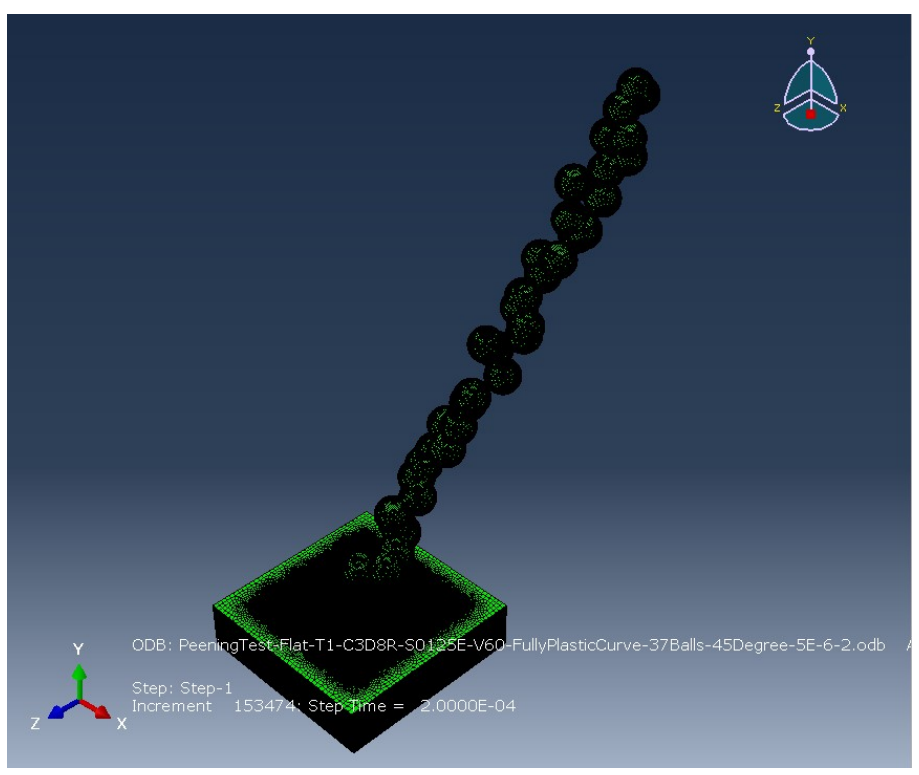

Figure AP-21 FEA model of flat target surface peened at $45^{\circ}$ angle impact

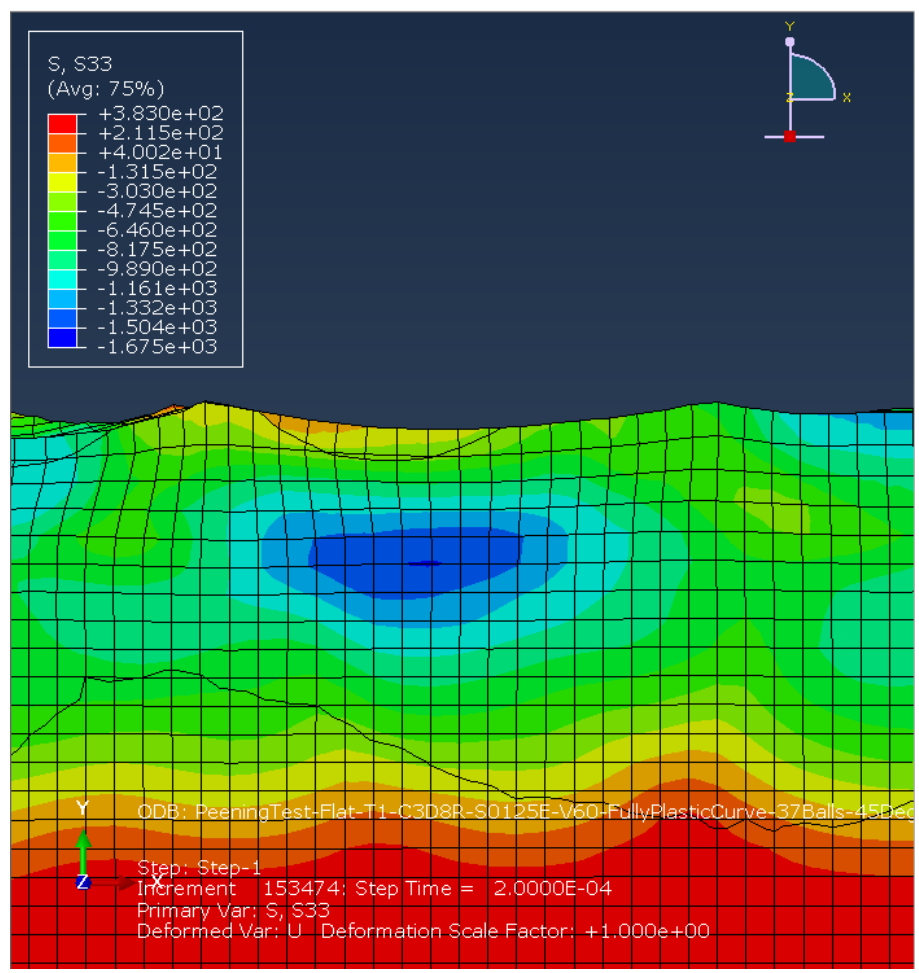

(a) 


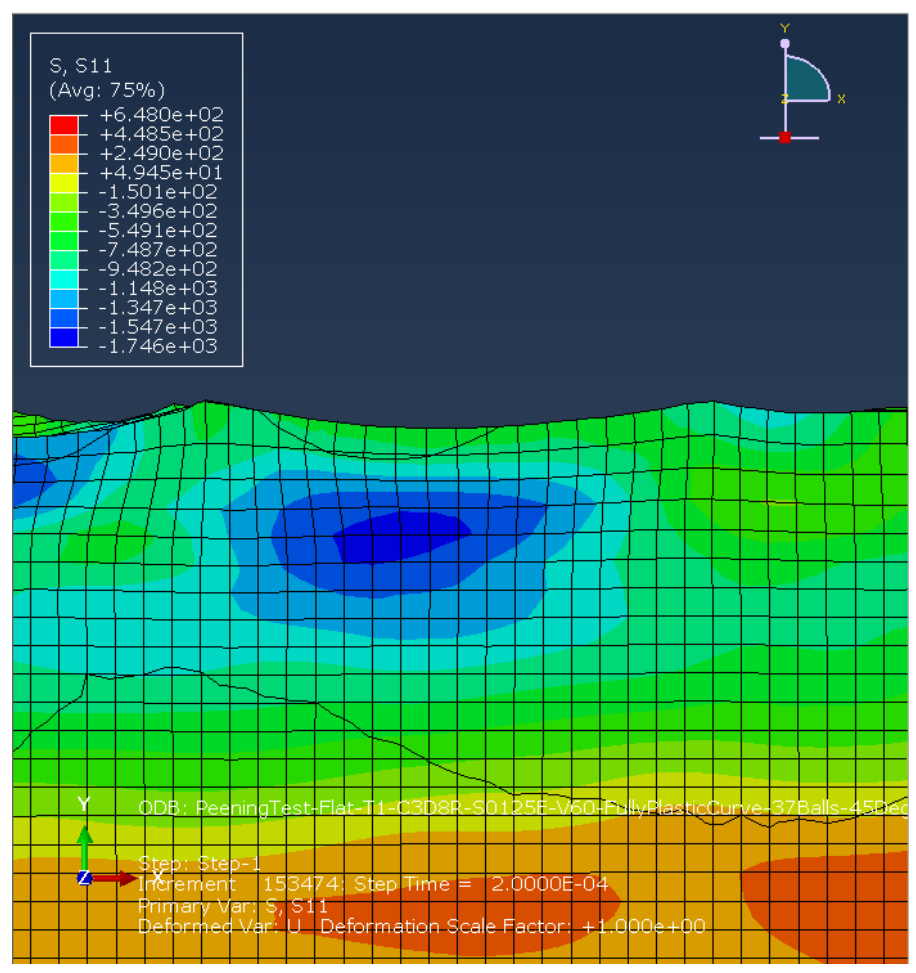

(b)

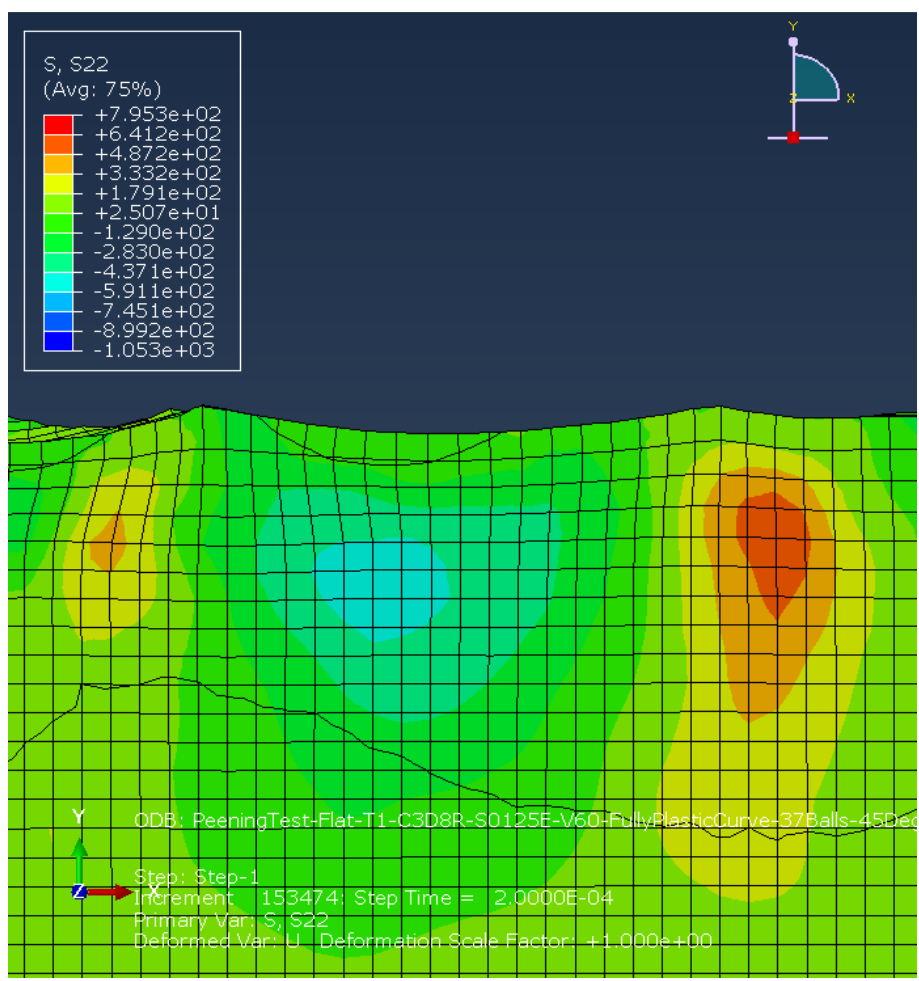

(c) 


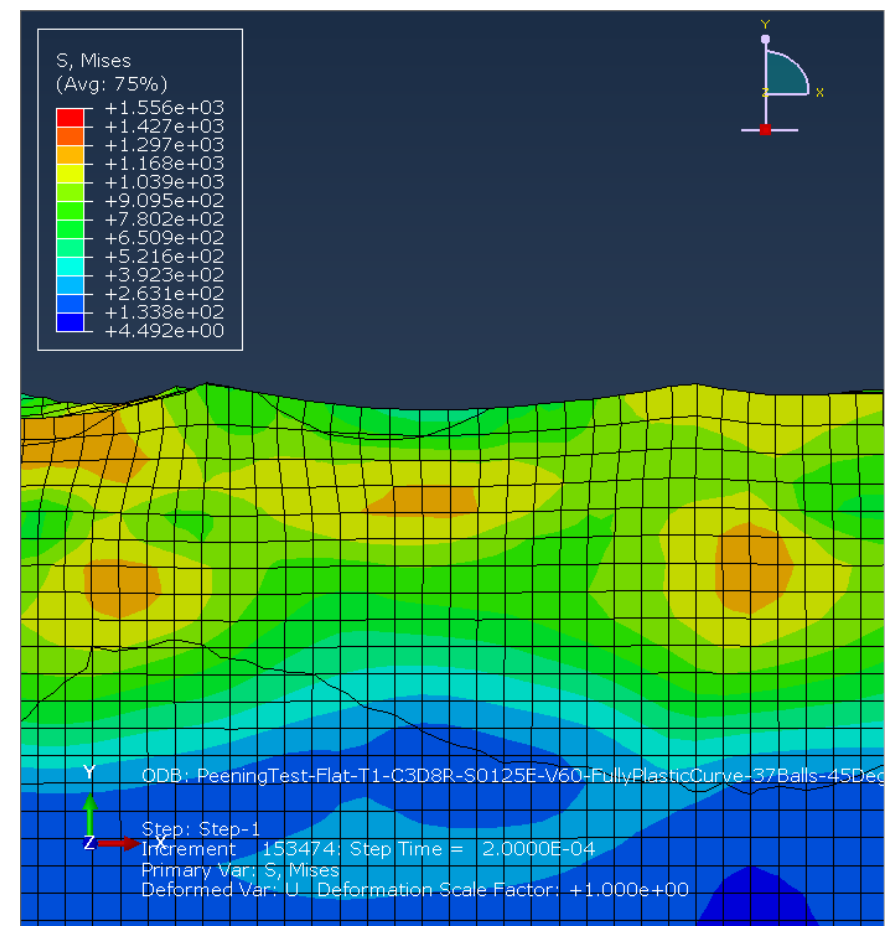

(d)

Figure AP-22 Residual stress profile in peened surface by $45^{\circ}$ angle impact: (a) longitudinal stress; (b) circumferential stress; (c) radial stress; (d) Von Mises stress

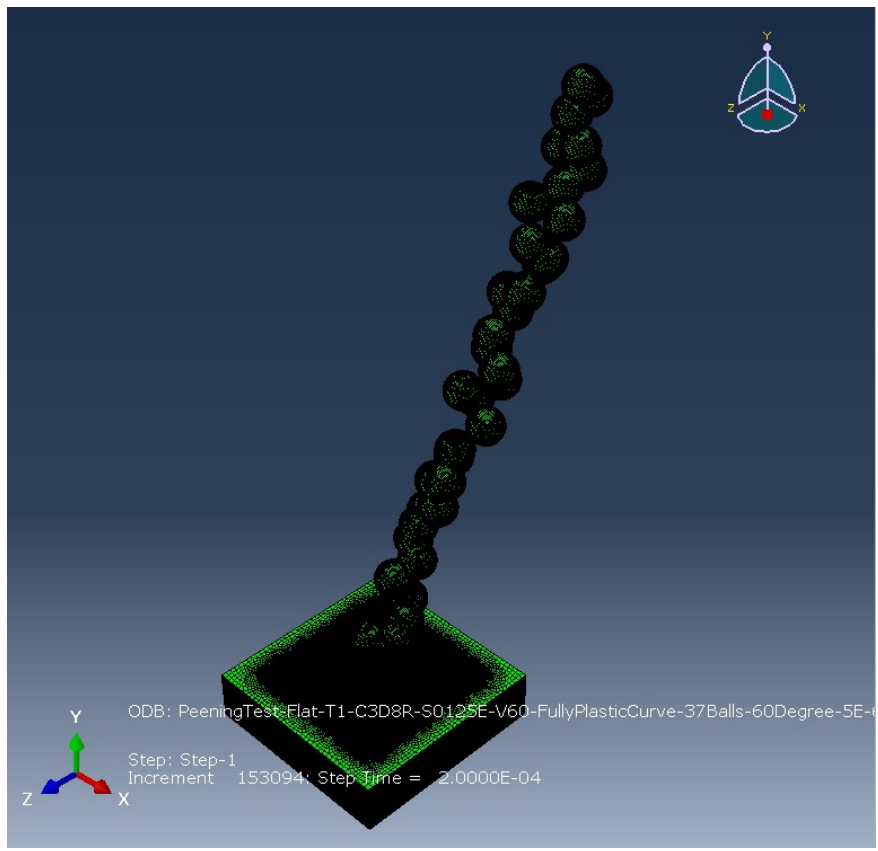

Figure AP-23 FEA model of flat target surface peened at $60^{\circ}$ angle impact 


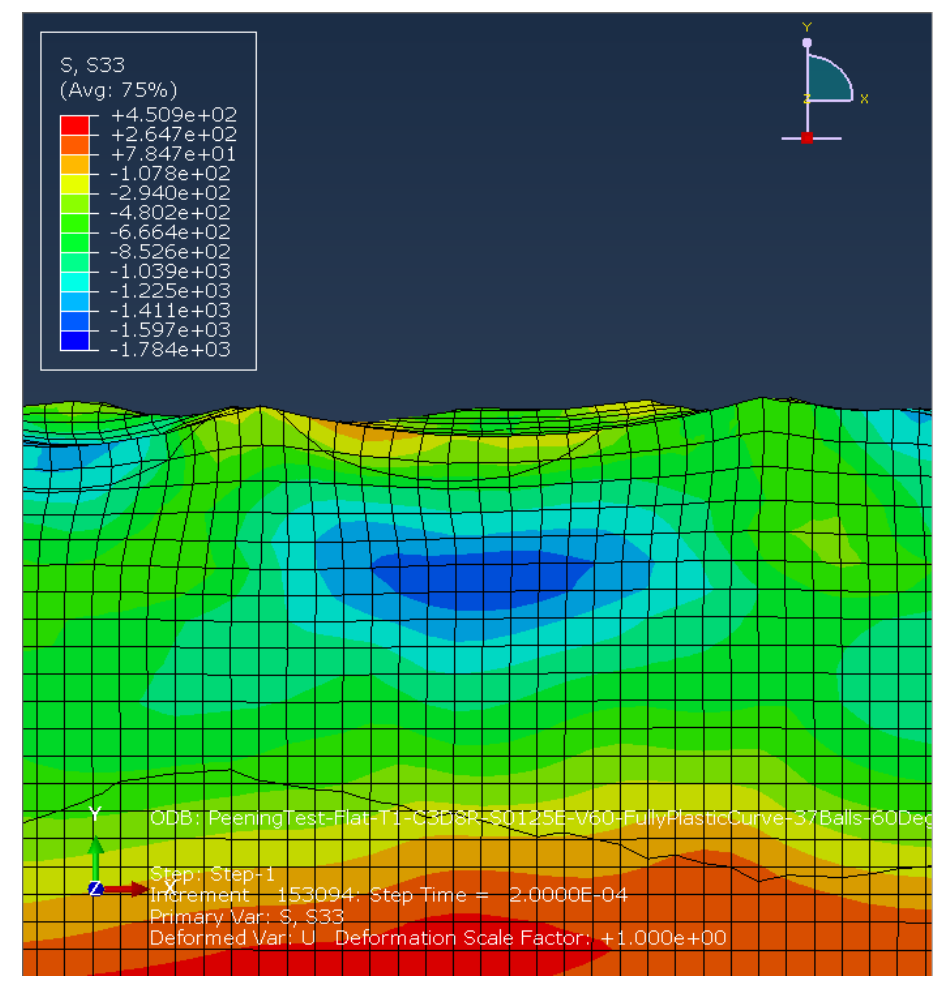

(a)

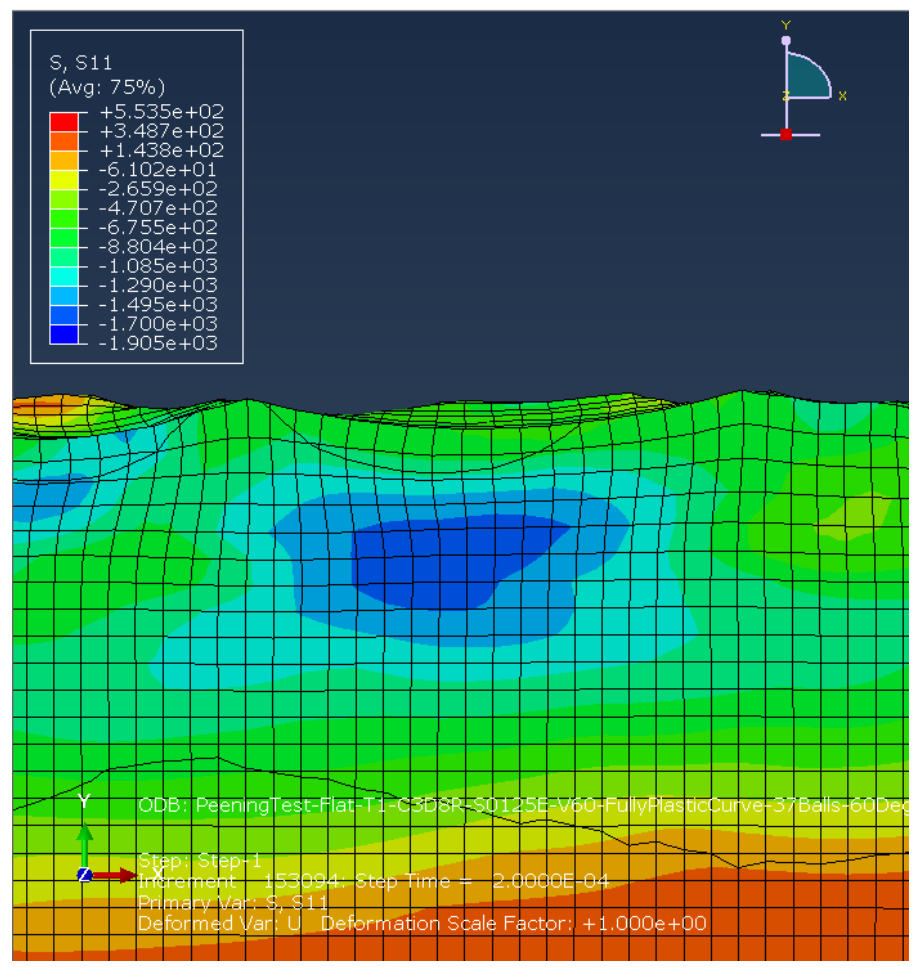

(b) 


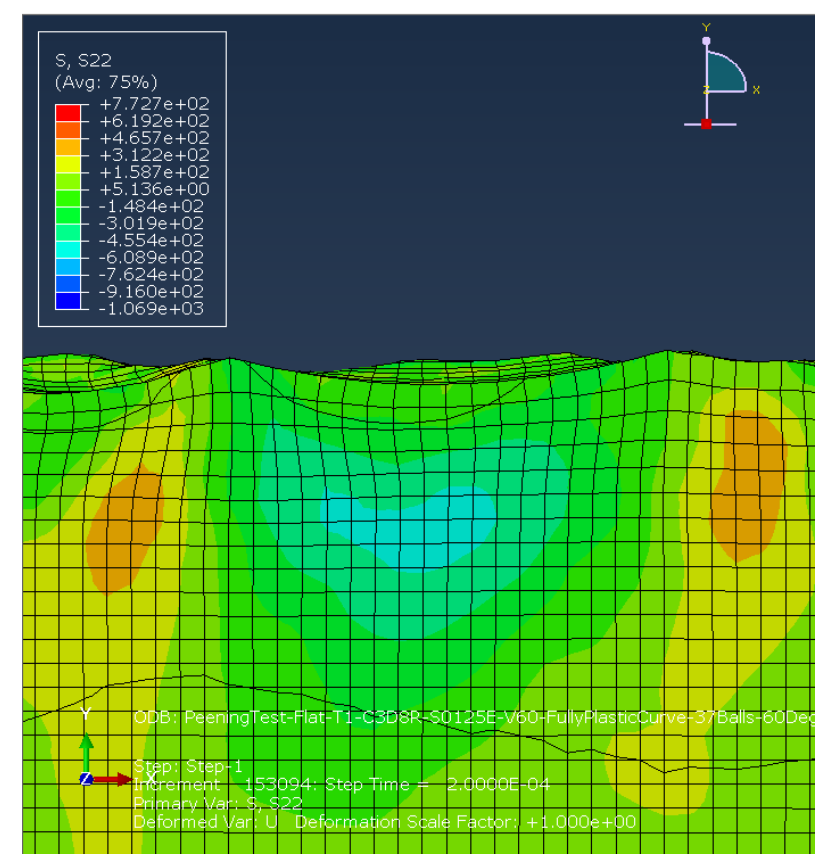

(c)

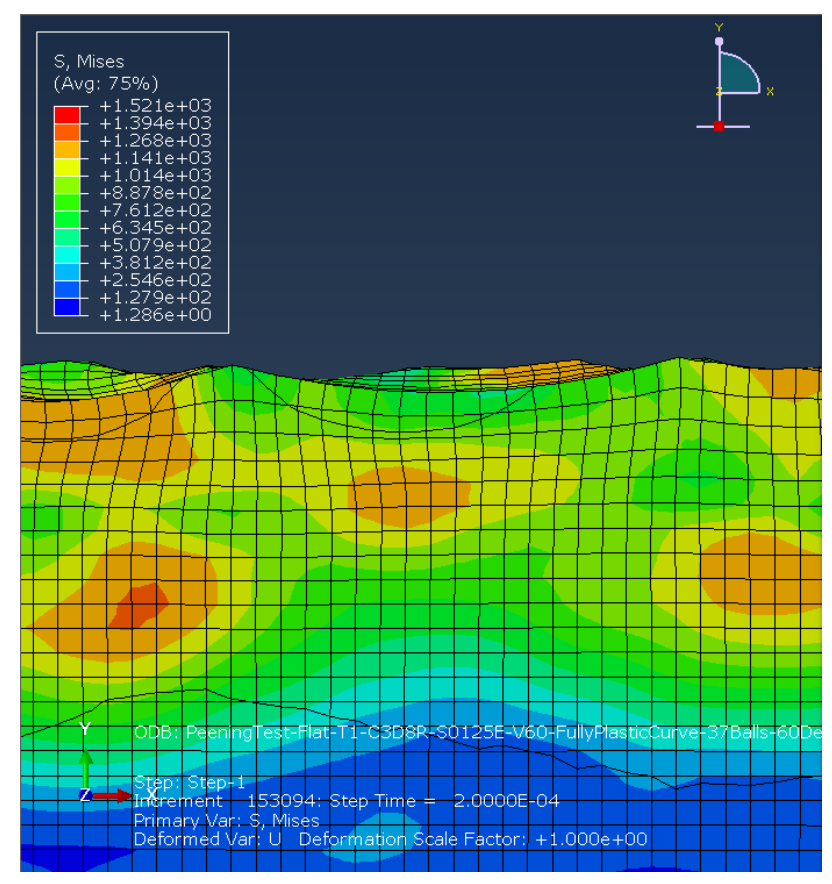

(d)

Figure AP-24 Residual stress profile in peened surface by $60^{\circ}$ angle impact: (a) longitudinal stress; (b) circumferential stress; (c) radial stress; (d) Von Mises stress 


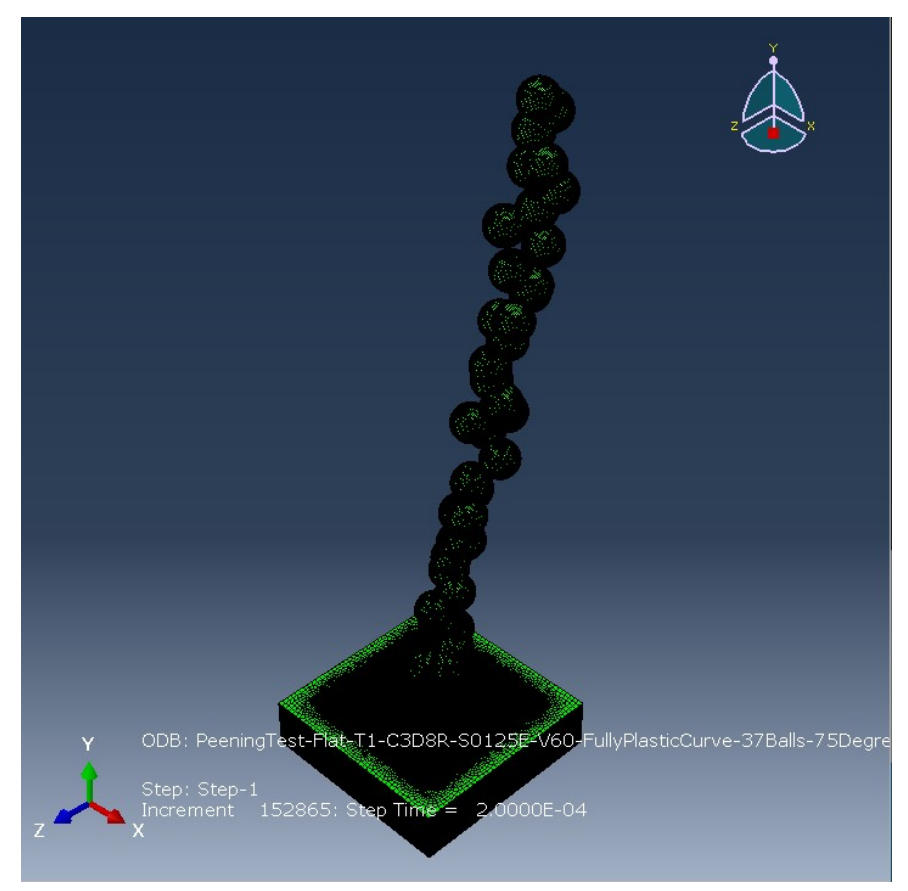

Figure AP-5-25 FEA model of flat target surface peened at $75^{\circ}$ angle impact

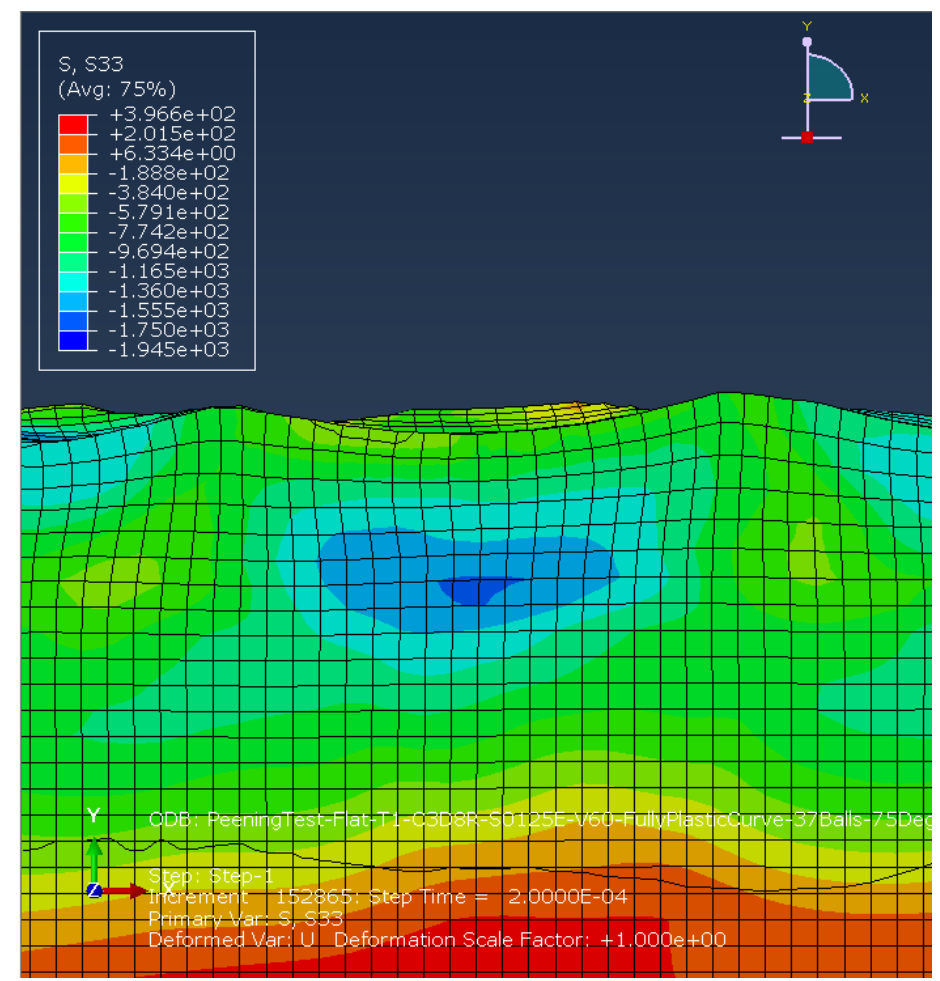

(a) 


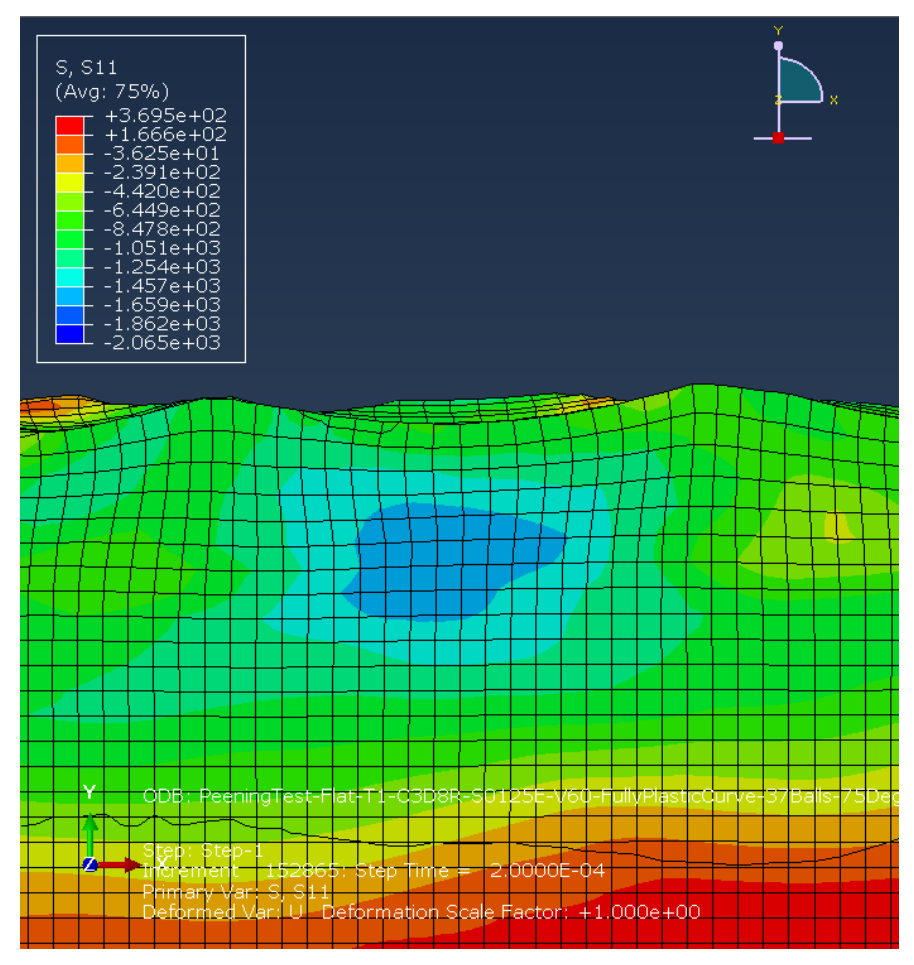

(b)

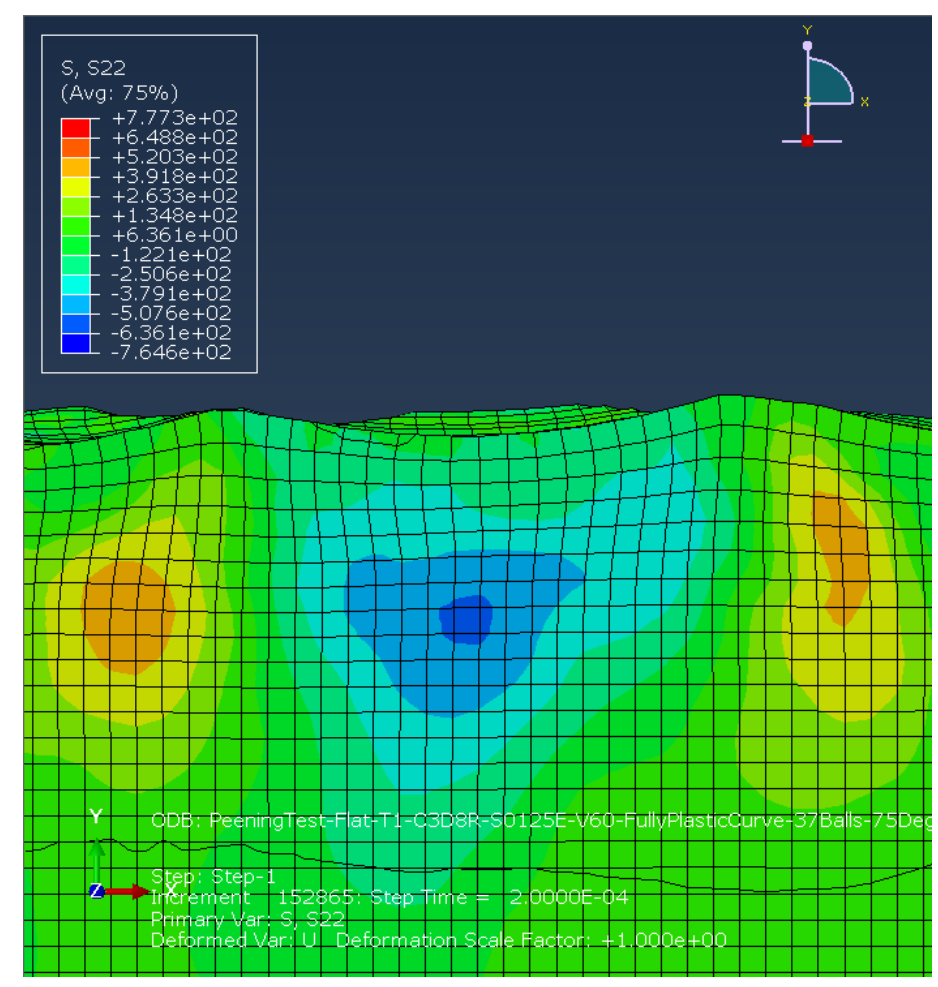

(c) 


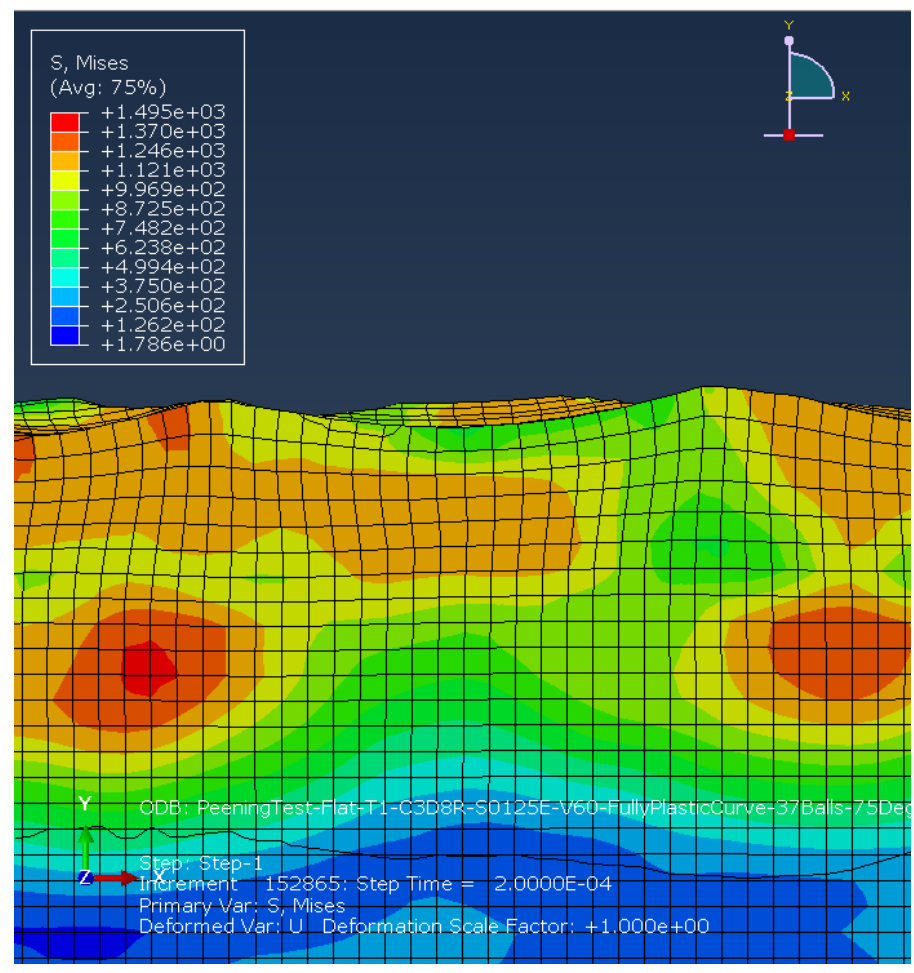

(d)

Figure AP-26 Residual stress profile in peened surface by $75^{\circ}$ angle impact:

(a) longitudinal stress; (b) circumferential stress; (c) radial stress; (d) Von Mises stress 